\title{
Exploring psychotic experiences in the context of multidimensional psychopathology
}

Citation for published version (APA):

Kirli, U. (2020). Exploring psychotic experiences in the context of multidimensional psychopathology: a longitudinal community-based approach. [Doctoral Thesis, Maastricht University]. Maastricht University. https://doi.org/10.26481/dis.20201118uk

Document status and date:

Published: 01/01/2020

DOI:

10.26481/dis.20201118uk

Document Version:

Publisher's PDF, also known as Version of record

\section{Please check the document version of this publication:}

- A submitted manuscript is the version of the article upon submission and before peer-review. There can be important differences between the submitted version and the official published version of record.

People interested in the research are advised to contact the author for the final version of the publication, or visit the DOI to the publisher's website.

- The final author version and the galley proof are versions of the publication after peer review.

- The final published version features the final layout of the paper including the volume, issue and page numbers.

Link to publication

\footnotetext{
General rights rights.

- You may freely distribute the URL identifying the publication in the public portal. please follow below link for the End User Agreement:

www.umlib.nl/taverne-license

Take down policy

If you believe that this document breaches copyright please contact us at:

repository@maastrichtuniversity.nl

providing details and we will investigate your claim.
}

Copyright and moral rights for the publications made accessible in the public portal are retained by the authors and/or other copyright owners and it is a condition of accessing publications that users recognise and abide by the legal requirements associated with these

- Users may download and print one copy of any publication from the public portal for the purpose of private study or research.

- You may not further distribute the material or use it for any profit-making activity or commercial gain

If the publication is distributed under the terms of Article $25 \mathrm{fa}$ of the Dutch Copyright Act, indicated by the "Taverne" license above, 


\section{Exploring Psychotic Experiences in the Context of Multidimensional Psychopathology:}

A Longitudinal Community-based Approach

Umut Kirlı 
DESIGN | EREN TAYMAZ • İstanbul

(C) COPYLEFT | U Kırlı • Izmir, Maastricht, Van • November 2020

This thesis may be reprinted, reproduced or utilized in any form in respect of any fair dealing for the supreme purposes of nature, life and history. The author will be happy to be informed via an e-mail to knidos1986@yahoo.com 


\section{EXPLORING PSYCHOTIC EXPERIENCES IN THE CONTEXT OF MULTIDIMENSIONAL PSYCHOPATHOLOGY:}

A Longitudinal Community-based Approach

\section{DISSERTATION}

to obtain the degree of Doctor at the Maastricht University, on the authority of the Rector Magnificus, Prof.dr. Rianne M. Letschert in accordance with the decision of the Board of Deans, to be defended in public on Wednesday November 18th 2020, at 10.00 hours 


\section{Supervisor:}

Prof J. van Os

\section{Co-supervisors:}

Dr M. Drukker

Dr T. Binbay (Dokuz Eylul University, Turkey)

\section{Assessment Committee:}

Prof Dr Ph.A.E.G. Delespaul (chair)

Dr S. Gülöksuz

Prof Dr B.P.F. Rutten

Prof Dr A. Üçok (Istanbul University, Turkey)

Prof Dr R. van Winkel (KU Leuven, Belgium)

The research presented in this thesis was conducted at the School of Medicine,

Department of Psychiatry, Ege University, Izmir, Turkey in conjunction with the Department of Psychiatry and Psychology at Maastricht University, South Limburg Mental Health Research and Teaching Network, School for Mental Health and Neuroscience, Maastricht, the Netherlands. This thesis is part of a TürkSch Project and has been supported by the Scientific and Technological Research Council of Turkey (programme 1001) with the grants 107S053 and 112 S476. 
To the best days we have not experienced yet... 
Paranymphs

Mesut Işık

Duygu Keskin Gökçelli 
Don't worry... It is common to ascribe madness to the souls that are not understood

\title{
Peyami Safa
}

Suspicion causes fatigue .

Sophocles

\begin{abstract}
Oh my loneliness, my plural songs
The more we live without lies, the better it is...

Can Yücel
\end{abstract}

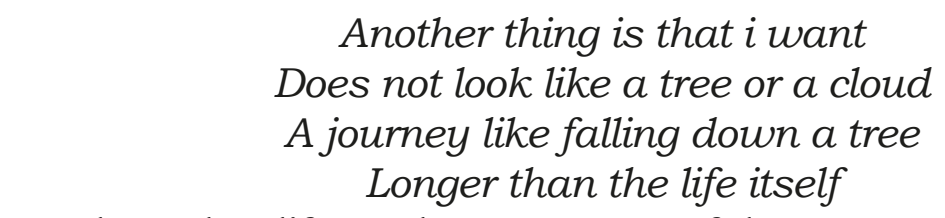

And another life, to the greenness of the grass you are into...

Can Yücel 



\section{TABLE OF CONTENTS}

\section{CHAPTER 1}

Introduction

- The Relativity of Psychosis

- Distribution of Psychosis Spectrum in Psychiatric Nosology

- Transdiagnostic Psychosis Phenotype in Relation to Psychosis Spectrum

- Hypothetical Network Model of Psychosis Dimensions across the Spectrum

- Aims

\section{CHAPTER 2}

Izmir mental health cohort for gene-environment interaction in psychosis (Türksch):

Assessment of the extended and transdiagnostic psychosis phenotype and analysis of attrition in a six years follow-up of a community-based sample.

\section{CHAPTER 3}

Psychotic experiences and mood episodes predict each other bidirectionally: a 6-year follow-up study in a community-based population

\section{CHAPTER 4}

DSM outcomes of psychotic experiences and associated risk factors: 6-year follow-up study in a community-based sample

\section{CHAPTER 5}

Is BDNF-Val66Met Polymorphism Associated with Psychotic Experiences and Psychotic Disorder Outcome? Evidence from a 6 Years Prospective Population-based Cohort Study

\section{CHAPTER 6}

Discussion

- Evaluating dynamic transitions over time within the full spectrum of psychosis

- Bidirectional associations between the extended psychosis phenotype and affective psychopathology over time

- Associations between clinically relevant subthreshold psychotic experiences and subsequent psychopathology

- Assessment of risk factors from a dynamic and dimensional perspective

- Methodological issues

- Directions for future research

\section{CHAPTER7}

Summary 



\section{CHAPTER 1 \\ Introduction}




\section{The Relativity of Psychosis}

"The whole development of the theory turns on the question of whether there are physically preferred states in Nature. Also, concepts and distinctions are only admissible to the extent that observable facts can be assigned to them without ambiguity. This postulate, pertaining to epistemology, proves to be of fundamental importance" (Einstein 1967).

These fundamental ideas on 'the Theory of Relativity' were expressed by Albert Einstein in a lecture delivered in acknowledgement of the Nobel Prize in 1923 (Einstein 1967), three decades before the release of the first edition of the Diagnostic and Statistical Manual of Mental disorders (DSM) (American Psychiatric Association 1952). Looking into this ground-breaking theory from the perspective of psychosis expression in the community, may provide some productive insights, as formulated below.

The theory is deceptively simple: An object's velocity, or its momentum, or how it experiences time can only be measured relative to something else. For example, there is no object with absolute 'zero' velocity in the universe (A mountain, which seems to be immobile according to an earthbound observer, in fact has a velocity of $1300 \mathrm{~km} / \mathrm{h}$ relative to the axis of the Earth). In other words, there is no 'absolute' frame of reference. In medicine, anything that phenotypically is a spectrum is commonly categorized for practical purposes (e.g. lower bound for hypertension is 120/80 mm Hg arterial blood pressure). This is accomplished by defining 'preferred states', namely thresholds, based on regularly reviewed scientific evidence. Following this type of reasoning, a question arises: To what degree is psychosis expression in the community best - in terms of clinical practice, public health and research - described as a binary phenomenon or as a spectrum, such as arterial blood pressure? (van Os and Kapur 2009)

Focusing on definitions of psychosis nomenclature in the glossary of technical terms in DSM-5 (American Psychiatric Association 2013) 
gives some guidance. Here, the term delusion is defined as a: "false and fixed belief that is not amenable to change in light of conflicting evidence". An overvalued idea is again a "false belief but not held 'as firmly as' is the case with the delusions". Finally, the term attenuated delusion (A1 criterion for attenuated psychosis syndrome-APS in DSM-5) is defined as "a delusion that does not have "the fixed nature' that is necessary for the diagnosis of a psychotic disorder" (American Psychiatric Association 2013). Therefore, by definition, the distinction between these thought content symptoms relies on the amount of 'fixation' on the belief, which is a quantitative rather than a qualitative difference. A similar type of graded spectrum reasoning may be found in the definition of (attenuated) disorganized speech in DSM-5 (American Psychiatric Association 2013).

Two points in the definition of the term hallucination similarly require attention:

i) "A hallucinating person 'may or may not have insight' into the non-veridical nature of the hallucination. One hallucinating person may recognize the false sensory experience, whereas another may be convinced that the experience is grounded in reality" (American Psychiatric Association 2013). However, the distinction of the severe form of the attenuated hallucination (A2 criterion of APS in DSM 5) with threshold hallucination is defined as: "These perceptual abnormalities may disrupt behaviour, but scepticism about their reality can still be induced" (American Psychiatric Association 2013). It is not easy to make a precise distinction between these two terms as both include the state of partly preserved reality testing and insight in the false sensory experience, indicating a partly intertwined state.

ii) "Transient hallucinatory experiences may occur without a mental disorder"(American Psychiatric Association 2013).

These statements, clearly, subscribe to the view that psychotic phenomena may form a spectrum which includes both illness and normality states in terms of intensity, persistence and re- 
ality testing. For the last decades, epidemiological research has provided robust evidence for this proposition: Psychosis expression in the community is not an all-or-none phenomenon. Rather, there are psychotic experiences (PEs) which are of subthreshold severity and impact but also share demographic, environmental, familial and psychopathological features with the psychotic syndromes (Linscott and van Os 2013). Thus, the extended psychosis phenotype can be defined as the range from subthreshold PEs in non-clinical populations gradually blending into clinical-threshold psychotic disorders (PDs) such as severe and recurrent schizophrenia (Kaymaz and van Os 2010).

Although weak expressions of negative and disorganization symptoms are prevalent in the community (Dominguez et al. 2010a;Walss-Bass et al. 2015), the term PEs mostly refer to subthreshold positive psychotic symptoms in the literature (van Os and Reininghaus 2016). In order to be consistent, the term PEs will be used in this meaning throughout this thesis. When subthreshold negative and disorganized expressions are indicated, these terms (negative/disorganised) will be used as such.

Current classification systems define an operational threshold of 'frank' psychosis in the context of a psychotic syndrome. The threshold is mainly based on persistence of distress or clearcut impairment in social, occupational, or other important areas of functioning, along with impact on reality testing and insight (American Psychiatric Association 2013). For example, in DSM5 , the distinction between the diagnoses 'substance intoxication or withdrawal, with perceptual disturbances' and 'substance-induced psychotic disorder' was defined in terms of being sufficiently severe to warrant clinical attention and the level of reality testing (American Psychiatric Association 2013). This threshold inevitably includes some grey areas (McGorry and van Os 2013), inducing a dilemma of reliability and validity as shown below in figure 1 (van Os et al. 2000a;Linscott et al. 2010). Along with other reasons detailed below, this dilemma demonstrates the 
need for the conceptualization of psychosis along a spectrum including normality states (Guloksuz and van Os 2017).

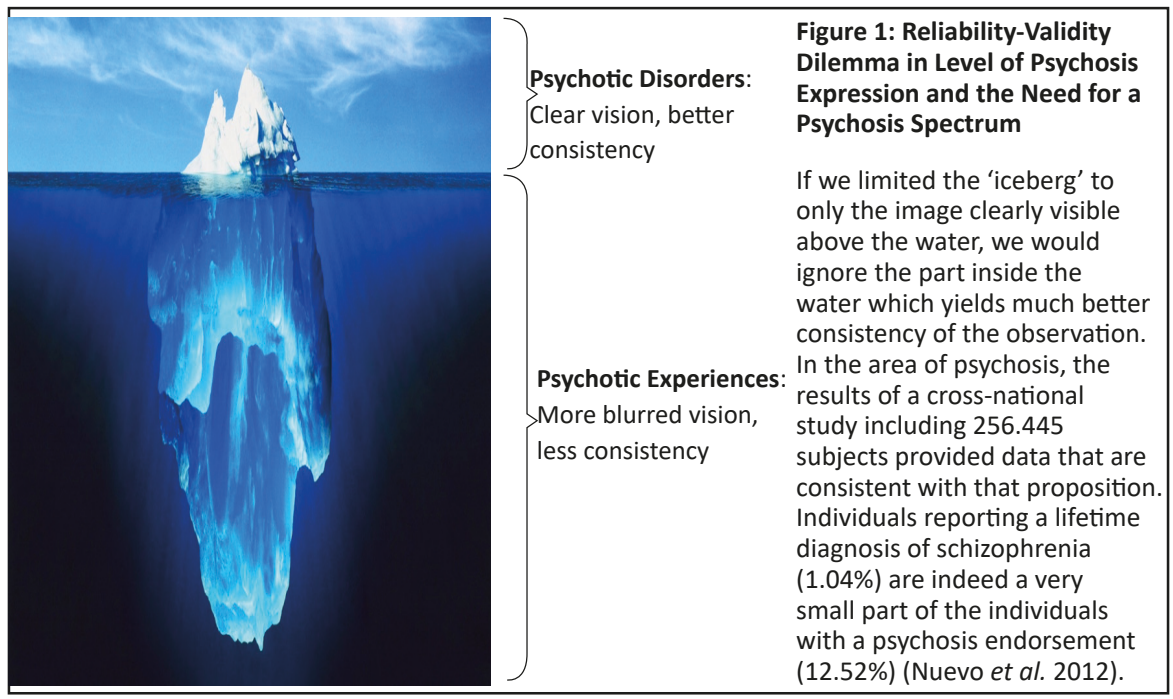

\section{Distribution of Psychosis Spectrum in Psychintric Nosology}

Epidemiological studies have consistently shown that subthreshold psychosis is more common in those who are helpseeking and distressed -so called clinical populations- than in the non-helpseeking general populations. PEs in clinical populations, mostly diagnosed with a non-psychotic disorder (i.e. depression/ anxiety/substance-use disorders), have similar risk factors but poorer outcomes than PEs in general non-helpseeking populations (Varghese et al. 2009; van Nierop et al. 2011; Saha et al. 2012;van Os and Linscott 2012; Wigman et al. 2012;DeVylder et al. 2014;Stochl et al. 2014;Johns et al. 2018;Scott et al. 2018).

Studies, sampling helpseeking and distressed individuals in clinical settings, have also evaluated psychosis expression below the operational threshold of 'frank' psychosis within high-risk categories, i.e. categories considered to predict a high risk of conversion to clinical psychotic disorder (McGorry and van Os 2013) (i.e. At Risk Mental States- ARMS, 
Ultra-High Risk-UHR, Clinical High Risk-CHR, DSM-5 Attenuated Psychosis Syndrome-APS) (Klosterkötter et al. 1996;Miller et al. 2003; Schultze-Lutter et al. 2008; Yung and Nelson 2011;American Psychiatric Association 2013;Schultze-Lutter et al. 2017). These clinical high risk categories phenotypically have substantial similarities and overlap with general population samples of helpseeking and distressed subjects with PEs as the majority of individuals meeting high-risk criteria have a diagnosis of a non-psychotic disorder (depression/ anxiety/substance use disorders) (Ruhrmann et al. 2010; $\mathrm{Si}$ mon and Umbricht 2010;van Os and Linscott 2012;American Psychiatric Association 2013;Addington et al. 2014;Fusar-Poli et al. 2014;Falkenberg et al. 2015; Lin et al. 2015;Lo Cascio et al. 2016;Woodberry et al. 2016; Schultze-Lutter et al. 2017;van Os and Guloksuz 2017). When the high-risk criteria, developed in clinical samples seeking help at psychiatric services, are assessed in non-helpseeking general population samples, attenuated positive symptoms meeting the threshold of highrisk criteria only apply to a fraction of PEs (about 10-20\%). Furthermore, risk factors associated with high risk categories were similar to those of the PEs in non-clinical populations (Zammit et al. 2013; Schultze-Lutter et al. 2017). Finally, attenuated positive symptoms within high risk categories in helpseeking clinical samples have poorer prognosis than PEs in non-clinical populations (van Os and Linscott 2012; Fusar-Poli et al. 2013;Linscott and van Os 2013;Fusar-Poli et al. 2014;Lin et al. 2015;van Os and Guloksuz 2017;Polari et al. 2018;Radua et al. 2018; Oliver et al. 2019). Taken together, these results point out to two propositions: i. High-risk categories in helpseeking non-psychotic clinical samples may be considered as a subsample of subthreshold psychosis in non-helpseeking general population samples. ii. Subthreshold psychosis in non-helpseeking general populations and in clinical populations may be related to each other in the sense of being at different positions of a spectrum of severity (van Os and Linscott 2012; van Os and Guloksuz 2017). 
There is substantial evidence demonstrating shared associations between subthreshold psychosis in general populations and threshold psychotic disorders (van Os et al. 2008; van Os and Linscott 2012; Linscott and van Os 2013). Similarly, shared associations between subthreshold psychosis in non-psychotic clinical populations and threshold psychotic disorders has caught attention (van Os and Reininghaus 2016; Fusar-Poli et al. 2017;:Schultze-Lutter et al. 2017;Radua et al. 2018; Oliver et al. 2019). Furthermore, individuals with subthreshold psychosis (in clinical non-psychotic and to a lesser extent in non-clinical general population samples) have much more risk for later psychotic disorders in comparison with those who do not, indicating a temporal continuity (van Os and Linscott 2012; Linscott and van Os 2013;McGorry et al. 2018).

Threshold psychotic disorders are currently classified across a myriad of categories, embracing a polythetic approach. Some of these disorders, in which the psychotic symptoms are considered to be the core factor, are classified in schizophrenia spectrum and other psychotic disorders in DSM-5: Schizophrenia, schizophreniform disorder, schizoaffective disorder, delusional disorder, brief psychotic disorder, substance/medication/another medical condition induced psychotic disorder (American Psychiatric Association 2013). Additionally, inclusion of a schizo-obsessive disorder category is being discussed (Scotti-Muzzi and Saide 2016). However, there are other disorders with threshold psychotic symptoms (i.e. psychotic features) which are classified elsewhere: Depression/bipolar disorders with psychotic features, obsessive compulsive and related disorders with absent insight/delusional beliefs, major neurocognitive disorders with behavioural disturbances (Guloksuz et al. 2015; van Os 2016;Guloksuz and van Os 2017). Furthermore, behavioural disturbances in the context of psychotic features is common in neurodevelopmental disorders (Cochran et al. 2013;Kokurcan and Atbasoglu 2015) (figure 2). 


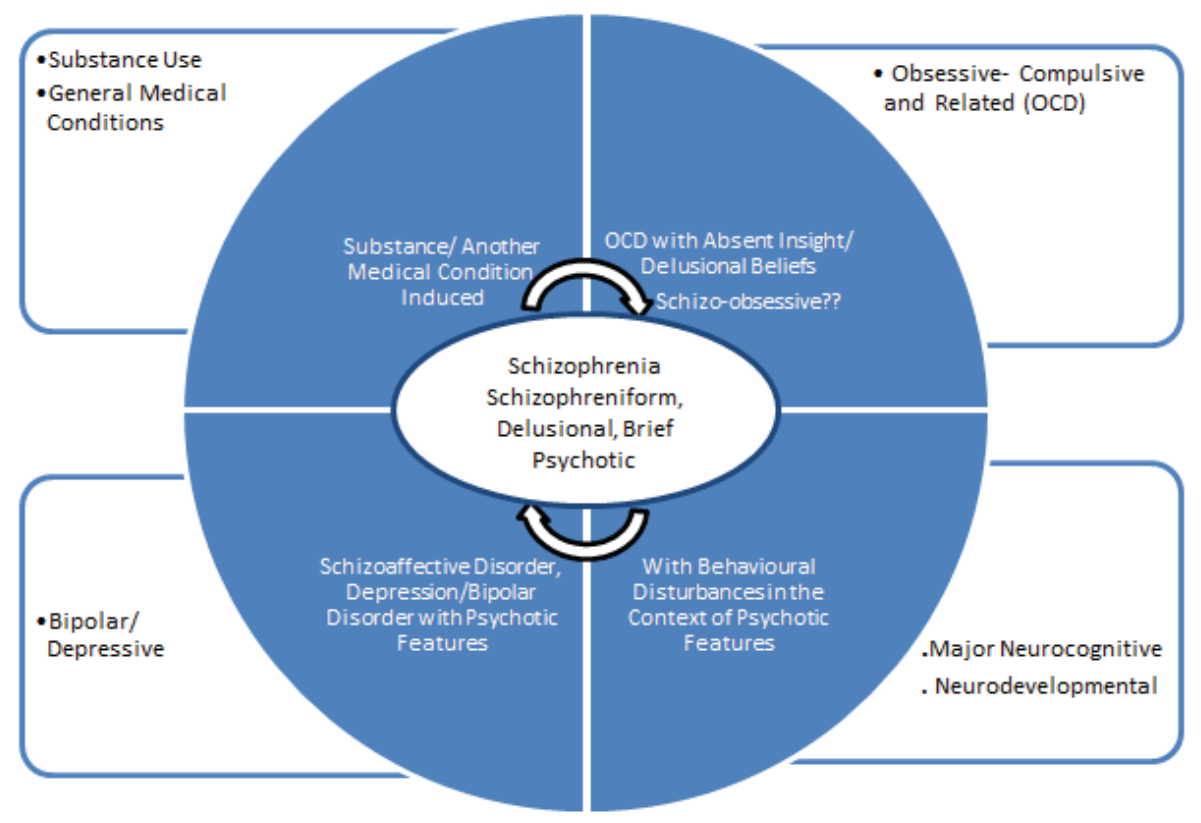

Figure 2: Current Categories of Threshold Psychosis

The primary objective of the abovementioned classification is to generate categories which are both as exhaustive as possible, and mutually exclusive (Reininghaus et al. 2012). However, from the perspective of the postulate mentioned in the starting point of the thesis, "concepts and distinctions are only admissible to the extent that observable facts can be assigned to them without ambiguity" (Einstein 1967), a question arises: Can we assign (at least most of the) observable facts to the current categories?

Recent large genome-wide genotype data has shown a remarkable amount of shared genetic risk loci among different diagnostic categories (i.e. schizophrenia, bipolar disorder and major depressive disorder) (Lee et al. 2013;Brainstorm et al. 2018; Cross-Disorder Group of the Psychiatric Genomics Consortium 2019). Furthermore, the polygenic risk for schizophrenia has been associated with the dimensional domains of psychosis across diagnostic categories (van Os et al. 2017). These results are consistent with the evidence from previous twin (Kendler et 
al. 2003) and family history studies (Dean et al. 2010;Mortensen et al. 2010;DeVylder and Lukens 2013;Chou et al. 2017). In addition to shared genetic liability, there are a remarkable number of shared factors between different diagnostic categories with threshold psychosis: phenomenology (van Os et al. 2000a;Tamminga et al. 2013), cognition (Bora et al. 2009;van Os and Linscott 2012;Hill et al. 2013;Menkes et al. 2019), neuroimaging findings (Ivleva et al. 2013;Goodkind et al. 2015; Jauhar et al. 2017) as well as environmental exposures (Radhakrishnan et al. 2014a;Guloksuz et al. 2015;Isvoranu et al. 2016; Misiak et al. 2017; Pries et al. 2018).

About half of first episode psychosis (FEP) patients are classified in schizophrenia spectrum and other psychotic disorders, and the remaining in disorders with 'psychotic features' specifiers (Henry et al. 2007;McGorry et al. 2018; Quattrone et al. 2019). The diagnoses are subject to considerable change over time (Pope et al. 2013;Fusar-Poli et al. 2016;Guloksuz and van Os 2017). Differential diagnoses between distinct disorders with threshold psychosis are based on: i. the duration, number, relative proportion and chronological association of symptom domains in the combination ii. being attributable to the physiological effects of a substance/medication use/general medical condition (van Os and Kapur 2009;American Psychiatric Association 2013). These diagnoses are both strongly correlated with each other and diagnosable concurrently, causing high rates of comorbidity (van Os et al. 2019). Relatedly, there is a lack of zones of relative rarity between these diagnoses (Andrews et al. 2009; Carpenter et al. 2009; Reininghaus et al. 2012). Furthermore, the medications that patients with different diagnoses respond to are similar (e.g. patients suffering from an affective disorder with an admixture of psychosis respond to second-generation antipsychotics, conversely, patients suffering from schizophrenia with an admixture of affective symptoms respond to lithium) (Guloksuz and van Os 2017). Finally, individuals within the same category have a high variability of prognosis (van Os et al. 1997;Allardyce and van Os 
2010;Zipursky et al. 2013;Castagnini and Fusar-Poli 2017;Guloksuz and van Os 2017).

In summary, the evidence for true diagnostic value of the distinction between these diagnoses is questionable, as evidenced by low diagnostic likelihood ratios as regards risk factors, symptoms, treatment and outcome (van Os et al. 2000b;Kelleher and Cannon 2014;van Os and Reininghaus 2016). Indeed, the distinction may obscure natural overlap throughout the psychosis spectrum (Crow 1990;van Os et al. 2000a;Moller 2003). Therefore, a research approach based on distinct categories of psychosis may cause a loss of power and precision (Kraemer 2007; Kelleher et al. 2018a; Isvoranu et al. 2019a). Furthermore, the approach to generate distinct categories of psychosis may be giving an implicit suggestion as these disorders are binary conditions which are possessed by a group of 'rare and unfortunate' individuals rather than being some end of a spectrum and thus, in part, fuelling stigmatization and internalized negative expectations (Zipursky et al. 2013;Lasalvia et al. 2015;Guloksuz and van Os 2017;Guloksuz and van Os 2018). Taken together with the evidence on subthreshold phenotypes, psychosis expression in psychiatric nosology may be considered along a spectrum of intensity and severity as follows (Guloksuz and van Os 2017):

i) Subthreshold psychosis in non-clinical populations

ii) Subthreshold psychosis in clinical populations (in the context of non-psychotic disorders, e.g. depression/anxiety/ substance-use disorders, including high risk groups)

iii) Threshold psychosis outside schizophrenia spectrum disorders (in disorders with 'psychotic features' specifiers)

iv) Schizophrenia spectrum disorders

From this point of view, the hypothetic distribution of psychosis spectrum in psychiatric nosology is summarised in figure 3. 


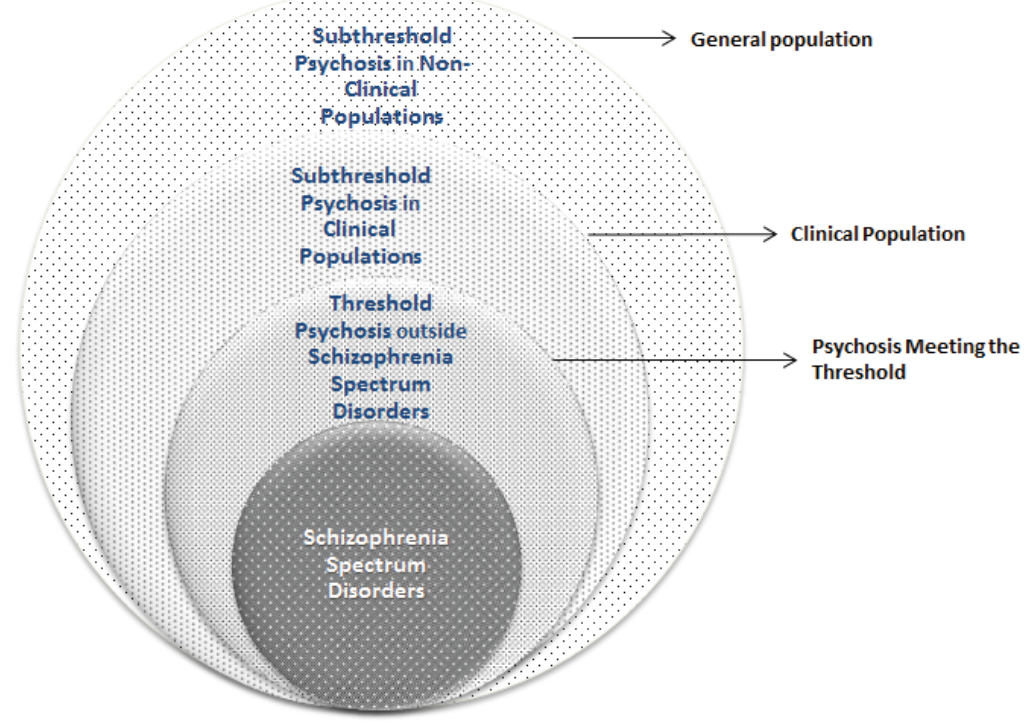

Figure 3: Distribution of Psychosis Spectrum in Psychiatric Nosology

*Intensity of dots represents the intensity of psychosis

Subthreshold Psychosis in Clinical Populations (including High Risk Groups): DSM-5 Attenuated Psychosis Syndrome-APS; At Risk Mental States- ARMS/ Ultra-High Risk-UHR/ Clinical High Risk-CHR, Common Non-Psychotic Disorders (Depression/Anxiety/Substance use etc.) with Subthreshold PEs

Threshold Psychosis outside Schizophrenia Spectrum Disorders (in Disorders with 'Psychotic Features' Specifiers): Bipolar and Related Disorders with Psychotic Features, Depressive Disorders with Psychotic Features, Major Neurocognitive/ Neurodevelopmental Disorders with Behavioural Disturbances in the Context of Psychotic Features, Obsessive-Compulsive and Related Disorders with Absent Insight/Delusional Beliefs" etc.

Schizophrenia Spectrum Disorders: Disorders included in this category in current classification systems

\section{Transdiagnostic Psychosis Phenotype in Relation to Psychosis Spectrum}

Psychosis expression in the community, from lower to higher levels of intensity and severity (figure 3), is typically expressed as a mixture of signs and symptoms within multiple domains (van Os 2013). For instance, in general non-clinical populations, there is a well-established link between PEs and motivational alterations, subclinical affective dysregulation and anxiety states (van Os et al. 1999; Verdoux et al. 1999;Hanssen et al. 
2003; Stefanis et al. 2004; van Rossum et al. 2009; van Os and Linscott 2012). Furthermore, subthreshold negative and disorganisation experiences commonly co-occur with PEs in these samples (van Os et al. 2000b;Krabbendam et al. 2004;Dominguez et al. 2010a; Walss-Bass et al. 2015;van Os and Reininghaus 2016). A similar pattern is observed at the level of subthreshold psychosis in clinical populations (including high risk for psychosis groups) (Fusar-Poli et al. 2014; van Os et al. 2017). PEs are 2-3 fold more common in individuals with non-psychotic mental disorders (i.e. affective/anxiety disorders), and the occurrence of PEs in these disorders is associated with the general severity of psychopathology, rather than the type of the disorder (Varghese et al. 2009;van Nierop et al. 2011; Saha et al. 2012; van Os and Linscott 2012; Wigman et al. 2012;DeVylder et al. 2014;Stochl et al. 2014;Johns et al. 2018; Scott et al. 2018). Negative symptoms are also common in these samples (i.e. high risk samples), with a similar prevalence as threshold psychotic disorders (Sauve et al. 2019). Finally, such co-occurrence of symptoms within multiple domains is also observed among individuals with threshold psychosis, as well as their relatives (Tsuang 1979;Buckley et al. 2008;McMillan et al. 2009;Dean et al. 2010;Mortensen et al. 2010;DeVylder and Lukens 2013). In summary, psychosis expression in the community throughout different levels of severity and intensity co-occurs and overlaps with symptoms from multiple dimensions, as well as with disorder states from different diagnostic spectra, suggesting a transdiagnostic psychosis phenotype in addition to the extended psychosis phenotype (van Os and Reininghaus 2016).

Growing research has suggested that the extended and transdiagnostic psychosis phenotype in the community may be complemented by specific non-affective (positive, negative and disorganisation) and affective dimensions, which, when used in combination, could help for a more accurate conceptualisation (Reininghaus et al. 2012; Shevlin et al. 2017; Reininghaus et al. 2018; Quattrone et al. 2019). 


\section{Hypothetical Network Model of Psychosis Dimensions across the Spectrum}

Emerging evidence has questioned the traditional framework that investigates 'direct' associations between risk factors and specific disorders (Isvoranu et al. 2019b). First, as described in detail above, risk factors do not seem to be specific to particular diagnostic categories, but rather appear to be shared across different categories (van Os and Reininghaus 2016;McGorry et al. 2018). Conversely, specific symptom domains within a single disorder may be associated with different risk factors (Dominguez et al. 2010b;Varese et al. 2012;Fried et al. 2013), which (at least to a degree) may explain various clinical presentations and prognostic states of a unique disorder (Gong et al. 2014; Isvoranu et al. 2016; Isvoranu et al. 2017). In addition, both environmental (Carpenter et al. 2009; Heinz et al. 2013; Gevonden et al. 2014;Radhakrishnan et al. 2014b;van Nierop et al. 2014;Misiak et al. 2017) and genetic risk (Carpenter et al. 2009; van Os et al. 2017;Isvoranu et al. 2019a) may influence multiple domains (Guloksuz et al. 2018a;Guloksuz et al. 2018b;Cross-Disorder Group of the Psychiatric Genomics Consortium 2019).

Recent research has demonstrated different pathways of risk exposure and emergence of psychosis: Exposure to risk may be expressed as an increasing severity and persistence of common subtle alterations in daily life, causing symptoms, and, subsequently, impairment (Cougnard et al. 2007; Linscott and van Os 2013;McGorry and van Os 2013). In addition, risk factors may impact on the connectivity between different domains of psychosis (Guloksuz et al. 2015; Smeets et al. 2015;Guloksuz et al. 2016; Isvoranu et al. 2016). Connectivity between subthreshold non-affective and affective domains seems to be associated with greater cross-sectional severity of psychopathology, as well as poorer long term outcomes (Kaymaz et al. 2007;Perlis et al. 2010;Rössler et al. 2011;Kaymaz et al. 2012; Wigman et al. 2012;American Psychiatric Association 2013;Kelleher et al. 2018b). As discussed in detail above, PEs and affective/anxiety states may 
bidirectionally indicate severity of the index psychopathology (van Rossum et al. 2009; Varghese et al. 2009;Dominguez et al. 2010a;van Nierop et al. 2011; Saha et al. 2012;van Os and Linscott 2012;Wigman et al. 2012;DeVylder et al. 2014;Stochl et al. 2014;McGrath et al. 2016; Johns et al. 2018; Scott et al. 2018). Furthermore, co-occurrence of the negative and disorganized experiences with PEs has been associated with an increased risk of psychotic impairment over time (Dominguez et al. 2010a;Werbeloff 2012;van Os and Reininghaus 2016;Pries et al. 2018).

A recent novel theoretical framework is also suggestive of some direct interactive effects between symptoms (Borsboom and Cramer 2013;Isvoranu et al. 2016;Epskamp 2017;Fried and Cramer 2017). In other words, some domains of psychopathology may be causal agents for others. For example, stress may lead to poor sleep which may lead to fatigue, and fatigue may lead to low concentration (Schmittmann et al. 2013;Fried et al. 2015). Another example may be the triggering of social withdrawal by paranoid ideation over time, and vice-versa. These causal associations may lead to feedback loops between domains, and may collectively constitute disorder states (Isvoranu et al. 2019b). Taken together, emergence of psychotic impairment cannot be explained by simple linear models, instead complemented by the complex interplay between symptoms and genetic and environmental exposures (Pries et al. 2018) (Figure 4).

$\begin{gathered}\text { Subthreshold Psychosis in Clinical } \\ \text { Populations (High Risk Groups } \\ \text { included) }\end{gathered}$




\section{Aims}

The extended and transdiagnostic psychosis phenotype represents an excellent framework from which to study the psychosis expression in the context of multidimensional psychopathology. In this thesis, psychosis was assessed along a spectrum of severity including both clinical and non-clinical individuals, based on a six-year follow-up of a representative general population-based sample. Predominantly longitudinal etiological and phenomenological associations along the whole phenotypic spectrum as well as with other dimensions of psychopathology were under investigation.

Chapter 2 describes the outlines, framework and methodology of the cohort project in detail. The Izmir Mental Health Cohort for Gene-Environment Interaction in Psychosis (TürkSch) is a prospective, longitudinal study consisting of several data collection stages. The design of the study provided unique opportunities to meet the challenges of evaluating the different dimensions of, and the multifactorial (genetic and non-genetic) risk for psychosis. Owing to the large, representative general population-based sample and diagnostic interviews conducted by a psychiatrist in the field, the psychosis phenotype from subthreshold-non clinical expressions to threshold psychotic disorders could be covered. Furthermore, the risk factors in the wider social environment such as neighbourhood-level risk factors could be taken into account besides factors at individual and family level. Blood sampling in the field also enabled to evaluate targeted gene-environment interactions in the psychosis spectrum covering the subthreshold phenotypes.

In this chapter, besides the detailed design of the project, analyses of factors associated with non-response and refusal at follow-up, which are of importance in planning future general population-based cohort studies, were presented. Finally, dynamic transitions in the psychosis spectrum over the six-year period were presented. 
In Chapter 3, the natural overlap as well as the reciprocal associations over time between the extended psychosis phenotype and affective states was investigated. For this aim, the extended psychosis phenotype was stratified by severity, using both self-report information and diagnostic interviews, including threshold psychotic disorders, clinical-subthreshold psychosis and subclinical-subthreshold psychosis. Longitudinal bidirectional associations between the extended psychosis phenotype and the affective states were assessed. Furthermore, plausible additive interactions as well as synchronous and cross-lagged correlations over time were evaluated. Finally, shared and unshared etiological associations were explored.

In chapter 4, the longitudinal outcomes of PEs in the context of psychopathology pertaining to any diagnostic spectrum were investigated. To this end, the six-year structured clinical interview for DSM (SCID) results of a sub-group of the cohort (individuals with baseline clinical-subthreshold psychosis) were given in detail. Furthermore, the role of co-occurrence of symptoms within a single domain (delusions and hallucinations) and within different domains (positive and affective) as well as socio-demographic and familial risk on the outcome (presence of any disorder, psychotic or non-psychotic disorder) were evaluated, adjusting for other familial and common environmental exposures.

In chapter 5, a genetic locus with multiple variants (BDNF), hypothesized a priori to have relevance in this context, was analysed in relation to the dimensional and transdiagnostically expressed psychosis phenotype. Analyses were based on the positive dimension (along a spectrum of severity including subthreshold as well as threshold levels), cutting across boundaries of the diagnostic categories of the current classification systems (expressed both in non-psychotic and psychotic disorders over time, detailed in chapter 4). The phenotype was epidemiological, longitudinally assessed through a nested case-control sample within the cohort, and the associations were adjusted for socio-demographics and common environmental exposures. 
Similar to various genetic and environmental risk factors, BDNF has been pleiotropically associated with various disorders cutting across diagnostic categories (mood, anxiety, schizophrenia spectrum disorders etc.). On the other hand, findings on the associations with single syndromal states (e.g. schizophrenia) are inconsistent, which suggests a need to explore the impact on dimensional liabilities (including subthreshold phenotypes) rather than syndromal states which consist of merely threshold symptoms from multiple dimensions, occasioning much heterogeneity from sample to sample. Therefore, the aim of the chapter, in regard to this thesis, is to contribute to the increasing need for a novel dynamic and dimensional perspective on risk assessment in the psychosis area (van Os and Reininghaus 2016;McGorry et al. 2018). 


\section{References}

- Addington J, Case N, Saleem MM, Auther AM, Cornblatt BA, Cadenhead KS (2014). Substance use in clinical high risk for psychosis: a review of the literature. Early Interv Psychiatry 8, 104-112.

- Allardyce J, van Os J (2010). The Natural History of the Course and Outcome of Schizophrenia. 51-65.

- American Psychiatric Association (1952). Diagnostic and statistical manual of mental disorders. American Psychiatric Association Mental Hospital Service: Washington, DC.

- American Psychiatric Association (2013). Diagnostic and statistical manual of mental disorders, - 5th edition: DSM-5. American Psychiatric Association: Washington, DC.

- Andrews G, Goldberg DP, Krueger RF, et al. (2009). Exploring the feasibility of a meta-structure for DSM-V and ICD-11: could it improve utility and validity?
Psychological medicine 39, 1993-2000.

- Bora E, Yucel M, Pantelis C (2009). Cognitive functioning in schizophrenia, schizoaffective disorder and affective psychoses: meta-analytic study. The British journal of psychiatry : the journal of mental science 195, 475-482.

- Borsboom D, Cramer AOJ (2013). Network Analysis: An Integrative Approach to the Structure of Psychopathology. Annual Review of Clinical Psychology 9, 91-121.

- Brainstorm C, Anttila V, Bulik-Sullivan B, et al. (2018). Analysis of shared heritability in common disorders of the brain. Science 360 .

- Buckley PF, Miller BJ, Lehrer DS , Castle DJ (2008). Psychiatric Comorbidities and Schizophrenia. Schizophrenia Bulletin 35, 383-402.

- Carpenter WT, Bustillo JR, Thaker GK, van Os J, Krueger RF , Green MJ (2009). The psychoses: 
cluster 3 of the proposed meta-structure for DSM-V and ICD-11. Psychological medicine 39, 2025-2042.

- Castagnini AC , Fusar-Poli P (2017). Diagnostic validity of ICD-10 acute and transient psychotic disorders and DSM-5 brief psychotic disorder. European psychiatry : the journal of the Association of European Psychiatrists 45, 104-113.

- Chou IJ, Kuo CF, Huang YS, et al. (2017). Familial Aggregation and Heritability of Schizophrenia and Co-aggregation of Psychiatric Illnesses in Affected Families. Schizophrenia Bulletin 43, 1070-1078.

- Cochran DM, Dvir Y, Frazier JA (2013). "Autism-plus" Spectrum Disorders. Child and Adolescent Psychiatric Clinics of North America 22, 609-627.

- Cougnard A, Marcelis M, Myin-Germeys I, et al. (2007). Does normal developmental expression of psychosis combine with environmental risk to cause persistence of psychosis? A psychosis proneness-per- sistence model. Psychological Medicine 37, 513.

- Cross-Disorder Group of the Psychiatric Genomics Consortium (2019). Genomic Relationships, Novel Loci, and Pleiotropic Mechanisms across Eight Psychiatric Disorders. Cell 179, 1469-1482 e1411.

- Crow TJ (1990). Nature of the genetic contribution to psychotic illness - a continuum viewpoint. Acta psychiatrica Scandinavica 81 , 401-408.

- Dean K, Stevens H, Mortensen PB, Murray RM, Walsh E, Pedersen CB (2010). Full spectrum of psychiatric outcomes among offspring with parental history of mental disorder. Archives of general psychiatry 67, 822-829.

- DeVylder JE, Burnette D , Yang LH (2014). Co-occurrence of psychotic experiences and common mental health conditions across four racially and ethnically diverse population samples. Psychological Medicine 44, 3503-3513. 
- DeVylder JE, Lukens EP (2013). Family history of schizophrenia as a risk factor for axis I psychiatric conditions. Journal of psychiatric research 47, 181-187.

- Dominguez M-d-G, Saka MC, Lieb R, Wittchen H-U , van Os J (2010a). Early Expression of Negative/Disorganized Symptoms Predicting Psychotic Experiences and Subsequent Clinical Psychosis: A 10-Year Study. American Journal of Psychiatry 167, 1075-1082.

- Dominguez MD, Saka MC, Lieb R, Wittchen HU, van Os J (2010b). Early expression of negative/disorganized symptoms predicting psychotic experiences and subsequent clinical psychosis: a 10-year study. American Journal of Psychiatry 167, 1075-1082.

- Einstein A (1967). "Fundamental Ideas and Problems of the Theory of Relativity," delivered 11 July 1923 to the Nordic Assembly of Naturalists at Gothenburg in acknowledgement of the
Nobel Prize. In Nobel Lectures: 1901-1921, pp. 482490. Elsevier: New York.

- Epskamp S (2017). Network psychometrics., p. 300. University of Amsterdam: Amsterdam.

- Falkenberg I, Valmaggia L, Byrnes M, et al. (2015). Why are help-seeking subjects at ultra-high risk for psychosis help-seeking? Psychiatry research 228, 808-815.

- Fried EI, Bockting C, Arjadi $\mathrm{R}$, et al. (2015). From loss to loneliness: The relationship between bereavement and depressive symptoms. Journal of abnormal psychology 124, 256-265.

- Fried EI, Cramer AOJ (2017). Moving Forward: Challenges and Directions for Psychopathological Network Theory and Methodology. Perspectives on Psychological Science 12, 999-1020.

- Fried EI, Nesse RM, Zivin K, Guille C, Sen S (2013). Depression is more than the sum score of its parts: 
individual DSM symptoms have different risk factors. Psychological medicine 44, 2067-2076.

- Fusar-Poli P, Borgwardt S, Bechdolf A, et al. (2013). The Psychosis High-Risk State. JAMA psychiatry 70, 107.

- Fusar-Poli P, Cappucciati M, Rutigliano G, et al. (2016). Diagnostic Stability of ICD/DSM First Episode Psychosis Diagnoses: Meta-analysis. Schizophrenia Bulletin 42, 1395-1406.

- Fusar-Poli P, Nelson B, Valmaggia L, Yung AR , McGuire PK (2014). Comorbid depressive and anxiety disorders in 509 individuals with an at-risk mental state: impact on psychopathology and transition to psychosis. Schizophr Bull 40, 120-131.

- Fusar-Poli P, Tantardini M, De Simone S, et al. (2017). Deconstructing vulnerability for psychosis: Meta-analysis of environmental risk factors for psychosis in subjects at ultra high-risk. European Psychiatry 40, 65-75.
- Gevonden MJ, Myin-Germeys I, van den Brink W, van Os J, Selten JP, Booij J (2014). Psychotic reactions to daily life stress and dopamine function in people with severe hearing impairment. Psychological Medicine 45, 1665-1674.

- Gong Q, Fried EI, Nesse RM (2014). The Impact of Individual Depressive Symptoms on Impairment of Psychosocial Functioning. Plos one 9, e90311.

- Goodkind M, Eickhoff SB, Oathes DJ, et al. (2015). Identification of a common neurobiological substrate for mental illness. JAMA psychiatry 72, 305-315.

- Guloksuz S, Rutten BPF, Pries LK, et al. (2018a). The Complexities of Evaluating the Exposome in Psychiatry: A Data-Driven Illustration of Challenges and Some Propositions for Amendments. Schizophrenia Bulletin 44, 1175-1179.

- Guloksuz S, van Nierop M, Bak M, et al. (2016). Exposure to environmental factors increases connectivity 
between symptom domains in the psychopathology network. BMC psychiatry 16.

- Guloksuz S, van Nierop M, Lieb R, van Winkel R, Wittchen HU, van Os J (2015). Evidence that the presence of psychosis in non-psychotic disorder is environment-dependent and mediated by severity of non-psychotic psychopathology. Psychological Medicine 45, 2389-2401.

- Guloksuz S , van Os J (2017). The slow death of the concept of schizophrenia and the painful birth of the psychosis spectrum. Psychological medicine 48, 229-244.

- Guloksuz S, van Os J (2018). Renaming schizophrenia: $5 \times 5$. Epidemiology and Psychiatric Sciences 28, 254-257.

- Guloksuz S, van Os J , Rutten BPF (2018b). The Exposome Paradigm and the Complexities of Environmental Research in Psychiatry. JAMA Psychiatry 75, 985-986.

- Hanssen M, Peeters F, Krabbendam L, Radstake $\mathrm{S}$, Verdoux H, van Os J
(2003). How psychotic are individuals with non-psychotic disorders? Social Psychiatry and Psychiatric Epidemiology 38, 149-154.

- Heinz A, Deserno L, Reininghaus U (2013). Urbanicity, social adversity and psychosis. World Psychiatry 12, 187-197.

- Henry LP, Harris MG, Amminger GP, et al. (2007). Early Psychosis Prevention and Intervention Centre long-term follow-up study of first-episode psychosis: methodology and baseline characteristics. Early Intervention in Psychiatry 1, 49-60.

- Hill SK, Reilly JL, Keefe RS, et al. (2013). Neuropsychological impairments in schizophrenia and psychotic bipolar disorder: findings from the Bipolar-Schizophrenia Network on Intermediate Phenotypes (B-SNIP) study. The American journal of psychiatry 170, 1275-1284.

- Isvoranu A-M, Borsboom D, van Os J , Guloksuz S (2016). A Network Approach to Environmental Impact in Psychotic Disorder: Brief 
Theoretical Framework.

Schizophrenia Bulletin 42, 870-873.

- Isvoranu A-M, Guloksuz S, Epskamp S, van Os J , Borsboom D (2019a). Toward incorporating genetic risk scores into symptom networks of psychosis. Psychological medicine, 1-8.

- Isvoranu A-M, van Borkulo CD, Boyette L-L, Wigman JTW, Vinkers CH, Borsboom D (2017). A Network Approach to Psychosis: Pathways Between Childhood Trauma and Psychotic Symptoms. Schizophrenia Bulletin 43, 187-196.

- Isvoranu AM, Boyette LL, Guloksuz S , Borsboom D (2019b). Symptom network models of psychosis. In Psychotic Disorders: Comprehensive Conceptualization and Treatments (ed. J. van Os, U. Reininghaus, E. I. Ivleva and C. A. Tamminga). Oxford University Press: Oxford.

- Ivleva EI, Bidesi AS, Keshavan MS, et al. (2013). Gray matter volume as an intermediate pheno- type for psychosis: Bipolar-Schizophrenia Network on Intermediate Phenotypes (B-SNIP). The American journal of psychiatry 170, 1285-1296.

- Jauhar S, Nour MM, Veronese M, et al. (2017). A Test of the Transdiagnostic Dopamine Hypothesis of Psychosis Using Positron Emission Tomographic Imaging in Bipolar Affective Disorder and Schizophrenia. JAMA psychiatry 74, 12061213.

- Johns LC, Cannon M, Singleton N, et al. (2018). Prevalence and correlates of self-reported psychotic symptoms in the British population. British Journal of Psychiatry 185, 298-305.

- Kaymaz N, Drukker M, Lieb R, et al. (2012). Do subthreshold psychotic experiences predict clinical outcomes in unselected non-help-seeking population-based samples? A systematic review and meta-analysis, enriched with new results. Psychological Medicine 42, 2239-2253. 
- Kaymaz N , van Os J (2010). Extended psychosis phenotype--yes: single continuum--unlikely. Psychological medicine 40, 1963-1966.

- Kaymaz N, van Os J, de Graaf R, ten Have M, Nolen W , Krabbendam L (2007). The impact of subclinical psychosis on the transition from subclinicial mania to bipolar disorder. Journal of affective disorders 98, 5564.

- Kelleher I, Cannon M (2014). Whither the psychosis-neurosis borderline. Schizophrenia Bulletin 40, 266-268.

- Kelleher I, Jenner JA, Cannon M (2018a). Psychotic symptoms in the general population - an evolutionary perspective. British Journal of Psychiatry 197, 167-169.

- Kelleher I, Keeley H, Corcoran P, et al. (2018b). Clinicopathological significance of psychotic experiences in non-psychotic young people: evidence from four population-based studies. British Journal of Psychiatry 201, 26-32.

- Kendler KS, Prescott CA, Myers J , Neale MC (2003). The structure of genetic and environmental risk factors for common psychiatric and substance use disorders in men and women. Archives of general psychiatry 60, 929-937.

- Klosterkötter J, Ebel H, Schultze-Lutter F, Steinmeyer EM (1996). Diagnostic validity of basic symptoms. European Archives of Psychiatry and Clinical Neuroscience 246, 147154.

- Kokurcan A, Atbasoglu EC (2015). [Differential Diagnosis of Schizophrenia: Psychotic Symptoms in Neurodevelopmental Disorders and Psychotic Disorders due to other Medical Conditions]. Turk psikiyatri dergisi $=$ Turkish journal of psychiatry 26, 279-290.

- Krabbendam L, Myin-Germeys I, De Graaf R, et al. (2004). Dimensions of depression, mania and psychosis in the general 
population. Psychological Medicine 34, 1177-1186.

- Kraemer HC (2007). DSM categories and dimensions in clinical and research contexts. International Journal of Methods in Psychiatric Research 16, S8-S15.

- Lasalvia A, Penta E, Sartorius N, Henderson S (2015). Should the label "schizophrenia" be abandoned? Schizophrenia Research 162, 276-284.

- Lee SH, Ripke S, Neale BM, et al. (2013). Genetic relationship between five psychiatric disorders estimated from genome-wide SNPs. Nature genetics 45, 984994.

- Lin A, Wood SJ, Nelson B, Beavan A, McGorry P , Yung AR (2015). Outcomes of Nontransitioned Cases in a Sample at Ultra-High Risk for Psychosis. American Journal of Psychiatry 172, 249-258.

- Linscott RJ, Allardyce J , van Os J (2010). Seeking Verisimilitude in a Class: A Systematic Review of
Evidence That the Criterial Clinical Symptoms of Schizophrenia Are Taxonic. Schizophrenia Bulletin 36, 811-829.

- Linscott RJ , van Os J (2013). An updated and conservative systematic review and meta-analysis of epidemiological evidence on psychotic experiences in children and adults: on the pathway from proneness to persistence to dimensional expression across mental disorders. Psychological medicine 43, 1133-1149.

- Lo Cascio N, Saba R, Hauser M, et al. (2016). Attenuated psychotic and basic symptom characteristics in adolescents with ultra-high risk criteria for psychosis, other non-psychotic psychiatric disorders and early-onset psychosis. European Child \& Adolescent Psychiatry 25, 1091-1102.

- McGorry P, van Os J (2013). Redeeming diagnosis in psychiatry: timing versus specificity. Lancet $381,343-345$. 
- McGorry PD, Hartmann JA, Spooner R , Nelson B (2018). Beyond the "at risk mental state" concept: transitioning to transdiagnostic psychiatry. World Psychiatry 17, 133-142.

- McGrath JJ, Saha S, Al-Hamzawi A, et al. (2016). The Bidirectional Associations Between Psychotic Experiences and DSM-IV Mental Disorders. American Journal of Psychiatry 173, 997-1006.

- McMillan KA, Enns MW, Cox BJ , Sareen J (2009). Comorbidity of Axis I and II Mental Disorders with Schizophrenia and Psychotic Disorders: Findings from the National Epidemiologic Survey on Alcohol and Related Conditions. The Canadian Journal of Psychiatry 54, 477-486.

- Menkes MW, Armstrong K, Blackford JU, Heckers S , Woodward ND (2019). Neuropsychological functioning in early and chronic stages of schizophrenia and psychotic bipolar disorder. Schizophrenia Research 206, 413-419.
- Miller TJ, McGlashan TH, Rosen JL, et al. (2003). Prodromal Assessment With the Structured Interview for Prodromal Syndromes and the Scale of Prodromal Symptoms: Predictive Validity, Interrater Reliability, and Training to Reliability. Schizophrenia Bulletin 29, 703-715.

- Misiak B, Krefft M, Bielawski T, Moustafa AA, Sasiadek MM , Frydecka D (2017). Toward a unified theory of childhood trauma and psychosis: A comprehensive review of epidemiological, clinical, neuropsychological and biological findings. Neuroscience and biobehavioral reviews 75 , 393-406.

- Moller HJ (2003). Bipolar disorder and schizophrenia: distinct illnesses or a continuum? The Journal of clinical psychiatry 64 Suppl 6, 23-27; discussion 28.

- Mortensen PB, Pedersen MG , Pedersen CB (2010). Psychiatric family history and schizophrenia risk in Denmark: which mental 
disorders are relevant?

Psychological medicine 40, 201-210.

- Nuevo R, Chatterji S, Verdes E, Naidoo N, Arango C , Ayuso-Mateos JL (2012). The continuum of psychotic symptoms in the general population: a cross-national study. Schizophrenia bulletin 38, 475-485.

- Oliver D, Radua J, Reichenberg A, Uher R , Fusar-Poli P (2019). Psychosis Polyrisk Score (PPS) for the Detection of Individuals At-Risk and the Prediction of Their Outcomes. Frontiers in psychiatry 10.

- Perlis RH, Uher R, Ostacher M, et al. (2010). Association Between Bipolar Spectrum Features and Treatment Outcomes in Outpatients With Major Depressive Disorder. Archives of general psychiatry 68, 351.

- Polari A, Lavoie S, Yuen HP, et al. (2018). Clinical trajectories in the ultra-high risk for psychosis population. Schizophrenia Research.

- Pope MA, Joober R , Malla AK (2013). Diagnostic stabil- ity of first-episode psychotic disorders and persistence of comorbid psychiatric disorders over 1 year. Canadian journal of psychiatry. Revue canadienne de psychiatrie 58, 588-594.

- Pries L-K, Guloksuz S, ten Have M, et al. (2018). Evidence That Environmental and Familial Risks for Psychosis Additively Impact a Multidimensional Subthreshold Psychosis Syndrome. Schizophrenia bulletin 44, 710-719.

- Quattrone D, Di Forti M, Gayer-Anderson C, et al. (2019). Transdiagnostic dimensions of psychopathology at first episode psychosis: findings from the multinational EU-GEI study. Psychological medicine 49, 1378-1391.

- Radhakrishnan R, Wilkinson ST, D'Souza DC (2014a). Gone to Pot - A Review of the Association between Cannabis and Psychosis. Frontiers in psychiatry 5, 54.

- Radhakrishnan R, Wilkinson ST, Dâ€TMSouza DC 
(2014b). Gone to Pot â€“ A Review of the Association between Cannabis and Psychosis. Frontiers in psychiatry 5 .

- Radua J, Ramella-Cravaro $\mathrm{V}$, Ioannidis JPA, et al. (2018). What causes psychosis? An umbrella review of risk and protective factors. World Psychiatry 17, 49-66.

- Reininghaus U, Böhnke JR, Hosang G, et al. (2018). Evaluation of the validity and utility of a transdiagnostic psychosis dimension encompassing schizophrenia and bipolar disorder. British Journal of Psychiatry 209, 107-113.

- Reininghaus U, Priebe S , Bentall RP (2012). Testing the Psychopathology of Psychosis: Evidence for a General Psychosis Dimension. Schizophrenia Bulletin 39, 884-895.

- Rössler W, Hengartner MP, Ajdacic-Gross V, Haker H, Gamma A, Angst J (2011). Sub-clinical psychosis symptoms in young adults are risk factors for sub- sequent common mental disorders. Schizophrenia research 131, 18-23.

- Ruhrmann S, Schultze-Lutter F, Salokangas RKR, et al. (2010). Prediction of Psychosis in Adolescents and Young Adults at High Risk. Archives of general psychiatry 67, 241.

- Saha S, Scott J, Varghese D , McGrath J (2012). Anxiety and depressive disorders are associated with delusional-like experiences: a replication study based on a National Survey of Mental Health and Wellbeing. BMJ open 2 .

- Sauvé G, Brodeur MB, Shah JL, Lepage M (2019). The Prevalence of Negative Symptoms Across the Stages of the Psychosis Continuum. Harvard Review of Psychiatry 27, 15-32.

- Schmittmann VD, Cramer AOJ, Waldorp LJ, Epskamp S, Kievit RA, Borsboom D (2013). Deconstructing the construct: A network perspective on psychological phenomena. New Ideas in Psychology 31, 43-53. 
- Schultze-Lutter F, Michel C, Ruhrmann S, Schimmelmann BG (2017). Prevalence and clinical relevance of interview-assessed psychosis-risk symptoms in the young adult community. Psychological medicine 48, 1167-1178.

- Schultze-Lutter F, Ruhrmann S, Berning J, Maier W , Klosterkotter J (2008). Basic Symptoms and Ultrahigh Risk Criteria: Symptom Development in the Initial Prodromal State. Schizophrenia Bulletin 36, 182-191.

- Scott J, Chant D, Andrews G, Martin G , McGrath J (2018). Association between trauma exposure and delusional experiences in a large community-based sample. British Journal of Psychiatry 190, 339-343.

- Scotti-Muzzi E, Saide OL (2016). Schizo-obsessive spectrum disorders: an update. CNS Spectrums 22, 258-272.

- Shevlin M, McElroy E, Bentall RP, Reininghaus U , Murphy J (2017). The Psy- chosis Continuum: Testing a Bifactor Model of Psychosis in a General Population Sample. Schizophrenia Bulletin 43, 133-141.

- Simon AE, Umbricht D (2010). High remission rates from an initial ultra-high risk state for psychosis. Schizophrenia Research 116, 168-172.

- Smeets F, Lataster T, Viechtbauer W, Delespaul P (2015). Evidence That Environmental and Genetic Risks for Psychotic Disorder May Operate by Impacting on Connections Between Core Symptoms of Perceptual Alteration and Delusional Ideation. Schizophrenia bulletin 41, 687697.

- Stefanis NC, Delespaul P, Smyrnis N, et al. (2004). Is the excess risk of psychosis-like experiences in urban areas attributable to altered cognitive development? Social Psychiatry and Psychiatric Epidemiology 39, 364-368.

- Stochl J, Khandaker GM, Lewis G, et al. (2014). 
Mood, anxiety and psychotic phenomena measure a common psychopathological factor. Psychological medicine 45, 1483-1493.

- Tamminga CA, Ivleva EI, Keshavan MS, et al. (2013). Clinical phenotypes of psychosis in the Bipolar-Schizophrenia Network on Intermediate Phenotypes (B-SNIP). The American journal of psychiatry 170 , 1263-1274.

- Tsuang MT (1979). Longterm Outcome of Major Psychoses. Archives of general psychiatry 36, 1302.

- van Nierop M, van Os J, Gunther N, et al. (2011). Phenotypically Continuous With Clinical Psychosis, Discontinuous in Need for Care: Evidence for an Extended Psychosis Phenotype. Schizophrenia bulletin 38, 231-238.

- van Nierop M, Viechtbauer W, Gunther N, et al. (2014). Childhood trauma is associated with a specific admixture of affective, anxiety, and psychosis symptoms cutting across tradition- al diagnostic boundaries. Psychological Medicine 45, 1277-1288.

- van Os J (2013). The dynamics of subthreshold psychopathology: implications for diagnosis and treatment. The American journal of psychiatry 170, 695-698.

- van Os J (2016). "Schizophrenia" does not exist. BMJ 352, i375.

- van Os J, Gilvarry C, Bale $\mathrm{R}$, et al. (2000a). Diagnostic value of the DSM and ICD categories of psychosis: an evidence-based approach. UK700 Group. Social psychiatry and psychiatric epidemiology 35, 305-311.

- van Os J , Guloksuz S (2017). A critique of the "ultra-high risk" and "transition" paradigm. World Psychiatry 16, 200-206.

- van Os J, Guloksuz S, Vijn TW, Hafkenscheid A , Delespaul P (2019). The evidence-based group-level symptom-reduction model as the organizing principle for mental health care: time for change? World psychi- 
atry : official journal of the World Psychiatric Association 18, 88-96.

- van Os J, Hanssen M, Bij1 RV , Ravelli A (2000b). Strauss (1969) revisited: a psychosis continuum in the general population? Schizophrenia Research 45, 11-20.

- van Os J , Kapur S (2009). Schizophrenia. The Lancet 374, 635-645.

- van Os J , Linscott RJ (2012). Introduction: The Extended Psychosis Phenotype--Relationship With Schizophrenia and With Ultrahigh Risk Status for Psychosis. Schizophrenia bulletin 38, 227-230.

- van Os J, Linscott RJ, Myin-Germeys I, Delespaul P , Krabbendam L (2008). A systematic review and meta-analysis of the psychosis continuum: evidence for a psychosis pronenesspersistence-impairment model of psychotic disorder. Psychological Medicine 39, 179-195.

- van Os J , Reininghaus U (2016). Psychosis as a trans- diagnostic and extended phenotype in the general population. World psychiatry : official journal of the World Psychiatric Association 15, 118-124.

- van Os J, van der Steen Y, Islam MA, Guloksuz S, Rutten BP , Simons CJ (2017). Evidence that polygenic risk for psychotic disorder is expressed in the domain of neurodevelopment, emotion regulation and attribution of salience. Psychological medicine 47, 2421-2437.

- van Os J, Verdoux H, Maurice-Tison $\mathrm{S}$, et al. (1999). Self-reported psychosis-like symptoms and the continuum of psychosis. Social Psychiatry and Psychiatric Epidemiology 34, 459-463.

- van Os J, Wright P, Murray RM (1997). Follow-up studies of schizophrenia I: Natural history and non-psychopathological predictors of outcome. European Psychiatry 12, 327s-341s.

- van Rossum I, Dominguez MdG, Lieb R, Wittchen HU , van Os J (2009). Affective Dysregulation and Real- 
ity Distortion: A 10-Year Prospective Study of Their Association and Clinical Relevance. Schizophrenia Bulletin 37, 561-571.

- Varese F, Smeets F, Drukker M, et al. (2012). Childhood Adversities Increase the Risk of Psychosis: A Meta-analysis of Patient-Control, Prospectiveand Cross-sectional Cohort Studies. Schizophrenia bulletin 38, 661-671.

- Varghese D, Scott J, Welham J, et al. (2009). Psychotic-Like Experiences in Major Depression and Anxiety Disorders: A Population-Based Survey in Young Adults. Schizophrenia Bulletin 37, 389-393.

- Verdoux H, Van Os J, Maurice-Tison $\mathrm{S}$, Gay $\mathrm{B}$, Salamon R , Bourgeois ML (1999). Increased occurrence of depression in psychosis-prone subjects: A follow-up study in primary care settings. Comprehensive Psychiatry 40, 462-468.

- Walss-Bass C, Werbeloff $\mathrm{N}$, Dohrenwend BP, et al. (2015). The Association between Negative Symptoms,
Psychotic Experiences and Later Schizophrenia: A Population-Based Longitudinal Study. PloS one 10, e0119852.

- Werbeloff N (2012). Self-reported Attenuated Psychotic Symptoms as Forerunners of Severe Mental Disorders Later in Life. Archives of general psychiatry 69, 467.

- Wigman JTW, van Nierop M, Vollebergh WAM, et al. (2012). Evidence That Psychotic Symptoms Are Prevalent in Disorders of Anxiety and Depression, Impacting on Illness Onset, Risk, and Severity--Implications for Diagnosis and Ultra-High Risk Research. Schizophrenia bulletin 38, 247-257.

- Woodberry KA, Seidman LJ, Bryant C, et al. (2016). Treatment Precedes Positive Symptoms in North American Adolescent and Young Adult Clinical High Risk Cohort. Journal of Clinical Child \& Adolescent Psychology 47, 69-78.

- Yung AR, Nelson B (2011). Young people at ultra high risk for psychosis: a re- 
search update. Early Intervention in Psychiatry 5, 52-57.

- Zammit S, Kounali D, Cannon M, et al. (2013). Psychotic experiences and psychotic disorders at age 18 in relation to psychotic experiences at age 12 in a longitudinal population-based cohort study. The American journal of psychiatry 170, 742-750.

- Zipursky RB, Reilly TJ , Murray RM (2013). The myth of schizophrenia as a progressive brain disease. Schizophrenia Bulletin 39, 1363-1372. 



\title{
CHAPTER 2
}

\section{Izmir mental health cohort for gene-environment interaction in psychosis (Türksch): Assessment of the extended and transdiagnostic psychosis phenotype and analysis of attrition in a six years follow-up of a community-based sample}

\author{
Umut Kirlı ${ }^{1,2}$ \\ Tolga Binbay ${ }^{3}$ \\ Hayriye Elbi 4 \\ Marjan Drukker ${ }^{2}$ \\ Bülent Kayahan 4 \\ Ferda Özkınay ${ }^{5}$ \\ Hüseyin Onay ${ }^{5}$ \\ Köksal Alptekin 3 \\ Jim van $O s^{2,6,7}$
}

Frontiers in Psychiatry 2019; 10, 554 DOI: 10.3389/fpsyt.2019.00554

1 Yuzuncu Yil University, Faculty of Medicine, Department of Psychiatry, 65040, Van, Turkey

2 Maastricht University Medical Centre, School of Mental Health and Neuroscience, Department of Psychiatry and Psychology, South Limburg Mental Health Research and Teaching Network, PO Box 616, Vijverdal, 6200 MD, Maastricht, The Netherlands

3 Dokuz Eylul University, Faculty of Medicine, Department of Psychiatry, 35340, Izmir, Turkey

4 Ege University, Faculty of Medicine, Department of Psychiatry, 35140, Izmir, Turkey

5 Ege University, Faculty of Medicine, Department of Medical Genetics, 35140, Izmir, Turkey

6 King's College, King's Health Partners, Department of Psychosis Studies, Institute of Psychiatry, De Crespigny Park, Denmark Hill, London, UK

7 Dept. Psychiatry, Brain Centre Rudolf Magnus, Utrecht University Medical Centre, PO BOX 85500, 3508 GA Utrecht, The Netherlands. 



\section{Abstract}

Objective: TürkSch is a prospective, longitudinal study in a representative community sample (İzmir, Turkey), consisting of several data collection stages, in order to screen and follow-up mental health outcomes with a special focus on the extended and transdiagnostic psychosis phenotype. The aim of the present paper is to describe the research methodology, data collection results and associations with non-contact and refusal in the longitudinal arm.

Methods: Households were contacted in a multistage clustered probability sampling frame covering 11 districts and 302 neighborhoods at baseline $(\mathrm{n}=4011)$ and at 6-year follow-up $(\mathrm{n}=2185)$. Both at baseline and at follow-up, participants were interviewed with the Composite International Diagnostic Interview. Participants with probable psychotic disorder were re-interviewed with the SCID-I either at the hospital or the participant's residence. Relevant neighborhood-level measures were assessed in a separate sample $(\mathrm{n}=5124)$ in addition to individual-level measures. Candidate gene-by-environment interactions were investigated using two nested case-control studies.

Results: Individuals with a mental health problem had lower refusal rates. Older and lower educated individuals had a lower probability of non-contact.

Discussion: The TürkSch study has an advanced design, in order to meet the challenges of evaluating the multidimensional etiological and phenomenological nature of the extended and transdiagnostic psychosis phenotype. 


\section{Introduction}

After nearly two decades of epidemiological studies, there is evidence suggesting that psychosis is distributed as a spectrum (Linscott and van Os 2013). The spectrum of psychosis extends from the clinical psychotic syndrome to non-psychotic diagnoses with a degree of psychosis admixture and, finally, to non-clinical populations with subthreshold psychotic experiences (Kaymaz and van Os 2010;van Nierop et al. 2011; van Os and Linscott 2012). Thus, the extended psychosis phenotype is the range from psychotic experiences (PEs) gradually blending into psychotic disorders (PDs) (Kaymaz and van Os 2010).

The majority of individuals with PEs have a diagnosis of non-psychotic disorder. Conversely, high prevalence of PEs has been demonstrated in individuals with non-psychotic disorders where they can be considered as a marker of clinical severity (Guloksuz et al. 2015). Furthermore, PEs and non-psychotic disorders have been shown to predict subsequent occurrence of each other, bidirectionally (McGrath et al. 2016). It has been suggested that these findings point to a transdiagnostic psychosis phenotype in the general population (van Os and Reininghaus 2016).

To date, the definition of PEs and the type of screening instrument used have varied across studies (Kelleher et al. 2011), contributing to heterogeneity of results in this area. In the majority of studies, definitions of PEs were based on attenuated forms of delusional thinking and hallucinatory perceptions (van Os et al. 2009; Linscott and van Os 2013;Fonseca Pedrero and Debbane 2017). However, negative, disorganization and affective dimensions of psychosis have been identified in addition to the positive dimension. These dimensions should also be taken into account (van Os and Reininghaus 2016).

Longitudinal studies have demonstrated that PEs are mostly transitory. Persistent PEs have been associated with greater risk of need for care (Dominguez et al. 2009) and prolonged exposure 
to environmental risks (childhood adversity, minority position, discrimination, urban upbringing and residency, stress in the wider social environment, substance misuse etc.), possibly interacting with genetic liability (Collip et al. 2007). Hence, a growing number of studies have tried to disentangle the components of interactions between genes and environment underlying the extended and trans-diagnostic psychosis phenotype (Dominguez et al. 2009;Wigman et al. 2012;Kelleher et al. 2013;Zammit et al. 2013). Although these studies provided new insights, most were not designed to specifically study the psychosis spectrum phenotype. Thus, risk factors included were not selected for their association with psychosis. In addition, factors in the wider social environment such as neighborhood-level risk factors were not included, and studies were not genetically sensitive, with a few notable exceptions (Linney et al. 2003;Hanssen et al. 2005;Polanczyk et al. 2010). Furthermore, diagnoses were mostly based on lay-interviewer assessments and re-interviews were mostly not performed by clinicians.

The Izmir Mental Health Survey for Gene-Environment Interaction in Psychosis (TürkSch) was therefore conducted to provide new insights into and knowledge of the extended and trans-diagnostic psychosis phenotype, and to identify effects of social-environmental risks in interaction with genetic background (Binbay et al. 2011;Binbay et al. 2012a;Binbay et al. 2012b).

The present paper describes the methods of the TürkSch follow-up. Furthermore, dynamic transitions over time in the extended psychosis phenotype are presented. Finally, the associations between various variables and non-contact/ refusal in the longitudinal arm are analyzed.

\section{Methods}

\section{Dverview of the Design of the TürlkSch Cohort}

TürkSch is a prospective, longitudinal study to screen and follow-up mental health outcomes in a representative general population sample of Izmir, Turkey. The TürkSch consists of two separate assessments $\left(\mathrm{T}_{1}\right.$ and $\left.\mathrm{T}_{2}\right)$, and several stages of data 
collection. The study assessed the prevalence of the extended psychosis phenotype. In addition, associations between various individual-level variables and the extended psychosis phenotype were investigated (stage 1, $T_{1}$ ). Associations between neighborhood-level variables (e.g. socioeconomic deprivation and social capital of neighborhoods) and the extended psychosis phenotype were assessed by a separate data collection independent from the main data collection (stage 2, $T_{1} n=5124$ ). Furthermore, a nested case-control study recruited individuals with PEs and PDs as well as individuals with no psychotic symptoms from stage 1 , and included blood sampling for analysis of gene-environment interactions (stage $3, T_{1}$ ).

Six years after baseline, mental health and environmental exposure were assessed (stage $4, T_{2}$ ). Finally, a longitudinal nested case-control study recruited individuals using the results of stage 1 and 4, and blood samples were collected for further genetic analysis (stage 5, $T_{2}$ ). The TürkSch study was approved by the Institutional Ethics Review Board of Ege University, Turkey, and is compliant with the precepts of the Declaration of Helsinki. Each participant provided written informed consent for examination and procedures.

\section{Sample}

At baseline, The Turkish Institute of Statistics (TurkStat) randomly selected 6000 households representative of the Izmir metropolitan area, using a multistage sampling procedure stratified by urbanicity in four categories, and covering 11 districts and 302 neighborhoods. Addresses were contacted in person. One household member aged between 15 and 64 years and available to complete the interview was randomly selected using the Kish within-household sampling method (Kish 1949). Out of 6000 addresses, 5242 households were eligible for interview. A total of 4011 individuals were successfully interviewed, yielding a response rate of $76.5 \%$ in stage 1 . Response was higher in older age groups and in females. Full details on the Izmir metropoli- 
tan area, sampling, representativeness, instruments, procedures of $\mathrm{T}_{1}$ and the map of neighborhoods included can be found in a previous article (Binbay et al. 2011). Participants and addresses of $\mathrm{T}_{1}$ formed the targeted population for $\mathrm{T}_{2}$.

\section{Fielduorrk}

Follow-up assessments $\left(\mathrm{T}_{2}\right)$ were performed approximately six years after the baseline assessments $\left(\mathrm{T}_{1}\right)$. To optimize response, $\mathrm{T}_{2}$ fieldwork was spread over a relatively long period (2 years) so that there was sufficient time to re-contact potential respondents. At $\mathrm{T}_{2}$, addresses of $\mathrm{T}_{1}$ participants were visited in person by trained lay-interviewers with a brochure reminding the study, providing results from baseline, seeking participation for a new interview, and explaining the study goals in detail. The brochure also referred to a website, full names of the study team, and a phone number of the research office. If the participant could not be reached at the address, the study team telephoned the participants using numbers from $\mathrm{T}_{1}$. In these calls, the team ascertained whether the participant was reachable, and if this was the case, appointments were made for face to face interviews. Any contact information of the participants who could not be reached was collected by asking neighbors in the area or the neighborhood authorities. If additional information was obtained, the person was contacted at the new contact address. Any $\mathrm{T}_{1}$ participant was defined as 'unreachable' at $\mathrm{T}_{2}$ after at least three consecutive visits to the address.

\section{Interviewers, interviewer training and quality control}

At $\mathrm{T}_{1}$, lay interviewers had at least high school education, a health-related profession, and/or were experienced in doing field surveys. At $\mathrm{T}_{2}$, lay interviewers were psychology graduates. At $\mathrm{T}_{2}$, both the lay interviewers and the psychiatrist who conducted the clinical re-interviews (UK) had not participated at $\mathrm{T}_{1}$, and thus were blind to baseline results. At both assessments, lay interview- 
ers had a two-week formal training which included basic information on common mental disorders, symptom dimensions of psychosis, and ethical aspects of the project, as well as practical training. The field work was closely monitored by the study team (UK, TB, HE, BK, KA). Each interview at $\mathrm{T}_{1}$ and $\mathrm{T}_{2}$ was conducted according to a standard procedure, with recording and quality coding. If any of the three following problems were determined: i) the quality of the interview was considered low ii) any missing value was present iii) there was a doubt on whether the endorsed symptom was a 'true' symptom, as described below, a phone call or a second visit $\left(T_{1} n=392 ; T_{2} n=560\right)$ was planned by the study team. The missing values still present after the second visit were assessed by the psychiatrist following the clinical re-interview.

\section{Screening Instrument}

In order to assess mental health outcomes, screening was based on the relevant sections of the Composite International Diagnostic Interview (CIDI) 2.1 (Andrews and Peters 1998). The CIDI is a fully structured interview developed by the World Health Organization (WHO) (Robins 1988) and has been used in various surveys around the world, including ones in Turkey (Cilli and Kaya 2003;Deveci et al. 2007;Alptekin et al. 2009). Primarily designed for use in epidemiological studies of mental disorders, the CIDI can be used by both clinicians and trained interviewers. CIDI-based screening of symptoms provides diagnoses in accordance with the definitions and criteria of the International Classification of Diseases, Tenth Revision (ICD-10), and the Diagnostic and Statistical Manual of Mental Disorders (Fourth Edition) (DSM-IV), along with information about frequency, duration, help-seeking, severity of symptoms, and psychosocial impairment. CIDI 2.1 has organic exclusion rules, which are used to construct final diagnoses, for each endorsed symptom, in order to ascertain that symptoms were not exclusively due to a somatic cause, an injury, or use of drugs, alcohol or medication. Previous research reported acceptable-to-good concordance between the CIDI 2.1 diagnoses and blind clinical diagnoses 
(Andrade et al. 2003;Kessler et al. 2004;Kessler et al. 2010). The CIDI was found to have excellent inter-rater reliability in almost all sections with kappa values ranging from 0.67 to 0.97 (Wittchen et al. 1991). In particular, kappa for agreement between clinicians for delusions and hallucinations was found to be 0.85 and 0.87 , respectively. Furthermore, the sensitivity of the CIDI was found to be higher than its specificity for both delusions $(0.93$ vs. 0.55) and hallucinations (0.86 vs. 0.50) (Cooper et al. 1998). The reliability and validity functions of the Turkish version of the CIDI were studied as part of an international study (Rezaki et al. 1995).

Mental health screening at both $\mathrm{T}_{1}$ and $\mathrm{T}_{2}$ included CIDI screening sections on alcohol and substance-related disorders, depressive and dysthymic disorders, manic and bipolar affective disorders, schizophrenia and other PDs, posttraumatic stress disorder, and 2 final sections containing concluding questions, interviewer observations, and interviewer ratings (Binbay et al. 2011). The time frame of the $\mathrm{T}_{2}$ CIDI interview was the last six years

\section{Assessment of the Dimensions of Psychosis}

Assessment of the positive dimension was based on 14 CIDI delusions items (G1, G2, G3, G4, G5, G7, G8, G9, G10, G11, G12, G13, G13b and G14) and 5 CIDI hallucinations items (G17, G18, G20, G20C, and G21). All items were rated dichotomously indicating presence or absence. Rating of the PEs can be difficult because sometimes individuals can be describing a plausible event or a religious or superstitious belief that in the CIDI may be rated as a PE. Therefore, the following procedure was followed. First, during the interview, each time a participant endorsed a CIDI PE, the participant was asked to give an example, which was written down verbatim by the interviewer for later review with the mental health clinician on the team. All CIDI interviews were reviewed by the study team. When it was not clear whether or not the participant had truly endorsed a positive PE, the participant was re-contacted by a clinician over the telephone to 
confirm the PE. Thus, delusional and hallucinatory experiences were coded positive if the team clinician confirmed the PE at review. Our results showed that the inter-rater reliability of the CIDI psychosis section had a kappa value of 0.45 at $\mathrm{T}_{1}$ (Binbay et al. 2011) and 0.67 at $\mathrm{T}_{2}$.

Assessment of the negative and disorganization dimensions were based CIDI P section which is on interviewer observations. The negative dimension was based on 4 symptom items (flat affect, slow speech, poverty of speech, and impaired ability to initiate activity) and the disorganization dimension was based on 3 symptom items (neologism, thought disorder, and hallucinatory behavior).

Assessment of the affective dimension was based on CIDI section $\mathrm{E}$ (depressive and dysthymic disorders) and section $\mathrm{F}$ (manic and bipolar affective disorders). For depression, participants were asked if they had experienced an episode lasting at least two weeks during which they felt depressed, or had a lack of interest. If endorsed, participants were asked if, during this period, they had experienced lack of energy, appetite change, sleep problems, being slow or restless, feelings of worthlessness or guilt, decreased self-esteem, trouble thinking or indecisiveness, and thoughts of death. For manic and hypomanic episodes, participants were asked whether they had experienced elevated mood or irritability for a period of at least four consecutive days either noticed by others or causing problems. If this was the case, participants were asked if, during this period, they had experienced excessive goal-directed activity, psychomotor agitation, spending sprees, sexual indiscretions, increased talkativeness, flight of ideas, loss of normal social inhibitions, increased self-esteem or grandiosity, decreased need for sleep, and distractibility. For both depressive and manic episodes, the final assessment included questions on probable association of symptoms with substance use or physical illness, help-seeking due to symptoms, the route of help-seeking, clinician diagnosis, and treatment history. All responses were re-evaluated by a team of clinicians. 
Depressive episode and hypomanic/manic episode were coded positive in accordance with the definitions and criteria of DSMIV.

\section{Diagnostic Intervieus and Construction of the Extended Psychosis Phenotype}

At both $T_{1}$ and $T_{2}$, sections were devoted to define patterns of help-seeking for mental health problems. Questions included any self-report mental problem, help-seeking for a mental problem, the route of help-seeking, the probable outcome of the help-seeking (diagnosis), as well as prescribed medicines and any hospitalization over the time frame (lifetime and last 12 months at $\mathrm{T}_{1}$ and last six years at $\mathrm{T}_{2}$ ). If this was the case, the person was asked for permission to contact the clinician involved in the diagnosis or the treatment of the participant in order to verify the diagnosis and review case material.

A measure of impairment associated with PEs was defined using CIDI items G25 (duration of the PE: between 1 day and 6 months or more), G26, G28, G29 and G29A (level of dysfunction), G16 and G23 (told doctor about psychotic beliefs) (Binbay et al. 2012a;Binbay et al. 2012b). Furthermore, a probable PD case was defined if any of the following screening findings were endorsed:

1) Any self-reported diagnosis of psychotic or bipolar disorder

2) Any self-reported hospitalization due to a mental health problem

3) Any self-reported medication of any antipsychotic (typical or atypical) and/or lithium or mood-stabilizing anticonvulsant drugs

4) In the CIDI section F for bipolar disorder: a lifetime manic episode 
5) In the CIDI section $G$ for positive dimension: any clinically relevant positive PE (led to dysfunction or help-seeking), or at least 3 symptoms regardless of clinical relevance. If the participant had a clinically relevant positive $\mathrm{PE}$ at $\mathrm{T}_{1}$, he/she was directly defined as a probable case regardless of the CIDI endorsement at $\mathrm{T}_{2}$.

6) In the CIDI section $P$ for negative and disorganization dimensions: a rating of positive formal thought disorder, negative symptoms, behavior that suggests the person is having hallucinations, or catatonic symptoms; or the interviewer comments were indicative of a PD.

If a participant was deemed to have a diagnosis of probable $P D$ according to the algorithm mentioned above, the participant was re-contacted by the team psychiatrist and invited to the hospital for a clinical evaluation with the Structured Clinical Interview for DSM-IV (SCID) (Spitzer 1992). When the participant did not attend the hospital, clinical interviews were conducted at the participant's residence by the psychiatrist. Thus, 225 participants at $T_{1}$ and 263 participants at $T_{2}$ were clinically re-interviewed in order to identify participants with PD.

An extended psychosis phenotype variable was constructed including 4 categories using the SCID results and the measure of impairment associated with PEs. The psychotic disorder group included all individuals diagnosed with any DSM-IV disorder with psychotic features. The clinical PE group included individuals who had a CIDI PE leading to any of the 7 CIDI impairment items but who did not have a diagnosis of a PD. The subclinical PE group included individuals with a CIDI PE not leading to any distress, impairment or help-seeking. All other individuals were included in the 'no psychosis' category. The flowchart of the assessment of the extended psychosis phenotype and the numbers of individuals in each group are presented in Figure 1 


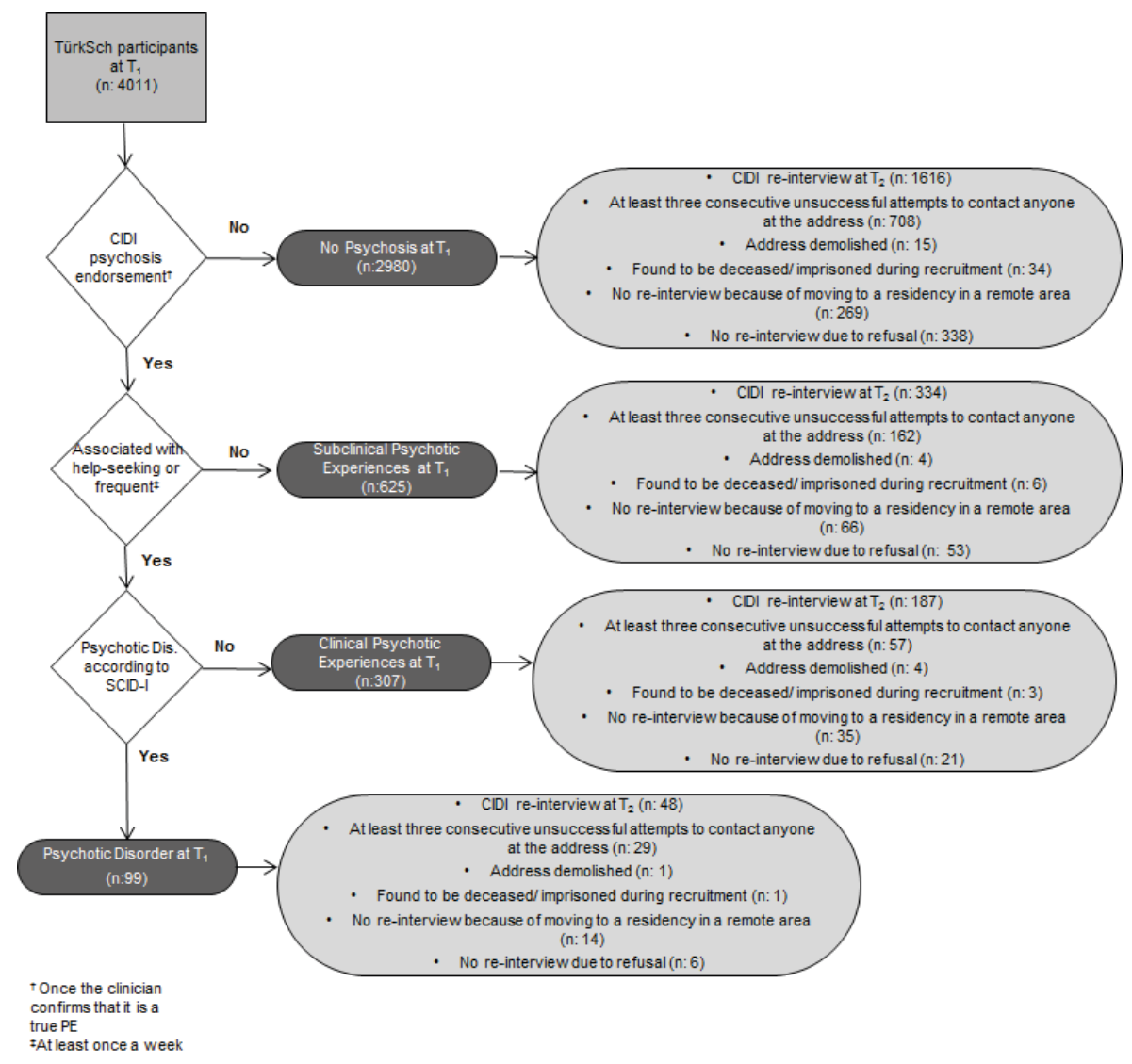

Figure 1: Assessment of the extended psychosis phenotype and data collection results at follow-up

\section{Assessment of Envirommental Exposures at the Individual Level}

A sociodemographic questionnaire was included at $\mathrm{T}_{2}$ in order to determine temporal changes in background characteristics (age, educational status, marital status, employment, socioeconomic status, health insurance, housing, and monthly household income). The $\mathrm{T}_{1}$ interview also included educational and occupational status of parents, birth year of parents, migration pattern and probable reasons for migration, ethnic group, and any history of early childhood adversity (parental loss, divorce, separation). Socioeconomic status was estimated using profession and recoded into 4 ordinal categories (1: I and II professional 
and IIIA non-manual high employees, 2: IIIB non-manual low employee and V and VI skilled workers and technicians, 3: IVA, IVB, and IVC owners of small businesses, and 4: VIIA and B manual workers (Binbay et al. 2012b;Goldthorpe 2016).

The variable 'traumatic events' was obtained using the post-traumatic stress disorder section of the CIDI. The events were war experience, life-threatening accident, fire, flood or other natural disaster, witnessing someone being badly injured or killed, rape, sexual molestation, being physically attacked or assaulted. Furthermore, the interview included the List of Threatening Life Events (Brugha and Cragg 1990) so as to cover most of the stressful life events experienced by individuals. Threatening life events were a serious illness, injury or an assault (suffering or happening to a close relative); death of a relative or a close friend, divorce, separation, serious problems with a relative/ neighbor/ close friend, being dismissed from the job, unemployment, major financial problems, police/ court appearance. Time frame was the last six years.

Alcohol, cannabis and other substance use were assessed using screening questions on CIDI alcohol and substance-related disorders section (Ulass et al. 2017). Using information from both $\mathrm{T}_{1}$ and $\mathrm{T}_{2}$, the continuum of alcohol, cannabis and other substance use during the follow-up period was defined.

\section{Assessment of Neighborlhodal-Level Measures}

At $\mathrm{T}_{1}$, urbanicity (birth place, places of residence at age 0-15 years, and current place of residence) were assessed. In a separate sample, socioeconomic deprivation and the social capital of the resided neighborhoods were assessed (Binbay et al. 2011). $\mathrm{T}_{2}$ assessment included questions on changes in place of residence. Furthermore, the description of the visited neighborhood and building was coded by the interviewer in five categories (village/ slum / semi-urban/ urban/ luxury area). Urbanicity 
of the place of residence was defined using the classification of the Turkish Institute of Statistics (TurkStat). The classification depended on the level of organized features of streets and buildings (regularity of sidewalks, status of road, completeness of drainage system, and quality of outer paintings of buildings, etc.) (Binbay et al. 2012a). Social capital of the neighborhood was assessed using two assessments: informal social control and social disorganization. Questions on informal social control were derived from the Sampson collective efficacy scale (Sampson 1997), adapted for use in the Turkish population (Binbay et al. 2012a). The informal social control scale measures the willingness to intervene in hypothetical neighborhood threatening situations, for example, in the case of children misbehaving. The items were assessed using a five-point Likert scale ranging from 'strongly agree ' to 'strongly disagree'. Eight items assessing the social disorganization were derived from the McCulloch instrument (Buckner 1988;McCulloch 2003). Respondents rated the frequency of certain scenarios occurring in their neighborhood (presence of graffiti, teenagers on street, vandalism, attacks due to race or skin color, other attacks, burglary and the theft of, or from, vehicles). Each item was assessed using a four-point Likert scale ranging from 'very common' to 'not at all common' (Binbay et al. 2012a).

\section{Assessment of Familial Measares}

Using questions derived from the Family Interview for Genetic Studies (NIMH 1992), history of mental disorders in the father, mother, siblings, and offspring was assessed. Thus, a family history of mental disorders variable was defined and coded guided by previous literature (Mortensen et al. 2010): 0=No or undefined family history of mental disorders; $1=$ Common mental disorder (depression/anxiety disorders) in at least one family member but no severe mental illness; $2=$ Severe mental illness (bipolar disorder/ psychotic disorder/ hospitalization/ completed suicide) in at least one family member (Binbay et al. $2012 b)$. 


\section{Blood Sampling and Assessment of Candidate Gene-Enviromment Inteructions}

At $\mathrm{T}_{1}$, a nested case-control study (stage 3, $\mathrm{n}=366$ ) recruited individuals with PEs and PDs as well as individuals with no psychotic symptoms in order to investigate gene-environment interactions in the extended and trans-diagnostic psychosis phenotype. In this subgroup, catechol-O-methyltransferase (COMT) val158met (rs4680) and brain-derived neurotrophic factor $(B D N F)$ val66met (rs6265) polymorphisms were assessed besides the clinical re-appraisals and exposures, mentioned above. At $\mathrm{T}_{2}$, environmental exposures for the last six years were assessed followed by clinical re-appraisals in eligible individuals $(n=254)$.

At $\mathrm{T}_{2}$, data subjects were selected for a second nested case-control study (stage 5) using the results of both $\mathrm{T}_{1}$ and $\mathrm{T}_{2}$. First, 200 individuals with any psychotic symptoms (either PE or PD) at either $\mathrm{T}_{1}$ or $\mathrm{T}_{2}$ were randomly selected. Then, these individuals were matched with 200 individuals who participated in both $\mathrm{T}_{1}$ and $\mathrm{T}_{2}$, and had no psychotic symptoms (neither PE nor PD) during the follow-up period. Matching variables were age, gender and neighborhood. The selected individuals were asked to provide a blood sample for further genetic analysis as well as clinical re-appraisals. A total of 174 individuals with any psychotic symptom (61 with PD; 113 with PE) and 151 individuals with no psychotic symptoms during follow-up provided a blood sample. In these samples, $B D N F$ and Neuregulin 1 (NRG1) whole gene sequence analysis procedure was conducted. Results were evaluated considering the environmental exposure results at both $\mathrm{T}_{1}$ and $\mathrm{T}_{2}$.

\section{Statistical Analysis}

In order to evaluate differential attrition over time, a two-step analysis was performed. First, a multinomial logistic regression model was performed (dependent variable with 3 categories: 0 = respondent, 1 = noncontact, 2 = refusal) in order to examine the role of baseline socio-demographics, psychopathology and environmental exposure variables on the association with the two types of attrition, separately. These associations were expressed as relative risk ratios (RRR) and their 95\% confidence intervals. Then, the overall effects of the abovementioned vari- 
ables on attrition were tested using chi-squared tests and the relevant effect size measure (Cramer's $V$ ). Cramer's $V$ equals 0 when there is no relationship between the two variables, and has a maximum value of 1 . A larger value for Cramer's $V$ indicated a stronger relationship between the variables.

\section{Results}

\section{Data collection results}

At $\mathrm{T}_{2}, 954$ individuals from the baseline sample could not be contacted (i.e. after at least three consecutive attempts to contact anyone at the address), and 386 individuals were lost to follow-up because of moving to a residency in a remote area. Forty-four individuals were deceased or imprisoned and 24 addresses were demolished. Furthermore, 418 individuals refused to participate in the follow-up assessment. As a result, a total of 2185 individuals were successfully re-interviewed at $\mathrm{T}_{2}$. Figure 1 shows details of the data collection results at $\mathrm{T}_{2}$ stratified by the baseline position across the extended psychosis phenotype. Dynamic transitions over time in the extended psychosis phenotype are presented in Figure 2.

\section{Associations with the tow types of attrition (nom- contact and refiusal)}

Attrition due to non-contact was significantly higher in individuals who were younger, non-married, more highly educated,

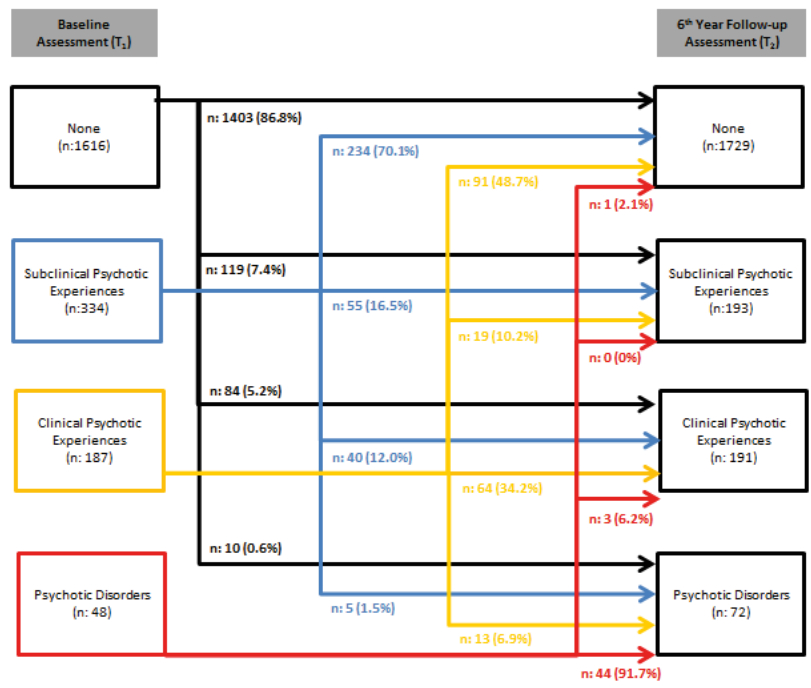

$\mathrm{N}=2185$ Participants interviewed at both assessments

Figure 2: Dynamic transitions over time in the extended psychosis phenotype 
non-helpseeking, without a valid health insurance and using cannabis and regular alcohol. The probability of refusal was significantly higher in individuals who were in paid employment, single, more educated and with higher socioeconomic status. Furthermore, refusal was lower in individuals with a baseline mood disorder, a baseline clinical PE, a history of a traumatic event, and a family history of a severe mental illness (table 1). However, analysis of overall effect on attrition showed that the

Table 1: Association between the Two Types of Attrition (Refusal/Noncontact) and Baseline Characteristics

\begin{tabular}{|c|c|c|c|c|c|c|c|}
\hline & \multirow{2}{*}{$\begin{array}{l}\text { Respondents } \\
\mathbf{n}(\%)\end{array}$} & \multicolumn{2}{|l|}{ Non-Contact } & \multicolumn{2}{|l|}{ Refusal } & \multicolumn{2}{|c|}{ Overall Effect on Attrition } \\
\hline & & n (\%) & RRR (95\%Cl) & n (\%) & RRR $(95 \% \mathrm{Cl})$ & $\chi^{2}(\mathrm{df})$ & Cramer's $V$ \\
\hline \multicolumn{8}{|c|}{ Sociodemographic Characteristics } \\
\hline \multicolumn{8}{|l|}{ Sex } \\
\hline Male & $890(52.9)$ & $612(36.4)$ & 1 & $181(10.7)$ & 1 & \multirow{2}{*}{$3.0(2)$} & \multirow{2}{*}{0.03} \\
\hline Female & $1295(55.6)$ & $796(34.2)$ & $0.89(0.78-1.02)$ & $237(10.2)$ & $0.89(0.72-1.11)$ & & \\
\hline \multicolumn{8}{|l|}{ Age } \\
\hline $46-65$ & $699(49.0)$ & $591(41.5)$ & 1 & $135(9.5)$ & 1 & \multirow{3}{*}{$48.9(4)^{* *}$} & \multirow{3}{*}{0.08} \\
\hline $31-45$ & $750(54.7)$ & $468(34.1)$ & $\begin{array}{l}1.31^{* *}(1.10- \\
1.56)\end{array}$ & $153(11.2)$ & $1.15(0.89-1.49)$ & & \\
\hline $15-30$ & $736(60.6)$ & $349(28.7)$ & $\begin{array}{l}1.78^{* *}(1.50- \\
2.10)\end{array}$ & $130(10.7)$ & $1.09(0.84-1.42)$ & & \\
\hline \multicolumn{8}{|l|}{ Educational Level } \\
\hline Basic & $966(58.2)$ & $543(32.7)$ & 1 & $151(9.1)$ & 1 & \multirow{3}{*}{$17.9(4)^{* *}$} & \multirow{3}{*}{0.05} \\
\hline High School & $360(52.0)$ & $261(37.7)$ & $\begin{array}{l}1.28^{* *}(1.06- \\
1.56)\end{array}$ & $71(10.3)$ & $1.26(0.92-1.71)$ & & \\
\hline University & $859(51.8)$ & $604(36.4)$ & $\begin{array}{l}1.25^{* *}(1.07- \\
1.45)\end{array}$ & $196(11.8)$ & $\begin{array}{l}1.45^{* *}(1.15- \\
.1 .83)\end{array}$ & & \\
\hline \multicolumn{8}{|l|}{ Marital Status } \\
\hline Married & $1638(57.7)$ & $912(32.1)$ & 1 & $289(10.2)$ & 1 & \multirow{3}{*}{$52.0(4)^{* *}$} & \multirow{3}{*}{0.08} \\
\hline Single & $458(47.0)$ & $400(41.0)$ & $\begin{array}{l}1.56^{* *}(1.34- \\
1.83)\end{array}$ & $117(12.0)$ & $1.44 * *(1.14-1.83)$ & & \\
\hline Divorced & $89(45.2)$ & $96(48.7)$ & $\begin{array}{l}1.93^{* *}(1.43- \\
2.61)\end{array}$ & $12(6.1)$ & $0.76(0.41-1.41)$ & & \\
\hline \multicolumn{8}{|l|}{ Ethnicity } \\
\hline Turkish & $1840(54.6)$ & $1175(34.8)$ & 1 & $358(10.6)$ & 1 & \multirow{2}{*}{$1.2(2)$} & \multirow{2}{*}{0.02} \\
\hline Non-Turkish & $345(54.1)$ & $233(36.5)$ & $1.05(0.88-1.26)$ & $60(9.4)$ & $0.89(0.66-1.20)$ & & \\
\hline \multicolumn{8}{|l|}{ Employment Status } \\
\hline In paid employment & $1020(54.4)$ & $639(34.0)$ & 1 & $218(11.6)$ & 1 & \multirow{2}{*}{$5.9(2)$} & \multirow{2}{*}{0.04} \\
\hline Not in paid employment & $1165(54.6)$ & $769(36.0)$ & $1.05(0.92-1.21)$ & $200(9.4)$ & $0.80 *(0.65-0.99)$ & & \\
\hline \multicolumn{8}{|l|}{ Health Insurance } \\
\hline Present & $1949(55.6)$ & $1174(33.5)$ & 1 & $381(10.9)$ & 1 & \multirow[b]{2}{*}{$32.3(2)^{* *}$} & \multirow[b]{2}{*}{0.09} \\
\hline Absent & $236(46.6)$ & $234(46.1)$ & $\begin{array}{l}1.64^{* *}(1.35- \\
2.00)\end{array}$ & $37(7.3)$ & $0.80(0.55-1.15)$ & & \\
\hline \multicolumn{8}{|l|}{ Socioeconomic status } \\
\hline 1 & $466(54.4)$ & $280(32.7)$ & 1 & $111(12.9)$ & 1 & \multirow{4}{*}{$17.6(6)^{* *}$} & \multirow{4}{*}{0.05} \\
\hline 2 & $585(54.1)$ & $382(35.3)$ & $1.08(0.89-1.32)$ & $115(10.6)$ & $0.82(0.61-1.10)$ & & \\
\hline 3 & $352(51.9)$ & $246(36.3)$ & $1.16(0.93-1.44)$ & $80(11.8)$ & $0.95(0.69-1.10)$ & & \\
\hline 4 & $782(56.1)$ & 500 (35.9) & $1.06(0.88-1.28)$ & $112(8.0)$ & $0.60^{* *}(0.45-0.80)$ & & \\
\hline
\end{tabular}




\begin{tabular}{|c|c|c|c|c|c|c|c|}
\hline Baseline Clinical Character & & & & & & & \\
\hline Mental help-seeking & & & & & & & \\
\hline None & $1872(53.7)$ & $1242(35.7)$ & 1 & $370(10.6)$ & 1 & \multirow{2}{*}{$5.9(2)$} & \multirow{2}{*}{0.04} \\
\hline Yes & $313(59.4)$ & $166(31.5)$ & $0.79 *(0.65-0.97)$ & $48(9.1)$ & $0.77(0.56-1.07)$ & & \\
\hline \multicolumn{8}{|l|}{ Baseline Mood Disorder } \\
\hline None & $1783(54.2)$ & $1143(34.8)$ & 1 & $363(11.0)$ & 1 & \multirow{2}{*}{$7.5(2)^{*}$} & \multirow{2}{*}{0.04} \\
\hline Yes & $402(55.7)$ & $265(36.7)$ & $1.02(0.86-1.22)$ & $55(7.6)$ & $0.67^{* *}(0.49-0.91)$ & & \\
\hline \multicolumn{8}{|l|}{ Baseline Cannabis } \\
\hline None & $2161(54.7)$ & $1377(34.8)$ & 1 & $413(10.5)$ & 1 & \multirow[b]{2}{*}{$7.4(2)^{*}$} & \multirow[b]{2}{*}{0.04} \\
\hline$>5$ times & $24(40.0)$ & $31(51.7)$ & $\begin{array}{l}2.02^{* *}(1.18- \\
3.46)\end{array}$ & $5(8.3)$ & $1.09(0.41-2.87)$ & & \\
\hline \multicolumn{8}{|l|}{ Baseline Alcohol } \\
\hline$<$ Once a week & $2055(55.2)$ & $1285(34.5)$ & 1 & $383(10.3)$ & 1 & \multirow[b]{2}{*}{$11.0(2)^{* *}$} & \multirow[b]{2}{*}{0.05} \\
\hline At least once a week & $130(45.1)$ & $123(42.7)$ & $\begin{array}{l}1.51^{* *}(1.17- \\
1.95)\end{array}$ & $35(12.2)$ & $1.44(0.97-2.13)$ & & \\
\hline \multicolumn{8}{|l|}{ Traumatic event } \\
\hline None & $1383(53.5)$ & $903(34.9)$ & 1 & $298(11.5)$ & 1 & \multirow{2}{*}{$9.9(2)^{* *}$} & \multirow{2}{*}{0.05} \\
\hline At least one & $802(56.2)$ & $505(35.4)$ & $0.96(0.83-1.10)$ & $120(8.4)$ & $0.69^{* *}(0.55-0.87)$ & & \\
\hline \multicolumn{8}{|l|}{ Family History } \\
\hline None or unknown & $1903(54.0)$ & $1245(35.3)$ & 1 & $379(10.7)$ & 1 & \multirow{3}{*}{$9.4(4)$} & \multirow{3}{*}{0.03} \\
\hline Common mental disorder & $222(56.8)$ & $132(33.8)$ & $0.90(0.72-1.14)$ & $37(9.5)$ & $0.83(0.58-1.20)$ & & \\
\hline Severe Mental Illness & $60(64.5)$ & $31(33.3)$ & $0.78(0.50-1.22)$ & $2(2.2)$ & $0.16 *(0.04-0.68)$ & & \\
\hline \multicolumn{8}{|c|}{ Extended Psychosis Phenotype } \\
\hline No PE & $1616(54.2)$ & $1026(34.4)$ & 1 & $338(11.4)$ & 1 & \multirow{4}{*}{$19.1(6)^{* *}$} & \multirow{4}{*}{0.05} \\
\hline Subclinical PE & $334(53.4)$ & $238(38.1)$ & $1.12(0.93-1.34)$ & $53(8.5)$ & $0.75(0.55-1.03)$ & & \\
\hline Clinical PE & $187(60.9)$ & $99(32.3)$ & $0.83(0.64-1.07)$ & $21(6.8)$ & $0.53^{* *}(0.33-0.85)$ & & \\
\hline Psychotic Disorder & $48(48.5)$ & $45(45.4)$ & $1.47(0.97-2.23)$ & $6(6.1)$ & $0.59(0.25-1.40)$ & & \\
\hline Baseline Clinical Characteri & & & & & & & \\
\hline Mental help-seeking & & & & & & & \\
\hline None & $1872(53.7)$ & $1242(35.7)$ & 1 & $370(10.6)$ & 1 & 50 (2) & Pח \\
\hline Yes & $313(59.4)$ & $166(31.5)$ & $0.79 *(0.65-0.97)$ & $48(9.1)$ & $0.77(0.56-1.07)$ & $5.9(2)$ & 0.04 \\
\hline Baseline Mood Disorder & & & & & & & \\
\hline None & $1783(54.2)$ & $1143(34.8)$ & 1 & $363(11.0)$ & 1 & $75(2) *$ & POP \\
\hline Yes & $402(55.7)$ & $265(36.7)$ & $1.02(0.86-1.22)$ & $55(7.6)$ & $0.67^{* *}(0.49-0.91)$ & $7.0(2)$ & 0.04 \\
\hline Baseline Cannabis & & & & & & & \\
\hline None & $2161(54.7)$ & $1377(34.8)$ & 1 & $413(10.5)$ & 1 & & \\
\hline$>5$ times & $24(40.0)$ & $31(51.7)$ & $\begin{array}{l}2.02 * *(1.18- \\
3.46)\end{array}$ & $5(8.3)$ & $1.09(0.41-2.87)$ & $7.4(2)^{*}$ & 0.04 \\
\hline Baseline Alcohol & & & & & & & \\
\hline$<$ Once a week & $2055(55.2)$ & $1285(34.5)$ & 1 & $383(10.3)$ & 1 & & \\
\hline At least once a week & $130(45.1)$ & $123(42.7)$ & $\begin{array}{l}1.51^{* *}(1.17- \\
1.95)\end{array}$ & $35(12.2)$ & $1.44(0.97-2.13)$ & $11.0(2)^{* *}$ & 0.05 \\
\hline Traumatic event & & & & & & & \\
\hline None & $1383(53.5)$ & $903(34.9)$ & 1 & $298(11.5)$ & 1 & (2)** & 005 \\
\hline At least one & $802(56.2)$ & $505(35.4)$ & $0.96(0.83-1.10)$ & $120(8.4)$ & $0.69 * *(0.55-0.87)$ & $5.0\{2\}$ & $0.0 \mathrm{~J}$ \\
\hline Family History & & & & & & & \\
\hline None or unknown & $1903(54.0)$ & $1245(35.3)$ & 1 & $379(10.7)$ & 1 & & \\
\hline Common mental disorder & $222(56.8)$ & $132(33.8)$ & $0.90(0.72-1.14)$ & $37(9.5)$ & $0.83(0.58-1.20)$ & $9.4(4)$ & 0.03 \\
\hline Severe Mental IIIness & $60(64.5)$ & $31(33.3)$ & $0.78(0.50-1.22)$ & $2(2.2)$ & $0.16 *(0.04-0.68)$ & & \\
\hline Extended Psychosis Pheno & & & & & & & \\
\hline No PE & $1616(54.2)$ & $1026(34.4)$ & 1 & $338(11.4)$ & 1 & & \\
\hline Subclinical PE & $334(53.4)$ & $238(38.1)$ & $1.12(0.93-1.34)$ & $53(8.5)$ & $0.75(0.55-1.03)$ & $10116) * *$ & 005 \\
\hline Clinical PE & $187(60.9)$ & $99(32.3)$ & $0.83(0.64-1.07)$ & $21(6.8)$ & $0.53 * *(0.33-0.85)$ & $19.1(0)$ & 0.05 \\
\hline Psychotic Disorder & $48(48.5)$ & $45(45.4)$ & $1.47(0.97-2.23)$ & $6(6.1)$ & $0.59(0.25-1.40)$ & & \\
\hline
\end{tabular}

${ }^{*} \mathrm{p}<0.05, * * p<0.001$

Abbreviations: $\mathrm{Cl}$, confidence interval; $\mathrm{RRR}$, relative risk ratio 
associations with any independent variable had a Cramer's $V$ value lower than 0.09 , indicating very small effect sizes.

\section{Discussiom}

The TürkSch study was conducted in a general population sample, representative of the urban and rural areas of the city of Izmir, representing the third most industrialized area of Turkey. The primary focus of the study was the extended and transdiagnostic psychosis phenotype, which was prospectively evaluated. Therefore, risk factors were chosen for their association with psychosis. Furthermore, the design of the study enabled us to assess the different symptom dimensions of psychosis (positive/ negative/ disorganization/ affective). The sample size was relatively large and included both helpseeking and non-helpseeking individuals, so we were able to prevent helpseeking bias (van Os and Guloksuz 2017). Furthermore, diagnostic interviews were performed by psychiatrists with individuals with positive screening results. Therefore, we could assess psychotic outcomes along a spectrum including both clinical and subclinical levels in the same sample. The assessments included family history as well as environmental exposures both at the individual and the neighborhood level. The inclusion of candidate gene-based genetic analysis provided the opportunity to longitudinally evaluate specific gene-environment interactions in psychosis along a spectrum of severity. In summary, design of the study enabled evaluation of the multidimensional etiological and phenomenological nature of the extended and transdiagnostic psychosis phenotype.

In spite of the strengths, the following limitations of the study should be noted. First, the relatively long period of time between the two data collection points (six years) might have decreased our ability to establish the course of psychosis in detail (Schlenger et al. 2015). Second, as with most longitudinal studies with general population-based samples, the possibility of bias caused by differential attrition over time was a limitation. However, the drop-out rate of participants in the current study is similar to studies using similar methodology (Domin- 
guez et al. 2009;Zammit et al. 2013). Furthermore, the comparison of baseline characteristics between respondents, refusals and non-contacts showed no large differences. Third, the two nested case-control studies (stages 3 and 5) in which gene-environment interactions were investigated had small sample sizes and lack of genome-wide genetic summary measures. However, nested case-control studies are most optimal in case data can only be collected in a small subsample because a sufficient number of cases can be included. In addition, the broader outcome variable including the subclinical phenotypes and the longitudinal design may help to detect smaller effect sizes. Fourth, general population-based cohort studies represent the naturalistic course of illnesses. It cannot be ruled out that among other variables, treatment modifies the course of an illness. Although we obtained information about the treatment, we cannot rule out that this limitation impacted the results. Finally, as a consequence of the sampling method, both homeless and institutionalized persons could not be included, which may have affected the level of representativeness. However, as both groups are relatively small, effects would be negligible (Binbay et al. 2011).

Analyses of attrition showed interesting results. Unlike what we expected, individuals with a mental health problem at baseline had lower refusal rates at follow-up. Furthermore, there was a difference in the sociodemographic correlates of attrition compared to studies of similar design conducted in western countries, as these studies showed higher attrition rates in individuals with a lower SES and a lower educational level (Dominguez et al. 2009; de Graaf et al. 2013). It may be important to make special efforts to contact individuals who are younger, more educated, non-married, having regular alcohol and cannabis use and no history of mental health problems in future prospective studies.

\section{Abbreviations}

PE: Psychotic experience, PD: Psychotic disorder 


\section{References}

- Alptekin K, Ulas H, Akdede BB, Tümüklü M , Akvardar Y (2009). Prevalence and risk factors of psychotic symptoms: in the city of Izmir, Turkey. Social psychiatry and psychiatric epidemiology 44, 905-910.

- Andrade L, Caraveo-anduaga JJ, Berglund P, et al. (2003). The epidemiology of major depressive episodes: results from the International Consortium of Psychiatric Epidemiology (ICPE) surveys. International Journal of Methods in Psychiatric Research 12, 3-21.

- Andrews G, Peters L (1998). The psychometric properties of the Composite International Diagnostic Interview. Social psychiatry and psychiatric epidemiology 33, 80-88.

- Binbay T, Drukker M, Alptekin K, et al. (2012a). Evidence that the wider social environment moderates the association between familial liability and psychosis spectrum outcome. Psychological Medicine 42, 2499-2510.
- Binbay T, Drukker M, Elbi $\mathrm{H}$, et al. (2012b). Testing the psychosis continuum: differential impact of genetic and nongenetic risk factors and comorbid psychopathology across the entire spectrum of psychosis. Schizophrenia bulletin 38, 992-1002.

- Binbay T, Elbi H, Alptekin $\mathrm{K}$, et al. (2011). Izmir Mental Health Survey for Gene-Environment in Psychoses (TurkSch): Objectives and Methodology. Turkish Journal of Psychiatry.

- Brugha TS, Cragg D (1990). The List of Threatening Experiences: the reliability and validity of a brief life events questionnaire. Acta psychiatrica Scandinavica 82, 77-81.

- Buckner JC (1988). The development of an instrument to measure neighborhood cohesion. American Journal of Community Psychology 16, 771-791.

- Cilli AS , Kaya N (2003). [Nicotine dependence and psychiatric comorbidity 
among university students].

Turk psikiyatri dergisi $=$ Turkish journal of psychiatry 14, 42-49.

- Collip D, Myin-Germeys I , Van Os J (2007). Does the Concept of "Sensitization" Provide a Plausible Mechanism for the Putative Link Between the Environment and Schizophrenia? Schizophrenia bulletin 34, 220225.

- Cooper L, Peters L, Andrews G (1998). Validity of the Composite International Diagnostic Interview (CIDI) psychosis module in a psychiatric setting. Journal of psychiatric research 32, 361-368.

- de Graaf R, van Dorsselaer $\mathrm{S}$, Tuithof $\mathrm{M}$, ten Have $\mathrm{M}$ (2013). Sociodemographic and psychiatric predictors of attrition in a prospective psychiatric epidemiological study among the general population. Result of the Netherlands Mental Health Survey and Incidence Study-2. Comprehensive psychiatry 54, 1131-1139.

- Deveci A, Taskin O, Dinc G, et al. (2007). Prevalence of pseudoneurologic conversion disorder in an urban community in Manisa, Turkey. Social psychiatry and psychiatric epidemiology 42, 857864.

- Dominguez MDG, Wichers M, Lieb R, Wittchen HU, van Os J (2009). Evidence That Onset of Clinical Psychosis Is an Outcome of Progressively More Persistent Subclinical Psychotic Experiences: An 8-Year Cohort Study. Schizophrenia bulletin 37, 84-93.

- Fonseca Pedrero E, Debbane M (2017). Schizotypal traits and psychotic-like experiences during adolescence: An update. Psicothema 29, 5-17.

- Goldthorpe JH (2016). Social class mobility in modern Britain: changing structure, constant process. Journal of the British Academy 4, 89111.

- Guloksuz S, van Nierop M, Lieb R, van Winkel R, Wittchen HU, van Os J (2015). Evidence that the presence of psychosis in non-psychotic disorder is 
environment-dependent and mediated by severity of non-psychotic psychopathology. Psychological Medicine 45, 2389-2401.

- Hanssen M, Bak M, Bijl R, Vollebergh W, Os J (2005). The incidence and outcome of subclinical psychotic experiences in the general population. British Journal of Clinical Psychology 44, 181191.

- Kaymaz N , van Os J (2010). Extended psychosis phenotype - yes: single continuum - unlikely. Psychological Medicine 40, 1963-1966.

- Kelleher I, Devlin N, Wigman JTW, et al. (2013). Psychotic experiences in a mental health clinic sample: implications for suicidality, multimorbidity and functioning. Psychological Medicine 44, 1615-1624.

- Kelleher I, Harley M, Murtagh A , Cannon M (2011). Are screening instruments valid for psychotic-like experiences? A validation study of screening questions for psychotic-like experiences using in-depth clinical interview.
Schizophrenia bulletin 37, 362-369.

- Kessler RC, Berglund P, Chiu WT, et al. (2004). The US National Comorbidity Survey Replication (NCS-R): design and field procedures. International Journal of Methods in Psychiatric Research 13, 69-92.

- Kessler RC, Green JG, Gruber MJ, et al. (2010). Screening for serious mental illness in the general population with the K6 screening scale: results from the WHO World Mental Health (WMH) survey initiative. International Journal of Methods in Psychiatric Research 19, 4-22.

- Kish L (1949). A Procedure for Objective Respondent Selection within the Household. Journal of the American Statistical Association 44, 380-387.

- Linney YM, Murray RM, Peters ER, MacDonald AM, Rijsdijk F , Sham PC (2003). A quantitative genetic analysis of schizotypal personality traits. Psychological Medicine 33, 803-816. 
- Linscott RJ , van Os J (2013). An updated and conservative systematic review and meta-analysis of epidemiological evidence on psychotic experiences in children and adults: on the pathway from proneness to persistence to dimensional expression across mental disorders. Psychological medicine 43, 1133-1149.

- McCulloch A (2003). An examination of social capital and social disorganisation in neighbourhoods in the British household panel study. Social Science \& Medicine 56, 1425-1438.

- McGrath JJ, Saha S, Al-Hamzawi A, et al. (2016). The Bidirectional Associations Between Psychotic Experiences and DSM-IV Mental Disorders. American Journal of Psychiatry 173, 997-1006.

- Mortensen PB, Pedersen MG , Pedersen CB (2010). Psychiatric family history and schizophrenia risk in Denmark: which mental disorders are relevant? Psychological Medicine 40, 201-210.
- NIMH (1992). NIMH Genetics Initiative: Family Interview for Genetic Studies (FIGS). MD National Institute of Mental Health: Rockville.

- Polanczyk G, Moffitt TE, Arseneault L, et al. (2010). Etiological and Clinical Features of Childhood Psychotic Symptoms. Archives of general psychiatry 67, 328.

- Rezaki M, Ozgen G, Kaplan I, Gursoy B, Sagduyu A , Ozturk O (1995). Results from Ankara center. In Mental Ilness in General Health Care: An International Study (ed. T. B. Ustun and N. Sartorius), pp. 39-56. John Willey \& Sons: Chichester.

- Robins LN (1988). The Composite International Diagnostic Interview. Archives of general psychiatry 45, 1069.

- Sampson RJ (1997). Collective Regulation of Adolescent Misbehavior:Validation Results from Eighty Chicago Neighborhoods. Journal of Adolescent Research 12, 227-244.

- Schlenger WE, Corry NH, Kulka RA, Williams CS, 
Henn-Haase C , Marmar CR (2015). Design and methods of the national Vietnam veterans longitudinal study. International Journal of Methods in Psychiatric Research 24, 186-203.

- Spitzer RL (1992). The Structured Clinical Interview for DSM-III-R (SCID). Archives of general psychiatry 49, 624.

- Ulaş H, Binbay T, Kırlı U, Elbi H , Alptekin K (2017). The epidemiology of alcohol use in Izmir, Turkey: drinking pattern, impairment and help-seeking. Social Psychiatry and Psychiatric Epidemiology 52, 887-899.

- van Nierop M, van Os J, Gunther N, et al. (2011). Phenotypically Continuous With Clinical Psychosis, Discontinuous in Need for Care: Evidence for an Extended Psychosis Phenotype. Schizophrenia bulletin 38, 231-238.

- van Os J , Guloksuz S (2017). A critique of the "ultra-high risk" and "transition" paradigm. World Psychiatry 16, 200-206.
- van Os J , Linscott RJ (2012). Introduction: The Extended Psychosis Phenotype--Relationship With Schizophrenia and With Ultrahigh Risk Status for Psychosis. Schizophrenia bulletin 38, 227-230.

- van Os J, Linscott RJ, Myin-Germeys I, Delespaul P , Krabbendam L (2009). A systematic review and meta-analysis of the psychosis continuum: evidence for a psychosis proneness-persistence-impairment model of psychotic disorder. Psychological medicine 39, 179195.

- van Os J , Reininghaus U (2016). Psychosis as a transdiagnostic and extended phenotype in the general population. World Psychiatry 15, 118-124.

- Wigman JTW, van Nierop M, Vollebergh WAM, et al. (2012). Evidence That Psychotic Symptoms Are Prevalent in Disorders of Anxiety and Depression, Impacting on Illness Onset, Risk, and Severity--Implications for Diagnosis and Ultra-High Risk 
Research. Schizophrenia

bulletin 38, 247-257.

- Wittchen HU, Robins LN, Cottler LB, Sartorius N, Burke JD , Regier D (1991).

Cross-cultural feasibility, reliability and sources of variance of the Composite International Diagnostic Interview (CIDI). The Multicentre WHO/ADAMHA Field Trials. The British journal of psychiatry : the journal of mental science 159, 645-653, 658.

- Zammit S, Kounali D, Cannon M, et al. (2013). Psychotic Experiences and Psychotic Disorders at Age 18 in Relation to Psychotic Experiences at Age 12 in a Longitudinal Population-Based Cohort Study. American Journal of Psychiatry 170, 742-750. 



\title{
CHAPTER 3
}

\section{Psychotic experiences and mood episodes predict each other bidirectionally: a 6-year follow-up study in a community-based population}

\author{
Umut Kirlı 1, 2 \\ Tolga Binbay ${ }^{3}$ \\ Marjan Drukker ${ }^{2}$ \\ Jim $\operatorname{van} O s^{2,4,5}$ \\ Köksal Alptekin ${ }^{3}$ \\ Bülent Kayahan 6 \\ Hayriye Elbi 6
}

Social Psychiatry and Psychiatric Epidemiology 2019; 54 (3):

331-341

1 Van Education and Research Hospital, Psychiatry Unit, Van, Turkey

2 Maastricht University Medical Centre, School of Mental Health and Neuroscience, Department of Psychiatry and Psychology, South Limburg Mental Health Research and Teaching Network, PO Box 616, Vijverdal, 6200 MD, Maastricht, The Netherlands

3 Dokuz Eylul University, Faculty of Medicine, Department of Psychiatry, 35340, Izmir, Turkey

4 King's College, King's Health Partners, Department of Psychosis Studies, Institute of Psychiatry, De Crespigny Park, Denmark Hill, London, UK

5 Dept. Psychiatry, Brain Centre Rudolf Magnus, Utrecht University Medical Centre, PO BOX 85500, 3508 GA Utrecht, The Netherlands.

6 Ege University, Faculty of Medicine, Department of Psychiatry, 35140, Izmir, Turkey 



\section{Abstract}

Background: Psychotic experiences (PEs) are not exclusive to psychotic disorders and highly correlated with mood episodes. In this representative general population-based study, longitudinal bidirectional associations between the extended psychosis phenotype and mood episodes were investigated, accounting for other possible causes.

Methods: Households were contacted in a multistage clustered probability sampling frame covering 11 districts and 302 neighbourhoods at baseline $(\mathrm{n}=4011)$ and at 6-year follow-up $(n=2185)$. Participants were interviewed with the relevant sections of the Composite International Diagnostic Interview (CIDI) both at baseline and at follow-up. Socio-demographic, familial and environmental risk factors associated with the extended psychosis phenotype and mood episodes were assessed. Logistic regression and cross-lagged panel correlation models were used for the associations between the extended psychosis phenotype and mood episodes

Results: PEs were associated with subsequent depressive and manic episodes. There was bidirectionality in that mood episodes were associated with subsequent PEs, and PEs were associated with subsequent mood episodes. The associations occurred in a sub-additive pattern. There were substantial synchronous and cross-lagged correlations between these psychopathology domains, with reciprocally similar cross-lagged correlations. Familial risk and adverse life events were associated with both psychopathology domains whereas some sociodemographic risk factors and alcohol/cannabis use were associated with only one domain.

Conclusion: The subadditive bidirectional associations between PEs and mood episodes over time and the similarity of crosslagged correlations are suggestive of mutually causal connections between affective and psychotic domains of psychopathology. 


\section{Introduction}

An extensive volume of literature suggests that psychotic experiences (PEs) are not exclusive to, and more common than psychotic disorders in the general population (van Os et al. 2009; Nuevo et al. 2012; Linscott and van Os 2013;McGrath et al. 2015).Cross-sectional studies have demonstrated high prevalence of PEs in individuals with mood disorders (Hanssen et al. 2003; Varghese et al. 2011; Kelleher et al. 2012; Saha et al. 2012). Conversely, mood disorders are prevalent in individuals with PEs (Armando et al. 2010; Kelleher et al. 2012). For example, among respondents with lifetime PEs, major depressive disorder was reported to be the most common disorder $(25.4 \%)$ of the 21 DSM-IV mental disorders examined in the World Health Organization World Mental Health (WMH) Surveys (McGrath et al. 2016). Furthermore, research has shown that PEs and mood episodes may represent markers of severity of each other, bidirectionally driving poor outcome (Perlis et al. 2011;van Rossum et al. 2011;Kelleher et al. 2012;Wigman et al. 2012;Guloksuz et al. 2015a;Stochl et al. 2015). Despite these clues, few studies have examined the longitudinal associations between PEs and mood episodes and these studies have produced conflicting results. PEs have been associated with subsequent mood episodes among both adolescent (Dhossche et al. 2002;De Loore et al. 2011;Sullivan et al. 2014;Zavos et al. 2016) and adult populations (Rossler et al. 2011). However, a study with an adult sample found no association between PEs and subsequent depression (Fowler et al. 2012). Furthermore, mood episodes have been associated with subsequent PEs among both adolescent (Zavos et al. 2016) and adult populations (Fowler et al. 2012). However, another study with an adolescent sample found no association in this direction (Sullivan et al. 2014). The majority of the above-mentioned studies did not take familial liability and social/environmental covariates into account and this can be the reason for the observed inconsistency in results.

It has been suggested that psychopathology may be represented by overlapping and reciprocally impacting dimension- 
al liabilities (e.g. psychotic, affective) (van Os and Linscott 2012). Phenomenologically, one of these dimensions might emerge, increasing the risk of the other. Given strong evidence linking the lifetime prevalence of PEs with high prevalence of mood episodes, we hypothesized that PEs and mood episodes would predict each other, bidirectionally over time. Furthermore, given evidence that co-occurrence of psychotic and affective domains may reflect general severity of multidimensional psychopathology, building up over time (van Rossum et al. 2011; van Os and Guloksuz 2017), the risk of subsequent psychopathology after PEs or mood episodes may be additive. Finally, meta-analysis of risk factors identified age, sex, education, marital status, alcohol use, cannabis use, life events, childhood adversity and family history of mental illness as important predictors of PEs (van Os et al. 2009; Linscott and van Os 2013). We hypothesized that a substantial part of these risk factors would be shared between PEs and mood episodes.

The first aim of this paper was to analyse the bidirectional associations between PEs and mood episodes; over a 6 years period, in a general population sample. The second aim was to analyse if baseline PEs would combine synergistically (on an additive scale) with baseline mood episodes to increase odds of subsequent PEs and mood episodes. The third aim was to evaluate the differential effect of risk factors on PEs and mood episodes.

\section{Methods}

\section{Sample and Study Design}

The TürkSch, Izmir Mental Health Survey for Gene-Environment Interaction in Psychosis is a longitudinal, general population-based study covering a time frame of approximately 6 years. The main objective of the TürkSch is to assess prevalence, incidence, risk factors, comorbidity and course of mental disorders (Binbay et al. 2011;Binbay et al. 2012a;Binbay et al. $2012 b)$. 
The baseline $\left(\mathrm{T}_{1}\right)$ sample was randomly selected from the wider Izmir metropolitan area using a multistage sampling procedure, stratified by urbanicity covering 11 districts and 302 neighbourhoods. Izmir is the third most urban area of Turkey with approximately 2.6 million residents in 2007 (TurkStat 2008). Addresses were provided by The Turkish Institute of Statistics (TurkStat) and the households were visited in person by trained lay interviewers between 2007 and 2009. One household member aged between 15 and 64 years was randomly selected using the Kish within-household sampling method (Kish 1949). A total of 4011 participants were interviewed at baseline. Full details on the Izmir metropolitan area, sampling, representativeness, instruments and procedures of this assessment $\left(\mathrm{T}_{1}\right)$ have been published previously (Binbay et al. 2011). At follow-up $\left(\mathrm{T}_{2}\right)$, addresses of all $\mathrm{T}_{1}$ participants were re-visited in person six years after the baseline assessment in average (years 2013-2015). Several attempts were made to reduce the number of non-respondents from the baseline sample. The study team telephoned the $\mathrm{T}_{1}$ participants to make appointments for interviews. Any contact information for $\mathrm{T}_{1}$ participants who could not be reached was collected by asking neighbours in the area or the neighbourhood authorities. If additional information was obtained on the $\mathrm{T}_{1}$ respondent, the person was contacted at the new contact address. At $\mathrm{T}_{2}, 954$ individuals from the baseline sample could not be contacted (i.e. after at least three consecutive attempts to contact anyone at the address), and 386 individuals were lost due to residency in a remote area. Forty-four individuals were found to be deceased or imprisoned and 24 addresses were demolished. Furthermore, 418 individuals refused to participate in the follow-up assessment. As a result, a total of 2185 individuals were successfully re-interviewed at $\mathrm{T}_{2}$. Baseline and follow-up TürkSch assessments were approved by the Ege University ethics committee and have therefore been performed in accordance with the ethical standards laid down in the 1964 Declaration of Helsinki and its later amendments. 


\section{Intervieuers, Interviewer Training and Quality Control}

At $\mathrm{T}_{1}$, lay interviewers had at least high school education, a health-related profession, and/or were experienced in doing field surveys. At $\mathrm{T}_{2}$, lay interviewers were psychology graduates. In both assessments, lay interviewers had a two-week formal training which included basic information on common mental disorders, symptom dimensions in psychosis, and ethical aspects of the project, as well as practical training on CIDI interviews. The field work was closely monitored by the study team (UK, TB, HE, $\mathrm{BK}, \mathrm{KA}$ ). Each interview at $\mathrm{T}_{1}$ and $\mathrm{T}_{2}$ was conducted according to a standard procedure, with recording and quality coding (Binbay et al. 2011). If the quality of the interview was considered low, a phone call $\left(T_{1} n=234 ; T_{2} n=156\right)$ or a second visit $\left(T_{1} n=392 ; T_{2}\right.$ $\mathrm{n}=560$ ) was planned by the study team (Binbay et al. 2011).

\section{Assessments}

Both at baseline and at follow-up participants were screened using the Composite International Diagnostic Interview (CIDI) 2.1 (Andrews and Peters 1998). The CIDI is a fully structured interview developed by the World Health Organization (Robins et al. 1988) and has been used in various surveys around the world including Turkey (Cilli and Kaya 2003;Deveci et al. 2007;Alptekin et al. 2009). Primarily designed for use in epidemiological studies of mental disorders, the CIDI can be used by both clinicians and trained lay interviewers. CIDI was found to have excellent inter-rater reliability in general population based samples in almost all sections with kappa values ranging from 0.67 to 0.97 (Wittchen et al. 1991).

CIDI-based screening of symptoms provides information on frequency, duration, help-seeking, severity of symptoms and psychosocial impairment. In both assessments of TürkSch, the CIDI assessment included screening sections on alcohol and substance-related disorders, depressive and dysthymic disorders, manic and bipolar affective disorders, schizophrenia and other psychotic disorders and two final sections with concluding questions, interviewer observations, and interviewer ratings (Binbay et al. 2011). 


\section{Assessment of Mood Episodes}

In order to assess depressive and hypo/manic episodes, the same case identification procedure was applied at baseline and follow-up. For depression (CIDI section E), participants were asked if they had experienced an episode lasting at least two weeks during which they felt depressed, or had a lack of interest. If endorsed, participants were asked if, during this period, they had experienced lack of energy, appetite change, sleep problems, being slow or restless, feelings of worthlessness or guilt, decreased self-esteem, trouble thinking or indecisiveness, and thoughts of death. For manic and hypomanic episodes (CIDI section F), participants were asked whether they had experienced elevated mood or irritability for a period of at least four consecutive days either noticed by others or causing problems. If this was the case, participants were asked if, during this period, they had experienced excessive goal-directed activity, psychomotor agitation, spending sprees, sexual indiscretions, increased talkativeness, flight of ideas, loss of normal social inhibitions, increased self-esteem or grandiosity, decreased need for sleep, and distractibility. For both depressive and manic episodes, the final assessment included questions on probable association of symptoms with substance use or physical illness, help-seeking due to symptoms, the route of help-seeking, clinician diagnosis, and treatment history. All responses were re-evaluated by a team of clinicians. Depressive episode and hypomanic/manic episode was coded positive in accordance with the definitions and criteria of DSM-IV. Furthermore, any mood episode variable was constructed and coded positive if there was either a depressive or a hypomanic/manic episode. Time frame was the past year at $\mathrm{T}_{1}$ and the last six years at $\mathrm{T}_{2}$ (since baseline).

\section{Assessment of Psychotic Experiences}

In order to assess PEs, the same case identification procedure was applied both at $\mathrm{T}_{1}$ and $\mathrm{T}_{2}$. PEs were rated using 14 CIDI delusions items (G1, G2, G3, G4, G5, G7, G8, G9, G10, G11, G12, G13, G13b and G14) and 5 CIDI hallucinations items (G17, G18, 
G20, G20C, and G21). All items were rated dichotomously indicating presence or absence. Kappa for agreement between clinicians for delusions and hallucinations was found to be 0.85 and 0.87, respectively (Cooper et al. 1998).

Rating of PE can be difficult because sometimes individuals can be describing a plausible event or a religious or superstitious belief that in the CIDI may be rated as a PE. Therefore, the following procedure was followed. First, during the interview, each time a participant endorsed a CIDI PE, the participant was asked to give an example, which was written down verbatim by the interviewer for later review with the mental health clinician on the team. All CIDI interviews were reviewed by the study team. When it was not clear whether or not the participant had truly endorsed a positive $\mathrm{PE}$, the participant was re-contacted by a clinician over the telephone to confirm the PE $(n=156)$. Thus, delusional and hallucinatory experiences were coded positive if the team clinician confirmed the $\mathrm{PE}$ at review.

Using CIDI items G25 (duration of the PE: between 1 day and 6 months or more), G26, G28, G29 and G29A (level of dysfunction), G16 and G23 (told doctor about psychotic beliefs), a measure of impairment associated with PEs was defined (Binbay et al. 2012b;Binbay et al. 2012c). In addition, all individuals endorsing at least one CIDI psychosis item associated with help-seeking or, if there was no help-seeking, occurring with a frequency of at least once per week, were re-contacted by the study team and invited for a clinical evaluation with the Structured Clinical Interview for DSM-IV (SCID) by the team psychiatrist. Thus, 225 participants at $T_{1}$ and 263 participants at $T_{2}$ were clinically re-interviewed in order to identify participants with psychotic disorder. Using the measure of impairment associated with PEs and the SCID results, an extended psychosis phenotype variable was constructed including 4 categories. The psychotic disorder group included all individuals diagnosed with any DSM-IV disorder with psychotic features. The clinical PE group included individuals who had a CIDI PE leading to any 
of the 7 CIDI impairment items but who did not have a diagnosis of psychotic disorder. The subclinical $P E$ group included individuals with a CIDI PE not leading to any distress, impairment or help-seeking. All other individuals were included in the 'no psychosis' category. The time frame for PEs was lifetime at baseline assessment $\left(\mathrm{T}_{1}\right)$ and the last six years at follow-up assessment $\left(\mathrm{T}_{2}\right)$.

In order to analyse the longitudinal bidirectional associations between PEs and mood episodes, an independent variable combining baseline PEs and mood episodes was constructed (baseline mental status) (0: no PE, no mood episodes; 1: PE, no mood episodes 2: no PE, mood episodes; 3: both PE and mood episodes). This variable was used in logistic regression models of the dichotomous outcome variables "any follow-up PE", "any follow-up mood episodes", "follow-up depressive episode", "follow-up hypomanic/manic episode".

\section{Dther Assessments}

The baseline and follow-up assessments included a sociodemographic questionnaire and additional questions to define patterns of help-seeking (the route of help-seeking, diagnosis, prescribed medication and hospitalization). Educational achievement was defined based on last graduated school including five categories (University or higher, high school, secondary school, primary school, non-graduate). Marital status was recoded into (living as) married and non-married (single, divorced or widowed). Socioeconomic status was based on profession and recoded into 4 ordinal categories (1: I and II professional and IIIA non manual high employees, 2: IIIB non manual low employee and V and VI skilled workers and technicians, 3: IVA, IVB, and IVC owners of small businesses, and 4: VIIA and B manual workers) (Goldthorpe 1987). The status of psychotropic medication use at baseline and follow-up was recoded into 4 categories (0: never 1: use at baseline, no use at follow-up 2: no use at baseline, use at follow-up 3: use at both assessments). 
Using questions derived from the Family Interview for Genetic Studies (NIMH.Genetics.Initiative 1992), history of mental disorders in the father, mother, siblings, and offspring was assessed. Thus, guided by previous works (Mortensen et al. 2010) a family history of mental disorders variable was defined and coded as " 0 " no or undefined family history of mental disorders, " 1 " common mental disorder (non-psychotic disorders of depression/anxiety, conversion, somatoform etc. in at least one family member), and “2" severe mental illness (bipolar disorder/ psychotic disorder/ hospitalization/completed suicide) in at least one family member (Binbay et al. 2012c).

Alcohol and cannabis use were assessed using screening questions on CIDI sections of alcohol and substance-related disorders. Conform previous CIDI-based research (Henquet et al. 2005;Binbay et al. 2012c) and using information from both $\mathrm{T}_{1}$ and $\mathrm{T}_{2}$, cannabis use of 5 times or more was defined as exposure status for cannabis. Regular alcohol use was defined as use of alcohol at least once a week. Using information from both $\mathrm{T}_{1}$ and $\mathrm{T}_{2}$, alcohol use was recoded into three variables: " 0 " never used, " 1 " non-regular user (history of alcohol use at any level but no regular use at follow-up assessment), and " 2 " regular user at follow-up assessment (Ulas et al. 2017). Life events were assessed using the List of Threatening Life Events (Brugha and Cragg 1990). The events were a serious illness, injury or an assault (suffering or happening to a close relative); death of a relative or a close friend, divorce, separation, serious problems with a relative/ neighbour/ close friend, being dismissed from the job, unemployment, major financial problems, police/ court appearance. Time frame was the last six years. The number of life events was a continuous variable with a minimum of 0 and maximum of 12 . Childhood adversity between age 0-5 years and between age 6-15 years were death of any parent, divorce of parents and separation from parents for at least for 3 months and dichotomized to none or at least one (Binbay et al. 2012c). 


\section{Statistical Amalyses}

All analyses were conducted using the software package STATA, version 13 (StataCorp, 2013). In order to evaluate the possibility of bias caused by differential attrition over time, we compared the participants at $\mathrm{T}_{2}$ with the individuals who participated at $\mathrm{T}_{1}$ and not at $\mathrm{T}_{2}$ on sociodemographic characteristics using the chisquared tests. Results were presented showing the $\mathrm{p}$ values and effect size measures (Cramer's V).

To analyse the longitudinal bidirectional associations between PEs and mood episodes (first aim); crude associations were analysed between PEs at $\mathrm{T}_{1}$ and mood episodes at $\mathrm{T}_{2}$, and vice versa. Subsequently, results were adjusted for socio-demographics, familial and environmental risk factors. Furthermore, considering the possible influence on expression of both PEs and mood episodes, models additionally included psychotropic medication use (reference category: none at $\mathrm{T}_{1}$ or at $\mathrm{T}_{2}$ ).

Besides the model with the binary PEs variable, we modelled PEs as a continuum stratified by the severity (the extended psychosis phenotype variable). Using a cross-lagged panel design, polychoric correlations between the extended psychosis phenotype and mood episodes at both time points were computed.

For the second aim, interaction contrast ratios (ICRs) were used to test departure from additivity (Knol et al. 2007). Using the odds ratios (OR) derived from the previous logistic regression models of the dichotomous outcome variables "any follow-up PE" and "any follow-up mood episodes", we calculated ICRs using the formula (i.e. ICR $=\mathrm{OR}$ both $P E$ and mood episodes $-\mathrm{OR}_{P E \text {, no mood episodes }-} \mathrm{OR}$ no $P E$, mood episodes +1$)$. Confidence intervals and $\mathrm{p}$-values for ICRs were generated using the nlcom procedure in Stata version 13.2 (StataCorp 2013).

For the third aim, logistic regression was used to assess the associations between risk factors and presence of mood episodes and PEs, separately. In all analyses, alpha was set at 0.05. 


\section{Results}

\section{Participant}

\section{Characteristics}

The average age of the participants at $\mathrm{T}_{1}$ was 44.7 years (range $=21-71 ; \mathrm{SD}=13.3$ ) .

Details of the sociodemographic, clinical and diagnostic characteristics of participants at $\mathrm{T}_{1}$ and $\mathrm{T}_{2}$ were presented in table 1. Attrition was slightly higher in males, and the difference between participants and non-participants was below the significance level (males: non-participants $43.4 \%$ male vs. participants $40.6 \%$; $x^{2}=$ 3.28, $d f=1, p=0.07$, Cramer's $V=0.02)$. Attrition was higher in the younger age group (15-29 years: non participants $39.8 \%$ vs. participants $32.0 \%$; $x^{2}=35.16, d f=2, p<0.01$, Cramer's $V=0.09$ ); in non-married participants (non-married: non-participants $34.2 \%$ vs. participants 25.0\%; $x^{2}=40.6, d f=1$, $p<0.01$, Cramer's $V=0.10$ ) and in participants with higher educational achievement (at least high school: non-participants 43. $8 \%$ vs. participants $39.3 \%$; $x^{2}=8.29, d f=1, p=0.004$, Cramer's $V=0.04$ ) with small effect sizes.
Table 1: Sociodemographic and Clinical Characteristics of Participants at Baseline and Follow-up Assessments

\begin{tabular}{|c|c|c|}
\hline & $\begin{array}{l}\text { Baseline } \\
\mathrm{n}(\%)\end{array}$ & $\begin{array}{l}\text { Follow-up } \\
\mathrm{n}(\%)\end{array}$ \\
\hline \multicolumn{3}{|l|}{ Age Categories } \\
\hline $15-30$ & $699(32.0)$ & $354(16.2)$ \\
\hline $31-45$ & $750(34.3)$ & $844(38.6)$ \\
\hline $46-71$ & $736(33.7)$ & $987(45.2)$ \\
\hline \multicolumn{3}{|l|}{ Sex } \\
\hline Male & $887(40.6)$ & $887(40.6)$ \\
\hline Female & $1298(59.4)$ & $1298(59.4)$ \\
\hline \multicolumn{3}{|l|}{ Education } \\
\hline Non-Graduate & $155(7.1)$ & $106(4.9)$ \\
\hline Primary School & $811(37.1)$ & 845 (38.7) \\
\hline Secondary School & $360(16.5)$ & $278(12.7)$ \\
\hline High School & $539(24.7)$ & $499(22.8)$ \\
\hline University or Higher & $320(14.6)$ & $457(20.9)$ \\
\hline \multicolumn{3}{|l|}{ Marital Status } \\
\hline Married & $1638(75.0)$ & $1741(79.7)$ \\
\hline Non-married & $547(25.0)$ & $444(20.3)$ \\
\hline \multicolumn{3}{|l|}{ Socioeconomic Status } \\
\hline 1 & $466(21.3)$ & $160(7.3)$ \\
\hline 2 & $585(26.8)$ & $415(19.0)$ \\
\hline 3 & $352(16.1)$ & $273(12.5)$ \\
\hline 4 & $782(35.8)$ & $1337(61.2)$ \\
\hline \multicolumn{3}{|l|}{$\begin{array}{l}\text { Contact with a Mental } \\
\text { Health Service }\end{array}$} \\
\hline None & $1872(85.7)$ & $1788(81.8)$ \\
\hline At least once & $313(14.3)$ & $397(18.2)$ \\
\hline \multicolumn{3}{|l|}{$\begin{array}{l}\text { Use of psychotropic } \\
\text { medication }\end{array}$} \\
\hline None & $1899(86.9)$ & $1798(82.3)$ \\
\hline At least once & $286(13.1)$ & $387(17.7)$ \\
\hline \multicolumn{3}{|l|}{$\begin{array}{l}\text { Extended Psychosis } \\
\text { Phenotype }\end{array}$} \\
\hline No PE & $1616(73.9)$ & $1729(79.1)$ \\
\hline Subclinical PE & $334(15.3)$ & $193(8.8)$ \\
\hline Clinical PE & $187(8.6)$ & $191(8.7)$ \\
\hline Psychotic Disorder & $48(2.2)$ & $72(3.3)$ \\
\hline \multicolumn{3}{|l|}{ Mood Episodes } \\
\hline None & $1783(81.6)$ & $1984(90.8)$ \\
\hline Present & $402(18.4)$ & $201(9.2)$ \\
\hline Total & $2185(100)$ & $2185(100)$ \\
\hline
\end{tabular}


Table 2: Differential Effect of Sociodemographic, Familial and Environmental Factors on Presence of Follow-up Mood Episodes and Psychotic Experiences

\begin{tabular}{|c|c|c|c|c|c|}
\hline \multicolumn{2}{|l|}{ Sample } & \multicolumn{2}{|c|}{ Psychotic Experience Present at $\mathrm{T}_{2}$} & \multicolumn{2}{|c|}{ Mood Episode Present at $T_{2}$} \\
\hline Categories & $\mathrm{N}(\%)$ & $\mathrm{n}(\%)$ & $\mathrm{OR}(\mathrm{Cl})$ & n (\%) & $\mathrm{OR}(\mathrm{Cl})$ \\
\hline \multicolumn{6}{|l|}{ Age Categories (at $\mathrm{T}_{1}$ ) } \\
\hline $46-65$ & $987(45.2)$ & 173 (37.9) & 1 (ref) & $83(41.3)$ & 1 (ref) \\
\hline $15-45$ & $1198(54.8)$ & $283(62.1)$ & $1.5^{* * *}(1.2-1.8)$ & $118(58.7)$ & $1.2(0.9-1.6)$ \\
\hline \multicolumn{6}{|l|}{ Sex } \\
\hline Male & $887(40.6)$ & $192(42.1)$ & 1 (ref) & $53(26.4)$ & 1 (ref) \\
\hline Female & $1298(59.4)$ & 264 (57.9) & $0.9(0.7-1.1)$ & $148(73.6)$ & $2.0 * * *(1.5-2.8)$ \\
\hline \multicolumn{6}{|l|}{ Education } \\
\hline University or Higher & 457 (20.9) & $67(14.7)$ & 1 (ref) & 34 (16.9) & 1 (ref) \\
\hline High School & $499(22.8)$ & $107(23.5)$ & $1.6 * *(1.1-2.2)$ & $45(22.4)$ & $1.2(0.8-2.0)$ \\
\hline Secondary School & $278(12.7)$ & $65(14.2)$ & $1.7 * *(1.2-2.6)$ & 24 (11.9) & $1.2(0.7-2.0)$ \\
\hline Primary School & $845(38.7)$ & $193(42.3)$ & $1.7^{* * *}(1.3-2.3)$ & $89(44.3)$ & $1.5(1.0-2.2)$ \\
\hline Non-Graduate & $106(4.9)$ & $24(5.3)$ & $1.7 *(1.1-2.9)$ & $9(4.5)$ & $1.2(0.5-2.5)$ \\
\hline \multicolumn{6}{|l|}{ Marital Status } \\
\hline Married & $1741(79.7)$ & $310(68.0)$ & 1 (ref) & $147(73.1)$ & 1 (ref) \\
\hline Non-married & $444(20.3)$ & $146(32.0)$ & $2.3^{* * *}(1.8-2.8)$ & 54 (26.9) & $1.5 *(1.1-2.1)$ \\
\hline \multicolumn{6}{|l|}{ Family History Of Mental Disorder } \\
\hline None/Undefined & 1789 (81.9) & $331(72.6)$ & 1 (ref) & $121(60.2)$ & 1 (ref) \\
\hline Common Mental Disorder & $336(15.4)$ & $102(22.4)$ & $1.9 * * *(1.5-2.5)$ & 68 (33.8) & $3.4^{* * *}(2.5-4.8)$ \\
\hline Severe mental Illness & $60(2.7)$ & $23(5.0)$ & $2.7^{* * *}(1.6-4.7)$ & $12(6.0)$ & $3.4^{* * *}(1.8-6.7)$ \\
\hline \multicolumn{6}{|l|}{ Alcohol Use } \\
\hline Never used & $1090(49.9)$ & $204(44.8)$ & 1 (ref) & $98(48.8)$ & 1 (ref) \\
\hline Non-regular user & $723(33.1)$ & $157(34.4)$ & $1.2(0.9-1.5)$ & $71(35.3)$ & $1.1(0.8-1.5)$ \\
\hline Regular user & $372(17.0)$ & $95(20.8)$ & $1.5^{* *}(1.3-2.0)$ & 32 (15.9) & $0.9(0.6-1.4)$ \\
\hline \multicolumn{6}{|l|}{ Cannabis Use } \\
\hline None & $2122(97.1)$ & $418(91.7)$ & 1 (ref) & $192(95.5)$ & 1 (ref) \\
\hline At least five times & $63(2.9)$ & $38(8.3)$ & $\begin{array}{l}6.2^{* * *}(3.7- \\
10.4)\end{array}$ & $9(4.5)$ & $1.7(0.8-3.4)$ \\
\hline \multicolumn{6}{|l|}{ Life Events for the last 6 years } \\
\hline None & $482(22.1)$ & $53(11.6)$ & 1 (ref) & $17(8.5)$ & 1 (ref) \\
\hline At least one & $1703(77.9)$ & $403(88.4)$ & $2.5^{* * *}(1.8-3.4)$ & $184(91.5)$ & $3.3^{* * *}(2.0-5.5)$ \\
\hline \multicolumn{6}{|l|}{ Childhood Adversity } \\
\hline None & $1870(85.6)$ & $375(82.2)$ & 1 (ref) & $162(80.6)$ & 1 (ref) \\
\hline At least one & $315(14.4)$ & $81(17.8)$ & $1.4^{*}(1.1-1.8)$ & 39 (19.4) & $1.5 *(1.1-2.2)$ \\
\hline \multicolumn{6}{|l|}{ Status of psychotropic medication use } \\
\hline None & $1644(75.2)$ & $244(53.5)$ & 1 (ref) & 30 (14.9) & 1 (ref) \\
\hline $\mathrm{T}_{1}(+) \mathrm{T}_{2}(-)$ & $154(7.1)$ & $28(6.2)$ & $1.3(0.8-2.0)$ & $5(2.5)$ & $1.8(0.7-4.7)$ \\
\hline$T_{1}(-) T_{2}(+)$ & $255(11.7)$ & $110(24.1)$ & $4.4 * * *(3.3-5.8)$ & $108(53.7)$ & $39.5(25.5-61.3)$ \\
\hline \multirow[t]{2}{*}{$T_{1}(+) T_{2}(+)$} & $132(6.0)$ & $74(16.2)$ & $7.3^{* * *}(5.1-10.6)$ & $58(28.9)$ & $42.2(25.6-69.4)$ \\
\hline & Mean (SD) & Mean (SD) & $\mathrm{OR}(\mathrm{Cl})$ & Mean (SD) & $\mathrm{OR}(\mathrm{Cl})$ \\
\hline $\begin{array}{l}\text { Number Of Life Events For The } \\
\text { Last } 6 \text { Years }\end{array}$ & $1.6(1.5)$ & $2.5(1.9)$ & $1.6^{* * *}(1.5-1.7)$ & $2.6(1.8)$ & $1.5^{* * *}(1.4-1.6)$ \\
\hline
\end{tabular}

$* \mathrm{p}<.05, * * \mathrm{p}<.01, * * * \mathrm{p}<.001$ 
About one-fourth of the sample (n: 578; 26.4\%) reported contact with a mental health service at least once in their lifetime. Furthermore, 541 participants $(24.8 \%)$ reported psychotropic medication use (table 1). About one third of subclinical PEs persisted (29.1\%) and a small proportion (1.5\%) evolved into psychotic disorder expression at $\mathrm{T}_{2}$. Of the clinical PEs, a higher proportion persisted (51.3\%) and evolved into psychotic disorder expression (6.9\%).

\section{Main efiects of socio-demographies, familial and envirommental risk factors on the presence of psychotic experiences and mood episodes at follow-up assessments}

Non-married marital status, family history of mental disorders (both common and severe), childhood adversity and number of life events exposed to for the last six years were significantly associated with both PEs and mood episodes at follow-up. Female sex was significantly associated with mood episodes but not with PEs. Younger age ( $\leq 45$ years), lower educational achievement and alcohol/cannabis use were significantly associated with PEs but not with mood episodes. As expected, the status of psychotropic medication use was associated with both follow-up PEs and mood episodes (table 2).

\section{Longitudimal bidirectional associations between psychotic experiences and mood episodes}

In comparison with the reference category of no PE, no mood episodes, the baseline group of mood episodes in isolation was significantly associated with the follow-up PEs. Bidirectionally, the baseline category of $P E$ in isolation was significantly associated with follow-up mood episodes (table 3). Furthermore, the association was significant with both follow-up depressive (unadjusted OR: 2.0, 95\% confidence interval [CI]: 1.3 to 3.2; adjusted OR: 1.5, 95\% CI: 1.1 to 2.5 ) and hypomanic/manic episodes (unadjusted OR: 4.8, 95\% CI: 1.6 to 14.2; adjusted OR: 3.2, 95\% CI: 1.1 to 
Table 3: Longitudinal Bidirectional Associations between Extended Psychosis Phenotype and Mood Episodes

\begin{tabular}{|c|c|c|c|c|c|c|c|}
\hline \multicolumn{2}{|c|}{ Baseline Mental Status ${ }^{a}$} & \multicolumn{3}{|c|}{ Extended Psychosis Phenotype Present at $\mathrm{T}_{2}$} & \multicolumn{3}{|c|}{ Mood Episode Present at $T_{2}$} \\
\hline Category & n (\%) & n (\%) & OR (CI) & $\mathrm{OR}^{\mathrm{b}}(\mathrm{CI})$ & N (\%) & OR (CI) & $\mathrm{OR}^{\mathrm{b}}(\mathrm{CI})$ \\
\hline PE (-) Mood (-) & $1427(65.3)$ & $168(36.8)$ & 1 (ref) & 1 (ref) & $68(33.8)$ & 1 (ref) & 1 (ref) \\
\hline PE (-) Mood (+) & $189(8.6)$ & $45(9.9)$ & $2.3^{* * *}(1.6-3.4)$ & $1.8^{* *}(1.2-2.7)$ & $39(19.4)$ & $5.2 * * *(3.4-8.0)$ & $3.4^{* * *}(2.2-5.4)$ \\
\hline PE (+) Mood (-) & $356(16.3)$ & $143(31.4)$ & $5.0 * * *(3.9-6.6)$ & $\begin{array}{l}3.9 * * *(3.0- \\
5.2)\end{array}$ & $33(16.4)$ & $2.0 * *(1.3-3.1)$ & $1.6^{*}(1.1-2.4)$ \\
\hline PE (+) Mood (+) & $213(9.8)$ & $100(21.9)$ & $6.6 * * *(4.8-9.0)$ & $\begin{array}{l}4.3^{* * *}(3.1- \\
6.1)\end{array}$ & $61(30.4)$ & $8.0 * * *(5.5-11.8)$ & $5.1^{* * *}(3.4-7.7)$ \\
\hline
\end{tabular}

$* \mathrm{p}<.05, * * \mathrm{p}<.01, * * * \mathrm{p}<.001$

a PE: Presence of baseline extended psychosis phenotype; Mood: Presence of baseline mood episode

${ }^{\mathrm{b}}$ Adjusted for age, sex, marital status, educational level, family history of mental disorders, childhood adversity, number of life events for the last 6 years, alcohol and cannabis use

10.1). The baseline category of $P E$ and mood episodes combined was the strongest predictors of both follow-up PE and mood episodes (Table 3). However, there was no significant evidence that baseline PEs combined synergistically (on an additive scale) with baseline mood episodes to increase odds of subsequent PEs (ICR: $0.3,95 \% \mathrm{CI}-2.0$ to $2.5, \mathrm{p}=0.82$ ) and mood episodes (ICR = $1.8,95 \% \mathrm{CI}-1.3$ to $4.8, \mathrm{p}=0.26)$. Finally, the bidirectional associations between PEs and mood episodes were attenuated, when adjusted for the status of psychotropic medication use (data not shown).

Polychoric correlations between mood episodes and the extended psychosis phenotype (stratified by severity) at $\mathrm{T}_{1}$ and $\mathrm{T}_{2}$ were demonstrated in figure 1. The synchronous correlations (r) between mood episodes and the extended psychosis phenotype were 0.48 at baseline and 0.51 at follow-up. The cross-lagged correlations $(\mathrm{r})$ were 0.34 and 0.32 .

\section{Discussion Findings}

In this representative general population-based study, we mainly investigated the longitudinal bidirectional associations between mood episodes and PEs. Mood episodes were associated with subsequent PEs and, bidirectionally, PEs were associated with 
subsequent mood episodes after accounting for other possible causes. Furthermore, in comparison with either PEs or mood episodes in isolation, the combined group had the higher odds for both subsequent PEs and mood episodes. However, no evidence was found that the latter associations are

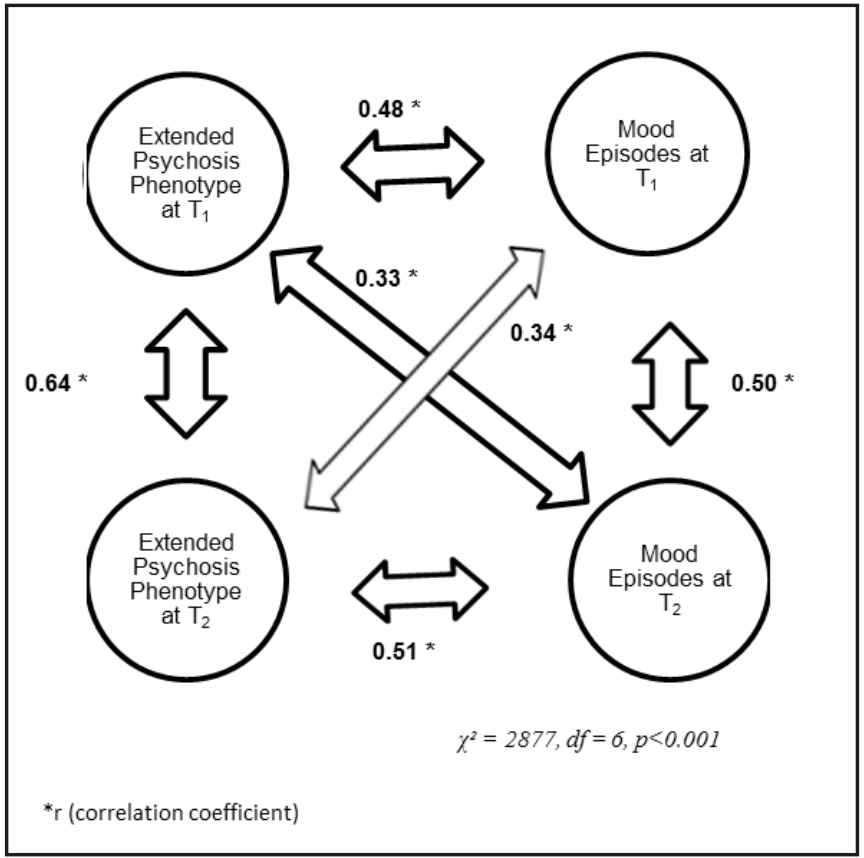

Figure 1: Polychoric correlations between mood episodes and the extended psychosis phenotype phenotype

additive. Therefore, we assume that PEs and mood episodes had sub-additive bidirectional associations over the follow-up period. The bidirectional associations between PEs and mood episodes were attenuated, when adjusted for psychotropic medication use. Considering that the decision of either prescribing or using a psychotropic medication is likely associated with impairment and severity of the psychopathology, adjustment for these can be expected to result in attenuation of reciprocal associations of mood episodes and PEs, representing an adjustment for the severity driving the association itself. Finally, mood episodes were correlated with the severity of the extended psychosis phenotype. In light of these results, PEs may be conceptualised as a marker for the severity of affective psychopathology, as argued elsewhere (van Os and Reininghaus 2016). Similarly, these results are in agreement with reports that affective dysregulation may be a marker for dysfunction associated with PE (van Rossum et 
al. 2011;Wigman et al. 2012;Guloksuz et al. 2015b;van Os and Guloksuz 2017).

The cross-lagged correlations between the extended psychosis phenotype and mood episodes were reciprocally similar $(0.34$ and 0.32), suggesting mutual causal connections between affective and psychotic domains of psychopathology (Anderson and Kida 1982). While some sociodemographic risk factors such as non-married marital status were associated with both psychopathology domains, some other factors were associated with only one domain. In line with previous epidemiological results (Regier et al. 1988; Linscott and van Os 2013), female sex was associated with mood episodes whereas no significant sex differences were found for the extended psychosis phenotype. Conversely, younger age ( $\leq 45$ years) was significantly associated with the extended psychosis phenotype but not with mood episodes, in agreement with previous findings (Regier et al. 1988;Bijl et al. 1998; van Os et al. 2000b;Verdoux and van Os 2002; van Os et al. 2009). Furthermore, educational achievement was significantly associated with the extended psychosis phenotype, but not with mood episodes. Familial risk (both common mental disorders and severe mental illness) were associated with both psychopathology domains, in agreement with previous evidence (Bij1 et al. 1998; van Os et al. 2009; Linscott and van Os 2013). Some environmental exposures such as life events over the last six years and childhood adversity were associated with both psychopathology domains at follow up. However, alcohol and cannabis use were associated with the extended psychosis phenotype, but not with mood episodes.

Our results demonstrated substantial synchronous and crosslagged correlations between mood episodes and the extended psychosis phenotype. There is growing evidence that affective and psychotic domains of psychopathology have strong overlap in terms of symptom dimensions (van Os et al. 2000a;van Rossum et al. 2011;Reininghaus et al. 2016). Similar to the epidemiological results, there are grey areas between the boundaries 
of psychotic and affective disorders in the current classification systems (Kelleher and Cannon 2014). A transdiagnostic approach based on the dimensional scores of both psychotic and affective domains (i.e. positive, negative, disorganisation, manic, depressive) may be useful to represent common 'psycho-affective' psychopathology more accurately (van Os and Reininghaus 2016). Such an approach might be effective to determine the place of psychopathology in the psychosis spectrum (i.e. affective/non-affective; clinical/ subclinical) (van Os and Reininghaus 2016). Keeping in mind the proposed sub-additive bidirectional associations between the psychotic and affective dimensions, future research on the reciprocal influences of these dimensions, and the underlying factors moderating these, might provide a useful framework for the clinical delineation of the spectrum of affective and psychotic psychopathology.

\section{Methodological Issues}

As far as we are aware, this is the first longitudinal study in a large community-based population that examines the bidirectional associations between PEs and mood episodes controlling for common risk factors. The longitudinal design enabled us to measure non-lifetime clinical features which were subject to change in time. Furthermore, adjustment addressed some other causes of psychopathology, like socio-demographic features, familial risk, alcohol and substance use, and adverse life events.

In spite of the strengths, the results need to be considered in the light of the following limitations. First, as with most longitudinal studies, our initial sample size was reduced because of the attrition. The comparison of baseline characteristics between non-participants and participants showed that attrition was higher in younger, non-married and higher-educated individuals. However, differences between participants and non-participants were quite small (Cramer's V $\leq 0.1$ ). In addition, associations between PEs and mood episodes would only be confounded by non-response if this was differential with regard to the two dimensions in the association, and this is unlikely. However, results of the study should be interpreted in the light of a degree of underlying selective drop-out. 
Second, despite the quality checks of the interviews using a standard procedure for formal consistency, appropriate recording and coding which was described above and in more detail elsewhere (Binbay et al. 2011), the assessment of PEs and mood episodes in the general population inevitably is associated with a degree of misclassification (false positives and false negatives) (Linscott and van Os 2010). However, there is little reason to assume that misclassification was differential with regard to PEs on the one hand and mood episodes on the other. Therefore, it is unlikely that findings are biased. Third, while clinical re-interviews were conducted to identify participants with psychotic disorders, the definitions of depressive and manic/hypomanic episodes were based on the CIDI results. Fourth, we only considered positive dimensions of PEs. However, negative and disorganized dimensions were also found to be predictive of later psychopathology (van Os and Reininghaus 2016). Thus, these results cannot be generalized to negative and disorganised dimensions.

\section{Semsitivity analyses in younger age group}

It is well-known that the incidence of psychosis is higher in younger age groups (Regier et al. 1988;Kirkbride et al. 2006) and may be of different origin than psychotic syndromes observed in older age groups. Thus, the associations studied in the present paper may be different in the youngest age group with the highest incidence. A sensitivity analysis was performed including participants aged 45 years or younger. Correlations were similar or a little stronger in this age group. The synchronous correlations $(r)$ between mood episodes and the extended psychosis phenotype were 0.53 at baseline and 0.58 at follow-up. The cross-lagged correlations $(r)$ were 0.34 and 0.36 . 


\section{References}

- Alptekin K, Ulas H, Akdede BB, Tumuklu M , Akvardar Y (2009). Prevalence and risk factors of psychotic symptoms: in the city of Izmir, Turkey. Social psychiatry and psychiatric epidemiology 44, 905-910.

- Anderson T, Kida T (1982). The Cross-Lagged Research Approach: Description and Illustration. J. Account. Res. 20, 403-414.

- Andrews G, Peters L (1998). The psychometric properties of the Composite International Diagnostic Interview. Social psychiatry and psychiatric epidemiology 33, 80-88.

- Armando M, Nelson B, Yung AR, et al. (2010). Psychotic-like experiences and correlation with distress and depressive symptoms in a community sample of adolescents and young adults. Schizophrenia research 119 , 258-265.

- Bijl RV, Ravelli A, van Zessen G (1998). Prevalence of psychiatric disorder in the general population: results of the Netherlands Mental
Health Survey and Incidence Study (NEMESIS). Social psychiatry and psychiatric epidemiology 33, 587-595.

- Binbay T, Alptekin K, Elbi $\mathrm{H}$, et al. (2012a). [Lifetime prevalence and correlates of schizophrenia and disorders with psychotic symptoms in the general population of Izmir, Turkey]. Turk psikiyatri dergisi $=$ Turkish journal of psychiatry 23, 149-160.

- Binbay T, Drukker M, Alptekin K, et al. (2012b). Evidence that the wider social environment moderates the association between familial liability and psychosis spectrum outcome. Psychological medicine 42, 2499-2510.

- Binbay T, Drukker M, Elbi $\mathrm{H}$, et al. (2012c). Testing the psychosis continuum: differential impact of genetic and nongenetic risk factors and comorbid psychopathology across the entire spectrum of psychosis. Schizophrenia bulletin 38, 992-1002.

- Binbay T, Elbi H, Alptekin $\mathrm{K}$, et al. (2011). Izmir mental 
health survey for gene-environment interaction in psychoses (TurkSch): objectives and methodology. Turk psikiyatri dergisi $=$ Turkish journal of psychiatry 22, 65-76.

- Brugha TS , Cragg D (1990). The List of Threatening Experiences: the reliability and validity of a brief life events questionnaire. Acta psychiatrica Scandinavica 82, 77-81.

- Cilli AS , Kaya N (2003). [Nicotine dependence and psychiatric comorbidity among university students]. Turk psikiyatri dergisi $=$ Turkish journal of psychiatry 14, 42-49.

- Cooper L, Peters L, Andrews G (1998). Validity of the Composite International Diagnostic Interview (CIDI) psychosis module in a psychiatric setting. Journal of psychiatric research 32, 361368.

- De Loore E, Gunther N, Drukker M, et al. (2011). Persistence and outcome of auditory hallucinations in adolescence: a longitudinal general population study of 1800 individuals. Schizo- phrenia research $127,252-$ 256.

- Deveci A, Taskin O, Dinc G, et al. (2007). Prevalence of pseudoneurologic conversion disorder in an urban community in Manisa, Turkey. Social psychiatry and psychiatric epidemiology 42, 857864.

- Dhossche D, Ferdinand R, Van der Ende J, Hofstra MB , Verhulst F (2002). Diagnostic outcome of self-reported hallucinations in a community sample of adolescents. Psychological medicine 32, 619-627.

- Fowler D, Hodgekins J, Garety $\mathrm{P}$, et al. (2012). Negative cognition, depressed mood, and paranoia: a longitudinal pathway analysis using structural equation modeling. Schizophrenia bulletin 38, 1063-1073.

- Goldthorpe J (1987). Social mobility and class structure in modern Britain. Clarendon Press: New York.

- Guloksuz S, van Nierop M, Lieb R, van Winkel R, Wittchen HU , van Os J (2015a). Evidence that the presence of psycho- 
sis in non-psychotic disorder is environment-dependent and mediated by severity of non-psychotic psychopathology. Psychological medicine 45, 2389-2401.

- Guloksuz S, van Nierop $M$, Lieb R, van Winkel $R$, Wittchen HU, van Os J (2015b). Evidence that the presence of psychosis in non-psychotic disorder is environment-dependent and mediated by severity of non-psychotic psychopathology. Psychological medicine 45, 2389-2401.

- Hanssen M, Peeters F, Krabbendam L, Radstake S, Verdoux H , van Os J (2003). How psychotic are individuals with non-psychotic disorders? Social psychiatry and psychiatric epidemiology 38, 149-154.

- Henquet C, Krabbendam L, Spauwen J, et al. (2005). Prospective cohort study of cannabis use, predisposition for psychosis, and psychotic symptoms in young people. BMJ 330, 11.

- Kelleher I, Cannon M (2014). Whither the psychosis-neurosis borderline.
Schizophrenia bulletin 40, 266-268.

- Kelleher I, Keeley H, Corcoran $\mathrm{P}$, et al. (2012). Clinicopathological significance of psychotic experiences in non-psychotic young people: evidence from four population-based studies. The British journal of psychiatry : the journal of mental science 201, 26-32.

- Kirkbride JB, Fearon P, Morgan C, et al. (2006). Heterogeneity in incidence rates of schizophrenia and other psychotic syndromes: findings from the 3-center AeSOP study. Archives of general psychiatry 63, 250-258.

- Kish L (1949). A procedure for objective respondent selection withinthe household. J Am Stat Assoc 44, 380-387.

- Knol MJ, van der Tweel I, Grobbee DE, Numans ME , Geerlings MI (2007). Estimating interaction on an additive scale between continuous determinants in a logistic regression model. International journal of epidemiology 36, 1111-1118. 
- Linscott RJ, van Os J (2010). Systematic reviews of categorical versus continuum models in psychosis: evidence for discontinuous subpopulations underlying a psychometric continuum. Implications for DSM-V, DSM-VI, and DSM-VII. Annual review of clinical psychology 6, 391-419.

- Linscott RJ, van Os J (2013). An updated and conservative systematic review and meta-analysis of epidemiological evidence on psychotic experiences in children and adults: on the pathway from proneness to persistence to dimensional expression across mental disorders. Psychological medicine 43, 1133-1149.

- McGrath JJ, Saha S, Al-Hamzawi A, et al. (2015). Psychotic Experiences in the General Population: A Cross-National Analysis Based on 31,261 Respondents From 18 Countries. JAMA psychiatry 72, 697705.

- McGrath JJ, Saha S, Al-Hamzawi A, et al. (2016). The Bidirectional Associ- ations Between Psychotic Experiences and DSM-IV Mental Disorders. The American journal of psychiatry, appiajp201615101293.

- Mortensen PB, Pedersen MG, Pedersen CB (2010). Psychiatric family history and schizophrenia risk in Denmark: which mental disorders are relevant? Psychological medicine 40, 201-210.

- NIMH.Genetics.Initiative (1992). Family Interview for Genetic Studies (FIGS). MD National Institute of Mental Health: Rockville.

- Nuevo R, Chatterji S, Verdes E, Naidoo N, Arango C, Ayuso-Mateos JL (2012). The continuum of psychotic symptoms in the general population: a cross-national study. Schizophrenia bulletin 38, 475-485.

- Perlis RH, Uher R, Ostacher $\mathrm{M}$, et al. (2011). Association between bipolar spectrum features and treatment outcomes in outpatients with major depressive disorder. Archives of general psychiatry 68, 351-360.

- Regier DA, Boyd JH, Burke JD, Jr., et al. (1988). One- 
month prevalence of mental disorders in the United States. Based on five Epidemiologic Catchment Area sites. Archives of general psychiatry 45, 977-986.

- Reininghaus U, Bohnke JR, Hosang G, et al. (2016). Evaluation of the validity and utility of a transdiagnostic psychosis dimension encompassing schizophrenia and bipolar disorder. The British journal of psychiatry : the journal of mental science 209, 107-113.

- Robins LN, Wing J, Wittchen HU, et al. (1988). The Composite International Diagnostic Interview. An epidemiologic Instrument suitable for use in conjunction with different diagnostic systems and in different cultures. Archives of general psychiatry 45, 1069-1077.

- Rossler W, Hengartner MP, Ajdacic-Gross V, Haker H, Gamma A , Angst J (2011). Sub-clinical psychosis symptoms in young adults are risk factors for subsequent common mental disorders. Schizophrenia research 131 , 18-23.
- Saha S, Scott J, Varghese D, McGrath J (2012). Anxiety and depressive disorders are associated with delusional-like experiences: a replication study based on a National Survey of Mental Health and Wellbeing. BMJ open 2 .

- StataCorp (2013). Stata Statistical Software: Release 13. College Station, TX: StataCorp LP.

- Stochl J, Khandaker GM, Lewis G, et al. (2015). Mood, anxiety and psychotic phenomena measure a common psychopathological factor. Psychological medicine 45, 1483-1493.

- Sullivan SA, Wiles N, Kounali D, et al. (2014). Longitudinal associations between adolescent psychotic experiences and depressive symptoms. PloS one 9, e 105758.

- TurkStat (2008). The results of address based population registration system. Turkish Statistical Institute: Ankara.

- Ulas H, Binbay T, Kirli U, Elbi H , Alptekin K (2017). The epidemiology of alcohol 
use in Izmir, Turkey: drinking pattern, impairment and help-seeking. Social psychiatry and psychiatric epidemiology.

- van Os J, Gilvarry C, Bale $\mathrm{R}$, et al. (2000a). Diagnostic value of the DSM and ICD categories of psychosis: an evidence-based approach. UK700 Group. Social psychiatry and psychiatric epidemiology 35, 305-311.

- van Os J , Guloksuz S (2017). A critique of the "ultra-high risk" and "transition" paradigm. World psychiatry : official journal of the World Psychiatric Association 16, 200-206.

- van Os J, Hanssen M, Bij1 RV , Ravelli A (2000b). Strauss (1969) revisited: a psychosis continuum in the general population? Schizophrenia research 45, 11-20.

- van Os J , Linscott RJ (2012). Introduction: The Extended Psychosis Phenotype--Relationship With Schizophrenia and With Ultrahigh Risk Status for Psychosis. Schizophrenia bulletin 38, 227-230.
- van Os J, Linscott RJ, Myin-Germeys I, Delespaul P , Krabbendam L (2009). A systematic review and meta-analysis of the psychosis continuum: evidence for a psychosis proneness-persistence-impairment model of psychotic disorder. Psychological medicine 39, 179195.

- van Os J , Reininghaus U (2016). Psychosis as a transdiagnostic and extended phenotype in the general population. World psychiatry : official journal of the World Psychiatric Association 15, 118-124.

- van Rossum I, Dominguez MD, Lieb R, Wittchen HU , van Os J (2011). Affective dysregulation and reality distortion: a 10-year prospective study of their association and clinical relevance. Schizophrenia bulletin 37, 561-571.

- Varghese D, Scott J, Welham $\mathrm{J}$, et al. (2011). Psychotic-like experiences in major depression and anxiety disorders: a population-based survey in young adults. Schizophrenia bulletin 37, 389-393. 
- Verdoux H , van Os J (2002). Psychotic symptoms in non-clinical populations and the continuum of psychosis. Schizophrenia research 54, 59-65.

- Wigman JT, van Nierop M, Vollebergh WA, et al. (2012). Evidence that psychotic symptoms are prevalent in disorders of anxiety and depression, impacting on illness onset, risk, and severity--implications for diagnosis and ultra-high risk research. Schizophrenia bulletin 38, 247-257.

- Wittchen HU, Robins LN, Cottler LB, Sartorius N, Burke JD, Regier D (1991). Cross-cultural feasibility, reliability and sources of variance of the Composite International Diagnostic Interview (CIDI). The Multicentre WHO/ADAMHA Field Trials. The British journal of psychiatry: the journal of mental science 159, 645-653, 658.

- Zavos HM, Eley TC, McGuire P, et al. (2016). Shared Etiology of Psychotic Experiences and Depressive Symptoms in Adolescence: A Longitudinal
Twin Study. Schizophrenia bulletin 42, 1197-1206. 



\title{
CHAPTER 4
}

\section{DSM outcomes of psychotic experiences and associated risk factors: 6-year follow-up study in a community-based sample}

\author{
Umut Kirlı 1, 2 \\ Tolga Binbay ${ }^{3}$ \\ Marjan Drukker ${ }^{2}$ \\ Hayriye Elbi 4 \\ Bülent Kayahan 4 \\ Duygu Keskin Gökçelli 4 \\ Ferda Özkınay ${ }^{5}$ \\ Hüseyin Onay ${ }^{5}$ \\ Köksal Alptekin ${ }^{3}$ \\ Jim van Os ${ }^{2,6,7}$
}

Psychological Medicine 2019; 49 (8): 1346-1356

1 Van Education and Research Hospital, Psychiatry Unit, Van, Turkey

2 Maastricht University Medical Centre, School of Mental Health and Neuroscience, Department of Psychiatry and Psychology, South Limburg Mental Health Research and Teaching Network, PO Box 616, Vijverdal, 6200 MD, Maastricht, The Netherlands

3 Dokuz Eylul University, Faculty of Medicine, Department of Psychiatry, 35340, Izmir, Turkey

4 Ege University, Faculty of Medicine, Department of Psychiatry, 35140, Izmir, Turkey

5 Ege University, Faculty of Medicine, Department of Medical Genetics, 35140, Izmir, Turkey

6 King's College, King's Health Partners, Department of Psychosis Studies, Institute of Psychiatry, De Crespigny Park, Denmark Hill, London, UK

7 Dept. Psychiatry, Brain Centre Rudolf Magnus, Utrecht University Medical Centre, PO BOX 85500, 3508 GA Utrecht, The Netherlands. 



\section{Abstruct}

Background: Psychotic experiences (PE) may predict a range of common, non-psychotic disorders as well as psychotic disorders. In this representative, general population-based cohort study, both psychotic and non-psychotic disorder outcomes of PE were analysed, as were potential moderators.

Methods: Addresses were contacted in a multistage clustered probability sampling frame covering 11 districts and 302 neighbourhoods at baseline $(n=4011)$. Participants were interviewed with the Composite International Diagnostic Interview (CIDI) both at baseline and at 6 year follow-up. Participants with PE at baseline were clinically re-interviewed with the SCID-I at follow-up. The role of socio-demographics, characteristics of PE, co-occurrence of mood disorders and family history of mental disorders were tested in the association between baseline PE and follow-up diagnosis.

Results: In the participants with baseline PE, the psychotic disorder diagnosis rate at follow up was $7.0 \%$ - much lower than the rates of DSM-IV mood disorders without psychotic features $(42.8 \%)$ and other non-psychotic disorders (24.1\%). Within the group with baseline $\mathrm{PE}$, female sex, lower socioeconomic status, co-occurrence of mood disorders, family history of a mental disorder and persistence of PE predicted any follow-up DSM diagnosis. Furthermore, onset of psychotic versus non-psychotic disorder was predicted by younger age (15-30 years), co-presence of delusional and hallucinatory $\mathrm{PE}$ and family history of severe mental illness.

Conclusion: The outcome of PE appears to be a consequence of baseline severity of multidimensional psychopathology and familial risk. It may be useful to consider PE as a risk indicator that has trans-diagnostic value. 


\section{Introduction}

Previous research has demonstrated that expression of the psychosis phenotype extends from subclinical psychotic experiences (PE) to clinical psychotic disorders (van Os et al. 2009; Linscott and van Os 2013;Fonseca Pedrero and Debbane 2017). Furthermore, individuals who report PE have elevated risk for later psychotic disorders in comparison with those who do not (Poulton et al. 2000;Hanssen et al. 2005;Dominguez et al. 2011; Werbeloff et al. 2012;Zammit et al. 2013). However, most PE are self-limiting and the predictive value of $\mathrm{PE}$ for subsequent psychotic disorders is typically low at less than $1 \%$ per year in previous community-based studies (Hanssen et al. 2005; Kaymaz et al. 2012; Linscott and van Os 2013;Zammit et al. 2013). Transition rates are higher in clinical studies of individuals with affective disorder and substance use disorders with a degree of psychosis admixture, considered at ultra-high risk (UHR) (Fusar-Poli et al. 2012; Schmidt et al. 2015; Schultze-Lutter et al. 2015; Fusar-Poli and Schultze-Lutter 2016). However, these were conducted in help-seeking samples and generating risk-enrichment, making it difficult to compare results to longitudinal studies of PE in the general population (van Os and Guloksuz 2017).

$\mathrm{PE}$ were associated with increased risk of later non-psychotic disorders as well as psychotic disorders among different age groups (McGrath et al. 2016). First, studies assessing outcomes of $\mathrm{PE}$ in adolescents found associations with later depression, suicide attempts, substance use disorders and PTSD (Dhossche et al. 2002;De Loore et al. 2011;Fisher et al. 2013;Sullivan et al. 2014;Zavos et al. 2016). Second, PE at age 19/20 years predicted dysthymia, bipolar disorder, social phobia, and obsessive-compulsive disorder by age 49/50 years (Rossler et al. 2011). Finally, PE were related to increased risk of later service use (Bhavsar et al. 2017) and hospitalization for non-psychotic disorders (Werbeloff et al. 2012). 
Definitions of PE and type of screening instruments used varied across studies (Kelleher et al. 2011), contributing to the heterogeneity of results in this area. Definitions of PE were mainly based on attenuated forms of delusional thinking and hallucinatory perceptions (van Os et al. 2009; Linscott and van Os 2013;Fonseca Pedrero and Debbane 2017), similar to those used in the current paper. However, negative, disorganization and affective dimensions were identified in addition to the positive dimension (van Os and Reininghaus 2016). It was suggested that positive and negative dimensions of PE might be associated with emergence of different types of psychopathology (Debbane et al. 2015).Moreover, many factors such as comorbid non-psychotic symptoms (Yung et al. 2003;Hanssen et al. 2005;Perlis et al. 2011;van Rossum et al. 2011; Kelleher et al. 2012; Wigman et al. 2012; Smeets et al. 2013;Falkenberg et al. 2015;Guloksuz et al. 2015;Honings et al. 2016; Salokangas et al. 2016), persistence (Poulton et al. 2000; Yung et al. 2003;Dominguez et al. 2011;Nelson et al. 2013), cognitive impairment (Shah et al. 2012; Carrion et al. 2013;Kelleher et al. 2015), familial risk (Cannon et al. 2008; Shah et al. 2012; Smeets et al. 2015) and environmental exposures (Cougnard et al. 2007; Cannon et al. 2008;Collip et al. 2008;Dragt et al. 2011; Smeets et al. 2013;Guloksuz et al. 2015; Smeets et al. 2015; van Dam et al. 2015) were shown to impact on outcome of PE (Fonseca Pedrero and Debbane 2017).

The above studies demonstrate that $\mathrm{PE}$ indexes risk for a variety of common mental disorders as well as psychotic disorder. However, this research has some limitations. Diagnoses at follow-up, with one notable exception (Werbeloff et al. 2012), were mostly based on lay-interviewer assessments and re-interviews were not performed by clinicians. Furthermore, research on follow-up DSM diagnoses in community-based populations with baseline $\mathrm{PE}$, and the role of baseline differences thereof, remains limited.

The aims of this paper were to analyse, over a 6 year period, in a general population sample, 
i) The follow-up diagnostic status of participants with baseline PE,

ii) To explore the role of socio-demographics, characteristics of PE, co-occurrence of mood disorders and family history of mental disorders in the association between baseline PE and presence of any follow-up DSM diagnosis.

iii) To explore the role of the same factors in discriminating between the outcome of psychotic and non-psychotic outcome in those with baseline PE.

\section{Methods}

\section{Sample and Study Design}

Data came from the TürkSch (Izmir Mental Health Survey for Gene-Environment Interaction in Psychosis) study which collected longitudinal data on the prevalence, incidence, risk factors, comorbidity, and course of mental disorders in a random, representative community-based sample covering a time frame of approximately 6 years(Binbay et al. 2011;Binbay et al. 2012a;Binbay et al. 2012b). The sample of the baseline assessment ( $\left.\mathrm{T}_{1}\right)$ was randomly selected from the wider Izmir metropolitan area using a multistage sampling procedure, stratified by urbanicity covering 11 districts and 302 neighbourhoods. The households were visited in person by trained lay interviewers between 2007 and 2009. One household member aged between 15 and 64 years was randomly selected using the Kish within-household sampling method (Kish 1949). A total of 4011 participants were interviewed with the Composite International Diagnostic Interview (CIDI) (Andrews and Peters 1998). Of those 4011 participants, 406 (10.1\%) endorsed a PE either with a duration of at least " 1 week" or with a frequency of at least "sometimes" or associated with help-seeking/ interference with functioning or enjoying relationships (Binbay et al. 2012b). Those 406 participants were re-contacted and the Structured Clinical Interviews for DSM-IV (SCID) (Spitzer et al. 1992) were conducted (Binbay et al. 2012b). Of the 406 participants, 99 were diagnosed with 
a DSM-IV disorder with psychotic features (baseline psychotic disorder- PD group), and thus excluded from the sample of the current analysis. The remaining participants (baseline PE group, $\mathrm{n}=307$ ) were included in the current analyses (Fig. 1). Full details on the Izmir metropolitan area, sampling, representativeness, instruments and procedures of $\mathrm{T}_{1}$ have been published previously (Binbay et al. 2011).

At follow-up assessment $\left(\mathrm{T}_{2}\right)$, addresses of all $\mathrm{T}_{1}$ participants were re-visited in person by trained lay interviewers 6 years after the baseline assessments (years 2013-2015). Attempts were made to reduce the number of non-respondents from the baseline sample (Binbay et al. 2011). 187 of the 307 individuals within the baseline PE group were successfully interviewed with CIDI (response rate: 60.9\%; sample and results of the visits were presented in Fig. 1). All of these 187 participants were re-interviewed with SCID by the team psychiatrist (122 interviews at the hospital and 65 at the participants' residence). Both assessments of TürkSch study were approved by the Ege University ethics committee and participants provided written informed consent.

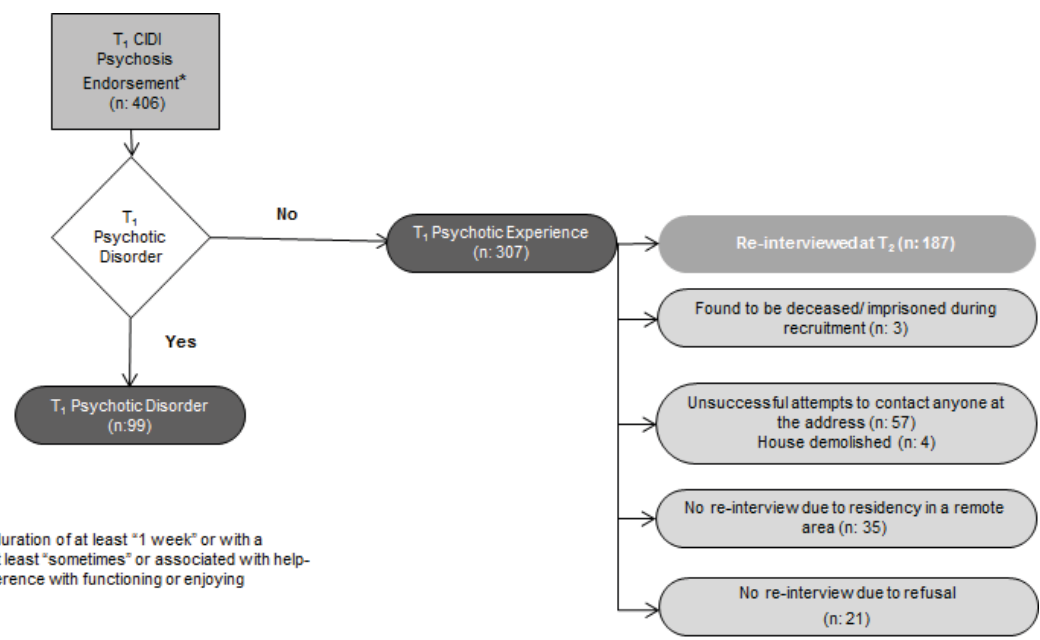

"Either with a duration of at least " 1 week" or with frequency of at least "sometimes" or associated with helpseeking/ interference with functioning or enjoying relationships

$$
(n: 21)
$$

Figure 1: General design and T2 outcome of participants with psychosis endorsement at T1. 


\section{Interviewers and Quality Control}

At $\mathrm{T}_{1}$, lay interviewers had at least high school education, a health-related profession, and/or were experienced in doing field surveys. At $\mathrm{T}_{2}$, lay interviewers were psychology graduates. At $\mathrm{T}_{2}$, both the lay interviewers and the psychiatrist who conducted the SCID interviews (UK) had not participated in $\mathrm{T}_{1}$, and thus were blind to baseline results. At both assessments, lay interviewers had a two-week formal training. Each CIDI interview was conducted according to a standard procedure, with recording and quality coding (Binbay et al. 2011). When the quality of the interview was considered low or if any missing value was present, a second visit was planned by a different lay-interviewer ( $\mathrm{n}=$ 65). The missing values still present after the second visit $(n=18)$ were assessed by the psychiatrist following the clinical interview. The inter-rater reliability of the CIDI psychosis section had a kappa value of 0.45 at $\mathrm{T}_{1}$ (Binbay et al. 2011) and 0.67 at $\mathrm{T}_{2}$.

\section{Assessments}

\section{Composite International Diagnostic Interview (CIDI)}

The CIDI is a fully structured interview developed by the World Health Organization (Robins et al. 1988). The CIDI can be used by both clinicians and trained lay interviewers. CIDI was found to be appropriate for use in different countries and cultures (Wittchen 1994) and was used in various epidemiological surveys around the world including Turkey (Cilli and Kaya 2003;Deveci et al. 2007;Alptekin et al. 2009). The reliability and validity functions of the Turkish version of the CIDI were studied as part of an international study (Rezaki et al. 1995). The CIDI was found to have excellent inter-rater reliability in almost all sections with kappa values ranging from 0.67 to 0.97 (Wittchen et al. 1991). In particular, kappa for agreement between clinicians for delusions and hallucinations was found to be 0.85 and 0.87 , respectively. Furthermore, the sensitivity of the CIDI was found to be higher than its specificity for both delusions (0.93 vs. 0.55) and hallucinations (0.86 vs. 0.50) (Cooper et al. 1998). 


\section{Assessment of Psychotic Experiences}

$\mathrm{PE}$ were rated using 14 CIDI delusions items (G1, G2, G3, G4, G5, G7, G8, G9, G10, G11, G12, G13, G13b and G14) and 5 CIDI hallucinations items (G17, G18, G20, G20C, and G21). All items were rated dichotomously indicating presence or absence. The time frame for $\mathrm{PE}$ was lifetime at $\mathrm{T}_{0}$ and the last six years at $\mathrm{T}_{1}$.

The rating of $\mathrm{PE}$ can be difficult because sometimes individuals can be describing a plausible event that in the CIDI may be rated as a psychotic experience. Therefore, the following procedures were followed. First, during the interview, each time a participant endorsed a CIDI psychotic experience, the participant was asked to give an example, which was written down verbatim by the interviewer for later review with the team psychiatrist and/ or senior psychologist. When it was not clear whether or not the participant had truly endorsed a positive psychotic experience, the participant was re-contacted by the team psychiatrist over the telephone to confirm the experience.

Persistence of $\mathrm{PE}$ was recoded into transient or persistent according to presence at follow-up assessment. Co-presence of delusional and hallucinatory $\mathrm{PE}$ was recoded into a dummy variable: $0=$ delusional or hallucinatory $1=$ combined delusional and hallucinatory

\section{Assessment of Baseline ( $\left.T_{1}\right)$ Modd Disorders}

In order to evaluate the presence of any mood disorder at baseline assessment, a binary variable was constructed and coded positive if there was either a CIDI depressive or a hypomanic/ manic episode, as described below.

For depression, participants were asked if they had experienced an episode lasting at least two weeks during which they felt depressed, or had a lack of interest. Depressive symptoms were only rated if any of the core items (depressed mood and loss of interest) were endorsed as having been present for 2 weeks. If endorsed, participants were asked if, during this period, they had 
experienced lack of energy, appetite change, sleep problems, being slow or restless, feelings of worthlessness or guilt, decreased self-esteem, trouble thinking or indecisiveness, and thoughts of death. For a manic/hypomanic episode, participants were asked whether they had experienced elevated mood or irritability for a period of at least 4 consecutive days either noticed by others or causing problems. If this was the case, participants were asked if, during this period, they had experienced excessive goal-directed activity, psychomotor agitation, spending sprees, sexual indiscretions, increased talkativeness, flight of ideas, loss of normal social inhibitions, increased self-esteem or grandiosity, decreased need for sleep, and distractibility. For both depressive and manic symptoms, association with substance use or physical conditions; help-seeking, clinician diagnosis and treatment history were assessed. Depressive and hypomanic/manic episode was coded positive in accordance with the definitions and criteria of DSM-IV. Time frame for baseline mood disorders was the past year.

\section{Dther Assessments}

The baseline and follow-up assessments included a sociodemographic questionnaire in order to determine various risk factors and background characteristics. In guidance of the previous literature revealing that onset of psychotic disorders occurs usually in late adolescence and progresses over time (Fusar-Poli et al. 2014), age (in years in 2008) was recoded into 15-30 and >30. Level of education was defined in regard to last graduated school. Socioeconomic status (SES proxy) was based on the profession of the participant (if the participant had no profession, father/husband's profession was used instead) and recoded into 3 ordinal categories: 1=Professional and non-manual employees, 2=Owners of small businesses, 3=Manual workers (Goldthorpe 1987).

Using questions derived from the Family Interview for Genetic Studies (NIMH 1992), history of mental disorders in the father, mother, siblings, and offspring was assessed. Thus, a family history of mental disorders' variable was defined and coded guided by previous literature (Mortensen et al. 2010): 0=No or undefined fami- 
ly history of mental disorders; $1=$ Common mental disorder (depression/anxiety disorders) in at least one family member but no severe mental illness; 2=Severe mental illness (bipolar disorder/ psychotic disorder/hospitalization/completed suicide) in at least one family member (Binbay et al. 2012b).

Alcohol and cannabis use were assessed using screening questions on CIDI alcohol and substance-related disorders sections. Conform previous CIDI-based research, cannabis use of 5 times or more was defined as exposure status for cannabis. Regular alcohol use was defined as use of alcohol at least once a week. Using information from both $\mathrm{T}_{1}$ and $\mathrm{T}_{2}$, alcohol use was recoded into 3 variables: $0=$ Never used; $1=$ History of alcohol use at any level but no regular use at follow-up assessment; 2=Regular alcohol use at follow-up assessment.

Life events were assessed at follow-up using the List of Threatening Life Events Questionnaire (Brugha and Cragg 1990). Time frame was the last six years. The number of life events was a continuous variable with a minimum of 0 and maximum of 12 .

\section{Dependent Variable}

The main outcome of the study was follow-up diagnosis of participants based on the SCID-I. Guided by previous research (Kessler et al. 2005), standardized diagnostic hierarchy rules among the disorders were applied when there was more than one diagnosis. Follow-up diagnostic outcomes were also categorised into two groups according to the psychotic features: the psychotic disorder (PD) group included participants who had any DSM-IV diagnosis with clinical psychotic features (including schizophrenia and other psychotic disorders; mood disorders with psychotic features; psychotic disorder due to general medical condition; substance-induced psychotic disorder). The non-psychotic disorders group included participants who had any DSM-IV disorder without psychotic features (e.g. mood disorders without psychotic features, anxiety disorders, somatoform disorders, substance use disorders, impulse control disorders, dementia, primary insomnia). 


\section{Statistical Amalyses}

All analyses were conducted using the software package STATA, version 13.1. First, we performed the analysis to explore the role of factors in the association between baseline PE and presence of any DSM diagnoses at follow-up. In these analyses, logistic regression was used with the dependent variable any/no follow-up DSM-IV diagnosis.

Table 1: Baseline characteristics and comparison of those participated with lost to follow-up

\begin{tabular}{|c|c|c|c|c|c|c|}
\hline & $\begin{array}{l}\text { Participated at Follow-up (n:187) } \\
\text { n (\%) }\end{array}$ & $\begin{array}{l}\text { Lost to Follow-up (n:120) } \\
\mathrm{n}(\%)\end{array}$ & $x^{2}$ & Df & $p$ & Cramer's V \\
\hline \multicolumn{7}{|l|}{ Age Categories (Year 2008) } \\
\hline$>30$ & $113(60.4)$ & $63(52.5)$ & \multirow{2}{*}{1.88} & \multirow{2}{*}{1} & \multirow{2}{*}{0.2} & \multirow{2}{*}{0.08} \\
\hline $15-30$ & 74 (39.6) & $57(47.5)$ & & & & \\
\hline \multicolumn{7}{|l|}{ Sex } \\
\hline Female & $129(31.0)$ & $45(37.5)$ & \multirow{2}{*}{1.38} & \multirow{2}{*}{1} & \multirow{2}{*}{0.2} & \multirow{2}{*}{0.07} \\
\hline Male & $58(69.0)$ & $75(62.5)$ & & & & \\
\hline \multicolumn{7}{|l|}{ Education } \\
\hline Higher & $51(27.3)$ & $42(35.6)$ & \multirow{2}{*}{2.36} & \multirow{2}{*}{1} & \multirow{2}{*}{0.1} & \multirow{2}{*}{0.09} \\
\hline Lower & $136(72.7)$ & $78(64.4)$ & & & & \\
\hline \multicolumn{7}{|l|}{ Marital Status } \\
\hline Married & $122(65.2)$ & $70(57.6)$ & \multirow{2}{*}{1.78} & \multirow{2}{*}{1} & \multirow{2}{*}{0.2} & \multirow{2}{*}{0.08} \\
\hline Non-married & $65(34.8)$ & $50(42.4)$ & & & & \\
\hline \multicolumn{7}{|l|}{ SES Proxy } \\
\hline Professional & $52(27.8)$ & $38(32.2)$ & \multirow{3}{*}{1.52} & \multirow{3}{*}{2} & \multirow{3}{*}{0.5} & \multirow{3}{*}{0.07} \\
\hline Owner of Small Business & $28(15.0)$ & $21(17.8)$ & & & & \\
\hline Manuel Workers & $107(57.2)$ & $61(50.0)$ & & & & \\
\hline \multicolumn{7}{|l|}{ Ethnicity } \\
\hline Turkish & $149(79.7)$ & $100(83.3)$ & \multirow{2}{*}{0.64} & \multirow{2}{*}{1} & \multirow{2}{*}{0.4} & \multirow{2}{*}{0.04} \\
\hline Non-Turkish & $38(20.3)$ & $20(16.7)$ & & & & \\
\hline $\begin{array}{l}\text { Contact with a Mental } \\
\text { Health Service }\end{array}$ & & & & & & \\
\hline None & $138(73.8)$ & $90(75.0)$ & 005 & 1 & 08 & (1) \\
\hline At least once & $49(26.2)$ & $30(25.0)$ & 0.00 & 1 & 0.0 & 0.01 \\
\hline Comorbid Mood Disorder & & & & & & \\
\hline None & $89(47.6)$ & $60(50)$ & 017 & 1 & 07 & רחת \\
\hline Present & $98(52.4)$ & $60(50)$ & 0.17 & 1 & 0.7 & 0.02 \\
\hline $\begin{array}{l}\text { Co-presence of Delusional } \\
\text { and Hallucinatory PE }\end{array}$ & & & & & & \\
\hline Delusional or Hallucinatory & $104(55.6)$ & $62(51.7)$ & & & & \\
\hline $\begin{array}{l}\text { Combined Delusional \& } \\
\text { Hallucinatory }\end{array}$ & $83(44.4)$ & $58(48.3)$ & 0.46 & 1 & 0.5 & 0.04 \\
\hline Cannabis Use & & & & & & \\
\hline None & $177(94.6)$ & $110(91.7)$ & 107 & 1 & 03 & ( \\
\hline Yes & $10(5.4)$ & $10(8.3)$ & 1.01 & 1 & 0.3 & 0.00 \\
\hline
\end{tabular}


We explored the role of factors in developing a psychotic disorder in comparison with non-psychotic disorder. Participants with a follow-up DSM diagnosis were included, logistic regression was performed with the dependent variable psychotic versus non-psychotic follow-up DSM-IV disorder. Associations were presented both without adjustment and also adjusted for other variables such as socio-demographic factors (age, sex, SES proxy and marital status), presence of baseline mood disorder, family history of mental disorders, alcohol/cannabis use and number of life events. Multicollinearity was assessed using correlation matrix and variance inflation factor (VIF).

\section{Results}

\section{Participant Characteristics}

Detailed characteristics of the sample were depicted in table 1. There were no large or significant differences between participants and non-participants at follow-up according to socio-demographic and clinical characteristics (table 1). Sixty-seven participants $(35.8 \%)$ reported use of psychotropic medication and thirteen $(7.0 \%)$ reported antipsychotic use.

\section{Follow-ap DSM Dutcomes of Participants with Baseline Psychotic Experiences}

Of the participants with baseline PE ( $\mathrm{n}=187), 7.0 \%(\mathrm{n}=13)$ transitioned to psychotic disorder at follow-up (6 with DSMIV schizophrenia and related disorder; 7 with DSM-IV mood disorders with psychotic features; Table 1). Of non-transitioned participants $(\mathrm{n}=174) ; 70.7 \%(\mathrm{n}=123)$ had at least one DSM-IV diagnosis at follow-up $(46.0 \%$ DSM-IV mood disorder without psychotic features, $24.7 \%$ other non-psychotic DSMIV disorder). Details of the follow-up DSM diagnoses are presented in table 2 . 
Table 2: DSM-IV diagnoses at 6-year follow-up in respondents with baseline PE

\begin{tabular}{|c|c|c|}
\hline Diagnostic Category & Cases (n) & $\%$ \\
\hline Schizophrenia and Related Disorders & 6 & 3.2 \\
\hline Schizophrenia & 3 & 1.7 \\
\hline Schizoaffective Disorder & 1 & 0.5 \\
\hline Substance-Induced Psychotic Disorder & 1 & 0.5 \\
\hline $\begin{array}{l}\text { Psychotic Disorder Due to General Medical } \\
\text { Conditions }\end{array}$ & 1 & 0.5 \\
\hline Mood Disorders & 87 & 46.5 \\
\hline Bipolar Disorder with Psychotic Features & 5 & 2.7 \\
\hline Bipolar Disorder without Psychotic Features & 9 & 4.8 \\
\hline Major Depressive Dis. with Psychotic Features & 2 & 1.1 \\
\hline $\begin{array}{l}\text { Major Depressive Dis. without Psychotic } \\
\text { Features }\end{array}$ & 68 & 36.3 \\
\hline Dysthymic Disorder & 3 & 1.6 \\
\hline Anxiety Disorders & 26 & 13.9 \\
\hline Generalized Anxiety Disorder & 18 & 9.6 \\
\hline Obsessive-Compulsive Disorder & 3 & 1.6 \\
\hline Panic Disorder & 3 & 1.6 \\
\hline Posttraumatic Stress Disorder & 2 & 1.1 \\
\hline Other Non-Psychotic Disorders & 17 & 9.1 \\
\hline Somatoform Disorders & 8 & 4.3 \\
\hline Substance-Related Disorders & 6 & 3.2 \\
\hline Dementia & 1 & 0.5 \\
\hline $\begin{array}{l}\text { Impulse Control Disorder Not Otherwise } \\
\text { Specified }\end{array}$ & 1 & 0.5 \\
\hline Primary Insomnia & 1 & 0.5 \\
\hline No diagnosis & 51 & 27.3 \\
\hline Total & 187 & 100 \\
\hline
\end{tabular}

\section{Factors associated with presence of any} follow-up DSM diagnosis in participants with baseline PE

Of participants with baseline PE ( $\mathrm{n}=187), 72.7 \%(\mathrm{n}=136)$ had a DSM-IV diagnosis (psychotic or non-psychotic) at follow-up. Female sex, co-occurrence of mood disorders and persistence of PE predicted any follow-up DSM diagnosis outcome. Family history of any mental disorder was also associated with presence of follow-up DSM diagnosis although this association was attenuated on inclusion of other factors (Table 3). 
Table 3: Factors associated with any DSM diagnosis at 6-year follow-up in respondents with baseline PE

\begin{tabular}{|c|c|c|c|c|c|c|c|c|c|c|c|}
\hline \multirow{2}{*}{\multicolumn{3}{|c|}{ Variables }} & \multicolumn{5}{|c|}{$\begin{array}{c}\text { Presence of Any Follow-up DSM } \\
\text { Diagnosis }\end{array}$} & \multirow{2}{*}{\multicolumn{4}{|c|}{$\begin{array}{c}\begin{array}{c}\text { Presence of Any Follow-up DSM } \\
\text { Diagnosis Adjusted }^{\text {a }}\end{array} \\
\text { Logistic Regression }\end{array}$}} \\
\hline & & & \multicolumn{2}{|c|}{ Prevalence } & \multicolumn{3}{|c|}{ Logistic Regression } & & & & \\
\hline & $\mathrm{N}$ & $\%$ & $\mathrm{~N}$ & $\%$ & OR & $95 \% \mathrm{Cl}$ & $p$ & OR & $95 \% \mathrm{Cl}$ & $P$ & $\begin{array}{l}\text { Mean } \\
\text { VIF }\end{array}$ \\
\hline \multicolumn{11}{|c|}{ Sociodemographic Variables } & \\
\hline \multicolumn{12}{|l|}{ Age Categories (Year 2008) } \\
\hline$>30$ & 113 & 60.4 & 83 & 73.4 & Ref & - & - & Ref & - & - & \\
\hline $15-30$ & 74 & 39.6 & 53 & 71.6 & 0.9 & $0.5-1.7$ & 0.8 & 0.6 & $0.3-1.3$ & 0.2 & 1.77 \\
\hline \multicolumn{12}{|l|}{ Sex } \\
\hline Male & 58 & 31.0 & 38 & 65.5 & Ref & - & - & Ref & - & - & \\
\hline Female & 129 & 69.0 & 98 & 76.0 & 1.7 & $0.8-3.3$ & 0.1 & 3.1 & $1.2-7.8$ & $<0.05$ & 2.25 \\
\hline \multicolumn{12}{|l|}{ Education } \\
\hline Higher & 70 & 37.4 & 51 & 72.8 & Ref & - & - & Ref & - & - & \\
\hline Lower & 117 & 62.6 & 85 & 72.6 & 0.9 & $0.5-1.9$ & 0.9 & 1.3 & $0.6-3.0$ & 0.5 & 2.52 \\
\hline \multicolumn{12}{|l|}{ Marital Status } \\
\hline Married & 125 & 66.8 & 87 & 69.6 & Ref & - & - & Ref & - & - & \\
\hline Non-married & 62 & 33.2 & 49 & 79.0 & 1.6 & $0.8-3.4$ & 0.2 & 1.1 & $0.4-2.7$ & 0.9 & 2.25 \\
\hline \multicolumn{12}{|c|}{ Baseline Psychopathology } \\
\hline \multicolumn{12}{|l|}{$\begin{array}{l}\text { Comorbid Mood } \\
\text { Disorder }\end{array}$} \\
\hline None & 89 & 47.6 & 52 & 58.4 & Ref & - & - & Ref & - & - & \\
\hline Present & 98 & 52.4 & 84 & 85.7 & 4.3 & 2.1-8.6 & $<0.001$ & 4.7 & $2.1-10$ & $<0.001$ & 2.25 \\
\hline \multicolumn{12}{|l|}{$\begin{array}{l}\text { Co-presence of } \\
\text { Delusional and } \\
\text { Hallucinatory PE }\end{array}$} \\
\hline $\begin{array}{l}\text { Delusional or } \\
\text { Hallucinatory }\end{array}$ & 104 & 55.6 & 70 & 67.3 & Ref & - & - & Ref & - & - & \\
\hline $\begin{array}{l}\text { Combined Delusional } \\
\text { \&Hallucinatory }\end{array}$ & 83 & 44.4 & 66 & 79.5 & 1.9 & 0.9-3.7 & 0.06 & 1.9 & $0.9-4.2$ & 0.1 & 2.24 \\
\hline \multicolumn{12}{|l|}{ Persistence of PE } \\
\hline Transient PE & 91 & 48.7 & 53 & 58.2 & Ref & - & - & Ref & - & - & \\
\hline Persistent PE & 96 & 51.3 & 83 & 86.5 & 4.6 & $2.2-9.4$ & $<0.001$ & 5.2 & $2.2-12$ & $<0.001$ & 2.28 \\
\hline \multicolumn{12}{|c|}{ Family History } \\
\hline \multicolumn{12}{|l|}{$\begin{array}{l}\text { Disorder in } 1 \text { family } \\
\text { member }\end{array}$} \\
\hline No or undefined & 137 & 73.3 & 94 & 68.6 & Ref & - & - & Ref & - & - & \\
\hline $\begin{array}{l}\text { A defined mental } \\
\text { disorder }\end{array}$ & 50 & 27.7 & 42 & 84.0 & 2.4 & 1.1-5.5 & $<0.05$ & 2.1 & $0.8-5.3$ & 0.1 & 2.37 \\
\hline \multicolumn{12}{|l|}{ Type of family history } \\
\hline No or undefined & 137 & 73.3 & 94 & 68.6 & Ref & - & - & Ref & - & - & \\
\hline $\begin{array}{l}\text { Common mental } \\
\text { disorders }\end{array}$ & 37 & 19.8 & 30 & 81.1 & 1.9 & $0.8-4.8$ & 0.1 & 1.9 & $0.7-5.3$ & 0.2 & 25 \\
\hline Severe mental illness & 13 & 6.9 & 12 & 92.3 & 5.5 & $\begin{array}{l}0.7- \\
43.5\end{array}$ & 0.1 & 2.9 & $0.3-25.8$ & 0.3 & 2.25 \\
\hline Baseline PE group & 187 & 100 & 136 & 72.7 & - & - & - & - & - & - & - \\
\hline
\end{tabular}

${ }^{a}$ Adjusted for age, gender, marital status, SES proxy, presence of baseline mood disorder, family history of mental disorders, alcohol use, cannabis use and number of life events 


\section{Factors associated with developing a psychotic disorder in comparison with mon- psychotic disorder}

Of the participants with any DSM diagnosis at follow-up ( $\mathrm{n}=136)$, $9.6 \%(n=13)$ had a psychotic disorder. Participants in the age range of adolescence or early adulthood (15-30 years old) had more risk to develop a psychotic disorder in comparison with older participants. Furthermore, participants with combined delusional and hallucinatory $\mathrm{PE}$ at baseline were more likely to develop a psychotic disorder than participants with only delusional or hallucinatory PE. However these latter associations were attenuated when adjusted for other factors. Family history of severe mental illness was significantly associated with developing a psychotic disorder in comparison with non-psychotic disorder (Table 4). Tests indicated that no significant multicollinearity was present (Table 3 and 4).

\section{Discussion}

\section{Follow-ap DSM-IV Diagnoses in Participants with Baseline Psychotic Experiences}

The six-year transition to PD rate in this study of $7.0 \%$ (i.e. around $1 \%$ per year) is consistent with the previous community-based findings (Kaymaz et al. 2012; Linscott and van Os 2013). $70.7 \%$ of non-transitioned participants with baseline PE had a DSM-IV diagnosis at follow-up. Forty-six percent of the non-transitioned participants had a mood disorder. Although any comparison with the UHR literature is problematic, as mentioned earlier, this proportion is similar to a recent UHR study showing that $68.1 \%$ of non-transitioned high-risk participants met criteria for at least one disorder and $48.7 \%$ met criteria for a mood disorder (Lin et al. 2015). The prevalence of non-psychotic disorders in participants with baseline PE was higher than the estimates of these disorders in the general population (Topuzoglu et al. 2015). Furthermore, the follow-up psychotic disorder rate was much lower than the rate of non-psychotic disorders. These findings are in line with previous evidence linking PE with 
Table 4: Factors associated with developing a psychotic DSM disorder versus a non-psychotic DSM disorder at 6-year follow-up in respondents with baseline PE

\begin{tabular}{|c|c|c|c|c|c|c|c|c|c|c|c|}
\hline & & & \multicolumn{5}{|c|}{ Psychotic Disorder Outcome } & \multirow{2}{*}{\multicolumn{4}{|c|}{$\begin{array}{l}\text { Psychotic Disorder Outcome Adjusted } \\
\text { Logistic Regression }\end{array}$}} \\
\hline & & & \multicolumn{2}{|c|}{ Incidence } & \multicolumn{3}{|c|}{ Logistic Regression } & & & & \\
\hline & $\mathrm{N}$ & $\%$ & $\mathrm{~N}$ & $\%$ & OR & $95 \% \mathrm{Cl}$ & $p$ & OR & $95 \% \mathrm{Cl}$ & $\mathrm{p}$ & $\begin{array}{l}\text { Mean } \\
\text { VIF }\end{array}$ \\
\hline \multicolumn{12}{|l|}{ Socio-demographics } \\
\hline \multicolumn{12}{|l|}{ Age Categories (2008) } \\
\hline$>30$ & 83 & 61.0 & 4 & 4.8 & Ref & - & - & Ref & - & - & \\
\hline $15-30$ & 53 & 39.0 & 9 & 17.0 & 4.0 & $1.2-13.9$ & $<0.05$ & 3.3 & $0.7-16.0$ & 0.1 & 1.94 \\
\hline \multicolumn{12}{|l|}{ Sex } \\
\hline Male & 38 & 27.9 & 4 & 10.5 & Ref & - & - & Ref & - & - & \\
\hline Female & 98 & 72.1 & 9 & 9.2 & 0.8 & $0.2-3.0$ & 0.8 & 4.1 & $0.6-29.2$ & 0.2 & 2.48 \\
\hline \multicolumn{12}{|l|}{ Education } \\
\hline Higher & 51 & 37.5 & 4 & 7.8 & Ref & - & - & Ref & - & - & \\
\hline Lower & 85 & 62.5 & 9 & 10.6 & 1.4 & $0.4-4.8$ & 0.6 & 2.2 & $0.4-13.8$ & 0.4 & 2.80 \\
\hline \multicolumn{12}{|l|}{ Marital Status } \\
\hline Married & 87 & 64.0 & 6 & 6.9 & Ref & - & - & Ref & - & - & \\
\hline Non-married & 49 & 36.0 & 7 & 14.3 & 2.2 & $0.7-7.1$ & 0.2 & 0.8 & $0.1-4.5$ & 0.8 & 2.48 \\
\hline \multicolumn{12}{|l|}{ Baseline Psychopathology } \\
\hline \multicolumn{12}{|l|}{ Comorbid Mood Disorder } \\
\hline None & 52 & 38.2 & 6 & 11.5 & Ref & - & - & Ref & - & - & \\
\hline Present & 84 & 61.8 & 7 & 8.3 & 0.7 & $0.2-2.2$ & 0.5 & 0.5 & $0.1-2.1$ & 0.3 & 2.48 \\
\hline \multicolumn{12}{|l|}{$\begin{array}{l}\text { Co-presence of Delusional } \\
\text { and Hallucinatory PE }\end{array}$} \\
\hline $\begin{array}{l}\text { Delusional or } \\
\text { Hallucinatory }\end{array}$ & 70 & 51.5 & 3 & 4.3 & Ref & - & - & Ref & - & - & \\
\hline $\begin{array}{l}\text { Combined Delusional } \\
\text { \&Hallucinatory }\end{array}$ & 66 & 48.5 & 10 & 15.2 & 4.0 & $1.1-15.2$ & $<0.05$ & 3.2 & $0.6-16.5$ & 0.2 & 2.47 \\
\hline \multicolumn{12}{|l|}{ Family History } \\
\hline \multicolumn{12}{|l|}{$\begin{array}{l}\text { Disorder in one family } \\
\text { member }\end{array}$} \\
\hline No or undefined & 94 & 69.1 & 6 & 6.4 & Ref & - & - & Ref & - & - & \\
\hline A defined mental disorder & 42 & 30.9 & 7 & 16.7 & 2.9 & $0.9-9.3$ & 0.06 & 3.1 & $0.8-12.6$ & 0.1 & 2.62 \\
\hline \multicolumn{12}{|l|}{ Type of Family History } \\
\hline No or undefined & 94 & 69.1 & 6 & 6.4 & Ref & - & - & Ref & - & - & \\
\hline Common mental disorders & 30 & 22.1 & 4 & 13.3 & 2.2 & $0.6-8.6$ & 0.2 & 2.0 & $0.4-10.2$ & 0.4 & \multirow{2}{*}{2.48} \\
\hline Severe mental illness & 12 & 8.8 & 3 & 25.0 & 4.9 & 1.1-22.9 & $<0.05$ & 7.4 & $1.1-50.0$ & $<0.05$ & \\
\hline $\begin{array}{l}\text { Baseline PE group with } \\
\text { any diagnoses at follow-up }\end{array}$ & 136 & 100 & 13 & 9.6 & - & - & - & - & - & - & - \\
\hline
\end{tabular}

${ }^{a}$ Adjusted for age, gender, marital status, SES proxy, presence of baseline mood disorder, family history of mental disorders, alcohol use, cannabis use and number of life events.

increased risk of later non-psychotic psychopathology (Chapman et al. 1994;Dhossche et al. 2002;Addington et al. 2011;De Loore et al. 2011;Rossler et al. 2011;Kaymaz et al. 2012;Werbeloff et al. 2012;Kelleher et al. 2014;Sullivan et al. 2014;McGrath et al. 2016;Bhavsar et al. 2017). Majority of individuals with PE in the general population does not develop a psychotic disorder but still need care for non-psychotic disorders. Outcome of PE over 
follow-up in the general population appears to take the form of a wide range of mental disorders including bipolar disorder, depression, anxiety disorder, somatoform disorder and impulse control disorder as well as psychotic disorders. It may be useful to consider $\mathrm{PE}$ as a risk indicator that has trans-diagnostic value (van Os and Reininghaus 2016).

\section{Factors Associated with the Follow-up Dutcomes of Baseline Psychotic Experiences}

The follow-up outcome of baseline PE may be usefully divided into three types (i) no clinical disorder; (ii) non-psychotic disorder (trans-diagnostic phenotype) and (iii) psychotic disorder (psychotic outcome). In addition, a range of moderators may be relevant.

Participants in the adolescent or early adulthood age range had a similar risk of developing a follow-up DSM disorder as older participants. However, they were more likely to a psychotic disorder outcome of baseline PE than older participants. This finding is in line with previous studies showing associations between younger age and different levels of the extended psychosis phenotype (van Os et al. 2000; Verdoux and van Os 2002; van Os et al. 2009). Developmental maturation of the frontal cortex and synaptic pruning accelerate during adolescence (Fatemi and Folsom 2009). The normal neurobiology of the adolescent and early adult human brain may have a unique sensitivity for manifesting psychosis in comparison with older individuals (Hyde et al. 1992;Paus et al. 2008). However, as psychotic disorders often emerge around the third decade, it should be kept in mind that in excluding the baseline 'psychosis caseness' the age-of-onset curve in the remaining sample may have been shifted to the right, resulting in relatively low rates. Therefore, this particular factor might have impacted on the analysis of the effect of age.

Women had a greater risk to develop a follow-up DSM disorder than men, adjusting for other variables. This finding is in line with a recent study, albeit in a help-seeking sample, reporting 
higher rates of persistent or recurrent non-psychotic disorder in women in a follow-up of a UHR sample (Lin et al. 2015). However, no significant differences between the sexes were found in risk of developing a psychotic disorder in comparison with non-psychotic disorder. A male excess in psychotic disorder is seen with narrow definitions, whereas broader definitions show a female excess (Castle et al. 1993). Our psychotic disorder outcome variable (including both non-affective and affective psychosis) thus may explain why no significant sex difference was found. Participants displaying both delusional and hallucinatory $\mathrm{PE}$ at baseline were more prone to psychotic disorder outcome of $\mathrm{PE}$ in comparison with participants having only delusional or hallucinatory PE. It has been shown that more severe genetic and environmental risk may underlie the co-presence of delusional and hallucinatory PE at baseline (Smeets et al. 2013), which the current result may predict poorer transition outcomes. The fact that the association between baseline co-presence of delusional and hallucinatory experiences and psychotic outcome was weakened after adjustment for other causes confirms the hypothesis that co-presence of delusional and hallucinatory experiences reflects greater exposure to risk.

$\mathrm{PE}$ at the population level are known to be closely associated with non-psychotic disorders (Linscott and van Os 2013). Our results demonstrated that more than half of participants with baseline PE had a concurrent mood disorder. Participants with both baseline PE and mood disorders had more risk to develop a follow-up DSM diagnosis than participants with PE in isolation. This result is line with epidemiological studies reporting that greater degree of affective dysregulation predicts help-seeking behaviour and dysfunction associated with $\mathrm{PE}$ (van Rossum et al. 2011; Wigman et al. 2012; Guloksuz et al. 2015). Nevertheless, baseline co-occurrence of mood disorders with PE was not associated with developing a psychotic disorder in comparison with non-psychotic disorder. This result is in line with a previous finding reporting that mania and depression have a stronger impact below the psychotic disorder end of the spectrum (Bin- 
bay et al. 2012b). However, the non-significance of the association might also be explained by the fact that the psychotic disorder group was not restricted to non-affective psychosis. A recent study with a clinical sample reported that co-occurrence of depression with $\mathrm{PE}$ predicts persistence of PE (Salokangas et al. 2016). Persistence of $\mathrm{PE}$ can be considered as a significant marker of emerging psychotic impairment (Dominguez et al. 2011). Furthermore, our results showed that persistence also increases the risk of non-psychotic disorders.

Having a family history of mental disorder significantly increased the risk of having a follow-up DSM diagnosis in participants with baseline PE, however this association was basically attenuated on inclusion of presence of baseline mood disorders. A plausible explanation is that genetic risk also impacts the risk of baseline mood disorder and can thus be considered on the same causal pathway. Furthermore, participants with a family history of severe mental illness were more prone to psychotic disorder outcome of $\mathrm{PE}$ in comparison with participants with no such family history. This result is in line with a previous finding reporting that loading with more severe mental illness was associated with increased risk of the disorder end of the psychosis spectrum (Binbay et al. 2012b).Thus, it may be hypothesized that 'severity' of familial risk translates to 'severity' of the transition outcome.

\section{Strengths and Limitations}

As far as we know, this is the first longitudinal study in a community-based population that examines follow-up 'any' clinical diagnosis of baseline PE based on interviews performed by psychiatrists. The design and the fact that the study was conducted in a representative population-based sample enabled us to include non-help-seeking individuals and so prevent potential help-seeking bias and increased transition rates due to sample enrichment (van Os and Guloksuz 2017). Furthermore, we were able to take baseline differences in multidimensional psychopathology, socio-demographic features and familial risk may into account. 
Moreover, the design of the study enabled us to adjust the results for other causes of psychopathology including life events and substances. Nevertheless, the results need to be considered in the light of the following limitations. First, as with most longitudinal studies with general population-based samples, a limitation is the possibility of selection bias caused by differential attrition over time. The comparison of baseline socio-demographic and clinical characteristics between non-participants and participants showed no large or significant differences. Furthermore, the sixyear transition rate from $\mathrm{PE}$ to psychotic disorders found in our sample $(7.0 \%)$ is consistent with previous meta-analytical findings (Kaymaz et al. 2012; Linscott and van Os 2013), supporting the present conclusions. Therefore, it is unlikely that attrition would have created bias in results. Second, the low number of participants who transitioned from $\mathrm{PE}$ to $\mathrm{PD}(\mathrm{n}=13)$ resulted in less than five participants in some subgroups of participants with follow-up psychotic disorder (age categories, sex, education, co-presence of delusional and hallucinatory $\mathrm{PE}$, type of family history; table 4). Therefore, the analyses with the dependent variable psychotic vs. non-psychotic disorder may have insufficient statistical power. Results of these analyses are explorative and need to be replicated. Third, our baseline PE group consisted of individuals with PE either with a duration of at least " 1 week" or with a frequency of at least "sometimes" or associated with help-seeking/interference with functioning or enjoying relationships. Thus, these results cannot be generalized to individuals with less severe forms of $\mathrm{PE}$. Furthermore, we considered only the positive dimension of PE, whereas negative and disorganized dimensions are also relevant (van Os and Reininghaus 2016). Therefore, these results cannot be generalized to negative and disorganised dimensions. Fourth, as we do not have follow-up SCID data of the participants who did not have PE at baseline, we unfortunately cannot introduce control comparisons. Therefore, we compared the prevalence of disorders in participants with baseline PE with the estimates of the disorders in the general population. Fifth, the baseline diagnostic interviews were conducted with a view to identify participants 
with psychotic disorder (Binbay et al. 2011). Thus, the baseline DSM-IV diagnoses of some participants were missing. Therefore, we were not able to define the rate of incident common mental disorders in participants with baseline PE. Finally, women were overrepresented which may bias toward higher levels of mood and anxiety disorders.

\section{Conclusion}

This longitudinal epidemiological study with clinical diagnostic interviews showed that the majority of participants with baseline PE develop a non-psychotic DSM disorder (particularly mood and anxiety disorders) rather than a psychotic disorder. Sociodemographic factors, genetic risk and baseline severity of multidimensional psychopathology may impact on course and outcome of PE. Results may have important implications for the conceptualisation of PE, decision-making in high risk settings and clinical care for individuals with PE seeking help at the level of health services. Future studies should take into account non-psychotic disorder outcome of $\mathrm{PE}$ in addition to psychotic disorder outcomes. 


\section{References}

- Addington J, Cornblatt BA, Cadenhead KS, et al. (2011). At clinical high risk for psychosis: outcome for nonconverters. The American journal of psychiatry 168, 800-805.

- Alptekin K, Ulas H, Akdede BB, Tumuklu M , Akvardar Y (2009). Prevalence and risk factors of psychotic symptoms: in the city of Izmir, Turkey. Social psychiatry and psychiatric epidemiology 44, 905-910.

- Andrews G, Peters L (1998). The psychometric properties of the Composite International Diagnostic Interview. Social psychiatry and psychiatric epidemiology 33, 80-88.

- Bhavsar V, Maccabe JH, Hatch SL, Hotopf M, Boydell J , McGuire P (2017). Subclinical psychotic experiences and subsequent contact with mental health services. BJPsych open 3, 64-70.

- Binbay T, Alptekin K, Elbi $\mathrm{H}$, et al. (2012a). [Lifetime prevalence and correlates of schizophrenia and disorders with psychotic symptoms in the general population of Izmir, Turkey]. Turk psikiyatri dergisi $=$ Turkish journal of psychiatry 23, 149-160.

- Binbay T, Drukker M, Elbi $\mathrm{H}$, et al. (2012b). Testing the psychosis continuum: differential impact of genetic and nongenetic risk factors and comorbid psychopathology across the entire spectrum of psychosis. Schizophrenia bulletin 38, 992-1002.

- Binbay T, Elbi H, Alptekin $\mathrm{K}$, et al. (2011). Izmir mental health survey for gene-environment interaction in psychoses (TurkSch): objectives and methodology. Turk psikiyatri dergisi $=$ Turkish journal of psychiatry 22, 65-76.

- Brugha TS, Cragg D (1990). The List of Threatening Experiences: the reliability and validity of a brief life events questionnaire. Acta psychiatrica Scandinavica 82, 77-81. 
- Cannon TD, Cadenhead K, Cornblatt B, et al. (2008). Prediction of psychosis in youth at high clinical risk:

a multisite longitudinal study in North America. Archives of general psychiatry 65, 28-37.

- Carrion RE, McLaughlin D, Goldberg TE, et al. (2013). Prediction of functional outcome in individuals at clinical high risk for psychosis. JAMA Psychiatry 70, 1133-1142.

- Castle DJ, Wessely S , Murray RM (1993). Sex and schizophrenia: effects of diagnostic stringency, and associations with and premorbid variables. British Journal of Psychiatry 162, 658-664.

- Chapman LJ, Chapman JP, Kwapil TR, Eckblad M , Zinser MC (1994). Putatively psychosis-prone subjects 10 years later. Journal of abnormal psychology 103, 171-183.

- Cilli AS, Kaya N (2003). [Nicotine dependence and psychiatric comorbidity among university students].
Turk psikiyatri dergisi $=$ Turkish journal of psychiatry 14, 42-49.

- Collip D, Myin-Germeys I , Van Os J (2008). Does the concept of "sensitization" provide a plausible mechanism for the putative link between the environment and schizophrenia? Schizophrenia bulletin 34, 220225.

- Cooper L, Peters L, Andrews G (1998). Validity of the Composite International Diagnostic Interview (CIDI) psychosis module in a psychiatric setting. Journal of psychiatric research 32, 361-368.

- Cougnard A, Marcelis M, Myin-Germeys I, et al. (2007). Does normal developmental expression of psychosis combine with environmental risk to cause persistence of psychosis? A psychosis proneness-persistence model. Psychological medicine 37, 513-527.

- De Loore E, Gunther N, Drukker M, et al. (2011). Persistence and outcome of auditory hallucinations 
in adolescence: a longitudinal general population study of 1800 individuals. Schizophrenia research 127 , 252-256.

- Debbane M, Eliez S, Badoud D, Conus P, Fluckiger $\mathrm{R}$, Schultze-Lutter F (2015). Developing psychosis and its risk states through the lens of schizotypy. Schizophrenia bulletin 41 Suppl 2, S396-407.

- Deveci A, Taskin O, Dinc G, et al. (2007). Prevalence of pseudoneurologic conversion disorder in an urban community in Manisa, Turkey. Social psychiatry and psychiatric epidemiology 42, 857-864.

- Dhossche D, Ferdinand R, Van der Ende J, Hofstra MB , Verhulst F (2002). Diagnostic outcome of self-reported hallucinations in a community sample of adolescents. Psychological medicine 32, 619-627.

- Dominguez MD, Wichers M, Lieb R, Wittchen HU, van Os J (2011). Evidence that onset of clinical psychosis is an outcome of pro- gressively more persistent subclinical psychotic experiences: an 8-year cohort study. Schizophrenia bulletin 37, 84-93.

- Dragt S, Nieman DH, Veltman D, et al. (2011). Environmental factors and social adjustment as predictors of a first psychosis in subjects at ultra high risk. Schizophrenia research 125, 69-76.

- Falkenberg I, Valmaggia L, Byrnes M, et al. (2015). Why are help-seeking subjects at ultra-high risk for psychosis help-seeking? Psychiatry research 228, 808-815.

- Fatemi SH, Folsom TD (2009). The neurodevelopmental hypothesis of schizophrenia, revisited. Schizophrenia bulletin 35, 528-548.

- Fisher HL, Caspi A, Poulton $\mathrm{R}$, et al. (2013). Specificity of childhood psychotic symptoms for predicting schizophrenia by 38 years of age: a birth cohort study. Psychological medicine 43, 2077-2086. 
- Fonseca Pedrero E, Debbane M (2017). Schizotypal traits and psychotic-like experiences during adolescence: An update. Psicothema 29, 5-17.

- Fusar-Poli P, Bonoldi I, Yung AR, et al. (2012). Predicting psychosis: meta-analysis of transition outcomes in individuals at high clinical risk. Archives of general psychiatry 69, 220-229.

- Fusar-Poli P, Carpenter WT, Woods SW , McGlashan TH (2014). Attenuated psychosis syndrome: ready for DSM-5.1? Annual review of clinical psychology 10, 155192.

- Fusar-Poli P, Schultze-Lutter F (2016). Predicting the onset of psychosis in patients at clinical high risk: practical guide to probabilistic prognostic reasoning. Evidence-based mental health 19, 10-15.

- Goldthorpe J (1987). Social mobility and class structure in modern Britain. Clarendon Press: New York.
- Guloksuz S, van Nierop M, Lieb R, van Winkel R, Wittchen HU, van Os J (2015). Evidence that the presence of psychosis in non-psychotic disorder is environment-dependent and mediated by severity of non-psychotic psychopathology. Psychological medicine 45, 2389-2401.

- Hanssen M, Bak M, Bij1 $\mathrm{R}$, Vollebergh W, van Os $\mathrm{J}$ (2005). The incidence and outcome of subclinical psychotic experiences in the general population. The British journal of clinical psychology 44, 181-191.

- Honings S, Drukker M, van Nierop M, et al. (2016). Psychotic experiences and incident suicidal ideation and behaviour: Disentangling the longitudinal associations from connected psychopathology. Psychiatry research 245, 267-275.

- Hyde TM, Ziegler JC, Weinberger DR (1992). Psychiatric disturbances in metachromatic leukodystrophy. Insights into the neurobiology of psychosis. Archives of neurology 49, 401-406. 
- Kaymaz N, Drukker M, Lieb R, et al. (2012). Do subthreshold psychotic experiences predict clinical outcomes in unselected non-help-seeking population-based samples? A systematic review and meta-analysis, enriched with new results. Psychological Medicine 42, 2239-2253.

- Kelleher I, Cederlof M , Lichtenstein P (2014). Psychotic experiences as a predictor of the natural course of suicidal ideation: a Swedish cohort study. World psychiatry : official journal of the World Psychiatric Association 13, 184188.

- Kelleher I, Harley M, Murtagh A, Cannon M (2011). Are screening instruments valid for psychotic-like experiences? A validation study of screening questions for psychotic-like experiences using in-depth clinical interview. Schizophrenia bulletin 37 , 362-369.

- Kelleher I, Keeley H, Corcoran P, et al. (2012).
Clinicopathological significance of psychotic experiences in non-psychotic young people: evidence from four population-based studies. The British journal of psychiatry : the journal of mental science 201, 26-32.

- Kelleher I, Wigman JT, Harley M, et al. (2015). Psychotic experiences in the population: Association with functioning and mental distress. Schizophrenia research 165, 9-14.

- Kessler RC, Chiu WT, Demler O, Merikangas KR , Walters EE (2005). Prevalence, severity, and comorbidity of 12-month DSM-IV disorders in the National Comorbidity Survey Replication. Archives of general psychiatry 62, 617-627.

- Kish L (1949). A procedure for objective respondent selection withinthe household. Journal of the American Statistical Association 44, 380-387.

- Lin A, Wood SJ, Nelson B, Beavan A, McGorry P , Yung AR (2015). Outcomes of nontransitioned cases in 
a sample at ultra-high risk for psychosis. The American journal of psychiatry 172 , 249-258.

- Linscott RJ , van Os J (2013). An updated and conservative systematic review and meta-analysis of epidemiological evidence on psychotic experiences in children and adults: on the pathway from proneness to persistence to dimensional expression across mental disorders. Psychological medicine 43, 1133-1149.

- McGrath JJ, Saha S, Al-Hamzawi A, et al. (2016). The Bidirectional Associations Between Psychotic Experiences and DSMIV Mental Disorders. The American journal of psychiatry, appiajp201615101293.

- Mortensen PB, Pedersen MG, Pedersen CB (2010). Psychiatric family history and schizophrenia risk in Denmark: which mental disorders are relevant? Psychological Medicine 40, 201-210.

- Nelson B, Yuen HP, Wood SJ, et al. (2013). Long-term follow-up of a group at ultra high risk ("prodromal") for psychosis: the PACE 400 study. JAMA psychiatry 70, 793-802.

- NIMH (1992). NIMH Genetics Initiative: Family Interview for Genetic Studies (FIGS). MD National Institute of Mental Health: Rockville.

- Paus T, Keshavan M , Giedd JN (2008). Why do many psychiatric disorders emerge during adolescence? Nat Rev Neurosci 9, 947957.

- Perlis RH, Uher R, Ostacher $\mathrm{M}$, et al. (2011). Association between bipolar spectrum features and treatment outcomes in outpatients with major depressive disorder. Archives of general psychiatry 68, 351-360.

- Poulton R, Caspi A, Moffitt TE, Cannon M, Murray R, Harrington H (2000). Children's self-reported psychotic symptoms and adult schizophreniform disorder: a 15-year longitudinal study. Archives of general psychiatry 57, 1053-1058. 
- Rezaki M, Ozgen G, Kaplan I, Gursoy B, Sagduyu A , Ozturk O (1995). Results from Ankara center. In Mental Illness in General Health Care: An International Study (ed. T. B. Ustun and N. Sartorius), pp. 3956. John Willey \& Sons: Chichester.

- Robins LN, Wing J, Wittchen HU, et al. (1988). The Composite International Diagnostic Interview. An epidemiologic Instrument suitable for use in conjunction with different diagnostic systems and in different cultures. Archives of general psychiatry 45, 10691077.

- Rossler W, Hengartner MP, Ajdacic-Gross V, Haker H, Gamma A , Angst J (2011). Sub-clinical psychosis symptoms in young adults are risk factors for subsequent common mental disorders. Schizophrenia research 131, 18-23.

- Salokangas RK, Schultze-Lutter F, Hietala J, et al. (2016). Depression predicts persistence of paranoia in clinical highrisk patients to psychosis: results of the EPOS project. Social psychiatry and psychiatric epidemiology 51 , 247-257.

- Schmidt SJ, Schultze-Lutter F, Schimmelmann BG, et al. (2015). EPA guidance on the early intervention in clinical high risk states of psychoses. European psychiatry : the journal of the Association of European Psychiatrists 30, 388-404.

- Schultze-Lutter F, Michel C, Schmidt SJ, et al. (2015). EPA guidance on the early detection of clinical high risk states of psychoses. European psychiatry : the journal of the Association of European Psychiatrists 30, 405-416.

- Shah J, Eack SM, Montrose DM, et al. (2012). Multivariate prediction of emerging psychosis in adolescents at high risk for schizophrenia. Schizophrenia research 141 , 189-196.

- Smeets F, Lataster T, van Winkel R, de Graaf R, ten Have M , van Os J (2013). 
Testing the hypothesis that psychotic illness begins when subthreshold hallucinations combine with delusional ideation. Acta psychiatrica Scandinavica 127, 34-47.

- Smeets F, Lataster T, Viechtbauer W , Delespaul P (2015). Evidence that environmental and genetic risks for psychotic disorder may operate by impacting on connections between core symptoms of perceptual alteration and delusional ideation. Schizophrenia bulletin 41, 687-697.

- Spitzer RL, Williams JB, Gibbon M , First MB (1992). The Structured Clinical Interview for DSM-III-R (SCID). I: History, rationale, and description. Archives of general psychiatry 49, 624629.

- Sullivan SA, Wiles N, Kounali D, et al. (2014). Longitudinal associations between adolescent psychotic experiences and depressive symptoms. PloS one 9, e105758.

- Topuzoglu A, Binbay T, Ulas H, et al. (2015). The epidemiology of major depressive disorder and subthreshold depression in Izmir, Turkey: Prevalence, socioeconomic differences, impairment and help-seeking. Journal of affective disorders 181, 78-86.

- van Dam DS, van Nierop $\mathrm{M}$, Viechtbauer W, et al. (2015). Childhood abuse and neglect in relation to the presence and persistence of psychotic and depressive symptomatology. Psychological medicine 45, 1363-1377.

- van Os J , Guloksuz S (2017). A critique of the "ultra-high risk" and "transition" paradigm. World Psychiatry 16, 200-206.

- van Os J, Hanssen M, Bijl RV , Ravelli A (2000). Strauss (1969) revisited: a psychosis continuum in the general population? Schizophrenia research 45, 11-20.

- van Os J, Linscott RJ, Myin-Germeys I, Delespaul P , Krabbendam L (2009). A systematic review and meta-analysis of the psychosis continuum: evidence for 
a psychosis proneness-persistence-impairment model of psychotic disorder. Psychological medicine 39, 179-195.

- van Os J , Reininghaus U (2016). Psychosis as a transdiagnostic and extended phenotype in the general population. World psychiatry : official journal of the World Psychiatric Association 15, 118-124.

- van Rossum I, Dominguez MD, Lieb R, Wittchen HU , van Os J (2011). Affective dysregulation and reality distortion: a 10-year prospective study of their association and clinical relevance. Schizophrenia bulletin 37, 561-571.

- Verdoux H, van Os J (2002). Psychotic symptoms in non-clinical populations and the continuum of psychosis. Schizophrenia research 54, 59-65.

- Werbeloff N, Drukker M, Dohrenwend BP, et al. (2012). Self-reported attenuated psychotic symptoms as forerunners of severe mental disorders later in life. Archives of general psychiatry 69, 467-475.

- Wigman JT, van Nierop M, Vollebergh WA, et al. (2012). Evidence that psychotic symptoms are prevalent in disorders of anxiety and depression, impacting on illness onset, risk, and severity--implications for diagnosis and ultra-high risk research. Schizophrenia bulletin 38, 247-257.

- Wittchen HU (1994). Reliability and validity studies of the WHO--Composite International Diagnostic Interview (CIDI): a critical review. Journal of psychiatric research 28, 57-84.

- Wittchen HU, Robins LN, Cottler LB, Sartorius N, Burke JD , Regier D (1991). Cross-cultural feasibility, reliability and sources of variance of the Composite International Diagnostic Interview (CIDI). The Multicentre WHO/ADAMHA Field Trials. The British journal of psychiatry : the journal of mental science 159, 645-653, 658.

- Yung AR, Phillips LJ, Yuen HP, et al. (2003). Psychosis 
prediction: 12-month follow up of a high-risk ("prodromal") group. Schizophrenia research 60, 21-32.

- Zammit S, Kounali D, Cannon M, et al. (2013). Psychotic experiences and psychotic disorders at age 18 in relation to psychotic experiences at age 12 in a longitudinal population-based cohort study. The American journal of psychiatry 170, 742-750.

- Zavos HM, Eley TC, McGuire P, et al. (2016). Shared Etiology of Psychotic Experiences and Depressive Symptoms in Adolescence: A Longitudinal Twin Study. Schizophrenia bulletin 42, 1197-1206. 


\title{
CHAPTER 5
}

\section{Is BDNF-Val66Met Polymorphism Associated with Psychotic Experiences and Psychotic Disorder Outcome? Evidence from a 6 Years Prospective Population-based Cohort Study}

\author{
Umut Kirlı ${ }^{1,2}$ \\ Tolga Binbay ${ }^{3}$ \\ Marjan Drukker ${ }^{2}$ \\ Hayriye Elbi 4 \\ Bülent Kayahan 4 \\ Duygu Keskin Gökçelli 4 \\ Ferda Özkınay ${ }^{5}$ \\ Hüseyin Onay ${ }^{5}$ \\ Köksal Alptekin ${ }^{3}$ \\ Jim van Os ${ }^{2,6,7}$
}

American Journal of Medical Genetics Part B:

Neuropsychiatric Genetics 2019; 180 (2), 113-121

1 Van Education and Research Hospital, Psychiatry Unit, Van, Turkey

2 Maastricht University Medical Centre, School of Mental Health and Neuroscience, Department of Psychiatry and Psychology, South Limburg Mental Health Research and Teaching Network, PO Box 616, Vijverdal, 6200 MD, Maastricht, The Netherlands

3 Dokuz Eylul University, Faculty of Medicine, Department of Psychiatry, 35340, Izmir, Turkey

4 Ege University, Faculty of Medicine, Department of Psychiatry, 35140, Izmir, Turkey

5 Ege University, Faculty of Medicine, Department of Medical Genetics, 35140, Izmir, Turkey

6 King's College, King's Health Partners, Department of Psychosis Studies, Institute of Psychiatry, De Crespigny Park, Denmark Hill, London, UK

7 Dept. Psychiatry, Brain Centre Rudolf Magnus, Utrecht University Medical Centre, PO BOX 85500, 3508 GA Utrecht, The Netherlands. 



\section{Abstruct}

There is little research on genetic risk for the extended psychosis phenotype ranging from psychotic experiences to psychotic disorders. In this general population-based prospective cohort study, the longitudinal associations between BDNF-Val66Met polymorphism and the different levels of the extended psychosis phenotype were investigated. Addresses were contacted in a multistage clustered probability sampling frame covering 11 districts and 302 neighborhoods at baseline $(\mathrm{n}=4011)$. A nested case-control study $(\mathrm{n}=366)$ recruited individuals with psychotic experiences and psychotic disorders as well as individuals with no psychotic symptoms. In this subgroup, blood sampling for genetic analysis and assessment of environmental exposures were carried out, followed by clinical re-appraisal at follow-up six years later $(\mathrm{n}=254)$. The BDNF Val66Met polymorphism was significantly associated with the extended psychosis phenotype. The pattern of the association was that the BDNF Val66Met polymorphism impacted in a dose-response but extra-linear fashion, with stronger impact at the psychotic disorder end of the extended psychosis phenotype. Associations were still significant after adjusting for socio-demographic factors and environmental exposures including life events, childhood adversity, socioeconomic status, urbanicity and cannabis use. The BDNF Val66Met polymorphism may index susceptibility to expression of psychosis along a spectrum. 


\section{Introduction}

Epidemiological studies have provided robust evidence that attenuated forms of delusional thinking and hallucinational perception are not exclusive to psychotic disorders in the general population (Linscott and van Os 2013). A wide range of literature suggests that psychotic experiences (PE) and psychotic disorders (PD) share both genetic and non-genetic features (van Os and Reininghaus 2016). In addition, the underlying biological mechanisms may be similar (van Os and Linscott 2012). Furthermore, dynamic transitions over time from PE to PD occur, as a result of the interaction between environmental exposure and genetic risk (Linscott and van Os 2013). Thus, the extended psychosis phenotype is comprised of PE gradually blending into PD (Kaymaz et al. 2012).

BDNF influences dopaminergic (Guillin et al. 2001), glutamatergic (Levine and Kolb 2000), serotonergic (Martinowich and Lu 2008) and cholinergic systems (Auld et al. 2001). Aberrant dopaminergic (Gourion et al. 2005), serotonergic (Vollenweider et al. 1998), cholinergic (Buckley et al. 2007) and glutamatergic function (Coyle 2012) have been characterized as some molecular phenotypes of psychosis. Therefore, BDNF gene variations may constitute risk factors for psychosis. However, there is distinct inconsistency in results between studies linking BDNF genotype and psychosis. These inconsistent results may be due to some design issues (Notaras et al. 2015b). First, an important proportion of studies did not take background characteristics into account as well as differential exposure to environmental factors. Second, most of the studies in the literature have been conducted with an approach based on searching for variation only between individuals with PD (e.g. schizophrenia) and the rest of the 'healthy population'. However, in the 'healthy population' $\mathrm{PE}$ are prevalent and thus possible shared genetic variation may have masked some of the associations (Kelleher et al. 2010). Furthermore, the symptoms that hallmark these disorders are heterogeneous. It is suggested that more studies should focus their attention on the effects of BDNF gene variants on clinical features of the disorders as opposed to merely exploring single 
syndromes (Notaras et al. 2015b). Finally, the majority of studies had a cross-sectional design which could not accurately measure the modulatory effects of BDNF genotype on symptom presence and severity that might change over time. Therefore, the cross-sectional design might not be sufficient to detect diminutive effect sizes (Numata et al. 2007).

Using data from a general population cohort that was followed for six years, the present paper has 3 aims:

i) To explore the role of BDNF Val66Met polymorphism in presence of any psychotic symptoms (PE or PD) during follow-up.

ii) To test the associations between different levels of the extended psychosis phenotype and BDNF Val66Met polymorphism if characterized by either graded linear or more discontinuous extra-linear relationships.

iii) To explore the role of BDNF Val66Met polymorphism in transition from PE to PD.

\section{Methods}

\section{Sample and Study Design}

The present paper uses longitudinal data of a nested case-control sample recruited from the TürkSch cohort. The TürkSch is a prospective study consisting of several data collection stages to assess genetic and environmental factors underlying the extended psychosis phenotype in a representative general population sample. The TürkSch study was described in more detail in previous papers (Binbay et al. 2011;Binbay et al. 2012a;Binbay et al. 2012c). Baseline sample ( $\mathrm{n}=4011)$ was randomly selected representing the wider Izmir metropolitan area (population approximately 2.650.000) (Binbay et al. 2011) using a multistage sampling procedure, stratified by urbanicity covering 11 districts and 302 neighborhoods. Trained lay interviewers visited those addresses in person between November 2007 and October 
2008. One household member aged between 15 and 64 years was randomly selected using the Kish within-household sampling method (Kish 1949). PE were assessed using the Composite International Diagnostic Interview (CIDI) (Andrews and Peters 1998). Socio-demographic and environmental exposure variables were also assessed, as described below. The nested case-control study selected individuals with PE and PD from the baseline sample and matched those individuals with individuals with no psychotic symptoms from the same sample (Fig. 1). In this subgroup, blood samples were collected for genetic analysis and individuals were reappraised by a psychiatrist $(n=366) .6$ years after the baseline assessment (years 2013-2015), a follow-up assessment was set to assess the mental health outcomes and

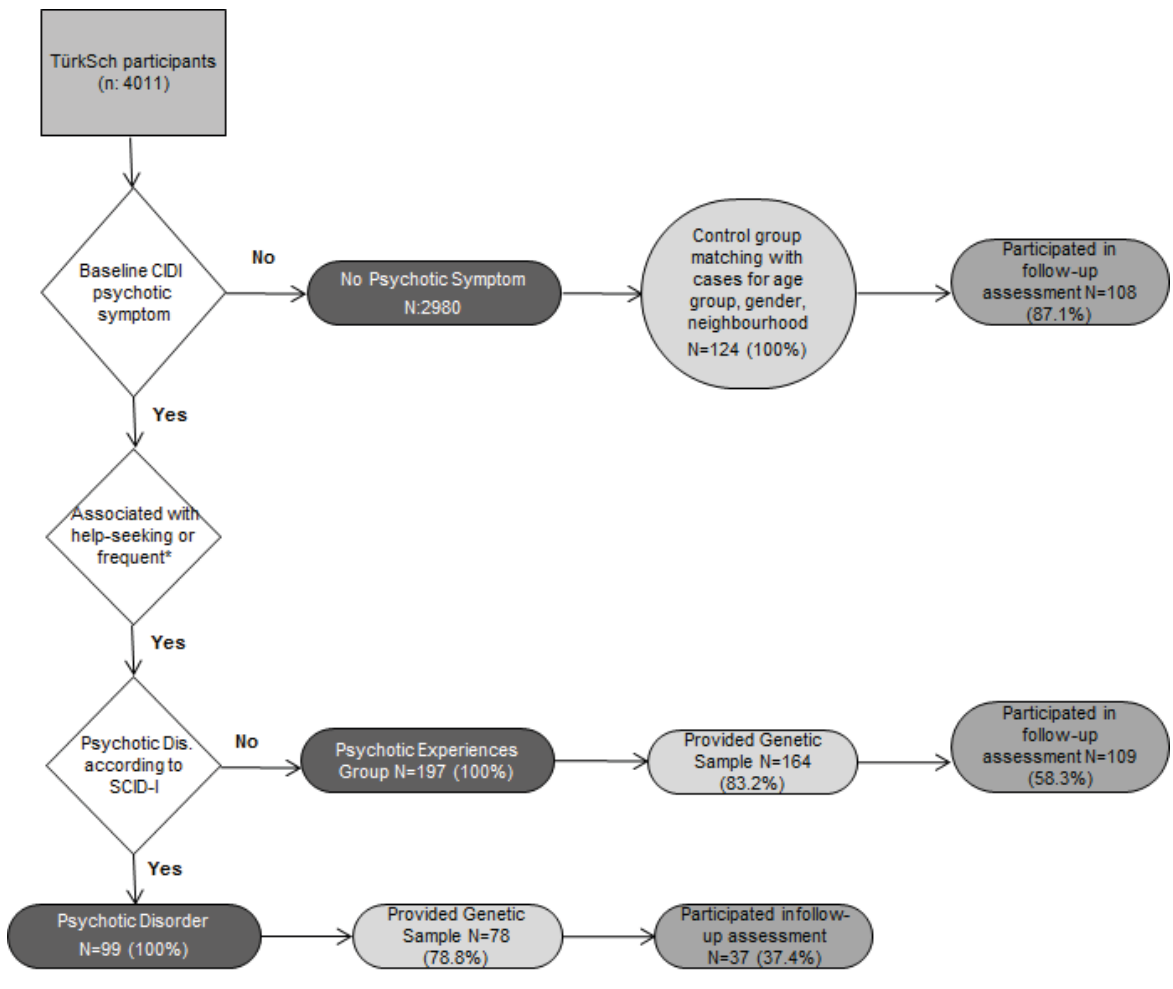

${ }^{*}$ At least once a week

Figure 1: Recruitment to the nested case-control study and attrition 
environmental exposures of the baseline sample. Addresses of baseline participants were re-visited in person by trained interviewers (psychology graduates) with several attempts to reduce the number of non-respondents from the baseline sample (Binbay et al. 2011). As a result of the follow-up visits; 55 individuals could not be contacted because of unsuccessful attempts (at least three consecutive) to contact anyone at the address (15.0\%). 3 individuals were found to be deceased or prisoned during recruitment $(0.8 \%)$ and 3 addresses were demolished and no new address could be found (0.8\%). Among the subjects that were contacted $(n=305,83.3 \%)$; interview was impossible with 33 individuals due to residency in a remote area $(9.0 \%)$ and with 18 individuals due to refusal (4.8\%). Consequently, 254 participants from the baseline nested case-control sample were successfully re-interviewed with CIDI at follow-up (response rate: 69.4\%). Furthermore, these participants were re-contacted for a clinical re-evaluation with the Structured Clinical Interview for DSM-IV (SCID-I) (Spitzer et al. 1992) by a psychiatrist (145 interviews at the hospital and 109 at the participants' residence). At the follow-up assessment, SCID was conducted by a psychiatrist (UK) who had not participated in the baseline assessment and was blind to the diagnostic status at baseline. Each participant provided written informed consent for examination and procedures. The TürkSch study was approved by the Institutional Ethics Review Board of Ege University, Turkey, and is compliant with the precepts of Declaration of Helsinki.

\section{Composite Intermational Diagnostic Interview (CIDI)}

The CIDI is a fully structured interview developed by the World Health Organization (Robins et al. 1988) and has been used in various epidemiological surveys around the world including Turkey (Cilli and Kaya 2003;Deveci et al. 2007;Alptekin et al. 2009). The CIDI can be used by both clinicians and trained lay interviewers. In the current study, assessments included screening sections on alcohol and substance-related disorders, depressive 
and dysthymic disorders, manic and bipolar affective disorders, schizophrenia and other psychotic disorders, and 2 final sections containing interviewer observations, and interviewer ratings. Each CIDI interview at baseline and follow-up was conducted according to a standard procedure, with recording and quality coding (Binbay et al. 2011). If the quality of the interview was considered low by the team psychiatrist, a phone call or a second visit was planned.

\section{Assessment of Psychotic Experiences and Disorders}

In order to assess $\mathrm{PE}$ and $\mathrm{PD}$, the same case identification procedure was applied at baseline and at follow-up. PE was rated using 14 CIDI delusions items (G1, G2, G3, G4, G5, G7, G8, G9, G10, G11, G12, G13, G13b and, G14) and 5 CIDI hallucinations items (G17, G18, G20, G20C, and G21). The time frame was lifetime at baseline assessment and the last six years at follow-up assessment. CIDI-based screening of PE provided information on frequency, duration, help-seeking, severity of symptoms and psychosocial impairment. In order to diagnose PD, participants endorsing a PE associated with help-seeking or, if there was no help-seeking, occurring with a frequency of at least once a week were re-contacted for a clinical re-evaluation with the SCID-I by the team psychiatrist.

\section{Dther Assessments}

Level of education was defined in regard to last graduated school and recoded into lower than high school and at least high school. Marital status was recoded into married and non-married. Socioeconomic status was based on the profession of the participant (if the participant had no profession, father/husband's profession was used instead) and recoded into 3 ordinal categories: $1=$ professional and non-manual employees, $2=$ owners of small businesses, $3=$ non-professional workers (Goldthorpe 1987). Cannabis use was assessed using screening questions on CIDI substance-related disorders sec- 
tions. Conform previous CIDI-based research, cannabis use of 5 times or more was defined as exposure status for cannabis. Life events were assessed at follow-up using the List of Threatening Life Events Questionnaire (Brugha and Cragg 1990). The time frame was last six years. The number of life events was a continuous variable with a minimum of 0 and maximum of 12. Childhood adversities were death of any parent, divorce of parents and separation from parents for at least for 3 months. The childhood adversities variable was dichotomized to none or at least one (Binbay et al. 2012c). Urbanicity was defined using the classification of the Turkish Institute of Statistics (TURKSTAT). Classification depends on the level of organized features of streets and buildings (regularity of sidewalks, status of road, completeness of drainage system, and quality of outer paintings of buildings, etc.) and includes four categories (Binbay et al. 2012b).

\section{Gemetic Amalyses}

Samples of peripheral venous blood $(2 \mathrm{~mL})$ with ethylenediaminetetraacetic acid (EDTA) were taken and directed to the Medical Genetics Department, Molecular Genetics Laboratory for the investigation of BDNF-Val66Met polymorphism (rs6265) (PCR and agarose gel imaging). Genomic DNA was extracted from peripheral blood cells then sequestered with the MagNa Pure LC DNA Isolation Kit I (Roche, USA). The localized gene regions for this single nucleotide polymorphism (SNP) were amplified by polymerase chain reaction (PCR). Restriction Fragment Length Polymorphism (RFLP) technique was conducted to reveal fragments relevant to SNP region. Obtained fragments were separated according to their lengths by agarose gel electrophoresis. The genotype of the BDNF (rs6265) SNP was identified (Val/Val, Val/Met, Met/Met). Since the Met/Met genotype had a much lower frequency than the $\mathrm{Val} / \mathrm{Met}$ and $\mathrm{Val} / \mathrm{Val}$ genotypes, the genotypes for this SNP were included in the analyses as a binary variable (Met allele carriers and Val homozygotes). 


\section{Dependent Variable}

The main outcome of the study was the extended psychosis phenotype variable ranging from $P E$ to $P D$, derived from CIDI and SCID results in both baseline and follow-up assessments. Psychotic disorder (PD) included participants with a DSM-IV diagnosis of any disorder with psychotic features either at baseline or at follow-up assessment, based on diagnosis at clinical re-evaluation with the SCID. Psychotic experiences (PE) included participants who endorsed a CIDI PE either at baseline or at follow-up assessments but did not have PD during follow-up. All other individuals were included in the no psychotic symptoms category.

Secondary outcome variable was transition from PE to PD. Transition was a binary variable and coded: 1) if the participant with baseline PE had a PD at follow-up assessment 0) if the participant with baseline PE did not have a PD at follow-up assessment (Fig. 2).

\section{Statistical Amalyses}

All analyses were conducted using the software package STATA, version 13.1. In order to evaluate issues of bias due to the loss at follow-up, the participants $(n=254)$ were compared with the non-participants $(\mathrm{n}=112)$ in terms of baseline clinical and demographic characteristics using chi-squared tests. Furthermore, in order to provide background information, differences in socio-demographic and environmental exposure variables between participants with and without any psychotic symptoms (PE or PD) during follow-up were assessed using chi-squared test or t-test as appropriate. To analyze the first research question, differences in BDNF-Val66Met genotypes between those with versus without any psychotic symptom (PE or PD) during follow-up were assessed using the chi-squared test and logistic regression. To assess the second research question, associations between different levels of the extended psychosis phenotype and BDNF-Val$66 \mathrm{Met}$ genotypes were analyzed using logistic regression analy- 
sis. Because psychosis phenotype had 3 categories, this variable could not be analyzed as the dependent variable. For this reason, we reversed the dependent and the independent variable. The psychosis phenotype thus was modelled as an independent variable, allowing analysis of deviation from linearity. Continuity and discontinuity in the pattern of associations were tested by modelling psychosis phenotype spectrum as linear effect and assessing the effect of adding a squared term of psychosis phenotype. A nonsignificant squared term suggests continuity (no deviation from linearity), a negative squared term suggests a qualitatively stronger association at the lower end of the psychosis phenotype, and a positive squared term suggests a qualitatively stronger association at the disorder end of the psychosis phenotype. The odds ratios (OR) were presented both without adjustment and after adjusting for age, sex, marital status, urbanicity, socioeconomic status, childhood adversity, number of life events for the last 6 years and cannabis use. No psychotic symptoms was the reference group (i.e. $\mathrm{OR}=1$ ). Due to multiple comparisons at different levels of the extended psychosis phenotype, the Bonferroni correction was applied. To assess the third research question, the association between the secondary outcome variable transition from $P E$ to $P D$ and the BDNF-Val66Met genotypes were analyzed. Given low numbers of participants who transitioned from PE to PD ( $n=9)$, Fisher's exact test was used.

\section{Results}

\section{Sample}

The average age of participants at follow-up was 46.2 years (range $=22-71 ; \mathrm{SD}=13.3$ ) $.45 .2 \%$ were male. The proportion that finished high school was $39.4 \% ; 40.1 \%$ were non-married, $72.8 \%$ were of Turkish origin and 27.2 were of non-Turkish origin. Eighty-seven participants (34.3\%) reported using psychiatric medication during follow-up period. Nineteen participants (7.5\%) reported having five or more standard alcoholic drinks on five or more occasions per month. Eleven participants $(4.3 \%)$ reported using cannabis more than five times and five participants 
(2.0\%) reported using other substances during follow-up period. Detailed group characteristics of those with any psychotic symptoms (PE or PD) and those with no psychotic symptoms during follow-up were presented in Table 1.

The sex distribution (non-participants: $38.4 \%$ male; $\mathrm{x}^{2}=1.5$, $\mathrm{df}=1, \mathrm{p}=0.2$ ), age (non-participants mean age: 44.8; $\mathrm{t}=0.8$; $\mathrm{p}=0.4$ ), baseline marital status (non-married: non-participants $42.0 \%$ vs. participants $38.6 \% ; \mathrm{x}^{2}=0.3, \mathrm{df}=1, \mathrm{p}=0.5$ ) and baseline

Table 1: Comparison of those with any psychotic symptom to those with no psychotic symptom during follow-up, according to sociodemographic factors, environmental exposure variables and BDNF genotypes

\begin{tabular}{|c|c|c|c|c|c|}
\hline Risk Factor & $\begin{array}{l}\text { No Psychotic Symptoms During Follow- } \\
\text { up (n:97) } \\
n(\%)\end{array}$ & $\begin{array}{l}\text { Any Psychotic Symptoms During } \\
\text { Follow-up ( } \mathrm{n}: 157) \\
\mathrm{n}(\%)\end{array}$ & $\chi^{2}$ & $p$ & Cramer's V \\
\hline \multicolumn{6}{|l|}{ Sex } \\
\hline Female & $47(48.4)$ & $91(58.0)$ & \multirow{2}{*}{2.18} & \multirow{2}{*}{0.139} & \multirow{2}{*}{0.09} \\
\hline Male & $50(51.6)$ & $66(42.0)$ & & & \\
\hline \multicolumn{6}{|l|}{ Education } \\
\hline Higher & $40(43.0)$ & $57(37.3)$ & \multirow{2}{*}{0.80} & \multirow{2}{*}{0.37} & \multirow{2}{*}{0.06} \\
\hline Lower & $53(57.0)$ & $96(62.7)$ & & & \\
\hline \multicolumn{6}{|l|}{ Marital Status } \\
\hline Married & $70(72.2)$ & $96(61.2)$ & \multirow{2}{*}{3.21} & \multirow{2}{*}{0.073} & \multirow{2}{*}{0.11} \\
\hline Non-married & $27(27.8)$ & $61(38.8)$ & & & \\
\hline \multicolumn{6}{|l|}{ Socioeconomic Status } \\
\hline Professional & $23(23.7)$ & 25 (15.9) & \multirow{3}{*}{4.99} & \multirow{3}{*}{0.082} & \multirow{3}{*}{0.14} \\
\hline Owner of Small Business & $16(16.5)$ & $17(10.8)$ & & & \\
\hline Non-professional & $58(59.8)$ & $115(73.3)$ & & & \\
\hline \multicolumn{6}{|l|}{ Cannabis Use } \\
\hline No & $94(96.9)$ & 149 (94.9) & \multirow{2}{*}{0.58} & \multirow{2}{*}{0.446} & \multirow{2}{*}{0.05} \\
\hline Yes & $3(3.1)$ & $8(5.1)$ & & & \\
\hline \multicolumn{6}{|l|}{ Urbanicity } \\
\hline 1 & $13(13.4)$ & $5(3.2)$ & \multirow{4}{*}{13.9} & \multirow{4}{*}{0.003} & \multirow{4}{*}{0.23} \\
\hline II & $57(58.8)$ & $89(56.7)$ & & & \\
\hline III & $24(24.7)$ & 46 (29.3) & & & \\
\hline IV & $3(3.1)$ & $17(10.8)$ & & & \\
\hline \multicolumn{6}{|l|}{ Childhood Adversity } \\
\hline None & $81(83.5)$ & $122(77.7)$ & \multirow{2}{*}{1.25} & \multirow{2}{*}{0.262} & \multirow{2}{*}{0.07} \\
\hline At least one & $16(16.5)$ & $35(22.3)$ & & & \\
\hline \multicolumn{6}{|l|}{ BDNF Genotype } \\
\hline Met carrier & $42(43.3)$ & $45(28.7)$ & \multirow{2}{*}{5.7} & \multirow{2}{*}{0.017} & 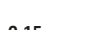 \\
\hline Val-Val & $55(56.7)$ & $112(71.3)$ & & & 0.15 \\
\hline & Mean (SD) & Mean (SD) & $t$ & $p$ & Cohen's $d$ \\
\hline Age & $47.2(12.9)$ & $44.0(13.4)$ & 1.87 & 0.03 & 0.24 \\
\hline Number of life events & $1.6(1.4)$ & 2.4 (1.9) & -3.49 & 0.0003 & -0.45 \\
\hline
\end{tabular}

SD: standard deviation, bold values are the values which have effect sizes $>0.1$. 
educational status (at least high school graduates: non-participants $26.8 \%$ vs. participants $36.6 \%$; $x^{2}=3.4$, df=1, $p=0.07$ ) did not significantly differ between participants and non-participants. Attrition was higher in individuals with baseline any psychotic symptoms (PE or PD) in comparison with individuals with no baseline psychotic symptoms (baseline any psychotic symptoms; non participants $85.7 \%$ vs. participants $57.5 \%$; $\mathrm{x}^{2}=$ 27.7, $\mathrm{df}=1, \mathrm{p}<0.01)$.

The genotype frequencies for the BDNF-Val66Met polymorphism were: Val/Val: 65.7\% ( $\mathrm{n}=167), \mathrm{Val} / \mathrm{Met}: 28.4 \%(\mathrm{n}=72)$ and Met/ Met: $5.9 \%(n=15)$. These frequencies did not differ from others described in previous studies conducted in white individuals (Egan et al. 2003;Alemany et al. 2011). Hardy-Weinberg equilibrium was verified for the present population $\left(\mathrm{x}^{2}=3.4, \mathrm{df}=2, \mathrm{p}>0.05\right)$.

\section{Dynamic Transitions over Time in the Extended Psychosis Phenotype}

Of those in the nested case-control sample who were successfully interviewed both at baseline and at follow-up $(n=254), 37$ participants (14.6\%) had PD and 109 participants $(30.8 \%)$ had $\mathrm{PE}$ at baseline. Nine of the 109 participants with baseline PE (8.2\%) transitioned to PD during follow-up. Therefore, a total of 46 participants (18.1\%) were in the $P D$ group. 111 participants were in the PE group (43.7\%). 97 participants (38.2\%) had neither $\mathrm{PE}$ nor PD at baseline and at follow-up (no psychotic symptoms group). Details of dynamic transitions over time in the extended psychosis phenotype are presented in Fig. 2.

\section{Main Efiects of Socio-demographies, Environmental Exposure and BDNF Val6GMet Gemotype}

Urbanicity, age and number of life events for the last six years were significantly associated with any psychotic symptoms (PE or PD) during follow-up (Table 1). BDNF-Val-Val genotype was significantly associated with presence of any psychotic symp- 


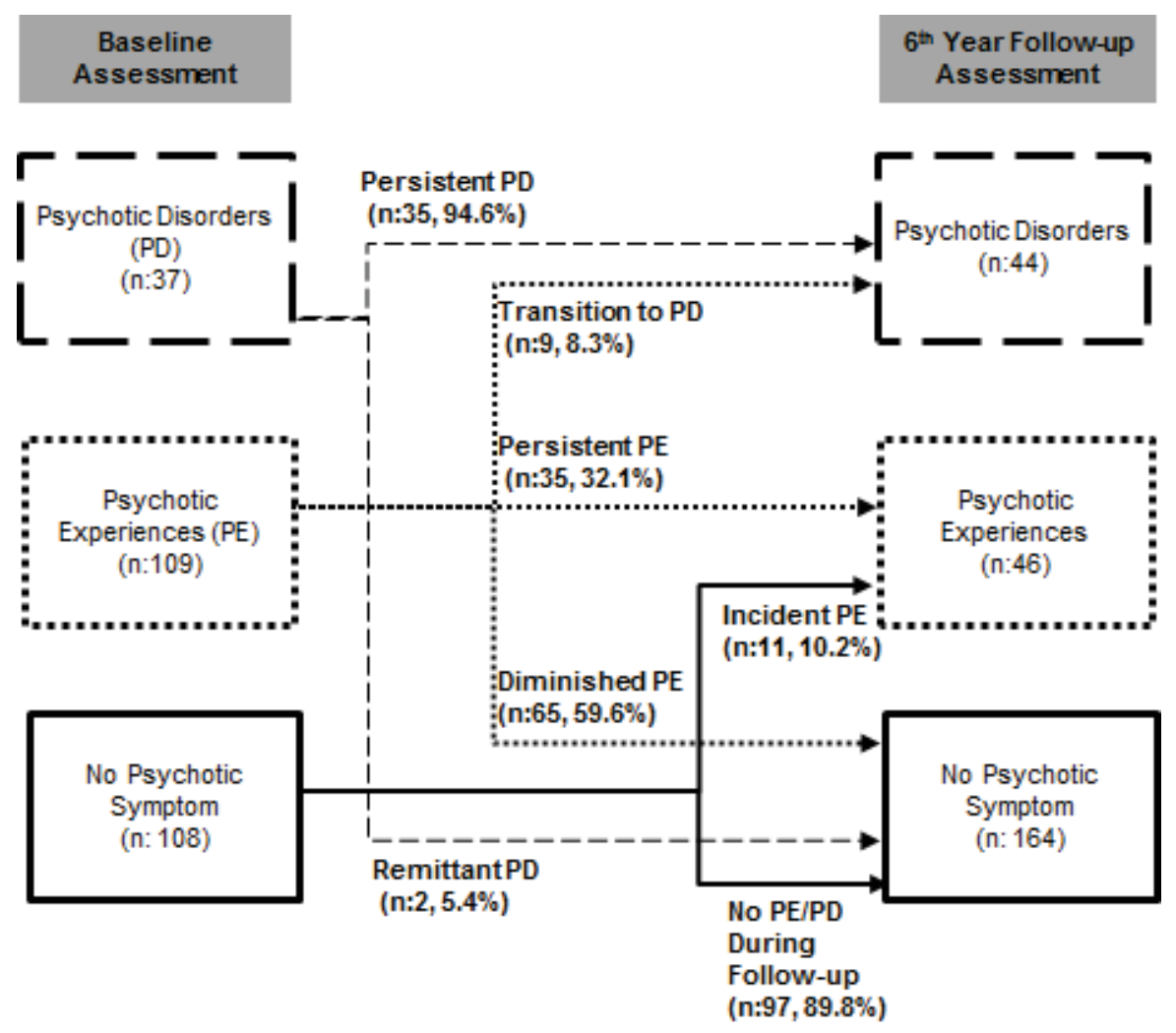

Figure 2: Dynamic transitions over time in the nested case-control sample

toms (PE or $\mathrm{PD})$ during follow-up $(\mathrm{OR}=1.9,95 \% \mathrm{CI}=1.12-3.23)$, and also after adjusting for socio-demographic features and environmental exposure variables $(\mathrm{OR}=1.9,95 \% \mathrm{CI}=1.05-3.46)$. The association between BDNF-Val-Val genotype and the extended psychosis phenotype showed a dose-response association, but it was extra-linear $\left(\mathrm{x}^{2}\right.$ for deviation from linearity: $2.50, \mathrm{df}=$ $2, p=0.0032)$. Thus, OR were disproportionately stronger at the psychotic disorder end of the extended psychosis phenotype (adjusted $\mathrm{OR}=2.7$, table 2) than at the $\mathrm{PE}$ section of the phenotype $(\mathrm{OR}=1.7)$ or at the no psychotic symptoms end $(\mathrm{OR}=1$, reference category). The corrected level of significance when the Bonferroni correction was applied remained marginally significant in the association between PD and BDNF-Val-Val genotype (the correct- 
ed p-value $=0.034)$. Finally, BDNF-Val66Met polymorphism was not significantly associated with transition from PE to PD (transition; Val-Val 9/78 vs. Met Carrier 0/31; $=0.058$, two-tailed Fisher's exact test, df $=1$, Cramer's $V=0.19$ ).

Table 2: Distribution of BDNF Val66Met genotypes per category of extended psychosis phenotype and regression results

\begin{tabular}{|c|c|c|c|c|c|c|c|c|}
\hline & \multicolumn{2}{|c|}{$\begin{array}{c}\text { No psychotic symptom } \\
(\mathrm{n}: 97)\end{array}$} & \multicolumn{3}{|c|}{ Psychotic Experiences (n: 111) } & \multicolumn{3}{c|}{ Psychotic Disorder (n:46) } \\
\cline { 2 - 9 } & $\mathrm{n}(\%)$ & $\mathrm{OR}(\% 95 \mathrm{Cl})$ & $\begin{array}{c}\mathrm{n} \\
(\%)\end{array}$ & $\mathrm{OR}(\% 95 \mathrm{Cl})$ & $\begin{array}{c}\mathrm{OR}^{+}(\% 95 \\
\mathrm{Cl})\end{array}$ & $\mathrm{n}(\%)$ & $\mathrm{OR}(\% 95 \mathrm{Cl})$ & $\mathrm{OR}^{+}(\% 95 \mathrm{Cl})$ \\
\hline $\begin{array}{c}\text { BDNF Val66Met Val-Val } \\
\text { Genotype }\end{array}$ & $\mathbf{5 5 ( 5 6 )}$ & $1(\mathrm{ref})$ & $\begin{array}{c}77 \\
(69)\end{array}$ & $1.73(0.98-3.05)$ & $\begin{array}{c}1.7(0.9- \\
3.21)\end{array}$ & $35(76)$ & $2.43^{*}(1.11-5.34)$ & $2.7^{*}(1.12-6.47)$ \\
\hline
\end{tabular}

$* p<0.05$

${ }^{+}$Adjusted for age, sex, marital status, socioeconomic status, urbanicity, childhood adversity, number of life events for the last 6 years, cannabis use

\section{Discussion}

\section{Findings}

In this 6 years prospective population-based cohort study, the BDNF-Val-Val genotype was found to be associated with the extended psychosis phenotype. The association was in a dose-response but extra-linear fashion, with a stronger impact at the psychotic disorder end. This is in agreement with a previous work which reported positive extra-linear associations between proxy variables of genetic risk and extended psychosis phenotype in TürkSch sample at baseline (Binbay et al. 2012c).

As far as we are aware, there are no studies to date investigating the association between the BDNF Val66Met polymorphism and the extended psychosis phenotype including both clinical and subclinical levels that we can directly compare with the results of this paper. However, significant associations between BDNF Val66Met polymorphism and psychosis expression at different levels of the extended psychosis phenotype have been presented. These results are in agreement with our results. First, the Val allele of the BDNF Val66Met polymorphism was associated with 
PD (including both affective and non-affective), and also all symptom dimensions of psychosis except the negative dimension (Rosa et al. 2006). Furthermore, the Val allele was associated with both affective PD (Neves-Pereira et al. 2002; Sklar et al. 2002; Geller et al. 2004; coLohoff et al. 2005), and also with schizophrenia (Neves-Pereira et al. 2005;Golimbet et al. 2008) separately. In addition, a recent study documented a gene-environment interaction involving BDNF-Val-Val genotype and PE (de Castro-Catala et al. 2016). Finally, there are studies which suggest that prognosis of $\mathrm{PD}$ is poorer in individuals with the BDNF-Val-Val genotype (Numata et al. 2006; Golimbet et al. 2008; Chang et al. 2009; Suchanek et al. 2013).

\section{BDNF and Psychosis as a Transdiagnostic and Extended Phemotype}

To date, studies assessing associations between BDNF Val66Met polymorphism and schizophrenia - the traditional poor outcome formulation of PD - have produced inconsistent results (Notaras et al. 2015b). Furthermore, BDNF has generally not transpired in GWAS as increasing risk for schizophrenia (Collins et al. 2012). While the BDNF Val66Met polymorphism may not be consistently associated with schizophrenia, there is substantial evidence that at least some of the clinical features of schizophrenia are modulated by the polymorphism (Notaras et al. 2015b). Furthermore, a growing number of studies have demonstrated the modulating role of the polymorphism on the association between social environmental stress and PE (Simons et al. 2009;Alemany et al. 2011; de Castro-Catala et al. 2016). In addition, BDNF Val66Met polymorphism has also been associated with a range of common mental disorders including mood, eating and some anxiety disorders (Gratacos et al. 2007; Hong et al. 2011;Notaras et al. 2015a). There is robust evidence that the risk of PE is significantly higher in individuals who have common mental disorders in comparison with individuals who do not (Kaymaz et al. 2012;McGrath et al. 2016;van Os and Reininghaus 2016). In addition, a cross-twin analysis indicated that PE might be genet- 
ically continuous with psychotic disorders (Lataster et al. 2009). In light of the previous results linking BDNF-Val66Met polymorphism with both non-psychotic and psychotic disorders, and the present result suggesting a dose-response association between the polymorphism and the extended psychosis phenotype including both subclinical and clinical expressions of psychosis; it may be suggested that BDNF-Val66Met polymorphism indexes susceptibility to expression of psychosis along a spectrum. Further research with the extended psychosis phenotype cutting across boundaries of diagnostic categories is needed to evaluate this hypothesis.

\section{Strengths and Limitations}

The current study, to our knowledge, is the first longitudinal study that investigates the associations between BDNF Val66Met polymorphism and the extended psychosis phenotype including both subclinical and clinical expressions of psychosis in a representative population-based sample. Longitudinal design enabled us to measure non-lifetime clinical features which were subject to change over time, such as symptom presence and severity. Furthermore, the main outcome variable extended psychosis phenotype enabled us to include the more common phenotype $P E$ next to $P D$. In addition, we were able to adjust the associations for socio-demographic features and environmental exposure variables including life events, childhood adversity, SES, urbanicity and, cannabis use.

Nevertheless, the results need to be considered in the light of the following limitations. First, as with most longitudinal studies, our initial sample size was reduced through attrition. The comparison of baseline socio-demographic characteristics between non-participants and participants showed no large or significant differences. However, in line with a simulation study of attrition (Wolke et al. 2009), the comparison of clinical characteristics between non-participants and participants showed that attrition was higher in individuals with any psychotic symp- 
toms at baseline. Furthermore, selective attrition of those who have transitioned to PD is possible, mainly because of refusal to participate (Williams and Macdonald 1986). Therefore, this may have impacted upon the findings. However, the number of those who have refused to participate in follow-up assessment is small (n: $18,4.8 \%$ ) and the transition rate from PE to PD found in the current sample $(8.2 \%)$ is consistent with previous meta-analytical findings (Linscott and van Os 2013). Second, although the sample size is similar to previous studies with a similar design (Ramsay et al. 2013), it can be still considered relatively small. However, the broader outcome variable including the subclinical phenotypes, the longitudinal design, and the epidemiological sample of the study including the non-helpseeking individuals next to the help-seeking individuals enabled us to detect smaller effect sizes. Third, the assessment of psychosis in the general population inevitably is associated with a degree of misclassification (false positives and false negatives). In order to reduce the risk of misclassification, gold-standard clinical interviews (SCID) were performed by a psychiatrist. Finally, as with the other candidate gene studies, we were not able to correct our results for other possible genetic variations. As BDNF has generally not transpired in GWAS as increasing risk for schizophrenia (Collins et al. 2012), the findings need replication in larger samples. 


\section{References}

- Alemany S, Arias B, Aguilera $\mathrm{M}$, et al. (2011). Childhood abuse, the BDNF-Val$66 \mathrm{Met}$ polymorphism and adult psychotic-like experiences. The British journal of psychiatry: the journal of mental science 199, 38-42.

- Alptekin K, Ulas H, Akdede BB, Tumuklu M , Akvardar $Y$ (2009). Prevalence and risk factors of psychotic symptoms: in the city of Izmir, Turkey. Social psychiatry and psychiatric epidemiology 44, 905-910.

- Andrews G, Peters L (1998). The psychometric properties of the Composite International Diagnostic Interview. Social psychiatry and psychiatric epidemiology 33, 80-88.

- Auld DS, Mennicken F, Day JC, Quirion R (2001). Neurotrophins differentially enhance acetylcholine release, acetylcholine content and choline acetyltransferase activity in basal forebrain neurons. Journal of neurochemistry 77, 253-262.
- Binbay T, Alptekin K, Elbi $\mathrm{H}$, et al. (2012a). [Lifetime prevalence and correlates of schizophrenia and disorders with psychotic symptoms in the general population of Izmir, Turkey]. Turk psikiyatri dergisi $=$ Turkish journal of psychiatry 23, 149-160.

- Binbay T, Drukker M, Alptekin K, et al. (2012b). Evidence that the wider social environment moderates the association between familial liability and psychosis spectrum outcome. Psychological medicine 42, 2499-2510.

- Binbay T, Drukker M, Elbi $\mathrm{H}$, et al. (2012c). Testing the psychosis continuum: differential impact of genetic and nongenetic risk factors and comorbid psychopathology across the entire spectrum of psychosis. Schizophrenia bulletin 38 , 992-1002.

- Binbay T, Elbi H, Alptekin $\mathrm{K}$, et al. (2011). Izmir mental health survey for gene-environment in- 
teraction in psychoses (TurkSch): objectives and methodology. Turk psikiyatri dergisi $=$ Turkish journal of psychiatry 22, 65-76.

- Brugha TS, Cragg D (1990). The List of Threatening Experiences: the reliability and validity of a brief life events questionnaire. Acta psychiatrica Scandinavica 82, 77-81.

- Buckley PF, Mahadik S, Pillai A , Terry A, Jr. (2007). Neurotrophins and schizophrenia. Schizophrenia research 94, 1-11.

- Chang HA, Lu RB, Shy MJ, Chang CC, Lee MS , Huang SY (2009). Brain-derived neurotrophic factor Val66Met polymorphism: association with psychopathological symptoms of schizophrenia? The Journal of neuropsychiatry and clinical neurosciences 21, 30-37.

- Cilli AS , Kaya N (2003). [Nicotine dependence and psychiatric comorbidity among university students]. Turk psikiyatri dergisi $=$ Turkish journal of psychiatry 14, 42-49.
- Collins AL, Kim Y, Sklar P, O’Donovan MC, Sullivan PF (2012). Hypothesis-driven candidate genes for schizophrenia compared to genome-wide association results. Psychological medicine 42, 607-616.

- coLohoff FW, Sander T, Ferraro TN, Dahl JP, Gallinat J , Berrettini WH (2005). Confirmation of association between the Val66Met polymorphism in the brain-derived neurotrophic factor (BDNF) gene and bipolar I disorder. American journal of medical genetics. Part B, Neuropsychiatric genetics : the official publication of the International Society of Psychiatric Genetics 139B, 51-53.

- Coyle JT (2012). NMDA receptor and schizophrenia: a brief history. Schizophrenia bulletin 38, 920-926.

- de Castro-Catala M, van Nierop M, Barrantes-Vidal $\mathrm{N}$, et al. (2016). Childhood trauma, BDNF Val66Met and subclinical psychotic experiences. Attempt at replication in two independent samples. Journal 
of psychiatric research 83 , 121-129.

- Deveci A, Taskin O, Dinc G, et al. (2007). Prevalence of pseudoneurologic conversion disorder in an urban community in Manisa, Turkey. Social psychiatry and psychiatric epidemiology 42, 857-864.

- Egan MF, Kojima M, Callicott JH, et al. (2003). The BDNF val66met polymorphism affects activity-dependent secretion of BDNF and human memory and hippocampal function. Cell 112, 257-269.

- Geller B, Badner JA, Tillman R, Christian SL, Bolhofner K, Cook EH, Jr. (2004). Linkage disequilibrium of the brain-derived neurotrophic factor Val66Met polymorphism in children with a prepubertal and early adolescent bipolar disorder phenotype. The American journal of psychiatry 161, 1698-1700.

- Goldthorpe J (1987). Social mobility and class structure in modern Britain. Clarendon Press: New York.
- Golimbet VE, Korovaitseva GI, Abramova LI, Kasparov SV, Uvarova LG (2008). [Association between the Val66Met polymorphism of brain-derived neurotrophic factor gene and schizophrenia in Russians]. Molekuliarnaia biologiia 42, 599-603.

- Gourion D, Goldberger C, Leroy S, Bourdel MC, Olie JP , Krebs MO (2005). Age at onset of schizophrenia: interaction between brain-derived neurotrophic factor and dopamine D3 receptor gene variants. $\mathrm{Neu}$ roreport 16, 1407-1410.

- Gratacos M, Gonzalez JR, Mercader JM, de Cid R, Urretavizcaya M , Estivill X (2007). Brain-derived neurotrophic factor Val66Met and psychiatric disorders: meta-analysis of case-control studies confirm association to substance-related disorders, eating disorders, and schizophrenia. Biological psychiatry 61, 911-922.

- Guillin O, Diaz J, Carroll P, Griffon N, Schwartz JC, Sokoloff P (2001). BDNF 
controls dopamine D3 receptor expression and triggers behavioural sensitization. Nature 411, 86-89.

- Hong CJ, Liou YJ, Tsai SJ (2011). Effects of BDNF polymorphisms on brain function and behavior in health and disease. Brain research bulletin 86, 287 297.

- Kaymaz N, Drukker M, Lieb R, et al. (2012). Do subthreshold psychotic experiences predict clinical outcomes in unselected non-help-seeking population-based samples? A systematic review and meta-analysis, enriched with new results. Psychological Medicine 42, 2239-2253.

- Kelleher I, Jenner JA, Cannon M (2010). Psychotic symptoms in the general population - an evolutionary perspective. The British Journal of Psychiatry 197, 167-169.

- Kish L (1949). A procedure for objective respondent selection within the household. Journal of the American Statistical Association 44, 380-387.
- Lataster T, Myin-Germeys I, Derom C, Thiery E, van Os J (2009). Evidence that self-reported psychotic experiences represent the transitory developmental expression of genetic liability to psychosis in the general population. American journal of medical genetics. Part B, Neuropsychiatric genetics : the official publication of the International Society of Psychiatric Genetics 150B, 1078-1084.

- Levine ES , Kolb JE (2000). Brain-derived neurotrophic factor increases activity of NR2B-containing N-methyl-D-aspartate receptors in excised patches from hippocampal neurons. Journal of neuroscience research 62, 357-362.

- Linscott RJ , van Os J (2013). An updated and conservative systematic review and meta-analysis of epidemiological evidence on psychotic experiences in children and adults: on the pathway from proneness to persistence to dimensional expression across mental disorders. Psychological medicine 43, 1133-1149. 
- Martinowich K, Lu B (2008). Interaction between BDNF and serotonin: role in mood disorders. Neuropsychopharmacology : official publication of the American College of Neuropsychopharmacology 33, 73-83.

- McGrath JJ, Saha S, Al-Hamzawi A, et al. (2016). The Bidirectional Associations Between Psychotic Experiences and DSMIV Mental Disorders. The American journal of psychiatry, appiajp201615101293.

- Neves-Pereira M, Cheung JK, Pasdar A, et al. (2005). $\mathrm{BDNF}$ gene is a risk factor for schizophrenia in a Scottish population. Molecular psychiatry 10, 208-212.

- Neves-Pereira M, Mundo E, Muglia P, King N, Macciardi F , Kennedy JL (2002). The brain-derived neurotrophic factor gene confers susceptibility to bipolar disorder: evidence from a family-based association study. American journal of human genetics 71, 651-655.

- Notaras M, Hill R, van den Buuse M (2015a). The
BDNF gene Val66Met polymorphism as a modifier of psychiatric disorder susceptibility: progress and controversy. Molecular psychiatry 20, 916-930.

- Notaras M, Hill R, van den Buuse M (2015b). A role for the BDNF gene Val66Met polymorphism in schizophrenia? A comprehensive review. Neuroscience and biobehavioral reviews 51 , 15-30.

- Numata S, Ueno S, Iga J, et al. (2007). Interaction between catechol-O-methyltransferase (COMT) Val108/158Met and brain-derived neurotrophic factor (BDNF) Val66Met polymorphisms in age at onset and clinical symptoms in schizophrenia. Journal of neural transmission 114, 255-259.

- Numata S, Ueno S, Iga J, et al. (2006). Brain-derived neurotrophic factor (BDNF) Val66Met polymorphism in schizophrenia is associated with age at onset and symptoms. Neuroscience letters 401, 1-5. 
- Ramsay H, Kelleher I, Flannery P, et al. (2013). Relationship between the COMT-Val158Met and BDNF-Val66Met polymorphisms, childhood trauma and psychotic experiences in an adolescent general population sample. PloS one 8, e79741.

- Robins LN, Wing J, Wittchen HU, et al. (1988). The Composite International Diagnostic Interview. An epidemiologic Instrument suitable for use in conjunction with different diagnostic systems and in different cultures. Archives of general psychiatry 45, 10691077.

- Rosa A, Cuesta MJ, Fatjo-Vilas M, Peralta V, Zarzuela A , Fananas L (2006). The Val66Met polymorphism of the brain-derived neurotrophic factor gene is associated with risk for psychosis: evidence from a family-based association study. American journal of medical genetics. Part $B$, Neuropsychiatric genetics : the official publication of the International Society of
Psychiatric Genetics 141B, 135-138.

- Simons CJ, Wichers M, Derom C, et al. (2009). Subtle gene-environment interactions driving paranoia in daily life. Genes, brain, and behavior 8, 5-12.

- Sklar P, Gabriel SB, McInnis MG, et al. (2002). Family-based association study of 76 candidate genes in bipolar disorder: BDNF is a potential risk locus. Brain-derived neutrophic factor. Molecular psychiatry 7, 579-593.

- Spitzer RL, Williams JB, Gibbon M , First MB (1992). The Structured Clinical Interview for DSM-III-R (SCID). I: History, rationale, and description. Archives of general psychiatry 49, 624629.

- Suchanek R, Owczarek A, Paul-Samojedny M, Kowalczyk M, Kucia K, Kowalski $\mathrm{J}$ (2013). BDNF val66met polymorphism is associated with age at onset and intensity of symptoms of paranoid schizophrenia in a Polish population. The 
Journal of neuropsychiatry and clinical neurosciences 25, 88-94.

- van Os J , Linscott RJ (2012). Introduction: The Extended Psychosis Phenotype--Relationship With Schizophrenia and With Ultrahigh Risk Status for Psychosis. Schizophrenia bulletin 38, 227-230.

- van Os J, Reininghaus U (2016). Psychosis as a transdiagnostic and extended phenotype in the general population. World psychiatry : official journal of the World Psychiatric Association 15, 118-124.

- Vollenweider FX, Vollenweider-Scherpenhuyzen MF, Babler A, Vogel H , Hell D (1998). Psilocybin induces schizophrenia-like psychosis in humans via a serotonin-2 agonist action. Neuroreport 9, 3897-3902.

- Williams P, Macdonald A (1986). The effect of non-response bias on the results of two-stage screening surveys of psychiatric disorder. Social psychiatry. Sozialpsychiatrie. Psychiatrie sociale $21,182-186$.

- Wolke D, Waylen A, Samara M, et al. (2009). Selective drop-out in longitudinal studies and non-biased prediction of behaviour disorders. The British journal of psychiatry : the journal of mental science 195, 249256. 



\section{CHAPTER 6}

Discussion 
For a long time, it was widely held that threshold psychotic experiences are dimensional. In the article on "the diagnosis and prognosis of dementia praecox", Kraepelin addressed the role of nonsensical delusions, dull mood and lack of interest, enduring mannerisms, negativism, stereotypy, and recurring changes of mood in bringing about the "peculiar state of mental impairment". Furthermore, he concluded that: "despite all efforts, no sharp boundaries between the individual clinical manifestations of dementia praecox could be determined" (Kraepelin 1899;Kendler 2020). Kraepelin's statements included four domains of threshold psychotic states: Positive, negative, disorganisation and affective. Furthermore, despite the distinct definitions of "neurosis and psychosis" in the psychoanalytic literature, common phenomenological (e.g. anhedonia) and etiological features (e.g. frustration of childhood desires) have also been reported since the age of Freud (Freud 1924;Dereboy 2000). These common features are represented in the current classification systems (Häfner et al. 2005; American Psychiatric Association 2013;Szczypiński and Gola 2018).

An earlier edition of DSM ( $3^{\text {rd }}$ edition) proposed a "symptom list of the pre-active or prodromal phase of the psychotic disorders" which is composed of symptoms from multiple domains including subthreshold psychotic experiences (PEs) (Table 1) (American Psychiatric Association 1987). Although this list was not included in the fourth and the fifth editions, recent evidence supports the notion that subthreshold psychotic states are also dimensional, and referred to as subthreshold psychotic experiences, (Dominguez et al. 2009; Rössler et al. 2011;Binbay et al. 2012b;Guloksuz et al. 2015), subthreshold negative and disorganization symptoms (van Os et al. 2000b;Krabbendam et al. 2004a;Dominguez et al. 2010;Walss-Bass et al. 2015;van Os and Reininghaus 2016; Sauvé et al. 2019), and affective dysregulation (van Os and Linscott 2012; Fusar-Poli et al. 2014; Pries et al. 2019b). 
Table 1: Symptom List of the Pre-active or Prodromal Phase of the Psychotic Disorders Included in DSM-III

\begin{tabular}{l}
\hline Social isolation or withdrawal \\
\hline Marked impairment in role functioning as wage-earner, student, or homemaker \\
\hline Markedly peculiar behaviour (e.g. collecting garbage, talking to self in public or hoarding food) \\
\hline Marked impairment in personal hygiene and grooming \\
\hline Blunted, flat, or inappropriate affect \\
\hline Digressive, vague, over-elaborate, circumstantial, or metaphorical speech \\
\hline $\begin{array}{l}\text { Odd or bizarre ideation, or magical thinking, e,g. superstitiousness, clairvoyance, telepathy, "sixth } \\
\text { sense" / "others can feel my feelings," overvalued ideas, ideas of reference }\end{array}$ \\
\hline $\begin{array}{l}\text { Unusual perceptual experiences, e.g., recurrent illusions, sensing the presence of a force or person } \\
\text { not actually present }\end{array}$
\end{tabular}

\section{Evaluating alymamic tramsitions} over time within the full spectrum of psychosis

\section{Longitudinal data collection in a} representative commanity-based popalation

The second chapter of this thesis covers the general outline, methods and details of attrition during the follow-up period. The detailed efforts to capture the full spectrum of psychosis expression and to evaluate multidimensional outcomes over time in the representative community-based population were also reported in this chapter (Kirli et al. 2019d).

Baseline characteristics of responders did not show large differences from characteristics of subjects who dropped out. In addition, the dropout rate of participants and the relevant socio-demographic characteristics were similar to studies with a similar design (Dominguez et al. 2009;Zammit et al. 2013b). However, there were also some differences in the sociodemographic correlates of attrition because these studies showed higher refusal rates in individuals with a baseline mental health problem, with a lower socioeconomic status and a lower educational level (Dominguez et al. 2009; de Graaf et al. 2013). These individuals showed lower refusal rates at follow-up in the TürkSch study (Kirli et al. 2019d). 
In this thesis, the positive domain of psychosis was evaluated from the perspective of a spectrum framework that encompassed subclinical, subthreshold and threshold states in order to generate evidence for research on the multidimensional liabilities underlying psychosis expression.

\section{Graded Nature of Risk Associated with Subthreshold Psychosis}

The results presented in the second chapter of this thesis showed that increasing severity of subthreshold psychosis at baseline was associated with the increasing rates of persistence and psychotic disorder outcome over the follow-up period (Kirli et al. 2019d). However, for the last decades, a series of attempts have classified subthreshold psychosis in 'high risk' or 'prodromal psychosis' concepts. The summary of symptom domains on which these classifications are mainly based on are shown in table 2 (Klosterkötter et al. 1996;Miller et al. 2003; Schultze-Lutter et al. 2008; Yung and Nelson 2011;American Psychiatric Association 2013;Schultze-Lutter et al. 2017). Among these symptom domains, the subjective cognitive disturbances were demonstrated to be the most common in the community (Schultze-Lutter et al. 2017). However, psychosis-risk studies have mainly targeted the attenuated positive or disorganisation symptoms, as the great majority of individuals had been referred to high risk centre through this domain (Fusar-Poli et al. 2016).

Table 2: High Risk for Psychosis Categories and Associated Symptom Domains

\begin{tabular}{|l|l|}
\hline High Risk Category & Symptom Domain \\
\hline DSM-5 Attenuated Psychosis Syndrome-APS & Attenuated positive or disorganisation symptoms \\
\hline & Presence of any of the following domains: \\
At Risk Mental States- ARMS & Attenuated positive or disorganisation symptoms \\
Ultra-High Risk-UHR & $\begin{array}{l}\text { Transient threshold positive or disorganisation } \\
\text { Symptoms }\end{array}$ \\
\hline Basic Symptoms-BS & Genetic risk and deterioration in functioning \\
\hline
\end{tabular}


When compared with individuals with subthreshold PEs in general, non-clinical populations, individuals meeting the high risk criterion have higher 'transition to frank psychosis' rates (van Os and Linscott 2012;Fusar-Poli et al. 2014;Lin et al. 2015;Polari et al. 2018; Radua et al. 2018; Oliver et al. 2019). The highest 'transition' rates among high risk samples were shown for individuals with 'transient threshold positive or disorganisation symptoms' which actually includes the most severe psychosis expression (Chan et al. 2019). These results are in line with studies in the general population, demonstrating that the severity of the baseline psychosis expression translates to 'transition' rates (Hanssen et al. 2005; van Os and Linscott 2012; Linscott and van Os 2013;Zammit et al. 2013b). Furthermore, emerging evidence from twin and molecular genetic studies showed that increasing frequency of PEs and associated distress may index increasing genetic liability to threshold psychotic disorders (Zavos et al. 2014;Martin et al. 2017;Legge et al. 2019). Robust evidence from epidemiological research and preliminary evidence from genetic studies suggest a graded nature of risk associated with subthreshold psychosis rather than categories with and without risk.

\section{Bidirectional associations between the extended psychosis phenotype and affective psychopathology over time}

\section{Afiective Psychopathology and the Psychosis Spectrum Prediet Each Dther over Time}

The results in the third chapter of this thesis showed that baseline PEs were associated with both subsequent depressive and hypomanic/manic episodes. The association with subsequent hypomanic/manic episodes was stronger (Kirli et al. 2019c). In line with this result, recent studies linked both depression and mania with the positive dimension of psychosis, demonstrating relatively stronger associations with mania (Zavos et al. 2016;Anttila et 
al. 2018;Xia et al. 2018;Baker et al. 2019;Legge et al. 2019;Stahl et al. 2019;Kotov et al. 2020).

Cross-sectional studies showed high comorbidity rates between psychotic and affective psychopathology at threshold level (Tsuang 1979;Buckley et al. 2008;McMillan et al. 2009;Dean et al. 2010; Mortensen et al. 2010;DeVylder and Lukens 2013), and also at subthreshold level (van Os et al. 1999;Verdoux et al. 1999;Hanssen et al. 2003;Stefanis et al. 2004;van Rossum et al. 2009; van Os and Linscott 2012;McGrath et al. 2016). A recent population-based cohort study of 5940778 individuals, followed up for 83.9 million person-years showed that mood disorders predicted psychotic disorders (i.e. schizophrenia) over time, and vice-versa (Plana-Ripoll et al. 2019). Findings from the present thesis suggest that these bidirectional associations over time also exist at the subthreshold level (Kirli et al. 2019c).

\section{Shared Etiopathogenesis across Afiective Psychopathology and the Psychosis Spectrum} An important proportion of symptoms classified in affective psychopathology overlap with threshold psychotic disorders (van Os et al. 2000a) and also with subthreshold psychosis (Krabbendam et al. 2004a;Kaymaz et al. 2007;Kafali et al. 2019). Furthermore, affective and psychotic disorders have shown common cognition dysfunction (Burdick et al. 2014;Owen and O'Donovan 2017;Bora et al. 2018; Kotov et al. 2020). Relatedly, childhood problems with communication, reading and mathematics predicted both subthreshold psychosis and mania symptoms in adolescence (Cederlöf et al. 2013).

Recent preliminary results suggest that dysregulation in tonic dopamine signalling (including lower and higher states) and the interactions with glutamatergic system may be common in both depression and psychosis (Szczypiński and Gola 2018). Similar electrophysiological alterations were reported in subthreshold psychosis as well as threshold psychotic and affective disorders (Hazlett et al. 2015;Wan et al. 2017;Hermens et 
al. 2018; Javitt et al. 2018). Furthermore, studies assessing pro-inflammatory markers reported no distinguishing pathways (Goldsmith et al. 2016). Finally, familial co-aggregation (Cardno et al. 2002; Lichtenstein et al. 2009; Chou et al. 2017), numerous shared molecular genetic (van Os et al. 2017; Anttila et al. 2018; Ronald and Pain 2018; Sullivan et al. 2018; Cross-Disorder Group of the Psychiatric Genomics Consortium 2019; Legge et al. 2019; Stahl et al. 2019) and post-mortem gene expression findings (Chen et al. 2012;Zhao et al. 2014) were reported across these states (albeit with different effect sizes). These results accord with the view that affective and psychotic disorders form a spectrum of severity (Mancuso et al. 2015;Guloksuz and van Os 2017). However, these results should be treated with caution because of the dissimilarities across the methodology of the studies, the presence of plausible unconsidered confounders, and low replicability of biological findings in psychosis (Ioannidis 2005; Ioannidis 2011), particularly in the area of neuroimaging (Botvinik-Nezer et al. 2020;Elliott et al. 2020). Therefore, these results need further replication.

Numerous studies reported shared socio-demographic and environmental factors across affective disorders and threshold psychotic disorders (Carpenter et al. 2009; van Os et al. 2010;Zhu et al. 2019). The results presented in chapter three of this thesis showed that a part of these factors are also shared across the extended psychosis phenotype and affective psychopathology (Kirli et al. 2019c). Childhood adversity and recent stressful life events were significantly associated with both the extended psychosis phenotype and affective psychopathology (Kirli et al. 2019c). This is in line with previous studies demonstrating shared associations across threshold psychotic and affective disorders (Matheson et al. 2012; Varese et al. 2012;Morgan and Gayer-Anderson 2016;Palmier-Claus et al. 2018), and subthreshold PEs and affective dysregulation (Fisher et al. 2012; Linscott and van Os 2013; van Nierop et al. 2014;Duhig et al. 2015;Misiak et al. 2017). Furthermore, non-married marital status has been associated with both dimensions (Kirli et al. 2019c), in 
line with earlier studies (Linscott and van Os 2013;Walker et al. 2019;Lunde et al. 2020;Narita et al. 2020b). Finally, family history of a mental illness was a very strong predictor of both dimensions (Kirli et al. 2019c), also in line with numerous studies (Dean et al. 2010; Mortensen et al. 2010;Linscott and van Os 2013). Stress and reward sensitivity refer to negative and positive affect in response to environmental stimulus. Stress and reward sensitivity were associated with both the affective and the psychotic spectrum in previous studies (Myin-Germeys and van Os 2007; Lataster et al. 2009b; Heinz et al. 2013;Gevonden et al. 2014;Misiak et al. 2017;Pries et al. 2019b). This is in accordance with the aforementioned shared risk factors.

Results in the third chapter of this thesis showed that the associations between cannabis / heavy alcohol use and the extended psychosis phenotype were significant (Kirli et al. 2019c). These results are in line with robust evidence linking the extended psychosis phenotype with cannabis use, and less consistent evidence with heavy alcohol use (Alptekin et al. 2009;Kuepper et al. 2011;Linscott and van Os 2013;Marconi et al. 2016;Ragazzi et al. 2018). However, the associations with affective psychopathology were weaker and below the significance level (Kirli et al. 2019c), also in line with previous studies (Addington and Addington 2007;Degenhardt et al. 2007; Foti et al. 2010; Ringen et al. 2016; Quattrone et al. 2019b). The extended psychosis phenotype was not associated with gender in this thesis (Kirli et al. 2019c), parallel to previous studies (Beauchamp and Gagnon 2004;Binbay et al. 2011a;Linscott and van Os 2013;Ringen et al. 2016;Castle et al. 2018). In contrast, the increased risk of affective psychopathology in females presented in this thesis has been consistently demonstrated (Regier 1988;Bijl et al. 1998;van Os et al. 2010;Sadock 2015). Younger individuals showed higher risk of the extended psychosis phenotype (Kirli et al. 2019c), in accordance with meta-analytical evidence (Linscott and van Os 2013). However, the association with affective psychopathology was below the significance level (Kirli et al. 2019c). Previous studies also showed weak associations between age and affective 
psychopathology and these associations did not shown a linear pattern (Regier 1988;Bijl et al. 1998;Pakriev et al. 1998;Kebede and Alem 1999;Mohammadi et al. 2005;Bradley et al. 2011).

Furthermore, educational level was associated with the extended psychosis phenotype in this thesis (Kirli et al. 2019c). Previous reports linking educational level and the extended psychosis phenotype were not consistent, but a meta-analysis reported significant associations with subthreshold psychosis when outlier results were removed (Linscott and van Os 2013). The association with affective psychopathology was weaker and below the conventional significance level (Kirli et al. 2019c), but showed similar odds with previous studies (Bijl et al. 1998;Pakriev et al. 1998; Schoeyen et al. 2011). In summary, an important proportion of the associations with sociodemographic and environmental factors are in the same direction across the extended psychosis phenotype and affective psychopathology. Finally, based on the similar cross-legged correlations between these dimensions over time, shown in the third chapter of this thesis (Kirli et al. 2019c), common causal pathways may be suggested across the extended psychosis phenotype and affective psychopathology (de Jonge et al. 2017;Kotov et al. 2017;Pries et al. 2018).

\section{Dutcomes of Co-oceurrence of the Afiective Psychopathology and the Psychosis Spectrum}

The baseline cross-sectional analysis of the TürkSch cohort showed significant associations between affective dysregulation and the severity of the extended psychosis phenotype (Binbay et al. 2012b). This thesis provided longitudinal evidence for this proposition (Kirli et al. 2019b; Kirli et al. 2019c). Co-occurrence of affective psychopathology with subthreshold PEs showed poorer outcomes than subthreshold PEs in isolation. Previous studies showed similar results (Kelleher et al. 2013; Guloksuz et al. 2015;McGrath et al. 2016;Navarro-Mateu et al. 2017;Pries et al. 2018). Conversely, co-occurring psychosis with affective psychopathology was associated with poorer outcomes of the index psychopathology over time, also in line with the previ- 
ous evidence (Kaymaz et al. 2007;Wigman et al. 2009;Perlis et al. 2010;Kelleher et al. 2011;Rössler et al. 2011; Wigman et al. 2011;Kaymaz et al. 2012;Wigman et al. 2012a;Kelleher et al. 2018b). A remarkable amount of evidence has demonstrated that greater exposure to risk factors additively drives greater co-occurrence of the positive and affective domains, which together predict poorer long-term outcomes (Cougnard et al. 2007;Guloksuz et al. 2015; Salokangas et al. 2015;Pries et al. 2018).

\section{Associations between climically relevant subthreshold psychotic experiences and subsequent psychopathology}

\section{Follow-np Diagnoses of Individuals with Baseline Subthreshold Psychosis}

The results presented in the fourth chapter of this thesis showed that the majority of participants with baseline clinically relevant subthreshold psychosis develop a common non-psychotic DSM disorder rather than a psychotic disorder. Furthermore, the follow-up diagnoses are included in various chapters of the DSM including bipolar and related disorders, depressive disorders, anxiety disorders, obsessive-compulsive and related disorders, trauma and stressor-related disorders, somatic symptom disorders, substance-related disorders, sleep-wake disorders, and impulse control disorders as well as schizophrenia spectrum disorders (Kirli et al. 2019b).

The main motivation driving the high risk for psychosis concepts (i.e. UHR, CHR, ARMS) has been to stimulate early intervention strategies and thus prevent 'transition to frank psychosis' (Srihari et al. 2012; van Os and Guloksuz 2017; Correll et al. 2018;McGorry and Mei 2018). However, research in the area has consistently shown that only a minority of the individuals with subthreshold PEs subsequently meet the diagnostic criteria of a psychotic dis- 
order. The majority has a diagnosis of a non-psychotic disorder with a degree of concurrent psychosis: i.e. anxiety, depression, bipolar, substance use disorders (Rössler et al. 2011;Kaymaz et al. 2012;Fisher et al. 2013;McGrath et al. 2016). However, a recent meta-analysis evaluating the longitudinal outcomes of subthreshold psychosis concluded that further longitudinal research was needed to precisely determine the associations with non-psychotic disorders. The reason was that most of the studies had a cross-sectional design or a retrospective cohort design, and the few prospective studies were lacking clinician-based diagnoses (Healy et al. 2019). Through the prospective evaluations in a representative community-based population and the clinical re-interviews performed in households when necessary, the design of the TürkSch study was able to meet these challenges.

The follow-up diagnoses of baseline clinically relevant subthreshold PEs, which were obtained from a general population sample (Kirli et al. 2019b), were similar to the previously reported follow-up diagnoses of the baseline high risk populations (Simon and Umbricht 2010;Addington et al. 2011;Ziermans et al. 2011;American Psychiatric Association 2013; Lin et al. 2015;Rutigliano et al. 2016;Guloksuz and van Os 2017;McGorry et al. 2018;McGorry and Mei 2018; Chan et al. 2019). Results from both the general population and the high-risk populations showed higher rates of subsequent non-psychotic disorders in individuals with subthreshold PEs. Therefore, subthreshold PEs (including high risk or prodromal psychosis concepts) should be treated in the context of multidimensional psychopathology rather than the mere consideration of a 'pre-psychotic' phase.

\section{Baseline Characteristies Associated with the Follow-ap Diagnoses of Individuals with Subthreshold Psychosis}

The results presented in the fourth chapter of this thesis showed that affective psychopathology co-occurring with subthreshold PEs yielded significantly higher rates of subsequent 
mental disorders. However, the co-occurrence of affective psychopathology with subthreshold psychosis was not associated with subsequent psychotic disorder in comparison with subsequent non-psychotic disorder (Kirli et al. 2019b). This result was in agreement with the baseline cross-sectional results of the TürkSch cohort demonstrating a disproportionate shift towards the non-psychotic disorder end of the psychosis spectrum in relation to affective dysregulation (Binbay et al. 2011a). However, the results comparing the follow-up subsequent psychotic disorders versus non-psychotic disorders should be interpreted considering two issues: First, the low number of participants with a subsequent psychotic disorder might result in false negative results when analysing psychotic disorders because of the low power. Second, this analysis comprised a baseline sample which already had distress associated with the subthreshold PEs. Therefore, the comparisons were between subthreshold PEs plus distress with and without affective disorder. This is the reason that these associations can be different in subclinical-subthreshold PEs, and results might be different if the whole spectrum of subthreshold psychosis was covered. In conclusion, these results showed that affective dysregulation co-occurring with PEs might be linked to higher impairment levels in line with numerous studies (Krabbendam et al. 2005;Krabbendam and van Os 2005; van Rossum et al. 2009; Salokangas et al. 2015).

The results in the fourth chapter demonstrated that co-occurrence of delusional and hallucinatory PEs was associated with a subsequent psychotic disorder (Kirli et al. 2019b). This result is in line with previous results (Krabbendam et al. 2004b;Smeets et al. 2010;Smeets et al. 2013;Smeets et al. 2015) and the baseline cross-sectional analysis of the TürkSch cohort, demonstrating associations between the degree of delusional and hallucinatory comorbidity of PEs and increased risk of the threshold psychotic disorder end of the extended psychosis phenotype (Binbay et al. 2011a). With these results, it can be suggested that comorbidity of symptoms within the same domain, as well as from different 
domains, is associated with poorer long term outcomes (Isvoranu et al. 2017; Isvoranu et al. 2019b).

Numerous studies reported graded associations between the severity of co-occurring common-nonpsychotic disorders and the severity of subthreshold PEs (DeVylder et al. 2014a;Guloksuz et al. 2015). The results in high risk samples were also in the same direction, as an important proportion of cases with transition consisted of individuals with affective dysregulation (Addington et al. 2007). Therefore, one of the most recent high risk for psychosis concepts (i.e. the Clinical High at Risk Mental State-CHARMS) have been updated to include affective dysregulation and some personality traits in addition to subthreshold PEs (Hartmann et al. 2019). Furthermore, a recent study reported that the population attributional fractions (PAF) for incident threshold psychotic disorders were higher for affective disorders than the high risk concepts (66.2 vs. 36.9) (Guloksuz et al. 2020). Although the high-risk concepts are associated with subsequent threshold psychotic disorders, the sensitivity of high risk concepts is relatively low due to the low prevalence in general populations (Schultze-Lutter et al. 2017). Therefore, the screening of positive PEs (and high risk concepts) may cause a high false negative rate with regard to the early expression of multidimensional psychopathology (Guloksuz and van Os 2017). A broader strategy taking the severity of several dimensions into account may represent a more sensitive and specific prevention strategy (van Os et al. 2019a).Results presented in chapter four of this thesis showed that a defined mental disorder in the family and persistence of subthreshold PEs were associated with a follow-up mental disorder in individuals with baseline PEs (Kirli et al. 2019b). These results are in line with the previous findings (Poulton et al. 2000; Yung et al. 2003;Dominguez et al. 2009; De Loore et al. 2011;Linscott and van Os 2013;Nelson et al. 2013;Fonseca Pedrero and Debbané 2017). Furthermore, younger age and family history of severe mental illness were associated with the follow-up psychotic disorders in comparison with the follow-up non-psychotic 
disorders (Kirli et al. 2019b). These variables also occasioned a disproportional shift in risk at the psychotic disorder end of the extended psychosis phenotype in the baseline cross-sectional analysis of the cohort (Binbay et al. 2011a). However, many sociodemographic factors did not significantly predict the follow-up psychotic disorders in comparison with the follow-up non-psychotic disorders in individuals with subthreshold PEs, also in line with the baseline cross-sectional analyses showing linear associations and no significant shift in risk across the extended psychosis phenotype (Binbay et al. 2011a). The dopamine and other neurobiological systems underlying different types of psychopathology may have the capacity to become sensitised over time (Boileau et al. 2006; van Os et al. 2009). Gradual exposure to risk might lead to gradual development from subthreshold psychosis to both common non-psychotic disorders and threshold psychotic disorders (Howes et al. 2020). Although many studies to date evaluated the risk factors associated with psychotic disorders, research on the determinants of the prospective outcomes of subthreshold PEs is limited, and further studies are needed.

\section{Assessment of pisk factors from a dymamic and dimensiomal perspective}

\section{BDNF and the Positive Spectrum of Psychosis}

The results presented in the fifth chapter of this thesis showed the association of a priori hypothesized single nucleotide polymorphism (SNP) (BDNF Val66Met) with the positive spectrum of psychosis covering subthreshold and threshold levels. The pattern of the association was that the SNP impacted in a dose-response but extra-linear fashion, with stronger impact at the threshold end. The associations were significant when adjusted for socio-demographics and common environmental exposures (Kirli et al. 2019a). 
BDNF plays a crucial role in dopaminergic signalling in the mesolimbic pathway (Hyman et al. 1991; Spencer et al. 1995). Dopamine neurons in the ventral tegmental area (VTA)-nucleus accumbens (NAc) pathway express substantial levels of BDNF protein, mRNA, and TrkB mRNA (the receptor of BDNF) (Hung and Lee 1996;Conner et al. 1997;Eisch et al. 2003). Altered dopamine signalling and dopamine-related behaviours were demonstrated as a result of BDNF infusion into to subcortical areas of adult rats (Altar et al. 1992;Altar et al. 1994;Siuciak et al. 1996). The Val allele of the BDNF Val66Met polymorphism has been associated with higher BDNF secretion in response to neuronal stimulation in comparison with the Met allele. Altered BDNF signalling in the VTA-NAc pathway, interacting with environmental factors, potently regulate dopaminergic signalling (Horger et al. 1999; Guillin et al. 2001;Nestler et al. 2002).

The aberrant salience theory refers to altered dopamine functioning in incentive salience of reward (Berridge and Robinson 1998; Radua et al. 2015; Howes et al. 2020). According to this theory, misattributions of thought, and blurred boundaries between internal and external experiences lead to expression of the positive domain of psychosis (Frith 1997;Buckner et al. 2008). Aforementioned effects of BDNF signalling on the mesolimbic dopaminergic pathway may impact on attribution of salience, mood and motivational states (Horger et al. 1999; Guillin et al. 2001; Nestler et al. 2002). It was proposed that increased BDNF activity in the mesolimbic (VTA-NAc) pathway has a "prolearning" effect (Eisch et al. 2003), which could then be associated with the positive domain of psychosis.

The increased activity of BDNF has been suggested in mania pathogenesis (Neves-Pereira et al. 2002;Tsai 2004), which has hypothesised neurobiological links with the positive domain (Kotov et al. 2020). In accordance, chronic administration of haloperidol in rats significantly decreased BDNF concentrations (Angelucci et al. 2000). The increased activity of BDNF has also been associated with increased anxiety-like traits in mice (Papa- 
leo et al. 2011). Finally, altered BDNF levels have been associated with the positive domain more consistently than the negative domain (Munkholm et al. 2015; Kotov et al. 2020;Lin and Huang 2020). However, further consistent replication is required before definitive conclusions can be drawn in this regard.

\section{Dimensional Genetic Risk Assessment in Psychosis}

Risk factors in psychosis are pluripotent in nature (McGorry et al. 2018).This pluripotency brings the need for a closer examination of individual symptom domains (van Os and Reininghaus 2016). Different symptoms of psychotic disorders, even taking part in the same disorder, might be associated with different biological pathways, thus with different genetic and environmental risk factors (van Winkel et al. 2008; Dominguez et al. 2010;Varese et al. 2012; Fried et al. 2013;Ruderfer et al. 2013;Isvoranu et al. 2017;Elliott et al. 2018;Baker et al. 2019). Therefore, individuals with psychosis considered in single categories in previous studies may actually have difference in associated risk factors. It was proposed that genetic risk might predominantly have an impact on the liability to develop the positive domain while environmental exposure might be predominantly related to symptoms of general psychopathology (Isvoranu et al. 2019a). These clues highlight the need for cross-disorder and dimensional assessments of genetic risk, particularly in the positive domain.

Threshold psychotic disorders are consistently associated with family history of psychotic disorders. Furthermore, these disorders are also associated with the family history of common non-psychotic disorders. A large register-based family history study showed interesting results on this topic. The family history of schizophrenia and related disorders accounted for a much lower population attributable risk of schizophrenia in comparison with the family history of mental disorders in general $(9.8 \%$ vs. 27.1) (Mortensen et al. 2010). Conversely, parental psychotic disorders were associated with both psychotic and non-psychotic disorders in the offspring (Dean et al. 2010;DeVylder and Lukens 
2013). These results clearly demonstrate the transdiagnostic nature of the genetic effects.

Similar to threshold psychotic disorders, the heritability of subthreshold psychosis was demonstrated using cross-twin analysis (Linney et al. 2003; Lataster et al. 2009a;Polanczyk et al. 2010;Zavos et al. 2014; Ronald 2015;Ronald and Pain 2018). A meta-analysis of general population-based studies reported that having a family history of mental illness was among the most important predictors of subthreshold psychosis. However, this meta-analysis did not report whether psychotic or common non-psychotic disorders contributed to the risk of PEs (Linscott and van Os 2013). There is consistent evidence from cross-twin and family history analysis linking the risk with the parental psychotic disorders (Lataster et al. 2009a;Polanczyk et al. 2010). Conversely, a family history of PEs was associated with the individuals' risk of psychotic disorders (van Os et al. 2003). Furthermore, there is preliminary evidence from family history studies linking the risk of PEs with non-psychotic family history. A general-population based birth cohort study reported that adolescents with a family history of a common mental disorder had 1.20 times higher risk of PEs, but this association was below the conventional significance level (Jeppesen et al. 2015). The baseline cross-sectional results of our cohort showed that the family history of common non-psychotic mental disorders was significantly associated with the different positions of the extended psychosis phenotype, including subthreshold psychosis (Binbay et al. 2012b). Results from other general-population based studies also showed significant associations between the risk of PEs and non-psychotic family history (Zammit et al. 2008; Wigman et al. 2012b;Zammit et al. 2013a).

Recent molecular genetic studies suggested modest SNP heritability $\left(\mathrm{SNP}-\mathrm{h}^{2}\right)$ for subthreshold psychosis $(3 \%-9 \%$ in adolescence, 20\%-27\% in adults) (Ortega-Alonso et al. 2017;Pain et al. 2018). A recent study using psychological network analysis between positive, negative, depressive symptoms showed that 
the polygenic risk score (PRS) for schizophrenia was directly connected to the spectrum of positive and depressive symptoms (Isvoranu et al. 2019a). Although recent studies showed significant associations between PRS for schizophrenia and the risk of PEs (Pain et al. 2018; Taylor et al. 2019), other studies did not (Potash et al. 2012;Zammit et al. 2013a;Potash et al. 2014;Jones et al. 2016; Ronald and Pain 2018). Another study showed an association only for those at higher than average risk such as relatives of patients (van Os et al. 2019b). The discrepancies in these results might be due to differences in phenotypes, in particular the severity of the phenotypes used (i.e. schizotypy, psychotic experiences and negative symptoms-PENS, PEs etc.), the sample sizes, the age range of the samples (adolescent or adults) and power of the versions of the PRS (van Os and Linscott 2012;van Os and Reininghaus 2016;Pries et al. 2019a). The largest GWAS with PEs to date showed significant genetic correlations with a wide range of disorders including psychotic disorders (schizophrenia), non-psychotic disorders (major depressive disorder, bipolar disorder, attention-deficit hyperactivity disorder), and neurodevelopmental disorders (Legge et al. 2019). Furthermore, two loci were genome-wide significant. Interestingly, the most significant gene (ANK3) was previously significant in the Psychiatric Genomics Consortium cross-disorder GWAS (Cross-Disorder Group of the Psychiatric Genomics Consortium 2013). This result is consistent with previous epidemiological results, as the PEs are strongly associated with a range of common non-psychotic mental disorders besides psychotic disorders (van Os et al. 1999; Verdoux et al. 1999;Hanssen et al. 2003; Stefanis et al. 2004;van Rossum et al. 2009; van Os and Linscott 2012;McGrath et al. 2016; Kirli et al. 2019b;Kirli et al. 2019c). In summary, there is emerging evidence from molecular genetic studies suggesting shared genetic influences along the extended and transdiagnostic psychosis phenotype.

Cross-twin and family history analyses consistently demonstrated the heritability of threshold psychotic disorders. However, few molecular genetic findings, if any, have been consistent (Par- 
diñas et al. 2018). One of the possible explanations why the molecular genetic studies have failed to generate replicated findings might be suboptimal phenotypes (Isvoranu et al. 2019a). The phenotypes used in previous case-control designs were embracing a polythetic approach, which might cause much heterogeneity from sample to sample. Actually, symptoms from different domains might have different genetic liabilities (Isvoranu et al. 2019a; Isvoranu et al. 2019b). Furthermore, phenotypes in most of the studies did not include subthreshold psychosis which may share genetic variations with threshold psychosis (van Os et al. 2003; Lataster et al. 2009a; Polanczyk et al. 2010; Binbay et al. 2012b). Including subthreshold psychosis could have increased power and precision. Additionally, the associations were not adjusted for socio-environmental factors. Finally, the phenotypes used in the majority of studies were not assessed longitudinally. Therefore, possible fluctuating manifestations might have been missed. Along with other methodological issues in the area (Sullivan 2008; Isvoranu et al. 2019a), a novel dynamic and dimensional perspective is needed. The phenotype used in the study presented in the fifth chapter of this thesis was dimensional including subthreshold phenotypes, and longitudinally evaluated. Furthermore, the socio-environmental factors were taken into account. Albeit several limitations discussed below, this design was able to meet some challenges of previous genetic studies in the area of psychosis, and might stimulate further studies with a dimensional perspective in the future (Kirli et al. 2019a).

The analysis of the association between the positive spectrum of psychosis and BDNF Val66Met SNP in the fifth chapter of this thesis has important limitations. BDNF did not give a significant signal in GWAS in schizophrenia (Schizophrenia Working Group of the Psychiatric Genomics Consortium 2014) and subthreshold PEs (Legge et al. 2019). However, previous GWAS in subthreshold PEs identified only two significantly associated loci (Legge et al. 2019). Many gene-gene interactions were previously reported for BDNF (Tsai 2018). The genetic analysis in this thesis included a priori hypothesized gene variations 
(BDNF), and lacking genome-wide associations, which is an important limitation while investigating genetic factors. Furthermore, while the positive spectrum of psychosis (including threshold and subthreshold levels) was significantly associated with BDNF Val66Met variation, the association with subthreshold PEs was close but below the conventional significance level (95\% Confidence Interval: 0.98-3.05). Probably this analysis suffered from the relatively small sample size in the nested case-control study. Because of these important limitations, this study should be considered as an explorative attempt which assesses a genetic variation for the positive spectrum of psychosis including subthreshold levels. In conclusion, the findings on BDNF warrant caution and need replication in larger samples with more comprehensive genetic analyses.

\section{Methodological issues}

The large and representative population-based sample, inclusion of subthreshold phenotypes in non-help seeking individuals, independent data collection at different time-points over six years and clinical re-interviews were the major strengths. Furthermore, parallel data collection on different phenomenology; sociodemographic, environmental, familial and genetic measures in a single sample brought some advantages to take a bigger part of the clinical picture of psychosis into account. However, the limitations of the study, introduced below, should be considered while interpreting the results.

A longitudinal design with a general population-based sample commonly brings the disadvantage of the possibility of bias caused by differential attrition over time. The TürkSch cohort was conducted in the third most populated city of Turkey, and one of the major cities in Europe (Binbay et al. 2011b;Turkish Statistical Institute 2019). As Turkey is a country with rapid migration, intra-city residency changes and urbanization for the last four decades (Guresci 2010;Binbay et al. 2011b;Ünal et al. 
2018; Turkish Statistical Institute 2019), this design required detailed preparation, education, supervision, monitoring and optimization of the use of resources. However, the dropout rate was similar to studies with a similar design (Dominguez et al. 2009;Zammit et al. 2013b), with satisfactory results on analysis of attrition, as described in detail in the second chapter of this thesis (Kirli et al. 2019d).

Evaluation of the full spectrum of psychosis in community-based populations, and particularly the subthreshold phenotypes, has methodological difficulties. The spectrum of psychosis may be conceptualized in various ways (Linscott and van Os 2013). There are lots of terms/definitions of subthreshold psychosis in the area: i.e. high risk, prodromal state, schizotypy, schizotaxia, psychotic experiences and negative symptoms (PENS), psychotic (like) experiences etc. Those terms indeed indicate different positions along the spectrum. Furthermore, phenomenological screening was conducted complemented by the frequency, associated distress, impairment and help-seeking (Binbay et al. 2011a;Binbay et al. 2011b). Then, these measures were also combined with DSM diagnoses as outcome variables (Kirli et al. 2019b). This type of consideration might lead to a degree of conceptual complexity. In order to be consistent, and for international comparisons of the results in the area, an international consortium on the operational definitions of the constructs pertaining to subthreshold psychosis is needed. Methodological uncertainties are still open with regard to defining and measuring psychosis expression (Nuevo et al. 2012; Linscott and van Os 2013).

Any screening tool may generate many false-positive and false-negative reports (van Os et al. 2009; Nuevo et al. 2012;Kelleher et al. 2018a). Although the sensitivity of lay-interviewer assessments is relatively high, the specificity may be scant. Therefore, confirmation of the lay-interviewer assessments is of high importance (Kline and Schiffman 2014). The two-stage screening procedure comprised of fully structured lay-interviewer assess- 
ments and clinician based-diagnoses in the field, and accessing multiple sources of information at both time points were the major advantages to overcome this issue. Furthermore, collecting data on admission to outpatient mental health services, lifetime use of psychotropic medication, lifetime diagnoses, and psychiatric hospitalisation probably helped to reduce the false-negative rates.

Detailed evaluation of environmental exposure is crucial in epidemiological research in order to make causality more plausible (van Os et al. 2010; Pries et al. 2019a). Although socio-environmental variables were measured at both time points, some limitations still exist. First, the childhood adversity assessments used in the analyses were predominantly capturing childhood neglect. However, different types of adversity may lead to different consequences as a recent study linked childhood emotional neglect to increased suspiciousness/persecutory ideas whereas the childhood sexual abuse to disorganized communication (Ered and Ellman 2019). Second, as childhood adversity was obtained retrospectively, these assessments may have suffered from the limitations of recall bias. Third, some of the socio-environmental measures were proxy variables, not the exposure per se (e.g. socioeconomic status). Furthermore, the impact of some environmental exposures on the longitudinal outcome of subthreshold PEs was not analysed in the present thesis (i.e. urbanicity, alcohol-substance use, individual social adversities, neighbourhood-level exposure variables etc.). However, additional data on these measures was obtained (detailed in the second chapter of this thesis). These data will be analysed in the near future.

Clinical re-interviews were not possible for the entire sample, as the households were placed around a $900 \mathrm{~km}^{2}$ of area including urban and rural wards (Binbay et al. 2011b;Turkish Statistical Institute 2019). The baseline clinical re-interviews were performed with a priority to recognize the threshold psychotic disorder cases among the psychosis spectrum. The follow-up cli- 
nician-based diagnoses were possible for a subgroup of individuals: (i). individuals with baseline clinically relevant subthreshold PEs; (ii). individuals with follow-up probable threshold psychotic disorder cases based on a systematic case assortment strategy (Kirli et al. 2019d). Lack of clinical re-interviews with the entire sample caused some limitations. First, the baseline co-occurrence of affective psychopathology with subthreshold PEs was based on lay-interviewer assessments. Hence, results on the incidence of common mental disorders associated with subthreshold PEs could not be obtained. Second, non-psychotic disorders at follow-up could not be compared between individuals who have baseline subthreshold PEs and who do not. Therefore, the non-psychotic disorder risk attributable to subthreshold PEs could not be analysed. Third, the analyses of subsequent psychotic disorders versus non-psychotic disorders covered only the baseline clinically relevant subthreshold PEs. Therefore, these results cannot be referred to the full spectrum of subthreshold psychosis. Furthermore, the low number of individuals with a subsequent threshold psychotic disorder caused low power in these analyses. Therefore, these results need to be replicated.

\section{Directions for future research}

To date, the majority of studies on phenomenology, risk factors as well as the neurobiological correlates of psychotic illness have focused on single syndromal states (Isvoranu et al. 2019b). However, it has been observed that these underlying factors do not comply well with existing mental disorders, but rather are associated with individual symptom domains across diagnostic categories (van Os and Reininghaus 2016;McGorry et al. 2018;Xia et al. 2018;Baker et al. 2019). Therefore, it is essential to identify dimensions of mental states in graded fashion in order to generate more accurate assumptions (Cuthbert and Insel 2013;van Os et al. 2019a; Beauchaine and Hinshaw 2020; Kotov et al. 2020). As stated earlier in this thesis, different domains of psychosis have different aspects in brain structure, neurotransmission, 
co-occurring psychopathology, and risk factors (van Winkel et al. 2008;Dominguez et al. 2010; Varese et al. 2012; Fried et al. 2013;Ruderfer et al. 2013; Corlett et al. 2016; Isvoranu et al. 2017;Elliott et al. 2018;Baker et al. 2019). There is an important need for further cross-disorder investigations to identify shared variables throughout the domains of psychosis and non-shared variables which may be specific to some disorder states (van Os and Reininghaus 2016;Walss-Bass et al. 2017; Quattrone et al. 2019a). These efforts may facilitate the attempts converging dimensional and categorical measures and definitions of cut-off points for dimensional measures in clinical decision making (Guloksuz et al. 2020; Kotov et al. 2020).

Substantial evidence demonstrating the relevance of subthreshold negative and disorganisation phenotypes on psychotic states is present (Bedwell et al. 2009; Cohen and Davis 2009;Dominguez et al. 2010; Fett and Maat 2011;Fonseca-Pedrero et al. 2011;DeVylder et al. 2014b;Korponay et al. 2014; Engel et al. 2015; Walss-Bass et al. 2015;Duman et al. 2017; Jones et al. 2017;Mekori-Domachevsky et al. 2017;Pelletier-Baldelli et al. 2017;Riehle and Lincoln 2017;Unterrassner et al. 2017;Acosta et al. 2019; Ered and Ellman 2019; Schultze-Lutter et al. 2019). Furthermore, baseline cross-sectional analyses of the TürkSch study showed the associations of the negative and disorganisation domains with the positive spectrum. The TürkSch study and literature studying similar research questions has generated substantial evidence for the graded fashion of the positive domain encompassing subclinical, clinically relevant subthreshold and threshold phenotypes across different disorders based on demographic variables, environmental risk factors, family traits, predictive power, neurobiological similarities and the associations with distress and functional impairment (van Os et al. 2009;Binbay et al. 2011a;American Psychiatric Association 2013; Linscott and van Os 2013;Unterrassner et al. 2017). Furthermore, evidence on the longitudinal bidirectional associations between the positive and the affective domain has been generated (McGrath et al. 2016; Kirli et al. 2019c;Plana-Ripoll et al. 2019). However, more research is 
necessary to generate evidence for a similar type of graded pattern for negative and disorganisation phenotypes in the community, as well as the associations with and between other dimensions. Data on these measures has been collected in the TürkSch study (detailed in the second chapter of this thesis), which are going to be analysed as a next step.

Although the prospective unidimensional assessments to capture the subsequent threshold psychotic disorders made important contributions to the area, these efforts did not generate specific and comprehensive results (van Os and Guloksuz 2017;McGorry et al. 2018;Guloksuz et al. 2020). The priority in the next years should be to understand the pathways from multidimensional liabilities of psychosis to specific forms of threshold disorder states (van Os 2013). The prospective evaluation of baseline subthreshold levels of dimensions in interaction with each other may generate essential findings (Kotov et al. 2017;Kotov et al. 2020). Studies have shown that exposure to risk factors leads to increasing interconnectivity across dimensions (Guloksuz et al. 2016; Pries et al. 2018). More research on this novel area is needed to evaluate how risk exposure impacts on the interconnectivity. Furthermore, the integration of neurodevelopmental alterations to dimensional measures (by early life epigenetic variations) would promisingly contribute to our understating of the gradual impairment (Pries et al. 2019b).

Associations between different dimensions of psychopathology may reflect the impact of various symptoms on each other in addition to shared etiological risk (Isvoranu et al. 2017; van den Heuvel and Sporns 2019;Taquet et al. 2020). Investigation of the longitudinal effects of symptoms on each other may enhance individual-based formulations as well as intervention strategies (van Os 2013; van Os et al. 2013). Despite the growing evidence, the symptom by symptom causal interactions are predominantly based on clinical observations. Further evidence is needed to identify which symptom domain commonly impacts on which, as well as the directions of the effects. 
To date, most of the studies suggestive for gene-environment interactions in psychosis (including the TürkSch study) have used proxy measures for genetic vulnerability such as family history of mental disorders or a priori hypothesized genetic variations (e.g. SNPs). Furthermore, these analyses were predominantly performed with single environmental measures. Recently, promising attempts were made to evaluate cumulative environmental risk based on the meta-analytical associations with psychosis (Padmanabhan et al. 2017;Pries et al. 2019a). As the additive impact of environmental exposures on the outcome of psychosis has been shown (Cougnard et al. 2007;Guloksuz et al. 2015;Pries et al. 2018), one of the future directions of TürkSch is to include "polyenvironmental risk score (PERS)" when analysing longitudinal data. The quality of the data enables to assess the associations with the threshold psychotic disorder outcome over time, as well as the associations with the extended psychosis phenotype. To further investigate the gene-environment interactions in psychosis, research in the upcoming period should focus on generating a graded measure of socio-environmental loading, interacting with stronger versions of PRS for psychosis, with dependent variables comprising dimensional measures (Pries et al. 2018).

Substantial evidence has demonstrated the impact of neighbourhood environment on various mental outcomes including the extended and transdiagnostic psychosis phenotype (Drukker and van Os 2003;Schneiders et al. 2003;Allardyce and Boydell 2006;Drukker et al. 2006;Drukker et al. 2007;Kirkbride et al. 2007; Keraite et al. 2016;O’Donoghue et al. 2016; Wilson et al. 2016; Narita et al. 2020b). The baseline cross-sectional analysis of the TürkSch study also showed that the impact of family history of severe mental illness on the extended psychosis phenotype was stronger in neighbourhoods with higher levels of socioeconomic disadvantage, and with higher levels of social control (Binbay et al. 2012a). Furthermore, recent studies proposed the perceived neighbourhood change as a contributing factor in psychosis expression (Hastings et al. 2019; Narita et al. 2020a). 
Further longitudinal studies are needed to examine the associations between neighbourhood change and psychosis expression in the community (Narita et al. 2020a). Additional data has been collected on these measures throughout the TürkSch study (detailed in the second chapter of this thesis). In the near future, the longitudinal associations between neighbourhood-contextual measures and the psychosis spectrum in the TürkSch data will be analysed.

To date, a remarkable number of studies have generated results on the odds of etiological factors and phenomenological states for particular psychotic states. However, for a community-based view of prevention, the population attributable fraction (PAF) is also important to comprehensively plan screening and intervention strategies. These measures in the current literature are somewhat scarce. Some recent studies started generating novel and important results on this issue (Di Forti et al. 2019;Guloksuz et al. 2020). As the TürkSch study prospectively evaluated risk factors in a representative-community based population, one of the future directions is to generate further findings on population attributable risk of clinical psychotic states.

Recent meta-analyses showed that early intervention in subthreshold psychosis might be beneficial in terms of treatment discontinuation and psychiatric hospitalization (van der Gaag et al. 2013;Correll et al. 2018). However, there are many open questions on how to intervene. As the current evidence for the available intervention methods is insufficient (Davies et al. 2018a;Davies et al. 2018b;Howes et al. 2020), further research to form evidence-based interventions in different dimensions of subthreshold psychopathology is necessary. Furthermore, some concerns are to be solved on the comprehensiveness of the early-intervention centre (van Os and Guloksuz 2017; Guloksuz et al. 2020).

In conclusion, the TürkSch study consisted of several multilevel data collection stages in a representative-community based 
population, and covered the full spectrum of psychosis including subclinical, subthreshold and threshold phenotypes. Therefore, the TürkSch study provided a comprehensive data set on the multidimensional nature of the extended and transdiagnostic psychosis phenotype. Through the analyses in the present thesis as well as the analyses which will be conducted in the future, the study may shed light to several etiological and phenomenological aspects of psychosis in the community. Future assessments of the cohort, with more comprehensive genetic analysis and broader clinical interviews, may answer some open questions on gene-environment interactions in psychosis, may provide important clues to improve screening strategies, and may further generate evidence for the socio-environmental factors that adversely affect public mental health. 


\section{References}

- Acosta H, Straube B , Kircher T (2019). Schizotypy and mentalizing: An fMRI study. Neuropsychologia 124, 299-310.

- Addington J , Addington D (2007). Patterns, predictors and impact of substance use in early psychosis: a longitudinal study. Acta psychiatrica Scandinavica 115, 304-309.

- Addington J, Cadenhead KS, Cannon TD, et al. (2007). North American Prodrome Longitudinal Study: A Collaborative Multisite Approach to Prodromal Schizophrenia Research. Schizophrenia bulletin 33, 665-672.

- Addington J, Cornblatt BA, Cadenhead KS, et al. (2011). At Clinical High Risk for Psychosis: Outcome for Nonconverters. American Journal of Psychiatry 168, 800-805.

- Allardyce J , Boydell J (2006). Review: the wider social environment and schizophrenia. Schizophre-

nia Bulletin 32, 592-598.

- Alptekin K, Ulas H, Akdede BB, Tümüklü M , Akvardar $Y$ (2009). Prevalence and risk factors of psychotic symptoms: in the city of Izmir, Turkey. Social psychiatry and psychiatric epidemiology 44, 905-910.

- Altar CA, Boylan CB, Fritsche M, Jackson C, Hyman C , Lindsay RM (1994). The Neurotrophins NT-4/5 and BDNF Augment Serotonin, Dopamine, and GABAergic Systems during Behaviorally Effective Infusions to the Substantia Nigra. Experimental Neurology 130, 31-40.

- Altar CA, Boylan CB, Jackson C, et al. (1992). Brain-derived neurotrophic factor augments rotational behavior and nigrostriatal dopamine turnover in vivo. Proceedings of the National Academy of Sciences 89, 11347-11351.

- American Psychiatric Association (1987). Diagnostic and statistical manual 
of mental disorders, -3rd edition-revised: DSM-III-R. American Psychiatric Association: Washington, DC.

- American Psychiatric Association (2013). Diagnostic and statistical manual of mental disorders, - 5th edition: DSM-5. American Psychiatric Association: Washington, DC.

- Angelucci F, Mathe AA , Aloe L (2000). Brain-derived neurotrophic factor and tyrosine kinase receptor TrkB in rat brain are significantly altered after haloperidol and risperidone administration. Journal of Neuroscience Research 60, 783-794.

- Anttila V, Bulik-Sullivan B, Finucane HK, et al. (2018). Analysis of shared heritability in common disorders of the brain. Science 360, eaap8757.

- Baker JT, Dillon DG, Patrick LM, et al. (2019).

Functional connectomics of affective and psychotic pathology. Proceedings of the National Academy of Sciences 116, 9050-9059.
- Beauchaine TP, Hinshaw SP (2020). RDoC and Psychopathology among Youth: Misplaced Assumptions and an Agenda for Future Research. Journal of Clinical Child \& Adolescent Psychology 49, 322-340.

- Beauchamp G, Gagnon A (2004). Influence of diagnostic classification on gender ratio in schizophrenia. Social psychiatry and psychiatric epidemiology 39, 1017-1022.

- Bedwell JS, Kamath V , Compton MT (2009). The relationship between interview-based schizotypal personality dimension scores and the continuous performance test. Schizophrenia Research 108, 158-162.

- Berridge KC, Robinson TE (1998). What is the role of dopamine in reward: hedonic impact, reward learning, or incentive salience? Brain Research Reviews 28, 309-369.

- Bijl RV, Ravelli A, van Zessen G (1998). Prevalence of psychiatric disorder in the general population: 
results of the Netherlands Mental Health Survey and Incidence Study (NEMESIS). Social psychiatry and psychiatric epidemiology 33, 587-595.

- Binbay T, Drukker M, Alptekin K, et al. (2012a). Evidence that the wider social environment moderates the association between familial liability and psychosis spectrum outcome. Psychological Medicine 42, 2499-2510.

- Binbay T, Drukker M, Elbi $\mathrm{H}$, et al. (2011a). Testing the Psychosis Continuum: Differential Impact of Genetic and Nongenetic Risk Factors and Comorbid Psychopathology Across the Entire Spectrum of Psychosis. Schizophrenia Bulletin 38, 992-1002.

- Binbay T, Drukker M, Elbi $\mathrm{H}$, et al. (2012b). Testing the psychosis continuum: differential impact of genetic and nongenetic risk factors and comorbid psychopathology across the entire spectrum of psychosis. Schizophrenia bulletin 38,
992-1002.

- Binbay T, Elbi H, Alptekin K, et al. (2011b). Izmir Mental Health Survey for Gene-Environment in Psychoses (TurkSch): Objectives and Methodology. Turkish Journal of Psychiatry.

- Boileau I, Dagher A, Leyton M, et al. (2006). Modeling Sensitization to Stimulants in Humans. Archives of general psychiatry 63.

- Bora E, Yucel M , Pantelis C (2018). Cognitive functioning in schizophrenia, schizoaffective disorder and affective psychoses: meta-analytic study. British Journal of Psychiatry 195, 475-482.

- Botvinik-Nezer R, Holzmeister F, Camerer CF, et al. (2020). Variability in the analysis of a single neuroimaging dataset by many teams. Nature 582, 84-88.

- Bradley B, DeFife JA, Guarnaccia C, et al. (2011). Emotion Dysregulation and Negative Affect. The Journal of clinical psychiatry 72, 685-691. 
- Buckley PF, Miller BJ, Lehrer DS , Castle DJ (2008). Psychiatric Comorbidities and Schizophrenia. Schizophrenia Bulletin 35, 383402.

- Buckner RL, Andrews-Hanna JR, Schacter DL (2008). The Brain's Default Network. Annals of the New York Academy of Sciences 1124, 1-38.

- Burdick KE, Russo M, Frangou S, et al. (2014). Empirical evidence for discrete neurocognitive subgroups in bipolar disorder: clinical implications. Psychological Medicine 44, 3083-3096.

- Cardno AG, Rijsdijk FV, Sham PC, Murray RM, McGuffin P (2002). A Twin Study of Genetic Relationships Between Psychotic Symptoms. American Journal of Psychiatry 159, 539545.

- Carpenter WT, Bustillo JR, Thaker GK, van Os J, Krueger RF , Green MJ (2009). The psychoses: Cluster 3 of the proposed meta-structure for DSM-V and ICD-11. Psychological Medicine 39, 2025-2042.

- Castle DJ, Wessely S , Murray RM (2018). Sex and Schizophrenia: Effects of Diagnostic Stringency, and Associations with Premorbid Variables. British Journal of Psychiatry 162, 658-664.

- Cederlöf M, Östberg P, Pettersson E, et al. (2013). Language and mathematical problems as precursors of psychotic-like experiences and juvenile mania symptoms. Psychological Medicine 44, 12931302 .

- Chan CT, Abdin E, Subramaniam M, Tay SA, Lim LK, Verma S (2019). TwoYear Clinical and Functional Outcomes of an Asian Cohort at Ultra-High Risk of Psychosis. Frontiers in psychiatry 9.

- Chen C, Cheng L, Grennan $\mathrm{K}$, et al. (2012). Two gene co-expression modules differentiate psychotics and controls. Molecular psychiatry 18, 1308-1314. 
- Chou IJ, Kuo C-F, Huang Y-S, et al. (2017). Familial Aggregation and Heritability of Schizophrenia and Co-aggregation of Psychiatric Illnesses in Affected Families. Schizophrenia bulletin 43, 1070-1078.

- Cohen AS, Davis TE (2009). Quality of life across the schizotypy spectrum: findings from a large nonclinical adult sample. Comprehensive Psychiatry 50, 408-414.

- Conner JM, Lauterborn JC, Yan Q, Gall CM , Varon $\mathrm{S}$ (1997). Distribution of Brain-Derived Neurotrophic Factor (BDNF) Protein and mRNA in the Normal Adult Rat CNS: Evidence for Anterograde Axonal Transport. The Journal of Neuroscience 17, 2295-2313.

- Corlett PR, Honey GD , Fletcher PC (2016). Prediction error, ketamine and psychosis: An updated model. Journal of Psychopharmacology 30, 1145 1155.

- Correll CU, Galling B, Pawar A, et al. (2018). Com- parison of Early Intervention Services vs Treatment as Usual for Early-Phase Psychosis. JAMA Psychiatry 75, 555.

- Cougnard A, Marcelis M, Myin-Germeys I, et al. (2007). Does normal developmental expression of psychosis combine with environmental risk to cause persistence of psychosis? A psychosis proneness-persistence model. Psychological Medicine 37, 513.

- Cross-Disorder Group of the Psychiatric Genomics Consortium (2013). Identification of risk loci with shared effects on five major psychiatric disorders: a genome-wide analysis. The Lancet 381, 1371-1379.

- Cross-Disorder Group of the Psychiatric Genomics Consortium (2019). Genomic Relationships, Novel Loci, and Pleiotropic Mechanisms across Eight Psychiatric Disorders. Cell 179, 14691482 e 1411 .

- Cuthbert BN, Insel TR (2013). Toward the future of psychiatric diagnosis: the 
seven pillars of RDoC. BMC Medicine 11.

- Davies C, Cipriani A, Ioannidis JPA, et al. (2018a). Lack of evidence to favor specific preventive interventions in psychosis: a network meta-analysis. World Psychiatry 17, 196-209.

- Davies C, Radua J, Cipriani A, et al. (2018b). Efficacy and Acceptability of Interventions for Attenuated Positive Psychotic Symptoms in Individuals at Clinical High Risk of Psychosis: A Network Meta-Analysis. Frontiers in psychiatry 9.

- de Graaf R, van Dorsselaer $\mathrm{S}$, Tuithof $\mathrm{M}$, ten Have $\mathrm{M}$ (2013). Sociodemographic and psychiatric predictors of attrition in a prospective psychiatric epidemiological study among the general population. Result of the Netherlands Mental Health Survey and Incidence Study-2. Comprehensive psychiatry 54, 1131-1139.

- de Jonge P, Wardenaar KJ, Lim CCW, et al. (2017). The cross-national structure of mental disorders: results from the World Mental Health Surveys. Psychological Medicine 48, 2073-2084.

- De Loore E, Gunther N, Drukker M, et al. (2011). Persistence and outcome of auditory hallucinations in adolescence: A longitudinal general population study of 1800 individuals. Schizophrenia research 127 , 252-256.

- Dean K, Stevens H, Mortensen PB, Murray RM, Walsh E, Pedersen CB (2010). Full spectrum of psychiatric outcomes among offspring with parental history of mental disorder. Archives of General Psychiatry 67, 822-829.

- Degenhardt L, Tennant C, Gilmour S, et al. (2007). The temporal dynamics of relationships between cannabis, psychosis and depression among young adults with psychotic disorders: findings from a 10-month prospective study. Psychological Medicine 37, 927-934.

- Dereboy F (2000). Şizofreniye İlişkin Psikanalitik 
Yaklaşımlar (Psychanalytical Approach to Schizophrenia). Şizofreni Dizisi 3, 11-19.

- DeVylder JE, Burnette D , Yang LH (2014a). Co-occurrence of psychotic experiences and common mental health conditions across four racially and ethnically diverse population samples. Psychological Medicine 44, 3503-3513.

- DeVylder JE, Lukens EP (2013). Family history of schizophrenia as a risk factor for axis I psychiatric conditions. Journal of psychiatric research 47, 181-187.

- DeVylder JE, Muchomba FM, Gill KE, et al. (2014b). Symptom trajectories and psychosis onset in a clinical high-risk cohort: The relevance of subthreshold thought disorder. Schizophrenia Research 159, 278-283.

- Di Forti M, Quattrone D, Freeman TP, et al. (2019). The contribution of cannabis use to variation in the incidence of psychotic disorder across Europe (EU-GEI): a multicentre case-control study. The Lancet Psychiatry 6, 427-436.
- Dominguez M-d-G, Saka MC, Lieb R, Wittchen H-U, van Os J (2010). Early Expression of Negative/Disorganized Symptoms Predicting Psychotic Experiences and Subsequent Clinical Psychosis: A 10-Year Study. American Journal of Psychiatry 167, 1075-1082.

- Dominguez MDG, Wichers M, Lieb R, Wittchen HU, van Os $\mathrm{J}$ (2009). Evidence That Onset of Clinical Psychosis Is an Outcome of Progressively More Persistent Subclinical Psychotic Experiences: An 8-Year Cohort Study. Schizophrenia bulletin 37, 84-93.

- Drukker M, Gunther N, van Os J (2007). Disentangling associations between poverty at various levels of aggregation and mental health. Epidemiologia e psichiatria sociale 16, 3-9.

- Drukker M, Krabbendam L, Driessen G , van Os J (2006). Social disadvantage and schizophrenia. Social Psychiatry and Psychiatric Epidemiology 41, 595-604.

- Drukker M , van Os J (2003). Mediators of neighbourhood 
socioeconomic deprivation and quality of life. Social psychiatry and psychiatric epidemiology 38, 698-706.

- Duhig M, Patterson S, Connell M, et al. (2015). The prevalence and correlates of childhood trauma in patients with early psychosis. Australian \& New Zealand Journal of Psychiatry 49, 651-659.

- Duman B, Sedes N, Baskak B (2017). Additive Effects of Former Methylenedioxymethamphetamine and Cannabis Use on Subclinical Psychotic Symptoms. Noro psikiyatri arsivi 54, 38-42.

- Eisch AJ, Bolaños CA, de Wit J, et al. (2003). Brain-derived neurotrophic factor in the ventral midbrain-nucleus accumbens pathway: a role in depression. Biological psychiatry 54, 994-1005.

- Elliott ML, Knodt AR, Ireland D, et al. (2020). What Is the Test-Retest Reliability of Common Task-Functional MRI Measures? New Empirical Evidence and a
Meta-Analysis. Psychological Science 31, 792-806.

- Elliott ML, Romer A, Knodt AR , Hariri AR (2018). A Connectome-wide Functional Signature of Transdiagnostic Risk for Mental Illness. Biological psychiatry 84, 452-459.

- Engel M, Fritzsche A, Lincoln TM (2015). Subclinical negative symptoms and the anticipation, experience and recall of emotions related to social interactions: An experimental study. Psychiatry research 230, 350-356.

- Ered A , Ellman LM (2019). Specificity of Childhood Trauma Type and Attenuated Positive Symptoms in a Non-Clinical Sample. Journal of Clinical Medicine 8, 1537.

- Fett AKJ, Maat A (2011). Social Cognitive Impairments and Psychotic Symptoms: What Is the Nature of Their Association? Schizophrenia Bulletin 39, 77-85.

- Fisher HL, Caspi A, Poulton $\mathrm{R}$, et al. (2013). Specificity of childhood psychotic symptoms for predicting 
schizophrenia by 38 years of age: a birth cohort study. Psychological medicine 43, 2077-2086.

- Fisher HL, Schreier A, Zammit S, et al. (2012). Pathways Between Childhood Victimization and Psychosis-like Symptoms in the ALSPAC Birth Cohort. Schizophrenia bulletin 39, 1045-1055.

- Fonseca-Pedrero E, Paino M, Lemos-Giráldez S , Muñiz J (2011). Schizotypal traits and depressive symptoms in nonclinical adolescents. Comprehensive Psychiatry 52, 293300.

- Fonseca Pedrero E, Debbané M (2017). Schizotypal traits and psychotic-like experiences during adolescence: An update. Psicothema 29, 5-17.

- Foti DJ, Kotov R, Guey LT , Bromet EJ (2010). Cannabis Use and the Course of Schizophrenia: 10-Year Follow-Up After First Hospitalization. American Journal of Psychiatry 167, 987-993.
- Freud S (1924). Neurosis and psychosis. Hogarth Press: London.

- Fried EI, Nesse RM, Zivin K, Guille C, Sen S (2013). Depression is more than the sum score of its parts: individual DSM symptoms have different risk factors. Psychological medicine 44, 2067-2076.

- Frith C (1997). The role of the prefrontal cortex in self-consciousness: the case of auditory hallucinations. Philosophical Transactions of the Royal Society of London. Series B: Biological Sciences 351, 15051512.

- Fusar-Poli P, Cappucciati M, Borgwardt S, et al. (2016). Heterogeneity of Psychosis Risk Within Individuals at Clinical High Risk: A Meta-analytical Stratification. JAMA Psychiatry 73, 113-120.

- Fusar-Poli P, Nelson B, Valmaggia L, Yung AR , McGuire PK (2014). Comorbid depressive and anxiety disorders in 509 individuals with an at-risk mental 
state: impact on psychopathology and transition to psychosis. Schizophr Bull 40, 120-131.

- Gevonden MJ, Myin-Germeys I, van den Brink W, van Os J, Selten JP , Booij J (2014). Psychotic reactions to daily life stress and dopamine function in people with severe hearing impairment. Psychological Medicine 45, 1665-1674.

- Goldsmith DR, Rapaport MH , Miller BJ (2016). A meta-analysis of blood cytokine network alterations in psychiatric patients: comparisons between schizophrenia, bipolar disorder and depression. Molecular psychiatry 21, 1696-1709.

- Guillin O, Diaz J, Carroll P, Griffon N, Schwartz J-C , Sokoloff P (2001). BDNF controls dopamine D3 receptor expression and triggers behavioural sensitization. Nature 411, 86-89.

- Guloksuz S, Pries LK, Have M, et al. (2020). Association of preceding psychosis risk states and non-psychotic mental disorders with inci- dence of clinical psychosis in the general population: a prospective study in the NEMESIS-2 cohort. World Psychiatry 19, 199-205.

- Guloksuz S, van Nierop M, Bak M, et al. (2016). Exposure to environmental factors increases connectivity between symptom domains in the psychopathology network. BMC psychiatry 16.

- Guloksuz S, van Nierop M, Lieb R, van Winkel R, Wittchen $\mathrm{HU}$, van Os J (2015). Evidence that the presence of psychosis in non-psychotic disorder is environment-dependent and mediated by severity of non-psychotic psychopathology. Psychological Medicine 45, 2389-2401.

- Guloksuz S, van Os J (2017). The slow death of the concept of schizophrenia and the painful birth of the psychosis spectrum. Psychological medicine 48, 229-244.

- Guresci E (2010). The phenomenon of the urban rural migration in Turkey. Journal of Dogus University 11, 77-86. 
- Häfner H, Maurer K, Trendler G, an der Heiden W, Schmidt M , Könnecke R (2005). Schizophrenia and depression: Challenging the paradigm of two separate diseases-A controlled study of schizophrenia, depression and healthy controls. Schizophrenia research 77, 11-24.

- Hanssen M, Bak M, Bijl R, Vollebergh W, Os J (2005). The incidence and outcome of subclinical psychotic experiences in the general population. British Journal of Clinical Psychology 44, 181-191.

- Hanssen M, Peeters F, Krabbendam L, Radstake $\mathrm{S}$, Verdoux H, van Os J (2003). How psychotic are individuals with non-psychotic disorders? Social Psychiatry and Psychiatric Epidemiology 38, 149-154.

- Hartmann JA, Nelson B, Spooner R, et al. (2019). Broad clinical high-risk mental state (CHARMS): Methodology of a cohort study validating criteria for pluripotent risk. Early Intervention in Psychiatry 13, 379-386.
- Hastings PD, Serbin LA, Bukowski W, et al. (2019). Predicting psychosis-spectrum diagnoses in adulthood from social behaviors and neighborhood contexts in childhood. Development and psychopathology, 1-15.

- Hazlett EA, Rothstein EG, Ferreira R, Silverman JM, Siever LJ , Olincy A (2015). Sensory gating disturbances in the spectrum: Similarities and differences in schizotypal personality disorder and schizophrenia. Schizophrenia research 161, 283-290.

- Healy C, Brannigan R, Dooley N, et al. (2019). Childhood and adolescent psychotic experiences and risk of mental disorder: a systematic review and meta-analysis. Psychological medicine 49, 1589-1599.

- Heinz A, Deserno L, Reininghaus U (2013). Urbanicity, social adversity and psychosis. World Psychiatry 12, 187-197.

- Hermens DF, Chitty KM , Kaur M (2018). Mismatch negativity in bipolar disor- 
der: A neurophysiological biomarker of intermediate effect? Schizophrenia research 191, 132-139.

- Horger BA, Iyasere CA, Berhow MT, Messer CJ, Nestler EJ , Taylor JR (1999). Enhancement of Locomotor Activity and Conditioned Reward to Cocaine by Brain-Derived Neurotrophic Factor. The Journal of Neuroscience 19, 4110-4122.

- Howes OD, Hird EJ, Adams RA, Corlett PR , McGuire P (2020). Aberrant Salience, Information Processing, and Dopaminergic Signaling in People at Clinical High Risk for Psychosis. Biological psychiatry.

- Hung H-C, Lee EHY (1996). The mesolimbic dopaminergic pathway is more resistant than the nigrostriatal dopaminergic pathway to MPTP and MPP+ toxicity: role of BDNF gene expression. Molecular Brain Research 41, 16-26.

- Hyman C, Hofer M, Barde $\mathrm{Y}-\mathrm{A}$, et al. (1991). BDNF is a neurotrophic factor for dopaminergic neurons of the substantia nigra. Nature 350, 230-232.

- Ioannidis JP (2005). Why most published research findings are false. PLoS Med 2, e124.

- Ioannidis JPA (2011). Excess Significance Bias in the Literature on Brain Volume Abnormalities. Archives of general psychiatry 68, 773 .

- Isvoranu A-M, Guloksuz S, Epskamp S, van Os J , Borsboom D (2019a). Toward incorporating genetic risk scores into symptom networks of psychosis. Psychological medicine, 1-8.

- Isvoranu A-M, van Borkulo $\mathrm{CD}$, Boyette L-L, Wigman JTW, Vinkers CH, Borsboom D (2017). A Network Approach to Psychosis: Pathways Between Childhood Trauma and Psychotic Symptoms. Schizophrenia Bulletin 43, 187-196.

- Isvoranu AM, Boyette LL, Guloksuz S , Borsboom D (2019b). Symptom network models of psychosis. In Psychotic Disorders: Compre- 
hensive Conceptualization and Treatments (ed. J. van Os, U. Reininghaus, E. I. Ivleva and C. A. Tamminga). Oxford University Press: Oxford.

- Javitt DC, Lee M, Kantrowitz JT, Martinez A (2018). Mismatch negativity as a biomarker of theta band oscillatory dysfunction in schizophrenia. Schizophrenia research 191, 51-60.

- Jeppesen P, Larsen JT, Clemmensen L, et al. (2015). The CCC2000 Birth Cohort Study of Register-Based Family History of Mental Disorders and Psychotic Experiences in Offspring. Schizophrenia Bulletin 41, 1084-1094.

- Jones HJ, Stergiakouli E, Tansey KE, et al. (2016). Phenotypic Manifestation of Genetic Risk for Schizophrenia During Adolescence in the General Population. JAMA psychiatry 73, 221.

- Jones JD, Calkins ME, Scott JC, Bach EC, Gur RE (2017). Cannabis Use, Polysubstance Use, and Psychosis Spectrum
Symptoms in a Community-Based Sample of U.S. Youth. Journal of Adolescent Health 60, 653-659.

- Kafali HY, Bildik T, Bora E, Yuncu Z, Erermis HS (2019). Distinguishing prodromal stage of bipolar disorder and early onset schizophrenia spectrum disorders during adolescence. Psychiatry research 275, 315-325.

- Kaymaz N, Drukker M, Lieb R, et al. (2012). Do subthreshold psychotic experiences predict clinical outcomes in unselected non-help-seeking population-based samples? A systematic review and meta-analysis, enriched with new results. Psychological Medicine 42, 2239-2253.

- Kaymaz N, van Os J, de Graaf R, ten Have M, Nolen W, Krabbendam L (2007). The impact of subclinical psychosis on the transition from subclinicial mania to bipolar disorder. Journal of affective disorders 98, 55-64.

- Kebede D, Alem A (1999). Major mental disorders in 
Addis Ababa, Ethiopia. II. Affective disorders. Acta psychiatrica Scandinavica 100, 18-23.

- Kelleher I, Devlin N, Wigman JTW, et al. (2013). Psychotic experiences in a mental health clinic sample: implications for suicidality, multimorbidity and functioning. Psychological Medicine 44, 1615-1624.

- Kelleher I, Jenner JA, Cannon M (2018a). Psychotic symptoms in the general population - an evolutionary perspective. British Journal of Psychiatry 197, 167-169.

- Kelleher I, Keeley H, Corcoran P, et al. (2018b). Clinicopathological significance of psychotic experiences in non-psychotic young people: evidence from four population-based studies. British Journal of Psychiatry 201, 26-32.

- Kelleher I, Murtagh A, Molloy C, et al. (2011). Identification and Characterization of Prodromal Risk Syndromes in Young Adolescents in the Commu- nity: A Population-Based Clinical Interview Study. Schizophrenia bulletin 38, 239-246.

- Kendler KS (2020). The Development of Kraepelin's Concept of Dementia Praecox. JAMA Psychiatry.

- Keraite A, Sumathipala A, Siriwardhana C, Morgan C, Reininghaus U (2016). Exposure to conflict and disaster: A national survey on the prevalence of psychotic experiences in Sri Lanka. Schizophrenia research 171 , 79-85.

- Kirkbride JB, Morgan C, Fearon P, Dazzan P, Murray RM , Jones PB (2007). Neighbourhood-level effects on psychoses: re-examining the role of context. Psychological medicine 37, 14131425.

- Kirli U, Binbay T, Drukker M, et al. (2019a). Is BDNF-Val66Met polymorphism associated with psychotic experiences and psychotic disorder outcome? Evidence from a 6 years prospective population-based cohort study. American journal of 
medical genetics. Part B, Neuropsychiatric genetics : the official publication of the International Society of Psychiatric Genetics 180, 113-121.

- Kirli U, Binbay T, Drukker M, et al. (2019b). DSM outcomes of psychotic experiences and associated risk factors: 6-year follow-up study in a community-based sample. Psychological Medicine 49, 1346-1356.

- Kirli U, Binbay T, Drukker $\mathrm{M}$, et al. (2019c). Psychotic experiences and mood episodes predict each other bidirectionally: a 6-year follow-up study in a community-based population. Social psychiatry and psychiatric epidemiology 54 , 331-341.

- Kirli U, Binbay T, Elbi H, et al. (2019d). Izmir Mental Health Cohort for Gene-Environment Interaction in Psychosis (TürkSch): Assessment of the Extended and Transdiagnostic Psychosis Phenotype and Analysis of Attrition in a 6-Year
Follow-Up of a Community-Based Sample. Frontiers in psychiatry 10, 554.

- Kline E, Schiffman J (2014). Psychosis risk screening: A systematic review. Schizophrenia research 158, 11-18.

- Klosterkötter J, Ebel H, Schultze-Lutter F, Steinmeyer EM (1996). Diagnostic validity of basic symptoms. European Archives of Psychiatry and Clinical Neuroscience 246, 147-154.

- Korponay C, Nitzburg GC, Malhotra AK, DeRosse P (2014). Positive and negative subclinical symptoms and MCCB performance in non-psychiatric controls. Schizophrenia Research: Cognition 1, 175-179.

- Kotov R, Jonas KG, Carpenter WT, et al. (2020). Validity and utility of Hierarchical Taxonomy of Psychopathology (HiTOP): I. Psychosis superspectrum. World Psychiatry 19, 151172.

- Kotov R, Krueger RF, Watson D, et al. (2017). The Hierar- 
chical Taxonomy of Psychopathology (HiTOP): A dimensional alternative to traditional nosologies. Journal of abnormal psychology 126, 454-477.

- Krabbendam L, Myin-Germeys I, De Graaf R, et al. (2004a). Dimensions of depression, mania and psychosis in the general population. Psychological Medicine 34, 1177-1186.

- Krabbendam L, Myin-Germeys I, Hanssen M, et al. (2004b). Hallucinatory experiences and onset of psychotic disorder: evidence that the risk is mediated by delusion formation. Acta psychiatrica Scandinavica 110, 264-272.

- Krabbendam L, Myin-Germeys I, Hanssen M, et al. (2005). Development of depressed mood predicts onset of psychotic disorder in individuals who report hallucinatory experiences. British Journal of Clinical Psychology 44, 113-125.

- Krabbendam L, van Os J (2005). Affective processes in the onset and persistence of psychosis. Euro- pean Archives of Psychiatry and Clinical Neuroscience 255, 185-189.

- Kraepelin E (1899). Zur Diagnose und Prognose der Dementia praecox. In Allgemeine Zeitschrift für Psychiatrie, pp. 254-264.

- Kuepper R, van Os J, Lieb $\mathrm{R}$, Wittchen HU, Hofler M , Henquet C (2011). Continued cannabis use and risk of incidence and persistence of psychotic symptoms: 10 year follow-up cohort study. Bmj 342, d738-d738.

- Lataster T, Myin-Germeys I, Derom C, Thiery E, van Os J (2009a). Evidence that self-reported psychotic experiences represent the transitory developmental expression of genetic liability to psychosis in the general population. American Journal of Medical Genetics Part B: Neuropsychiatric Genetics 150B, 1078-1084.

- Lataster T, Wichers M, Jacobs N, et al. (2009b). Does reactivity to stress cosegregate with subclinical psychosis? A general 
population twin study. Acta psychiatrica Scandinavica 119, 45-53.

- Legge SE, Jones HJ, Kendall KM, et al. (2019). Association of Genetic Liability to Psychotic Experiences With Neuropsychotic Disorders and Traits. JAMA Psychiatry 76, 1256.

- Lichtenstein P, Yip BH, Björk C, et al. (2009). Common genetic determinants of schizophrenia and bipolar disorder in Swedish families: a population-based study. The Lancet 373, 234-239.

- Lin A, Wood SJ, Nelson B, Beavan A, McGorry P , Yung AR (2015). Outcomes of Nontransitioned Cases in a Sample at Ultra-High Risk for Psychosis. American Journal of Psychiatry 172, 249-258.

- Lin C-C , Huang T-L (2020). Brain-derived neurotrophic factor and mental disorders. Biomedical Journal 43, 134142.

- Linney YM, Murray RM, Peters ER, MacDonald AM, Ri- jsdijk F , Sham PC (2003). A quantitative genetic analysis of schizotypal personality traits. Psychological Medicine 33, 803-816.

- Linscott RJ , van Os J (2013). An updated and conservative systematic review and meta-analysis of epidemiological evidence on psychotic experiences in children and adults: on the pathway from proneness to persistence to dimensional expression across mental disorders. Psychological medicine 43, 1133-1149.

- Lunde KB, Mehlum L, Melle I , Qin P (2020). Deliberate self-harm and associated risk factors in young adults: the importance of education attainment and sick leave. Social psychiatry and psychiatric epidemiology.

- Mancuso SG, Morgan VA, Mitchell PB, Berk M, Young A, Castle DJ (2015). A comparison of schizophrenia, schizoaffective disorder, and bipolar disorder: Results from the Second Australian national psycho- 
sis survey. Journal of affective disorders 172, 30-37.

- Marconi A, Di Forti M, Lewis CM, Murray RM, Vassos E (2016). Meta-analysis of the Association Between the Level of Cannabis Use and Risk of Psychosis.

Schizophrenia bulletin 42, 1262-1269.

- Martin J, Taylor MJ , Lichtenstein P (2017). Assessing the evidence for shared genetic risks across psychiatric disorders and traits. Psychological Medicine 48, 1759-1774.

- Matheson SL, Shepherd AM, Pinchbeck RM, Laurens KR, Carr VJ (2012). Childhood adversity in schizophrenia: a systematic meta-analysis. Psychological Medicine 43, 225-238.

- McGorry PD, Hartmann JA, Spooner R, Nelson B (2018). Beyond the "at risk mental state" concept: transitioning to transdiagnostic psychiatry. World Psychiatry 17, 133-142.

- McGorry PD, Mei C (2018). Ultra-high-risk paradigm: lessons learnt and new directions. Evidence Based Mental Health 21, 131-133.

- McGrath JJ, Saha S, Al-Hamzawi A, et al. (2016). The Bidirectional Associations Between Psychotic Experiences and DSM-IV Mental Disorders. American Journal of Psychiatry 173, 997-1006.

- McMillan KA, Enns MW, Cox BJ , Sareen J (2009). Comorbidity of Axis I and II Mental Disorders with Schizophrenia and Psychotic Disorders: Findings from the National Epidemiologic Survey on Alcohol and Related Conditions. The Canadian Journal of Psychiatry 54, 477-486.

- Mekori-Domachevsky E, Guri Y, Yi J, et al. (2017). Negative subthreshold psychotic symptoms distinguish 22q11.2 deletion syndrome from other neurodevelopmental disorders: A two-site study. Schizophrenia Research 188, 42-49.

- Miller TJ, McGlashan TH, Rosen JL, et al. (2003). Prodromal Assessment With 
the Structured Interview for Prodromal Syndromes and the Scale of Prodromal Symptoms: Predictive Validity, Interrater Reliability, and Training to Reliability. Schizophrenia Bulletin 29, 703-715.

- Misiak B, Krefft M, Bielawski T, Moustafa AA, Sasiadek MM , Frydecka D (2017). Toward a unified theory of childhood trauma and psychosis: A comprehensive review of epidemiological, clinical, neuropsychological and biological findings. Neuroscience \& Biobehavioral Reviews 75, 393-406.

- Mohammadi M-R, Davidian H, Noorbala A, et al. (2005). An epidemiological survey of psychiatric disorders in Iran. Clinical Practice and Epidemiology in Mental Health 1, 16.

- Morgan C, Gayer-Anderson C (2016). Childhood adversities and psychosis: evidence, challenges, implications. World Psychiatry 15, 93-102.

- Mortensen PB, Pedersen MG , Pedersen CB (2010).
Psychiatric family history and schizophrenia risk in Denmark: which mental disorders are relevant? Psychological Medicine 40, 201-210.

- Munkholm K, Vinberg M , Kessing LV (2015). Peripheral blood brain-derived neurotrophic factor in bipolar disorder: a comprehensive systematic review and meta-analysis. Molecular psychiatry 21, 216-228.

- Myin-Germeys I, van Os J (2007). Stress-reactivity in psychosis: Evidence for an affective pathway to psychosis. Clinical Psychology Review 27, 409-424.

- Narita Z, Knowles K, Fedina L, et al. (2020a). Neighborhood change and psychotic experiences in a general population sample. Schizophrenia research 216, 316321.

- Narita Z, Stickley A , DeVylder J (2020b). Loneliness and psychotic experiences in a general population sample. Schizophrenia research 218, 146-150. 
- Navarro-Mateu F, Alonso J, Lim CCW, et al. (2017). The association between psychotic experiences and disability: results from the WHO World Mental Health Surveys. Acta psychiatrica Scandinavica 136, 74-84.

- Nelson B, Yuen HP, Wood SJ, et al. (2013). Long-term Follow-up of a Group at U1tra High Risk ("Prodromal") for Psychosis. JAMA Psychiatry 70, 793.

- Nestler EJ, Barrot M, DiLeone RJ, Eisch AJ, Gold SJ , Monteggia LM (2002). Neurobiology of Depression. Neuron 34, 13-25.

- Neves-Pereira M, Mundo E, Muglia P, King N, Macciardi F , Kennedy JL (2002). The Brain-Derived Neurotrophic Factor Gene Confers Susceptibility to Bipolar Disorder: Evidence from a Family-Based Association Study. The American Journal of Human Genetics 71, 651-655.

- Nuevo R, Chatterji S, Verdes E, Naidoo N, Arango C , Ayuso-Mateos JL (2012). The continuum of psychotic symptoms in the general population: a cross-national study. Schizophrenia bulletin 38, 475-485.

- O'Donoghue B, Roche E , Lane A (2016). Neighbourhood level social deprivation and the risk of psychotic disorders: a systematic review. Social Psychiatry and Psychiatric Epidemiology 51, 941-950.

- Oliver D, Radua J, Reichenberg A, Uher R , Fusar-Poli P (2019). Psychosis Polyrisk Score (PPS) for the Detection of Individuals At-Risk and the Prediction of Their Outcomes. Frontiers in psychiatry 10.

- Ortega-Alonso A, Ekelund $\mathrm{J}$, Sarin A-P, et al. (2017). Genome-Wide Association Study of Psychosis Proneness in the Finnish Population. Schizophrenia Bulletin 43, 1304-1314.

- Owen MJ , O’Donovan MC (2017). Schizophrenia and the neurodevelopmental continuum:evidence from genomics. World Psychiatry 16, 227-235. 
- Padmanabhan JL, Shah JL, Tandon N , Keshavan MS (2017). The "polyenviromic risk score": Aggregating environmental risk factors predicts conversion to psychosis in familial highrisk subjects. Schizophrenia research 181, 17-22.

- Pain O, Dudbridge F, Cardno AG, et al. (2018). Genome-wide analysis of adolescent psychotic-like experiences shows genetic overlap with psychiatric disorders. American Journal of Medical Genetics Part B: Neuropsychiatric Genetics 177, 416-425.

- Pakriev S, Vasar V, Aluoja A, Saarma M, Shlik J (1998). Prevalence of mood disorders in the rural population of Udmurtia. Acta psychiatrica Scandinavica 97, 169-174.

- Palmier-Claus JE, Berry K, Bucci S, Mansell W, Varese F (2018). Relationship between childhood adversity and bipolar affective disorder: systematic review and meta-analysis. British Journal of Psychiatry 209, 454-459.
- Papaleo F, Silverman JL, Aney J, et al. (2011). Working memory deficits, increased anxiety-like traits, and seizure susceptibility in BDNF overexpressing mice. Learning \& Memory 18, 534-544.

- Pardiñas AF, Holmans $\mathrm{P}$, Pocklington AJ, et al. (2018). Common schizophrenia alleles are enriched in mutation-intolerant genes and in regions under strong background selection. Nature genetics 50, 381-389.

- Pelletier-Baldelli A, Strauss GP, Visser KH , Mittal VA (2017). Initial development and preliminary psychometric properties of the Prodromal Inventory of Negative Symptoms (PINS). Schizophrenia Research 189, 43-49.

- Perlis RH, Uher R, Ostacher $\mathrm{M}$, et al. (2010). Association Between Bipolar Spectrum Features and Treatment Outcomes in Outpatients With Major Depressive Disorder. Archives of general psychiatry 68, 351 . 
- Plana-Ripoll O, Pedersen CB, Holtz Y, et al. (2019). Exploring Comorbidity Within Mental Disorders Among a Danish National Population. JAMA Psychiatry 76, 259.

- Polanczyk G, Moffitt TE, Arseneault L, et al. (2010). Etiological and Clinical Features of Childhood Psychotic Symptoms. Archives of general psychiatry 67, 328.

- Polari A, Lavoie S, Yuen HP, et al. (2018). Clinical trajectories in the ultra-high risk for psychosis population. Schizophrenia Research.

- Potash JB, Derks EM, Vorstman JAS, Ripke S, Kahn RS , Ophoff RA (2012). Investigation of the Genetic Association between Quantitative Measures of Psychosis and Schizophrenia: A Polygenic Risk Score Analysis. PloS one 7 , e37852.

- Potash JB, Sieradzka D, Power RA, et al. (2014). Are Genetic Risk Factors for Psychosis Also Associated with Dimension-Specific Psychotic Experiences in
Adolescence? PloS one 9, e94398.

- Poulton R, Caspi A, Moffitt TE, Cannon M, Murray R, Harrington H (2000). Children's Self-Reported Psychotic Symptoms and Adult Schizophreniform Disorder. Archives of general psychiatry 57, 1053.

- Pries L-K, Guloksuz S, ten Have M, et al. (2018). Evidence That Environmental and Familial Risks for Psychosis Additively Impact a Multidimensional Subthreshold Psychosis Syndrome. Schizophrenia bulletin 44, 710-719.

- Pries L-K, Lage-Castellanos A, Delespaul P, et al. (2019a). Estimating Exposome Score for Schizophrenia Using Predictive Modeling Approach in Two Independent Samples: The Results From the EUGEI Study. Schizophrenia bulletin 45, 960-965.

- Pries L-K, Snijders C, Menne-Lothmann C, et al. (2019b). TwinssCan Gene-Environment Interaction in Psychotic and 
Depressive Intermediate Phenotypes: Risk and Protective Factors in a General Population Twin Sample. Twin Research and Human Genetics 22, 460-466.

- Quattrone D, Di Forti M, Gayer-Anderson C, et al. (2019a). Transdiagnostic dimensions of psychopathology at first episode psychosis: findings from the multinational EU-GEI study. Psychological medicine 49, 1378-1391.

- Quattrone D, Ferraro L, Tripoli G, et al. (2019b). Cannabis associated symptom profiles in patients with first episode psychosis and population controls. bioRxiv 2019:577932.

- Radua J, Ramella-Cravaro V, Ioannidis JPA, et al. (2018). What causes psychosis? An umbrella review of risk and protective factors. World Psychiatry 17, 49-66.

- Radua J, Schmidt A, Borgwardt S, et al. (2015). Ventral Striatal Activation During Reward Processing in Psychosis. JAMA Psychiatry 72, 1243.
- Ragazzi TCC, Shuhama R, Menezes PR, Del-Ben CM (2018). Cannabis use as a risk factor for psychotic-like experiences: A systematic review of non-clinical populations evaluated with the Community Assessment of Psychic Experiences. Early intervention in psychiatry 12, 10131023.

- Regier DA (1988). OneMonth Prevalence of Mental Disorders in the United States. Archives of general psychiatry 45, 977.

- Riehle M , Lincoln TM (2017). Social consequences of subclinical negative symptoms: An EMG study of facial expressions within a social interaction. Journal of behavior therapy and experimental psychiatry 55, 90-98.

- Ringen PA, Nesvåg R, Helle S, et al. (2016). Premorbid cannabis use is associated with more symptoms and poorer functioning in schizophrenia spectrum disorder. Psychological Medicine 46, 3127-3136. 
- Ronald A (2015). Recent quantitative genetic research on psychotic experiences: new approaches to old questions. Current Opinion in Behavioral Sciences 2, 81-88.

- Ronald A, Pain O (2018). A systematic review of genome-wide research on psychotic experiences and negative symptom traits: new revelations and implications for psychiatry. Human molecular genetics.

- Rössler W, Hengartner MP, Ajdacic-Gross V, Haker H, Gamma A , Angst J (2011). Sub-clinical psychosis symptoms in young adults are risk factors for subsequent common mental disorders. Schizophrenia research 131, 18-23.

- Ruderfer DM, Fanous AH, Ripke S, et al. (2013). Polygenic dissection of diagnosis and clinical dimensions of bipolar disorder and schizophrenia. Molecular Psychiatry 19, 1017-1024.

- Rutigliano G, Valmaggia L, Landi P, et al. (2016). Persistence or recurrence of non-psychotic comorbid mental disorders associated with 6-year poor functional outcomes in patients at ultra high risk for psychosis. Journal of Affective Disorders 203, 101-110.

- Sadock B, Sadock, VA. (2015). Kaplan \& Sadock's synopsis of psychiatry : behavioral sciences/clinical psychiatry. Wolters Kluwer: Philadelphia

- Salokangas RKR, Schultze-Lutter F, Hietala J, et al. (2015). Depression predicts persistence of paranoia in clinical highrisk patients to psychosis: results of the EPOS project. Social Psychiatry and Psychiatric Epidemiology 51, 247-257.

- Sauvé G, Brodeur MB, Shah JL, Lepage M (2019). The Prevalence of Negative Symptoms Across the Stages of the Psychosis Continuum. Harvard Review of Psychiatry 27, 15-32.

- Schizophrenia Working Group of the Psychiatric Genomics Consortium (2014). Biological insights 
from 108 schizophrenia-associated genetic loci. Nature 511, 421-427.

- Schneiders J, Drukker M, van der Ende J, Verhulst FC, van Os J , Nicolson NA (2003). Neighbourhood socioeconomic disadvantage and behavioural problems from late childhood into early adolescence. Journal of epidemiology and community health 57, 699-703.

- Schoeyen HK, Birkenaes AB, Vaaler AE, et al. (2011). Bipolar disorder patients have similar levels of education but lower socio-economic status than the general population. Journal of affective disorders 129, 68-74.

- Schultze-Lutter F, Michel C, Ruhrmann S, Schimmelmann BG (2017). Prevalence and clinical relevance of interview-assessed psychosis-risk symptoms in the young adult community. Psychological medicine 48, 1167-1178.

- Schultze-Lutter F, Nenadic I , Grant P (2019). Psychosis and Schizophre-
nia-Spectrum Personality Disorders Require Early Detection on Different Symptom Dimensions. Frontiers in psychiatry 10.

- Schultze-Lutter F, Ruhrmann S, Berning J, Maier W, Klosterkotter J (2008). Basic Symptoms and Ultrahigh Risk Criteria: Symptom Development in the Initial Prodromal State. Schizophrenia Bulletin 36, 182-191.

- Simon AE, Umbricht D (2010). High remission rates from an initial ultra-high risk state for psychosis. Schizophrenia Research 116, 168-172.

- Siuciak JA, Boylan C, Fritsche M, Altar CA, Lindsay RM (1996). BDNF increases monoaminergic activity in rat brain following intracerebroventricular or intraparenchymal administration. Brain Research 710, 11-20.

- Smeets F, Lataster T, Dominguez MdG, et al. (2010). Evidence That Onset of Psychosis in the Population Reflects Early Hallucinatory Experiences 
That Through Environmental Risks and Affective Dysregulation Become Complicated by Delusions. Schizophrenia bulletin 38, 531-542.

- Smeets F, Lataster T, van Winkel R, de Graaf R, ten Have M , van Os J (2013). Testing the hypothesis that psychotic illness begins when subthreshold hallucinations combine with delusional ideation. Acta psychiatrica Scandinavica 127, 34-47.

- Smeets F, Lataster T, Viechtbauer W, Delespaul P (2015). Evidence That Environmental and Genetic Risks for Psychotic Disorder May Operate by Impacting on Connections Between Core Symptoms of Perceptual Alteration and Delusional Ideation. Schizophrenia bulletin 41, 687-697.

- Spencer C, Hyman C, Studer L, et al. (1995). Effect of BDNF on Dopaminergic, Serotonergic, and GABAergic Neurons in Cultures of Human Fetal Ventral Mesencephalon. Experimental Neurology 133, 50-63.
- Srihari VH, Shah J, Keshavan MS (2012). Is Early Intervention for Psychosis Feasible and Effective? Psychiatric Clinics of North America 35, 613-631.

- Stahl EA, Breen G, Forstner AJ, et al. (2019). Genome-wide association study identifies 30 loci associated with bipolar disorder. Nature genetics 51, 793-803.

- Stefanis NC, Delespaul P, Smyrnis N, et al. (2004). Is the excess risk of psychosis-like experiences in urban areas attributable to altered cognitive development? Social Psychiatry and Psychiatric Epidemiology 39, 364-368.

- Sullivan PF (2008). Schizophrenia genetics: the search for a hard lead. Current opinion in psychiatry 21, 157-160.

- Sullivan PF, Agrawal A, Bulik CM, et al. (2018). Psychiatric Genomics: An Update and an Agenda. American Journal of Psychiatry 175, 15-27. 
- Szczypiński JJ , Gola M (2018). Dopamine dysregulation hypothesis: the common basis for motivational anhedonia in major depressive disorder and schizophrenia? Reviews in the Neurosciences 29, 727744.

- Taquet M, Smith SM, Prohl AK, et al. (2020). A structural brain network of genetic vulnerability to psychiatric illness. Molecular psychiatry.

- Taylor MJ, Martin J, Lu Y, et al. (2019). Association of Genetic Risk Factors for Psychiatric Disorders and Traits of These Disorders in a Swedish Population Twin Sample. JAMA psychiatry 76, 280.

- Tsai S-J (2004). Is mania caused by overactivity of central brain-derived neurotrophic factor? Medical Hypotheses 62, 19-22.

- Tsai S-J (2018). Critical Issues in BDNF Val66Met Genetic Studies of Neuropsychiatric Disorders. Frontiers in Molecular Neuroscience 11 .
- Tsuang MT (1979). Longterm Outcome of Major Psychoses. Archives of general psychiatry 36, 1302.

- Turkish Statistical Institute (2019). Population of Province/District Centers, Towns/Villages by Provinces and Districts and Annual Growth Rate of Population. 26 April 2019, http://www. turkstat.gov.tr/PreIstatistikTablo.do?istab id=2305

- Unterrassner L, Wyss TA, Wotruba D, Ajdacic-Gross V, Haker H , Rössler W (2017). Psychotic-Like Experiences at the Healthy End of the Psychosis Continuum. Frontiers in psychology 8.

- Ünal HE, Birben Ü , Bolat F (2018). Rural population mobility, deforestation, and urbanization: case of Turkey. Environmental Monitoring and Assessment 191.

- van den Heuvel MP, Sporns O (2019). A cross-disorder connectome landscape of brain dysconnectivity. $\mathrm{Na}$ ture Reviews Neuroscience 20, 435-446. 
- van der Gaag M, Smit F, Bechdolf A, et al. (2013). Preventing a first episode of psychosis: Meta-analysis of randomized controlled prevention trials of 12 month and longer-term follow-ups. Schizophrenia research 149, 56-62.

- van Nierop M, Viechtbauer W, Gunther N, et al. (2014). Childhood trauma is associated with a specific admixture of affective, anxiety, and psychosis symptoms cutting across traditional diagnostic boundaries. Psychological Medicine 45, 1277-1288.

- van Os J (2013). The Dynamics of Subthreshold Psychopathology: Implications for Diagnosis and Treatment. American Journal of Psychiatry 170, 695698.

- van Os J, Delespaul P, Wigman J, Myin-Germeys I , Wichers M (2013). Beyond DSM and ICD: introducing "precision diagnosis" for psychiatry using momentary assessment technology. World Psychiatry 12, 113-117.
- van Os J, Gilvarry C, Bale $\mathrm{R}$, et al. (2000a). Diagnostic value of the DSM and ICD categories of psychosis: an evidence-based approach. UK700 Group. Social psychiatry and psychiatric epidemiology 35, 305-311.

- van Os J , Guloksuz S (2017). A critique of the "ultra-high risk" and "transition" paradigm. World Psychiatry 16, 200-206.

- van Os J, Guloksuz S, Vijn TW, Hafkenscheid A, Delespaul P (2019a). The evidence-based group-level symptom-reduction model as the organizing principle for mental health care: time for change? World Psychiatry 18, 88-96.

- van Os J, Hanssen M, Bak M, Bij1 RV , Vollebergh W (2003). Do Urbanicity and Familial Liability Coparticipate in Causing Psychosis? American Journal of Psychiatry 160, 477-482.

- van Os J, Hanssen M, Bij1 RV , Ravelli A (2000b). Strauss (1969) revisited: a psychosis continuum in the general population? Schizophrenia Research 45, 11-20. 
- van Os J, Kenis G, Rutten BPF (2010). The environment and schizophrenia. Nature 468, 203-212.

- van Os J , Linscott RJ (2012). Introduction: The Extended Psychosis Phenotype--Relationship With Schizophrenia and With Ultrahigh Risk Status for Psychosis. Schizophrenia bulletin 38, 227-230.

- van Os J, Linscott RJ, Myin-Germeys I, Delespaul P , Krabbendam L (2009). A systematic review and meta-analysis of the psychosis continuum: evidence for a psychosis proneness-persistence-impairment model of psychotic disorder. Psychological medicine 39, 179-195.

- van Os J, Pries LK, Delespaul P, et al. (2019b). Replicated evidence that endophenotypic expression of schizophrenia polygenic risk is greater in healthy siblings of patients compared to controls, suggesting gene-environment interaction. The EUGEI study. Psychological Medi- cine, 1-14; doi: 10.1017/ S003329171900196X. Online ahead of print.

- van Os J , Reininghaus U (2016). Psychosis as a transdiagnostic and extended phenotype in the general population. World Psychiatry 15, 118-124.

- van Os J, van der Steen Y, Islam MA, Guloksuz S, Rutten BP , Simons CJ (2017). Evidence that polygenic risk for psychotic disorder is expressed in the domain of neurodevelopment, emotion regulation and attribution of salience. Psychological medicine 47, 2421-2437.

- van Os J, Verdoux H, Maurice-Tison $\mathrm{S}$, et al. (1999). Self-reported psychosis-like symptoms and the continuum of psychosis. Social Psychiatry and Psychiatric Epidemiology 34, 459-463.

- van Rossum I, Dominguez MdG, Lieb R, Wittchen HU , van Os J (2009). Affective Dysregulation and Reality Distortion: A 10-Year Prospective Study of Their Association and Clinical 
Relevance. Schizophrenia Bulletin 37, 561-571.

- van Winkel R, Stefanis NC , Myin-Germeys I (2008). Psychosocial Stress and Psychosis. A Review of the Neurobiological Mechanisms and the Evidence for Gene-Stress Interaction. Schizophrenia Bulletin 34, 1095-1105.

- Varese F, Smeets F, Drukker M, et al. (2012). Childhood Adversities Increase the Risk of Psychosis:

A Meta-analysis of $\mathrm{Pa}$ tient-Control, Prospectiveand Cross-sectional Cohort Studies. Schizophrenia bulletin 38, 661-671.

- Verdoux H, Van Os J, Maurice-Tison $\mathrm{S}$, Gay $\mathrm{B}$, Salamon R , Bourgeois ML (1999). Increased occurrence of depression in psychosis-prone subjects: A follow-up study in primary care settings. Comprehensive Psychiatry 40, 462-468.

- Walker S, Mackay E, Barnett $\mathrm{P}$, et al. (2019). Clinical and social factors associated with increased risk for involuntary psychiatric hospitalisation: a systematic review, meta-analysis, and narrative synthesis. The Lancet Psychiatry 6, 1039-1053.

- Walss-Bass C, Forstner AJ, Hecker J, et al. (2017). Identification of shared risk loci and pathways for bipolar disorder and schizophrenia. PloS one 12, e0171595.

- Walss-Bass C, Werbeloff $\mathrm{N}$, Dohrenwend BP, et al. (2015). The Association between Negative Symptoms, Psychotic Experiences and Later Schizophrenia: A Population-Based Longitudinal Study. PloS one 10, e0119852.

- Wan L, Thomas Z, Pisipati S, Jarvis SP , Boutros NN (2017). Inhibitory deficits in prepulse inhibition, sensory gating, and antisaccade eye movement in schizotypy. International Journal of Psychophysiology 114, 47-54.

- Wigman JTW, van Nierop M, Vollebergh WAM, et al. (2012a). Evidence That Psychotic Symptoms Are Prevalent in Disorders of 
Anxiety and Depression, Impacting on Illness Onset, Risk, and Severity--Implications for Diagnosis and Ultra-High Risk Research. Schizophrenia bulletin 38, 247-257.

- Wigman JTW, van Winkel R, Ormel J, Verhulst FC, van Os J , Vollebergh WAM (2012b). Early trauma and familial risk in the development of the extended psychosis phenotype in adolescence. Acta psychiatrica Scandinavica 126, 266-273.

- Wigman JTW, van Winkel $\mathrm{R}$, Raaijmakers QAW, et al. (2011). Evidence for a persistent, environment-dependent and deteriorating subtype of subclinical psychotic experiences: a 6-year longitudinal general population study. Psychological Medicine 41, 2317-2329.

- Wigman JTW, Vollebergh WAM, Raaijmakers QAW, et al. (2009). The Structure of The Extended Psychosis Phenotype in Early Adolescence--A Cross-sample Replication. Schizophrenia bulletin 37, 850-860.
- Wilson C, Smith ME, Thompson E, et al. (2016). Context matters: The impact of neighborhood crime and paranoid symptoms on psychosis risk assessment. Schizophrenia Research 171, 56-61.

- Xia CH, Ma Z, Ciric R, et al. (2018). Linked dimensions of psychopathology and connectivity in functional brain networks. Nature Communications 9.

- Yung AR, Nelson B (2011). Young people at ultra high risk for psychosis: a research update. Early Intervention in Psychiatry 5, 52-57.

- Yung AR, Phillips LJ, Yuen HP, et al. (2003). Psychosis prediction: 12-month follow up of a high-risk ("prodromal") group. Schizophrenia research 60, 21-32.

- Zammit S, Hamshere M, Dwyer S, et al. (2013a). A Population-Based Study of Genetic Variation and Psychotic Experiences in Adolescents. Schizophrenia Bulletin 40, 1254-1262. 
- Zammit S, Horwood J, Thompson A, et al. (2008). Investigating if psychosis-like symptoms (PLIKS) are associated with family history of schizophrenia or paternal age in the ALSPAC birth cohort. Schizophrenia Research 104, 279-286.

- Zammit S, Kounali D, Cannon M, et al. (2013b). Psychotic Experiences and Psychotic Disorders at Age 18 in Relation to Psychotic Experiences at Age 12 in a Longitudinal Population-Based Cohort Study. American Journal of Psychiatry 170, 742-750.

- Zavos HMS, Eley TC, McGuire P, et al. (2016). Shared Etiology of Psychotic Experiences and Depressive Symptoms in Adolescence: A Longitudinal Twin Study. Schizophrenia bulletin 42, 1197-1206.

- Zavos HMS, Freeman D, Haworth CMA, et al. (2014). Consistent Etiology of Severe, Frequent Psychotic Experiences and Milder, Less Frequent Manifesta- tions. JAMA Psychiatry 71, 1049.

- Zhao Z, Xu J, Chen J, et al. (2014). Transcriptome sequencing and genome-wide association analyses reveal lysosomal function and actin cytoskeleton remodeling in schizophrenia and bipolar disorder. Molecular psychiatry 20, 563-572.

- Zhu K, Ou Yang T-H, Dorie $\mathrm{V}$, Zheng T , Anastassiou D (2019). Meta-analysis of expression and methylation signatures indicates a stress-related epigenetic mechanism in multiple neuropsychiatric disorders. Translational Psychiatry 9.

- Ziermans TB, Schothorst PF, Sprong M, van Engeland $H$ (2011). Transition and remission in adolescents at ultra-high risk for psychosis. Schizophrenia Research 126, 58-64. 


\title{
CHAPTER7
}

\author{
Summary
}


In Chapter 1, a background was provided on the conceptualization of psychosis as laid out in current classification systems. In addition, the concept of an extended psychosis phenotype in the general population was described, as was the notion that there is a distribution or spectrum of psychosis across current psychiatric nosology. Evidence on the transdiagnostic nature of the psychosis spectrum was discussed, and a multidimensional view of psychosis was introduced. Research describing a network of overlapping and interacting dimensions across the psychosis spectrum was reviewed. Finally, the aims and the outlines of the thesis were described.

In Chapter 2, the design of the TurkSch study was presented. This included the assessment of the different dimensions of the extended and transdiagnostic psychosis phenotype, as well as the description of the multilevel data collection including socio-environmental exposures and blood sampling in a representative community-based population. Outcomes of household visits and analysis of attrition, based on noncontacts and refusals in the longitudinal arm were introduced. Finally, dynamic transitions over time, within the spectrum of the extended psychosis phenotype, were demonstrated. Results showed that attrition over time showed no large differential effect sizes as a function of important variables. Furthermore, increasing severity of subthreshold psychosis at baseline was associated with increasing rates of persistence and psychotic disorder outcomes over the follow-up period. However, an even higher proportion of clinically relevant subthreshold psychosis did not persist over time.

In Chapter 3, longitudinal bidirectional associations between the spectrum of the positive psychosis domain and affective psychopathology were evaluated, accounting for other possible influences. The analyses revealed reciprocal sub-additive longitudinal associations between these domains, as well as similar cross-lagged correlations over time. Finally, there was considerable sharing of socio-environmental and familial risk factors 
across these domains. These results suggest mutually causal connections between the affective and positive domains.

In Chapter 4, clinician-based longitudinal diagnoses of clinically relevant subthreshold psychosis were presented as well as moderating factors. Results showed that the psychotic disorder diagnosis rate at follow up was $7.0 \%$. This is much lower than the rates of mood disorders without psychotic features $(42.8 \%)$ and other non-psychotic disorders (24.1\%). Female sex, lower socio-economic status, co-occurrence of mood disorders, family history of a mental disorder, and persistence of psychotic experiences predicted any follow-up DSM diagnosis. Furthermore, follow-up psychotic versus non-psychotic disorder outcome was predicted by younger age (15-30 years), co-presence of delusional and hallucinatory PE and family history of severe mental illness. The results demonstrated the importance of subthreshold psychosis as a marker of transdiagnostic risk.

In Chapter 5, the association of a priori hypothesized SNP (rs6265) with a longitudinally assessed dimensional phenotype covering subthreshold and threshold levels of the positive psychosis domain was investigated. The SNP was significantly associated with the positive spectrum of psychosis. The pattern of the association was that the SNP impacted in a dose-response but extra-linear fashion, with stronger impact at the threshold end. Associations were still significant when adjusted for sociodemographic factors and environmental exposures including life events, childhood adversity, socioeconomic status, urbanicity, and cannabis use. The results potentially indicate the relevance of dimensional risk assessment in relation to genetic association.

In Chapter 6, the results of the studies in this thesis were summarized, discussed and integrated in light of the current literature. Strengths and limitations were stated. Finally, future directions were provided. 



\title{
CHAPTER 8
}

\author{
Impact
}




\section{Main objectives, results and conclusions}

The assessment of the different dimensions of psychosis in a graded fashion is progressively replacing the classification of threshold phenotypes in the form of distinct categories. Examples are the release of the National Institute of Mental Health, Research Domain Criteria and Clinician-Rated Dimensions of Psychosis Symptom Severity in the Emerging Measures and Models section of the DSM-5. This paradigm shift is supported by 'grey areas' between illness and normality, lack of zones of relative rarity, high rates of comorbidity, shared ethiopathogenesis, heterogeneity within disorders, and diagnostic instability. Longitudinal assessment of the extended and transdiagnostic psychosis phenotype in general populations is a productive way to generate evidence for the expression of psychosis as multidimensional psychopathology. In this thesis, psychosis was assessed along a spectrum of severity including both helpseeking and non-helpseeking individuals in a representative community-based population of Izmir, which is one of the major cities in Europe and the Middle East, with around three million residents. Etiological and phenomenological associations (within the same domain and across different domains of psychopathology) over a six year follow-up period were the major focus of attention.

The summary of the main results described in different chapters of this thesis is as follows:

Results in chapter 2 showed that baseline characteristics of responders did not show large differences from characteristics of subjects who dropped out. In addition, socio-demographic characteristics were similar to studies with a similar design, but also had differences. Thus, results are sufficiently representative of the Izmir population. Furthermore, the spectrum of the positive psychosis domain showed a fluctuating phenotype over time. Chapter 3 demonstrated that affective psychopathology and the spectrum of the positive domain of psychosis were bi-directionally associated with each other over 
time, in a sub-additive pattern. A remarkable number of socio-environmental and familial risk factors were shared across these domains. Similar cross-lagged correlations over time were demonstrated across these domains, suggesting mutually causal connections. In chapter 4 , the prospective diagnostic evaluation of clinically relevant subthreshold psychosis showed that subsequent psychotic disorder diagnoses represented only a minority of outcomes whereas the majority had diagnoses of common non-psychotic disorders at follow-up. Furthermore, baseline characteristics of individuals (e.g. age range, sex, familial risk, socioeconomic status, comorbidity of symptoms, and persistence of subthreshold psychosis) were predictive of the longitudinal diagnostic outcome (i.e. any mental disorder and psychotic vs. non-psychotic disorder). The results of chapter 5 showed that an SNP (rs6265), hypothesized a priori, was significantly associated with the longitudinally assessed spectrum of the positive domain, including subthreshold and threshold phenotypes, adjusting for socio-environmental factors. The associations were in a dose-response but extra-linear fashion with stronger associations at the threshold level.

\section{RELEVANCE}

\section{Seientific Impact}

To date, few longitudinal community-based studies on the extended psychosis phenotypes have been performed, and they were conducted predominantly in western populations. Cultural and socio-economic characteristics of populations across geographical regions may lead to differences in findings. The TurkSch study is a unique example of a longitudinal community-based study conducted at the cross-border between Europe and the Middle-East. Hence, the design of the TurkSch study has the potential to stimulate similar studies in other regions in this part of the world. Furthermore, the sociodemographic correlates of attrition may guide future studies to make special efforts to include these particular groups. 
There are a number of terms/definitions used in research in the area of subthreshold psychosis (i.e. schizotypy, schizotypal traits, schizotaxia, psychotic (like) experiences, psychotic symptomatology, attenuated psychotic symptoms, prodromal psychotic symptoms, high risk for psychosis) and associated outcomes (i.e. psychotic impairment, transition, clinical psychosis, psychotic disorders, first episode psychosis, affective psychosis, non-affective psychosis, schizophrenia spectrum). These terms usually differ based on aspects of the particular sample (i.e. general population-based, early intervention centre-based, help seeking, non-help seeking, presence of co-occurring distress and common mental disorder), and the outcome measures used (DSM diagnoses, questions on help seeking and dysfunction, Comprehensive Assessment of At-risk Mental State-CAARMS, Scale of Psychosis-Risk Symptoms-SOPS). These definitions indicate different positions within the psychosis spectrum. Standardized terms/definitions are necessary for the area to progress, for example in an international consortium testing the reliability and validity of these operational definitions. This thesis and the previous results of the TurkSch study demonstrated that clinical and general-population phenotypes in this research area have important similarities with regard to risk factors and longitudinal outcomes. Given the fact that the TurkSch study covered the full spectrum of psychosis from subclinical phenotypes gradually blending into clinically-relevant subthreshold phenotypes, threshold psychosis outside schizophrenia spectrum disorders and finally schizophrenia spectrum disorders, as well as associated risk factors, co-occurring dimensions and longitudinal outcomes, it may be used as an initial step towards the standardization efforts of psychosis spectrum terminology.

Subthreshold psychosis is represented in current classification systems as categorical entity, based on positive psychosis phenomena. For instance, the attenuated psychosis syndrome, classified under subheadings of both 'other specified schizophrenia spectrum and other psychotic disorder' and 'conditions for further study' in DSM 5, is characterized by clinically relevant 
subthreshold delusions, hallucinations and disorganized speech. Results in this thesis and previous results in the TurkSch study question the validity of this type of classification and demonstrates the need for multidimensional assessments and dynamic interplay between affective and psychosis domains.

The results on dynamic transitions over time in the extended psychosis phenotype in this thesis showed that a high proportion of clinically relevant subthreshold psychosis does not persist over time. These results demonstrate the need to reconsider the view that psychosis itself is 'toxic' for the brain and/or part of a phenotype that progresses through stages. Research in the area of high-risk for psychosis predominantly leans on unidimensional assessment strategies with a reliance on positive phenotypes. However, this strategy unintentionally may set a self-limiting barrier for research in this area. Results described in this thesis clearly show that the subthreshold positive domain usually co-occurs with symptoms from other domains. The outcomes are also heterogeneous and dependent on the degree of interplay between dimensions. Through unidimensional assessment strategies, the associations between emerging outcomes and prior symptom domains outside the positive domain (or the interconnectivity between domains) are missed. Furthermore, various outcomes outside the positive domain are overlooked. Therefore, this thesis may contribute to the methodology of future prospective research to include broader phenotypes of psychopathology in order to evaluate different pathways to psychotic impairment.

Studies designed to investigate etiological associations predominantly compare 'cases' that have distinct categories of mental disorders with 'healthy' controls. However, this methodology has some limitations. Different domains of psychopathology, even as they are co-occurring in the same disorder, may be associated with different pathways, thus with different genetic and environmental risk factors, which may cause much heterogeneity from sample to sample. Furthermore, controls may share some 
phenotypes with cases, in particular subthreshold phenotypes, which could cause loss of power and precision. Additionally, data is usually collected on a single factor (e.g. molecular data only, socioenvironmental exposure only etc.) which hampers insight into confounding, moderation, mediation and moderated mediation for many other influences. Finally, the descriptions of 'caseness' are mostly based on a single assessment, not taking into account fluctuating manifestations over time. However, case-control studies have advantages of getting more rapid results and being cheaper. Therefore, integrating dimensional assessments of psychopathology as well as cumulative measures of different risk factors can add extra value. The design of risk assessment in this thesis is dimensional and longitudinal, providing opportunity to adjust for other factors. This design may stimulate further research on risk assessment in the future.

\section{Socioeconomic Impact}

Meta-analyses have reported that dimensional measures have increased validity, explaining more variance in risk factors, neurophysiological markers, and functioning in comparison with categorical measures. The perspective of research on dimensional assessments and the interconnectivity between dimensions in this thesis, along with other studies with similar research questions, can accelerate the rise of personalised medicine in psychiatry with enhanced diagnostic and prognostic accuracy. Furthermore, this framework may improve the search for biomarkers in psychiatry.

Screening psychosis risk in the community through a unidimensional assessment strategy has two major limitations. First, most of the individuals with this 'risk state' do not develop a psychotic disorder, but rather develop a common non-psychotic disorder. Furthermore, some individuals even do not develop any mental disorder over time. Second, a high proportion of individuals who develop psychotic disorders does not meet the criteria of risk categories. Along with other studies with similar research questions, the results of this thesis showed that early expres- 
sions of psychotic psychopathology comprise multiple signs and symptoms from multiple domains. The results on the characteristics of individuals with subthreshold psychosis (e.g. age range, sex, familial risk, socioeconomic status, comorbidity of symptoms, persistence of subthreshold psychosis) who develop psychotic disorders as well as common-non psychotic disorders over time may help to plan personalized early intervention strategies. Therefore, these results contribute to the growing evidence for ways to improve screening strategies.

The traditional consideration of psychosis as a dichotomous event, in some degree, may add to the stigmatization of individuals with psychosis. The TurkSch study evaluated psychosis as a common phenomenon lying on a spectrum from illness to normal mentation, and showed substantial shared aspects across these ends. Furthermore, the longitudinal results show that the majority of individuals with baseline clinically relevant subthreshold psychosis do not develop 'schizophrenia'. Therefore, psychosis over time does not concur with the social image of schizophrenia as a 'devastating progressive and desperate mental illness'. These results might be an important basis for the fight against stigmatization of psychosis in society.

\section{Target Groups}

\section{Academic commanity in other disciplines}

This thesis provides an advanced design to meet the challenges of longitudinal data collections in representative-community-based populations. Furthermore, genetic analyses within a general population-based sample were performed. Therefore, the results may be of interest not only for psychiatrists and psychologists, but also for geneticists, physicians from various disciplines working in the area of epidemiology as well as social scientists. A multidisciplinary perspective within an epidemiological framework can productively bring together different areas of research that sometimes have difficulties finding each other. 


\section{Patients and their relatives}

For patients with psychosis, the results of the TurkSch study demonstrate that the condition they experience has shared aspects, or connectedness, with experiences of a substantial part of the general population. For any person with psychotic experiences, and particularly for relatives of individuals with subthreshold psychosis, it is a vital question if a psychotic disorder may arise in the future. The answer is that the majority is not going to be diagnosed with a psychotic disorder, although there is an apparent risk for mental disorders in general, with an increasing risk if they have persistent psychotic experiences, co-occurring mental distress, low socioeconomic status, substance use, and family history of mental disorders. Therefore, a devastating worry for a future psychotic disorder is not useful. However, the modifiable risk factors among these, such as substance use, may be targeted to reduce the risk of impairment.

\section{Society at large}

Stigmatization of psychosis is common in society. The results of the TurkSch study have shown that psychosis is a much more common phenomenon than is generally assumed, lying on a spectrum from normal mentation to need for care. Furthermore, psychotic experiences are generally transient, and not antecedents of 'devastating' mental illness, so these experiences may be considered as part of human variation with deep roots in evolution of mind.

\section{Policy makers}

The findings in this thesis support the view that psychotic experiences may be a useful marker for mental distress that has transdiagnostic value. Furthermore, psychotic experiences have close associations with socio-environmental exposures, which are therefore associated with the longitudinal outcomes of individuals' mental states. Community-based prevention strategies should be organised taking into account a multidimensional perspective, prioritizing the impact of socio-environmental expo- 
sures in order to reduce the burden of mental problems. Furthermore, efforts to fight against stigmatization of psychosis in society are of value.

\section{Mental health care providers}

The results of this thesis provide an important base for physicians and other professionals working in the area of mental health. Subthreshold psychosis should not be considered merely as the 'pre-psychotic' phase. However, considering frequency and distress associated with the experiences, socio-environmental and genetic risk of individuals, and interactions with other dimensions of psychopathology, may result in more precise predictions of transdiagnostic outcomes over time. Therefore, avoiding 'schizo'-discourse when considering psychosis phenotypes is required. Rather, follow-up of these individuals in a supportive environment, treatment of co-occurring disorders leading to impairment in social, occupational, or other important areas of functioning, and psychoeducation on plausible socio-environmental risk may be of value.

\section{Netuorrk Product}

The TurkSch study was based on interdepartmental and international collaborations. Results of the study have been presented in many national and international conferences. A new assessment of the cohort $\left(\mathrm{T}_{3}\right)$ is being planned. Furthermore, a $\mathrm{PhD}$ thesis at Maastricht University, focussing on the longitudinal neighbourhood-contextual measures of the TurkSch study is in progress.

\section{Summary and Conclusion}

The results of this thesis have several scientific and social impacts. First, the assessments covered the full spectrum of psychosis, as well as the dynamic interplay between symptom domains. Therefore, results may contribute to the efforts to achieve a consistent terminology for multidimensional psychotic pheno- 
types as well as more comprehensive and precise classification of psychosis. Second, the results on longitudinal outcomes of subthreshold psychosis as well as the moderating factors were presented. These results may have impact on clinical practice when considering individuals with subthreshold psychosis. Furthermore, these results may help to improve screening strategies in order to provide more comprehensive community-based prevention strategies. Third, the methodology may stimulate further research on assessment of risk factors with more accurate results. Finally, the consideration of psychosis as a common phenomenon lying on a spectrum from illness to normal mentation as well as the longitudinal outcomes of these phenotypes may be an important basis for the fight against stigmatization of psychosis in society. 


\section{ACKNOWLEDGEMENT}

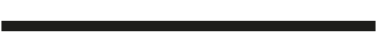


Life is the time passing while waiting for the inspiring moments. This thesis actually started in a very stressful moment which then turned into one of the most inspiring moments of my life... I was at the early times of my psychiatry training in Ege University. A patient burned himself at the inpatient unit... I was in a desperate mood. After the emergency treatment of the patient and transfer to a burn unit, following a deep breath, my professor Hayriye Elbi asked me to plan and coordinate the longitudinal arm of a unique epidemiological project, which I would learn the name "TürkSch" after. I remember the words "you look like a swift and bright person. I trust you, you can manage". It was unexpected for me, but also very inspiring, encouraging and honouring... That was also one of the exceptional opportunities of my life. My aim to be in medical school and in psychiatry was to touch humans' lives. This was a great opportunity to touch thousands of individuals' lives maybe whom I would not meet at any times. Throughout the project I always felt the encouraging trust of Professor Elbi. I will be grateful to her throughout my life...

The baseline wave of the TürkSch project was coordinated by Tolga Binbay. I first met him when he was a psychiatric trainee and I was a medical student in Ege University. I remember talking on student organisations. We did not meet for several years after. However, I remember to be impressed by his calm and wise attitude. Professor Elbi told me to contact him, which was a very nice surprise. He has been very helpful and desiring to teach till this moment. Both an older brother and a sophisticated teacher... Also, a role model... He also introduced me to Jim van Os, so my collaboration with Maastricht University started. Then he introduced me to MheNs. Since the time in Maastricht, many storms have broken out around, but he has always been nearby. I will be grateful to him throughout my life, too.

While preparing the details of the TürkSch, I met Prof. Köksal Alptekin, who has been the mentor of the project since the be- 
ginning. He is one of the greatest scientists to be met for a young trainee who wants to take part in science. And a great mentor to think wider. I would like to thank to him for the scientific identity borrowed, for many things learnt and to be learnt.

One of the most inspiring moments of my life was the moment I first met Jim van Os. I talked about the TürkSch project, and he suddenly asked if I would like to do a $\mathrm{PhD}$ in Maastricht. It was a great chance to learn the subtleties of epidemiology from one of the most outstanding scientists and centres of the world. His view, which combines both being practical and also achieving to miss no details, is one of the most inspiring experiences of my life. I'm sure that this view has contributed a lot to my way of thinking. Furthermore, I would like to thank Marjan Drukker as a great scientist for her excellent guidance. Her detailed and educative comments importantly contributed to my scientific view. Furthermore, she taught me to use STATA that now I can help my colleagues. They are both Pole Stars of my scientific journey.

The TürkSch project was conducted under the sustained supportive environment of Ege University Department of Psychiatry. It is a warm place to be a psychiatric trainee. You better understand how a precious department it is after a piece of time you work outside. I would like to thank Prof. Şebnem Pirıldar for teaching what to do with your anxiety as well as with the patients'... And also my professors Simavi Vahip, Yusuf Alper, Baybars Veznedaroğlu, Fisun Akdeniz, Hakan Coşkunol, Ali Saffet Gönül, Ayşin Noyan, Özen Önen Sertöz, Ender Altıntoprak, and Çağdaş Eker who have great signs on my understanding of the human mind. They provided knowledge, skills and confidence as a physician as well as the scientific way of thinking. I would also like to thank Prof. Bülent Kayahan for his mentorship and encouragement in the TürkSch project and the great contribution to my psychiatric training. I am also grateful to the co-senior residents and all my colleagues for the warm environment in Ege University. 
I would like to thank Prof. Hüseyin Onay and Prof. Ferda Özkınay from Ege University, Department of Genetics for their collaboration in the project. Furthermore, I would like to thank Nesli Zagli, Kübra Yıldırım, Bertan Turgut, Duygu Keskin Gökçelli and many others to be shoulder to shoulder on various streets of Izmir during the project, for about three years. I also would like to thank the great people residing in urban and rural areas of Izmir, who opened their doors, lives and souls many times for the TürkSch project...

I am also grateful to my family for supporting me to decide the things I desire and work hard for them ... I can never forget preparing my father's talks to be read in special days of his school, when I was a primary school kid. Now i understand how big gifts those preparations are. Esteem and confidence by your father... And my mother... When I feel stressed, just drawing on her imagination has always made me feel that it is going to be over. This is what connects one to life.... And Fatos.... She has always been the naughty and sweet piece of my life, bringing curiosity and joy. Thank you all for your existence and love...

And Melike... The moment I first met in a class for the preparation of TUS (medical specialty entrance exam), I felt that it was the exceptional turning point of my life. Despite the short time to that 'hard' exam, I could never stop thinking her for a moment. She has been the unconditional peace in my soul which is described to be in the womb... Besides many things, I also would like to thank her for her patience during the preparation of this thesis. During this project we had our baby, Ekin. She is now three years old. With her 'unstoppable' curiosity, i everyday review my views about life. Thank you for your great existence and love...

Life is the time passing while waiting for inspiring moments. And this thesis is one of the most inspiring experiences of my life... 


\section{Curriculum Vitae}


Umut K1rl1 was born in September, 1986 in Manisa, Turkey. He attended to medical school at Ege University, Izmir, Turkey (2004-2010), and was an exchange medical student in Lund University, Sweden (2008). During these years, he completed the international project "the same differently" on the social disadvantages of migrants funded by the European Union Youth in Action commission. After finishing medical education, he worked as a general practitioner in the emergency department of Erzurum Karayazi State Hospital. Then he got trained in psychiatry in Ege University between 2011 and 2015. Starting from his residency in psychiatry, he attended to analytically oriented group therapy for 7 years. Then, he completed supportive psychotherapy theoretical educations and supervisions. After completing his residency, he worked in Hakkari State Hospital for 2 years, followed by working in Van Training and Research Hospital for 1 year as a psychiatrist. He has been working in Yuzuncu Yil University, School of Medicine, Department of Psychiatry as an assistant professor since 2019.

His research interest has started in early years of his medical education. At the early years of his residency in psychiatry, he started to coordinate the longitudinal arm of the TurkSch project, which is one of the leading projects about psychiatric epidemiology and gene-environment interactions in Turkey. The TürkSch project was supported by 1001 programme of the Scientific and Technological Research Council of Turkey with two separate funds as well as research funds of Ege University. With this project, his research interest focused on psychosis epidemiology, gene-environment interactions in psychosis and dimensional approach in psychiatry. He was awarded in European Psychiatric Association (EPA) Annual Forum of European Federation of Psychiatric Trainees (2012) as best poster presenter, in 23rd World Congress of Psychiatric Genetics (WCPG) Early Career Investigator Programme as travel award (2015), in Psychiatric Association of Turkey (PAT) 51st National Psychiatry Congress as best research award (2015), and in the European College of Neuropsychopharmacology (ECNP) Workshop for Junior Scientists in Europe participation funds (2016). 
He became a non-residential PhD candidate at the School of Mental and Neuroscience (MHeNS) at the Maastricht University, the Netherlands in 2016. He was an observer at MHeNS in July 2016. He is a member of International Society of Psychiatric Genetics (ISPG), Psychiatric Association of Turkey (PAT) and was a board member of PAT Izmir Branch (2013-2015). 


\section{Publications}

- Kırlı U, Binbay T, Drukker M et al. (2019). DSM outcomes of psychotic experiences and associated risk factors: six year follow-up study in a community-based sample. Psychological Medicine, 49 (8), 1346-1356 DOI: $10.1017 /$ S0033291718001964

- Kırlı U, Binbay T, Drukker M et al. (2019). Is BDNF-Val66Met Polymorphism Associated with Psychotic Experiences and Psychotic Disorder Outcome? Evidence from a 6 Years Prospective Population-based Cohort Study. American Journal of Medical Genetics Part B: Neuropsychiatric Genetics 180 (2), 113-121, DOI: 10.1002/ ajmg.b.32641

- Kırlı U, Binbay T, Drukker M, van Os J, Alptekin K, Kayahan B, Elbi H (2019). Psychotic experiences and mood episodes predict onset of each other bi-directionally: six years follow-up study in a community-based population. Social Psychiatry and Psychiatric Epidemiology 54 (3): 331-341 DOI: 10.1007/s00127-018-1641-8

- Kırlı U, Binbay T, Elbi H et al. (2019). Izmir Mental Health Cohort for Gene-Environment Interaction in Psychosis (TürkSch): Assessment of the Extended and Transdiagnostic Psychosis Phenotype and Analysis of Attrition in a Six Years Follow-up of a Community-based Sample. Frontiers in Psychiatry. 10, 554 DOI: 10.3389/ fpsyt.2019.00554

- Kırlı U, Binbay T (2019). Pre-psychosis: symptoms leading to prodrome and psychotic disorder. Update in Psychiatry, 9(4), 284-294

- Kırlı U, Binbay T, Elbi H, Alptekin K (2020). COVID-19 Pandemic and Psychotic Symptoms. Journal of Clinical Psychiatry 23(1): 81-85, DOI: $10.5505 / \mathrm{kpd} .2020 .27122$ 
- Kırlı U, Alptekin K. (2020). Acute and Maintenance Pharmacotherapy of Schizophrenia (Review). Archieves of Neuropsychiatry (in press)

- Özdemir PG, Kırlı U, Işık M et al. (2020). The role of thought suppression in conversion disorder in relation to depression, symptom interpretation, and sleep hygiene: A case-control study. Archives of Clinical Psychiatry. 47(3):59-64. DOI: 10.1590/0101-60830000000233

- Ulas H, Binbay T, Kırlı U et al. (2017). The epidemiology of alcohol use in Izmir, Turkey: drinking pattern, impairment and help-seeking. Social Psychiatry Psychiatric Epidemiology. 52 (7), 887-899. DOI 10.1007/s00127017-1345-5

- Zai G, Kırlı U, Alberry B et al. (2016). Rapporteur summaries of plenary, symposia, and oral sessions from the XXIIIrd World Congress of Psychiatric Genetics Meeting in Toronto, Canada, 16-20 October 2015.. Psychiatric Genetics. 26(6):229-257 DOI: 10.1097/ YPG.0000000000000148

\section{Book Sections}

- Kırlı U, Binbay T. Epidemiology of Psychosis and Schizophrenia: in Şchizophrenia and other Psychotic Disorders $2^{\text {nd }}$ Edition Editors: Ayşen Esen-Danac1, Ömer Böke, Meram Can Saka, Almila Erol, Semra Ulusoy Kaymak, Ankara: Psychiatric Association of Turkey: 2018.29-51

- Kayahan B, Elbi H, Kırlı U (2018) Attenuated Psychotic Symptoms in Adolescence: in Adolescence and Mental Disorders Editor: Tezan Bildik, Ankara: Turkish Clinics: 2018. 180-186. 
- Kırlı U. The Effects of COVİ-19 Pandemic on Mental Health: in Current Approach to Covid-19, Editors: Ümit Haluk İliklerden, Kamuran Karaman, Nurettin Yüzkat, Ali İrfan Baran, Hanifi Y1ldız. Ankara: Akademisyen Press: 2020. 165-169

- Kırlı U, Akgül Ö, Alptekin K. Neurodevelopmental Roots of Schizophrenia: in Şchizophrenia and other Psychotic Disorders $3^{\text {rd }}$ Edition, Editors: Ayşen Esen-Danac1, Ömer Böke, Meram Can Saka, Almıla Erol, Semra Ulusoy Kaymak, Ankara: Psychiatric Association of Turkey (in press)

- Kırlı U, Akgül Ö, Alptekin K. The Biochemistry of Schizophrenia (Dopamine and Others): in Şchizophrenia and other Psychotic Disorders 3rd Edition, Editors: Ayşen Esen-Danac1, Ömer Böke, Meram Can Saka, Almila Erol, Semra Ulusoy Kaymak, Ankara: Psychiatric Association of Turkey (in press)

\section{Abstracts}

- Kırlı U, Binbay T, Elbi H, Alptekin K et al. (2019). Outcome of DSM-5 attenuated psychosis syndrome over follow-up: Six years follow-up study in a large general population-based population. European Neuropsychopharmacology. 29: 73-74. doi:10.1016/j. euroneuro.2019.09.138

- Kırlı U, Binbay T, Elbi H, Kayahan B et al. (2016). Psychotic experiences convert not only to psychotic disorders; also to depression and anxiety disorders: Evidence from a 6 years follow-up of a large general population sample. 5th Biennial Schizophrenia International Research Society (SIRS) Conference, Florence, İtaly; Nature Partner Journals Schizophrenia, doi:10.1038/npjschz.2016.10 
- Kırlı U, Binbay T, Elbi H, Kayahan B et al. (2016) Psychotic experiences, alcohol-cannabis abuse, stressful events and familial risk is associated with onset of clinical psychosis: Evidence from a 6 years longitudinal population-based cohort. European Psychiatry 33: 256-257, http://dx.doi.org/10.1016/j.eurpsy.2016.01.526

- Kırlı U, Binbay T, Elbi H, Kayahan B et al. (2016) Quitting cannabis decreases but does not eliminate psychosis risk: evidence from a 7 years large population-based cohort. European Neuropsychopharmacology 26: 53-54

- Kırlı U, Binbay T, Elbi H, Alptekin K et al. (2015) Are BDNF-Val66Met and COMT-Val158Met polymorphisms associated with psychotic experiences and clinical psychotic outcome? Evidence from a prospective population-based cohort, 2008-2015. European Neuropsychopharmacology doi:10.1016/j.euroneuro.2015.09.009

- Kırlı U, Binbay T, Elbi H, Alptekin K et al. (2015). TurkSCH II: Evaluation of psychotic experiences, onset of clinical psychosis and associated risk factors in a 6 years prospective community-based follow-up. Turkish Journal of Psychiatry, 26 (Suppl. 2): 4-5

- Kırlı U, Parildar S, Cakir M (2014) Low quality sleep , general psychopathology and association with quality of life in cases with bruxism. Turkish Journal of Psychiatry 25 (Suppl. 1): 40

- Kırlı U, Çiftci S (2014) Bipolar Disorder and Multiple Sclerosis. Etiological Association? Coincidence? Turkish Journal of Psychiatry 25 (Suppl. 1): 40-41

- Kırlı U, Aydogdu I (2014) Interictal psychosis Turkish Journal of Psychiatry 25 (Suppl. 2): 116 
- Kırlı U (2012) Psychotic like experiences, risk factors for conversion to psychotic disorders, gene-environment interactions: A follow-up study on a community based population; New Directions In Psychiatry, Annual Forum of European Federation of Psychiatric Trainees, Sorrento- İtaly, Congress Book 206-208

- $\quad$ Binbay T, Kırlı U, Elbi H, Alptekin K et al. (2016). Exploring the impact of catechol-O-methyltransferase (COMT) and brain-derived neurotrophic factor (BDNF) polymorphisms on association between psychotic experiences and depression-suicidal ideation in a sixyear follow-up of general population based sample. Nature Partner Journals Schizophrenia, doi:10.1038/ npjschz.2016.10

- $\quad$ Binbay T, Kırlı U, Elbi H, Alptekin K et al. (2016). Which Social Environment Is More Important In Persistence Of Psychotic Experiences? Differential Impact of Neighborhood and Family Context In a Six Year Longitudinal Population Based Cohort. European Psychiatry 33: 202-203

- $\quad$ Elbi H, Kırlı U, Binbay T, Alptekin K et al. (2015). Extended Psychosis Phenotype, Gene-Environment Interactions. A Follow-up Study on a Community Based Population. European Neuropsychopharmacology doi:10.1016/j.euroneuro.2015.09.009

- Atan YS, Kırlı U (2019). Fahr syndrome diagnosed with first episode psychosis. Turkish Journal of Psychiatry 30 (Suppl. 2): 76

- Elbi H, Binbay T, Kırlı U, Kayahan B et al. (2016). Subthreshold Depression As A Predictor of Emergence and Persistence of Psychotic Experiences: A Six Years Longitudinal Population Based Cohort. European Psychiatry 33: $268-269$ 
- Alptekin K, Binbay T, Kırlı U, Elbi H et al. (2016). A Six-Year Longitudinal Population-Based Cohort for the Extended Psychosis Phenotype: An Epidemiological Study of the Gene-Environment Interactions (TürkSch). European Psychiatry 33: 284-285 


\section{The PhD ceremonies of the last year in MHeNs*}

- Shenghua Zong. Autoantibodies in disorders of the brain: expanding the spectrum. Supervisor: prof.dr. P. Marinez; co-supervisor: dr. M. Losen; dr. R. Rouhl.

- Jan-Willem Kallewaard. Diagnosis and minimally invasive treatment of chronic discogenic low back pain. Supervisor: prof.dr. M. van Kleef; co-supervisors: prof. dr. H. van Santbrink; dr. P. Willems.

- Simone M. Crivelli. Sphingolipid metabolism in the pathophysiology and treatment of Alzheimer's disease. Supervisors: prof.dr. P. Martinez-Martinez; prof.dr. E. de Vries, VUmc. Co-supervisors: dr. M. Losen; dr. M. Mulder, Rotterdam.

- Natasha Pahuja. Etiopathogenesis, advanced imaging and treatment outcomes in Asian Indians with keratoconus. Supervisor: prof.dr. R. Nuijts, co-supervisor: dr. R. Shetty, Bengaluru. Pooja Khamar Mayur Raksha.

- Clinical, Molecular and Biomechanical outcomes of SMILE (small incision lenticule extraction) and other refractive surgery techniques. Supervisor: prof.dr. R. Nuijts, co-supervisor: dr. R. Shetty, Bengaluru.

- Niels Janssen. Patterns and pathways. Indicators for potential improvements of dementia care. Supervisors: prof.dr. F. Verhey; prof.dr.mr. S. Evers; Co-supervisor: dr. R. Handels.

- Giovanni Mansueto. Childhood adversities and Psychosis: investigation of the potential aetio-pathogenetic mechanisms. Supervisor: prof.dr. K. Schruers; co-supervisors: prof.dr. F. Cosci, University of Florence, It; prof.dr. R. van Winkel, KU Leuven. 
- Joke Debruyne. Cochlear implantation in adults with early-onset deafness. Supervisors: prof.dr. B. Kremer; prof.dr.ir. T. Francart, KU Leuven; Co-supervisor: dr.ir. J. Brokx.

- Koenraad Meuwissen, Burst Spinal Cord Stimulation in a Rat Model of Chronic Neuropathic Pain: Spinal and Supraspinal Mechanisms. Supervisors: prof. dr. E.A.J. Joosten; prof. dr. M. van Kleef.

- Lisa Schmiedek, Episodic memory in ageing and AD: a possible target for electrical stimulation ? Supervisors: prof. dr. F.R.J. Verhey; prof. dr. A.T. Sack; co-supervisor: dr. H.I.L. Jacobs

- Paolo Maino, Implantable Intrathecal Drug Delivery in Treatment of Chronic Intractable Pain and Spasticity: Improvement of Safety and the Use of Imaging Techniques. Supervisors: prof. dr. E.A. Joosten; prof. dr. M. van Kleef.

- José Geurts, Chronic Pain; Impact of Chronic Pain on a Societal, Personal, and Treatment Level. Supervisors: prof. dr. C.D. Dirksen; prof.dr. M. van Kleef; co-supervisor: dr. P.C. Willems.

- Brigitte Brouwer, Painful Small Fiber Neuropathy; Symptoms, assessments and interventions. Supervisor: prof. dr. C.F. Faber; co-supervisors: dr. I.S.J. Merkies, Willemstad, Curaçao; dr. J.G.J. Hoeijmakers.

- Ruth Gussenhoven, Antenatal inflammatory insults and preterm brain injury: Pathophysiology and therapeutic strategies. Supervisors: prof. dr. B.W. Kramer; prof. dr. L.J.I. Zimmermann; Dr. T.G.A.M. Wolffs.

- Adriana (Janine) Collet, Specific Care on the Interface of Mental health and Nursing home "SpeCIMeN". 
Supervisors: prof. dr. M.E. de Vugt; prof. dr. J.M.G.A. Schols; Prof. dr. F.R.J. Verhey.

- Fares Nigim, Glioblastoma and Meningioma Biology, Targeted Therapy and Oncolytic Virus Therapy. Supervisors: prof. dr. Y. Temel; prof. dr. S.D. Rabkin, Harvard; cosupervisors: dr. H. Wakimoto, Harvard; dr. L. Ackermans.

- Leonie Banning, Neuropsychiatric symptoms in Alzheimer's disease; Associations with biomarkers. Supervisor: prof. dr. F.R.J. Verhey; co-supervisors: dr. P. Aalten; Dr. I.H.G.B. Ramakers.

- Johan Haumann, Prevalence and pharmacological treatment of pain in patients with cancer; The role of opioids with and without NMDA receptor affinity. Supervisor: prof.dr. E.A. Joosten; co-supervisors: Prof. dr. M.H.J. van den Beuken-van Everdingen; dr. S.M.J. Van Kuijk.

- Joost Riphagen, Vascular matters in aging and dementia. Supervisor: prof.dr. F.R.J. Verhey; co-supervisor: Dr. H.I.L. Jacobs. Nikos Priovoulos, Structural and functional imaging of the locus coeruleus at 7T: from methodological to clinical application. Supervisor: prof.dr. F.R.J. Verhey; co-supervisors: Dr. H.I.L. Jacobs; dr. B.A. Poser.

- Simone Verhagen, The power of individual landscapes; A clinical exploration of personal experience sampling and new horizons. Supervisors: prof.dr. P.A.E.G. Delespaul; prof.dr. J.J. van Os, UM/UU; co-supervisor: dr. C.J.P. Simons.

- Nagy Youssef, Epigenetics, resilience and brain stimulation: advances in the mechanistic and therapeutic utility in patients with affective (PTSD and mood) dis- 
orders. Supervisor: Prof.dr. B.P.F. Rutten; co-supervisor: Prof. dr. P. Sienaert, KU Leuven.

- Abhishek Appaji, Retinal vascular features as a biomarker for psychiatric disorders. Supervisor: Prof. Dr. C.A.B. Webers; co-supervisor: Dr. T.T.J.M. Berendschot, Dr. Naren P. Rao.

- Koos Hovinga, Angiogenesis Inhibition in Glioblastoma. Supervisor: prof. dr. Y. Temel; co-supervisor: Prof. V. Tabar, New York, USA.

- Gerhard Drenthen, Myelin and networks, Magnetic Resonance Imaging in Epilepsy. Supervisors: prof. dr.ir. W.H. Backes; Prof.dr. A.P. Aldenkamp; co-supervisor: dr. J.F.A. Jansen.

- Anna Gorlova, Understanding the Molecular Mechanisms of Aggression in BALB/C and TPH2-Deficient Mice. Supervisor: prof.dr. K. Lesch, Universitätsklinikum Würzburg, cosupervisors: dr. T. Strekalova; prof.dr. L. Bettendorff, University of Liège.

- Ekaterina Veniaminova, The impact of the 'Western Diet' on Emotional, Social and Cognitive Behaviours as revealed by a study on conventional and serotonin Transporter-Deficient Mice. Supervisor: prof.dr. K. Lesch, Universitätsklinikum Würzburg, co-supervisors: dr. T. Strekalova; prof. D.C. Anthony, Oxford.

- Dmitrii Pavlov, The contribution of CNS inflammation and Glycogen Synthase Kinase-3 (GSK-3)-cascades on adverse memory learning on mouse models of emotional stress. Supervisor: prof.dr. K. Lesch, Universitätsklinikum Würzburg, co-supervisors: dr. T. Strekalova; prof.dr. L. Bettendorff, University of Liège. 
- Eric Fonseca Wald, Absence Epilepsy and Panayiotopoulos Synrome: Neurocognition and Brain Development. Supervisor: prof.dr. R.J. Vermeulen; co-supervisors: Dr. S. Klinkenberg; dr. M.J.A. Debeij-van Hall; Dr. J.G.M. Hendriksen, Epilepsiecentrum Kempenhaeghe.

- Kimberley S. Noij, Cervical vestibular evoked myogenic potentials; Toward optimizing clinical use. Supervisors: prof.dr. H. Kingma; prof. S.D. Rauch, MD, Massachusetts Eye and Ear, Harvard; co-supervisor: Dr. R. van de Berg.

- Mark J. van Tilburg, Advancement in cVEMP's. Supervisors: prof.dr. H. Kingma; prof.dr. S. Rauch, Harvard; co-supervisors: dr. R. van de Berg; dr. B. Herrmann, Boston.

- Nalini Atcharayam, Duchenne Muscular Dystrophy: The NIMHANS Experience. Supervisors: prof.dr. T. Delhaas; prof.dr. B.W. Kramer.

- Murat L Atagün, Cognitive neurophsysiology and neurochemistry in bipolar disorder. Supervisor: Prof. Dr. Therese van Amelsvoort; co-supervisors: Dr. Sinan Guloksuz; Dr. Marian Drukker.

- $\quad$ Majed Aldehri, Deep brain stimulation, memory functions and mechanisms. Supervisor: Prof. dr. Y. Temel; co-supervisors: dr. S. Hescham; dr. A. Jahanshahianvar.

- Printha Kentheeswaran-Wijesinghe, Age-related cytoskeletal pathologies: A study on elderly brains to investigate the extent of neuropathological and cerebrovascular changes at death ad their risk factors. Supervisor: Prof. dr. H. Steinbusch, Prof. dr. R. De Silva - (University of Sri Jayewardenepura), Prof. dr. D. Shankar - (NIMHANS Bangalore). 
- Mahmoud Elbatrik, Network pharmacology for mechanistically redefined comorbidities. Supervisor: Prof. dr. H.H.H.W. Schmidt; co-supervisors: Dr. A.I. Casas Guijarro.

- Alexander Grønning, Big Data Analytics in Bioinformatics. Supervisors: Prof. dr. J. Baumbach - (University of Southern, Denmark), Prof. dr. H.H.H.W. Schmidt; co-supervisor: Dr. R. Röttger.

- Britta Nijsse, Cognition after stroke; various perspectives. Supervisors: Prof. dr. C.M. van Heugten, Prof. dr. J.M.A. Visser/Meily, Prof. dr. J.M. Spikman; co-supervisor: Dr. P.L.M. de Kort.

- Eva Koetsier. Dorsal Root Ganglion Stimulation for Pain Relief in Painful Polyneuropathy: Efficacy and Mechanism of Action. Supervisors: Prof. dr. E.A.J Joosten Prof. dr. J.A.M. van Zundert; co-supervisor: Dr. S.M.J. van Kuijk.

- Youssef Yakkioui, Molecular biomarkers in skull base chordoma. Supervisors: Prof. dr. Y. Temel, Prof. dr. M. van Engeland.

- Sascha Meyer, Visual Associative Learning in Alzheimer's Disease and Performance Validity. Supervisor: Prof. dr. R.W.H.M. Ponds; co-supervisor: Dr. J.F.M. de Jonghe.

- Daniël Verberne, Psychosocial outcome after stroke and traumatic brain injury - Longitudinal perspectives and recommendations for aftercare. Supervisors: Prof. dr. C.M. van Heugten, Prof. dr. R.W.H.M. Ponds; co-supervisor: Dr. M.E.A.L. Kroese.

- Britt van Hagen, Improving Pattern Separation and Cognition: Effects of Pharmacological Interventions 
on Rodent Behavior and Neuroplasticity. Supervisors: Prof. dr. J. Prickaerts, Prof. dr. H. Schmidt.

- Sara Bartels, Monitoring Everyday Life in Aging \& Dementia - Perspectives from Experience Sampling and Technology Use. Supervisors: Prof. dr. F.R.J. Verhey, Prof. dr. M.E. de Vugt; co-supervisors: Dr. R.J.M. van Knippenberg, Dr. C. Malinowsky - (Karolinska Institutet, Sweden).

- Roel van Reij, Genetic Risk Factors in prediction and treatment of Chronic Post-Surgical Pain. Supervisor: Prof. dr. E.A.J. Joosten; co-supervisor: Dr. N.J. van den Hoogen.

- Hannah Christie, The Implementation of EHealth in Dementia Care: Lessons Learned. Supervisors: Prof. dr. M.E. de Vugt, Prof. dr. F.R.J. Verhey; co-supervisor: Dr. H.J. Tange.

- Antoine Bernas, Resting-state fMRI neurodynamics in neuropsychiatric disorders. Supervisors: Prof.dr. A.P. Aldenkamp Dr. ir. S. Zinger, TUE Gwendoline Montes Diaz, Immune regulation by mimethyl fumarate (DMF) in relapsingremitting multiple sclerosis patients. Supervisors: prof.dr. R. Hupperts, prof.dr. V. Somers, Hasselt, Dr. J. Fraussen, Hasselt

* Full list of PhD ceremonies in MHeNs can be found in the following website:

https://mhens.mumc.maastrichtuniversity.nl/sites/intranet.mumc.maastrichtuniversity.nl/files/mhens_mumc_ maastrichtuniversity_nl/public_article/phd_theses_-_tot_ okt_2020.pdf 



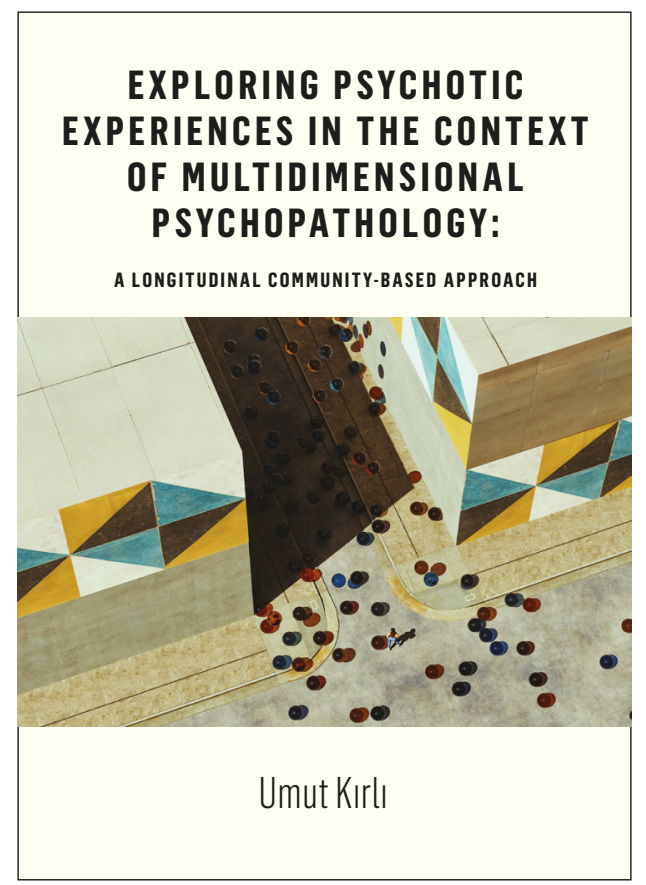

The extended and transdiagnostic psychosis phenotype represents an excellent framework from

which to study the psychosis expression in the context of multidimensional psychopathology. In this dissertation, some results of a cohort project are presented which is conducted in a community-based population, representative of the Izmir metropolitan area. Psychosis is assessed across a spectrum of severity including experiences in healthy individuals, in individuals with non-psychotic disorders and in individuals with psychotic disorders. The associations with multidimensional psychopathology, genetic and socio-environmental factors are assessed based on a six-year follow-up. 